Centro Brasileiro de Pesquisas Físicas

Murilo Santana Rangel

\title{
Produção de Dijatos por Dupla Troca de Pomeron Exclusiva no Experimento D
}

RiO DE JANEIRO 2008 


\section{Abstract}

The first search for exclusive diffractive dijet production with invariant mass $\gtrsim 100 \mathrm{GeV}$ in Run II of the Fermilab Tevatron Collider is performed. The set of data used is the Run IIa, corresponding to an integrated luminosity of $30 \mathrm{pb}^{-1}$ of $p \bar{p}$ collisions at $\sqrt{s}=1.96$ $\mathrm{TeV}$ taken with the DØ detector. At 95\% CL, an upper limit for the ratio between the number of diffractive exclusive events and the number of non diffractive events is set to be $7.5 \times 10^{-6}$, excluding two of the three models proposed to explain this production. 


\section{Resumo}

A primeira busca pela produção difrativa exclusiva de dijatos com massa invariante $\gtrsim$ $100 \mathrm{GeV}$ no Run IIa do Fermilab Tevatron Collider é realizada. A amostra de dados corresponde a uma luminosidade integrada de $30 \mathrm{pb}^{-1}$ de colisões $p \bar{p}$ com $\sqrt{s}=1.96$ TeV obtida pelo detector D $\varnothing$. Com $95 \%$ de nível de confiança, um limite superior para razão entre o número de eventos difrativos exclusivos e o número de eventos não difrativos é determinado como sendo $7,5 \times 10^{-6}$, excluindo dois dos três modelos propostos para explicar a produção exclusiva. 
Para Natália e minha família 


\section{Agradecimentos}

Agradeço a minha família. Aos meus pais, Clóvis e Angélica, por investirem e acreditarem em mim, tornando possíveis as escolhas que fiz, permitindo a existência desta tese. Todos seus ensinamentos, levarei comigo para sempre. À minha irmã, Monique, devo eterno agradecimento, pelo seu suporte, companhia e carinho. Ao Thiago, marido da Monique, por tornar a família maior e mais alegre. À tia Cândida e ao Zé, por estarem sempre torcendo pelo meu sucesso. Aos pais da minha esposa, Itamar e Sheila, e à Babi, por terem oferecido-me mais uma família feliz para conviver. Aos meus primos e tios, por estarem sempre presentes em minha vida.

A todos os meus amigos. Ao Diogo, Gabriel, André e Luíz, pelas discussões de física e pelas conversas filosóficas. Em especial, ao Diogo, pela convivência nos últimos meses estressantes desta tese, sempre me suportando para lutar por minha vida acadêmica. Ao amigo Andres, agradeço pela companhia e fiel amizade durante minha estada no Fermilab.

Agradeço aos físicos com quem colaborei. Aos professores Maria Elena Pol e Luíz Mundim, por tudo que me ensinaram e acima de tudo, pela amizade. Aos físicos Christophe Royon e Robi Peschanski, por terem apostado em mim e pelas discussões sobre física, com as quais muito aprendi. Ao Mikko Voutilainen, por ter ajudado-me no início do trabalho com jatos no DØ, e oferecido sua amizade. Ao Aurelio Juste e Brendan Casey, pela colaboração dentro do DØ, da qual tirei muitos ensinamentos. Ao Bernard Andrieu e Jiri Kvita, por me ajudarem quando entrei na colaboração D $\varnothing$ e pela amizade que se formou. À todo grupo brasileiro que participa do experimento D $\varnothing$, pelas discussões importantes e terem sempre me tratado como um colega de trabalho.

Agradeço aos meus orientadores, Gilvan Alves e Jorge Barreto, por tudo que me ensinaram, pelas discussões construtivas, por acreditarem sempre em minhas idéias e terem sido meus amigos. Ao Jorge, por ter despertado em mim o interesse pela física de altas energias logo no início de meu bacharelado e ter dividido comigo tantos ensinamentos sobre sua vida científica. Ao Gilvan, por ter acreditado em mim desde o início de nossa colaboração e ter me mostrado importantes caminhos para minha vida acadêmica.

Agradeço às forças da natureza que regem nossas vidas materiais e não materiais, por serem justas, onipresentes e terem permitido-me trilhar os caminhos que me trouxeram até esse importante momento.

Agradeço e dedico esta tese à minha esposa Natália, companheira de todos os momentos, sempre presente no andamento deste trabalho, pacientemente ouvindo as explicações sobre minha pesquisa, seriamente corrigindo os erros gramaticais de minha escrita, carinhosamente suportando-me nos meus momentos de fraqueza, incondicionalmente apoiandome com muito amor, dessa forma, tendo a mais importante participação nos bastidores deste manuscrito.

Às agências de fomento CAPES e CNPq pelo suporte financeiro que tornou possível esta tese. 
"Durante toda a minha vida, novas visões da natureza sempre me deixaram feliz como uma criança." Marie Curie

"No meio da dificuldade encontra-se a oportunidade." Albert Einstein

"Foi o tempo que dedicaste a tua rosa que fez a tua rosa tão importante." Antoine de Saint-Exupéry 


\section{Sumário}

Abstract ................................ ii

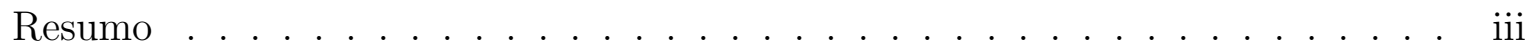

Agradecimentos . . . . . . . . . . . . . . . . . .

Lista de Tabelas 2

$\begin{array}{lr}\text { Lista de Figuras } & 8\end{array}$

1 Introdução $\quad 9$

2 Teoria 11

2.1 Modelo Padrão . . . . . . . . . . . . . . . . . . . . . . . . . . . 11

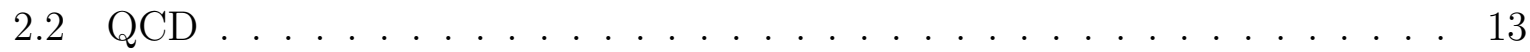

2.2.1 Fatoração em QCD . . . . . . . . . . . . . . . . . . 15

2.2 .2 Jatos . . . . . . . . . . . . . . . . . . . 16

2.3 Difração . . . . . . . . . . . . . . . . . . . . . . . . . . 19

2.3 .1 Teoria de Regge . . . . . . . . . . . . . . . . . . 20

2.3.2 Lacunas de Rapidez . . . . . . . . . . . . . . . . . . . . . 21

2.3.3 Difração Dura . . . . . . . . . . . . . . . . . . . . . . . . . . 21

2.4 Produção de Dijatos no Tevatron . . . . . . . . . . . . . . . . . . . . 22

2.4 .1 Espalhamento Inelástico . . . . . . . . . . . . . . . . . . . 23

2.4.2 Difração Simples . . . . . . . . . . . . . . . . . . 24

2.4.3 Dupla Troca de Pomeron . . . . . . . . . . . . . . . . . . . 25

2.5 Dupla Troca Pomeron Exclusiva . . . . . . . . . . . . . . . . . . . . 28

2.5.1 Modelo de Bialas-Landshoff . . . . . . . . . . . . . . . . . 28

2.5.2 Modelo KMR . . . . . . . . . . . . . . . . . . . . 32

2.5.3 Modelo Híbrido . . . . . . . . . . . . . . . . . . . . . . . 33

2.6 Observações . . . . . . . . . . . . . . . . . . . . . . . . . . . . . . 38

3 O Experimento DØ $\quad 39$

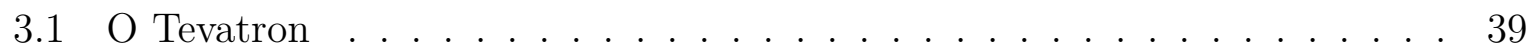

3.2 O Detector $\mathrm{D} \varnothing \ldots \ldots \ldots \ldots \ldots \ldots \ldots \ldots$

3.2.1 Sistema de Coordenadas . . . . . . . . . . . . . . . . 43 
3.2.2 Sistema de Traços Centrais . . . . . . . . . . . . . . . . . . . 45

3.2.3 Calorímetro . . . . . . . . . . . . . . . . . . . . . . . 48

3.2.4 Espectrômetros de Múons . . . . . . . . . . . . . . 53

3.2.5 Detector de Prótons Frontais _. . . . . . . . . . . . . . 55

3.2 .6 Monitor de Luminosidade . . . . . . . . . . . . . . . . . . 56

3.2.7 Seleção de Eventos em Tempo Real . . . . . . . . . . . . . . . . . 59

3.2 .8 Reconstrução de Eventos no D $\varnothing \ldots \ldots$. . . . . . . . . . 60

3.3 Observações . . . . . . . . . . . . . . . . . . . . . . . 60 60

4 Jatos no DØ $\quad 61$

4.1 Reconstrução de Jatos . . . . . . . . . . . . . . . . . . . . . . 61

4.2 Identificação de Jatos . . . . . . . . . . . . . . . . . . . . . . . . . . . 63

4.2 .1 Fração Máxima no CH . . . . . . . . . . . . . . . . . 63

4.2 .2 Fração Mínima e Máxima no EM . . . . . . . . . . . . . . . . . 64

4.2 .3 Confirmação no L1 . . . . . . . . . . . . . . . . . . . . . . . . 64

4.3 Correção da Energia dos Jatos . . . . . . . . . . . . . . . . . . . . . . 65

4.4 Eficiência da Reconstrução e Identificação de Jatos . . . . . . . . . . . . . 66

4.5 Resolução da Energia dos Jatos . . . . . . . . . . . . . . . . . 70

4.6 Medida do Espectro da Seção de Choque da Produção Inclusiva de Jatos . 70

4.7 Observações . . . . . . . . . . . . . . . . . . . . . . . 70

5 Calorimetria no DØ $\quad 79$

5.1 Lista de Células Problemáticas _ . . . . . . . . . . . . . . . . . 79

5.1.1 Seleção de Eventos . . . . . . . . . . . . . . . . . . . . . . . 79

5.1 .2 Método . . . . . . . . . . . . . . . . . . 80

5.2 Calibração Relativa das Células Calorimétricas . . . . . . . . . . . . . . . 82

5.2.1 Seleção de Eventos . . . . . . . . . . . . . . . . . . . . . . . . 82

5.2 .2 Método . . . . . . . . . . . . . . . . . . . . 83

5.2 .3 Testes de Consistência . . . . . . . . . . . . . . 86

5.2 .4 Resultados . . . . . . . . . . . . . . . . 86

5.3 Observações . . . . . . . . . . . . . . . . . . . . . . . 93

6 Análise dos Dados Obtidos $\quad 94$

6.1 Amostras de Eventos Simulados . . . . . . . . . . . . . . . . . . . 94

6.2 Seleção de Eventos . . . . . . . . . . . . . . . . . . . . . . 96

6.3 Luminosidade Instantânea . . . . . . . . . . . . . . . . . . . . 96

6.4 Correção da Eficiência do trigger . . . . . . . . . . . . . . . . . . 97

6.5 Contribuição não difrativa . . . . . . . . . . . . . . . . . . . . 97

6.6 Contribuições difrativas . . . . . . . . . . . . . . . . . . . . . . . . . . 99

6.7 Análise Linear . . . . . . . . . . . . . . . . . . . . . . . . 101 
6.8 Método Multivariável de Verossimilhança . . . . . . . . . . . . . . . . 103

6.8.1 Variáveis de entrada . . . . . . . . . . . . . . . . . . . . 104

6.9 Resultados . . . . . . . . . . . . . . . . 116

6.9.1 Limite para Produção Exclusiva de Dijatos . . . . . . . . . . . . . . 119

7 Conclusões $\quad 122$

A Melhoria da Resolução da Energia dos Jatos $\quad 124$

B Lista de Células Calorimétricas Problemáticas 136

$\begin{array}{lr}\text { C Estatística de Bayes } & 148\end{array}$

$\begin{array}{ll}\text { D Matriz de Correlação } & 150\end{array}$

Glossário e Acrônimos $\quad 153$ 


\section{Lista de Tabelas}

Tabela

Pág.

2.1 As 4 interações fundamentais e suas respectivas intensidades (considerando a força forte de intensidade unitária) e alcances. [4] . . . . . . . . . . . . . 12

2.2 Partículas elementares da natureza até o presente momento. Entre parênteses estão os anos de suas respectivas observações $[1,2,6,8] \ldots 12$

2.3 Propriedades dos quarks $[15] . \ldots \ldots \ldots \ldots . \ldots \ldots$

2.4 Seção de choque de IDP para diferentes cortes de $F_{M}$ e diferentes densidades de glúon como explicado no texto. . . . . . . . . . . . . . . . . . . 31

2.5 Número de eventos exclusivos com produção de $\chi_{c_{0}}$ (erro estatístico da simulação é menor que 10\%) no Tevatron. O cenário 0 representa todos os canais de decaimento sem cortes de seleção. As colunas representam o número de eventos: A - todos (sem detecção dos hádrons difratados); B com detecção do próton; C - com detecção do antipróton; D - com detecção de ambos hádrons difratados. . . . . . . . . . . . . . . . . .

2.6 Lista de parâmetros usados no modelo híbrido. A segunda coluna apresenta os valores padrões, a terceira coluna mostra os limites inferiores e superiores de cada parâmetro devido às suas incertezas. A quarta coluna apresenta os valores para o modelo do espalhamento dipolo-próton quando o quark $c$ é considerado. . . . . . . . . . . . . . . . . . . . . 36

3.1 Especificações do SMT . . . . . . . . . . . . . . . . . . . . . . . 46

3.2 Relação das camadas de cada célula com relação a ilayer. . . . . . . . . . . 51

3.3 Relação da pseudorapidez de cada célula com relação a ieta. . . . . . . . . . . 51

5.1 Divisão em períodos de tempo para o Run IIa, usando o número da Store como unidade de tempo. . . . . . . . . . . . . . . . . . . . . 81

6.1 Número de eventos gerados com o gerador PYTHIA para produção não difrativa de dijatos para diferentes regiões de $\hat{p}_{T}$ e suas respectivas seções de choque em LO. . . . . . . . . . . . . . . . . . . 95

6.2 Número de eventos gerados para cada modo de produção difrativo . . . . 95

6.3 Razões teóricas entre o número de eventos de cada produção difrativa e número de eventos da produção não difrativa. . . . . . . . . . . . . . . . . 100

6.4 Número de eventos reais em excesso com relação à simulação NDF. . . . . 116

6.5 Razão entre eventos difrativos e eventos não difrativos medida através do método explicado no texto. . . . . . . . . . . . . . . . . . 116 
Tabela

Página

6.6 Razão entre o número de eventos difrativos e o número de eventos não difrativos após variar os fatores de calibração do calorímetro ( \pm calib) e os fatores de correção da energia dos jatos ( \pm jes $). . . . . .118$

6.7 Resultados finais: o primeiro erro é estatístico e o segundo, sistemático. . . 118

A.1 Valores usados para $\eta_{b i n} \ldots \ldots \ldots \ldots \ldots$

B.1 Lista de células problemáticas para o Run IIa para camadas do calorímetro EM. A coluna L representa a camada, a coluna E o ieta e a coluna P o iphi das células. . . . . . . . . . . . . . . . . . . . 137

B.2 Lista de células problemáticas para o Run IIa para camadas do calorímetro FH. A coluna L representa a camada, a coluna E o ieta e a coluna P o iphi

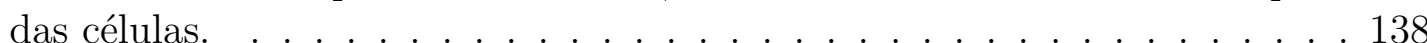




\section{Lista de Figuras}

Figura

Pág.

2.1 Diagramas de Feynman de primeira ordem para o espalhamento elástico de quarks e fusão de quarks. . . . . . . . . . . . . . . . . . . . .

2.2 Representação da colisão de dois hádrons com produção de partículas de

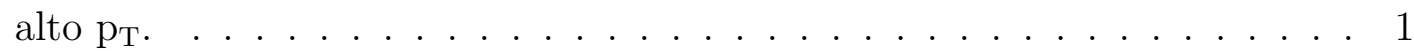

2.3 Exemplo de um diagrama de Feynman de ordem seguinte à dominante para o espalhamento elástico entre dois quarks. . . . . . . . . . . . . . . . . 18

2.4 Os quatro tipos de difração hadrônica que podem ocorrer em um colisor de hádron-hádron. . . . . . . . . . . . . . . . . . . . .

2.5 Alguns diagramas de Feynman de ordem seguinte à dominante para o espalhamento de dois quarks. O diagrama (a) inclui correção devido radiação do estado inicial. O diagrama (b) leva em conta radiação do estado final. Os diagramas (c) e (d) consideram interações entre os campos. . . . . . .

2.6 Distribuição de probabilidades $x f\left(x, Q^{2}\right)$ de um párton com fração de momentum do (anti)próton $x$, na escala de energia $Q^{2}=10 \mathrm{GeV}^{2}$ ajustadas pelas colaborações H1, ZEUS e CTEQ [24]. A função $S$ representa o quark estranho s; a função $g$, os glúons; a função $u_{v}$, os quarks de valência u; e a função $d_{v}$, os quarks de valência d.

2.7 Contribuição fracional de diferentes combinações de pártons para a produção de jatos centrais no Tevatron com relação ao $\mathrm{p}_{\mathrm{T}}$ dos jatos produzidos [24].

2.8 Produção de dijatos em um evento de difração simples, no qual o antipróton foi difratado. . . . . . . . . . . . . . . . . 26

2.9 Produção de dijatos em um evento de dupla troca de pomeron inclusiva. . 26

2.10 Produção de dijatos em um evento de dupla troca de pomeron exclusiva. $\quad 26$

2.11 Comparação do resultado do CDF [42] com três modelos de EDP. . . . . . 28

2.12 Diagrama para a produção de um objeto de alto $\mathrm{p}_{\mathrm{T}}$ em EDP no modelo de Bialas-Landshoff. . . . . . . . . . . . . . . . .

2.13 Diagrama representativo para a produção de um objeto de alto $\mathrm{p}_{\mathrm{T}}$ no modelo KMR de EDP.

2.14 Diagrama para produção de um objeto massivo no modelo de pomeron híbrido. . . . . . . . . . . . . . . . . . . 34

2.15 Diagrama do espalhamento elástico dipolo-próton. . . . . . . . . . . 35

2.16 Variação do modelo devido às incertezas dos parâmetros determinados para a parte dura do pomeron (hard parameter). . . . . . . . . . . . . . . 37

2.17 Variação do modelo devido às incertezas dos parâmetros determinados para a parte mole do pomeron (soft parameter). 
Figura

Página

2.18 Variação do modelo devido à inclusão da contribuição do quark $c$ na determinação dos parâmetros da parte dura do pomeron (including heavy quark). 37

3.1 Visão esquemática do complexo de aceleradores Tevatron 3.1. . . . . . . . . 40

3.2 Ilustrações do detector $\mathrm{D} \varnothing \ldots \ldots \ldots$. . . . . . . . . . . . . . . 42

3.3 Sistema de coordenadas. . . . . . . . . . . . . . . . . . . 43

3.4 Ilustração do detector SMT. . . . . . . . . . . . . . . . . . . . . 45

3.5 Ilustração da seção transversa do SMT. . . . . . . . . . . . . . . . . . 46

3.6 Visão do campo magnético (em $\mathrm{kG}$ ) do solenóide no eixo $y-z$. . . . . . . 48

3.7 Calorímetro central e frontal ilustrados. . . . . . . . . . . . . . . . . 49

3.8 Ilustração das células pseudo-projetivas do calorímetro. . . . . . . . . . . . 50

3.9 Esquema de uma típica célula calorimétrica [58] . . . . . . . . . . . . . 50

3.10 Ilustração da geometria das células calorimétricas no plano [58]. . . . . . . 52

3.11 Geometria das tiras do detector CPS [58]. . . . . . . . . . . . . . . . 53

3.12 Imagem ilustrativa do sistema de detecção de múons [58]. . . . . . . . . . 54

3.13 Ilustração da posição dos cintiladores de múons [58]. . . . . . . . . . . . 55

3.14 Localizações dos detectores de prótons frontais com relação à região de interação (DØ Interation Region) $[58]$. . . . . . . . . . . . . . . . . . . . . 56

3.15 Ilustração do tipo de detector usado no FPD [58]. . . . . . . . . . . . . 56

3.16 Disposição dos detectores de luminosidade do dØ [58]. . . . . . . . . . . . 57

3.17 Visão esquemática dos cintiladores do LM [58] . . . . . . . . . . . . . . 57

3.18 Ilustração de uma interação inelástica e de um halo detectados pelo LM. $\quad$. 59

4.1 Esquema da evolução temporal da formação dos jatos, passando pela fragmentação em pártons ( parton jet), depois pela formação de partículas sem cor (particle jet) e, finalmente, pela observação dessas pelo conjunto de detectores (calorimeter jet) [70]. . . . . . . . . . . . . .

4.2 Deslocamento de rapidez dos jatos reconstruídos $\left(y_{j e t}^{r e c o}\right)$ com relação aos jatos de partículas $\left(y_{j e t}^{p t c l}\right)$ em vários intervalos de energia dos jatos de partículas $\left(E_{p t c l}\right)[75] \ldots \ldots \ldots \ldots \ldots$

4.3 Pico na distribuição $\mathrm{p}_{\mathrm{T}} / E_{T}$ devido ao ruído cósmico poder imitar um evento de dijato. A região sombreada mostra os jatos que passam pelo

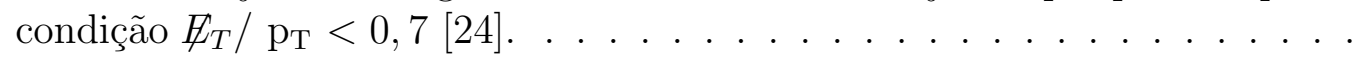

4.4 Eficiência da reconstrução de jatos em relação ao $\mathrm{p}_{\mathrm{T}}$ do jato de traços $\left(p_{T}^{\text {TrackJet }}\right)$ para diferentes regiões de pseudorapidez do jato de traços ( Track

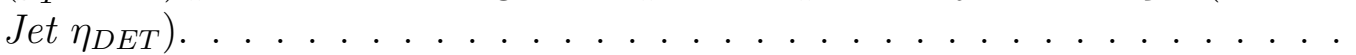

4.5 Fatores de escala (SF) da eficiência da identificação de jatos com relação à $Z_{P V}$ multiplicada pelo sinal da pseudorapidez do jato nas coordenadas do detector em diferentes regiões de pseudorapidez nas coordenadas do detector (Probe Jet detEta). Nota-se que na região mais frontal não há estatística para essa medida. . . . . . . . . . . . . . .

4.6 Eficiência da identificação de jatos com relação ao $\mathrm{p}_{\mathrm{T}}$ do jato em diferentes regiões de pseudorapidez nas coordenadas do detector (Probe Jet detEta) para dados reais (azul) e simulação (vermelho).

4.7 Fatores de escala (SF) da eficiência da identificação de jatos com relação ao $\mathrm{p}_{\mathrm{T}}$ do jato em diferentes regiões de pseudorapidez nas coordenadas do detector $($ Probe Jet detEta) . . . . . . . . . . . . . . . . 
4.8 Fatores de escala da eficiência da identificação de jatos com relação à pseudorapidez do jato nas coordenadas do detector (Probe Jet detEta). . . . . . 74

4.9 Fatores de escala da eficiência da identificação de jatos com relação à pseudorapidez do jato nas coordenadas do detector (Probe Jet detEta) para cada corte da identificação de jatos. . . . . . . . . . . . . . . . . . .

4.10 Fatores de escala da eficiência da reconstrução e identificação de jatos com relação à pseudorapidez do jato de traços nas coordenadas do detector (Track Jet $\eta_{D E T}$ ) após a correção da simulação como explicada no texto. As curvas sólidas representam o erro sistemático. . . . . . . . . . . . . . 75

4.11 Resolução típica de jatos no DØ [79]. . . . . . . . . . . . . . . . . . 75

4.12 Incertezas da medida do espectro da seção de choque da produção inclusiva de jatos, incluindo a incerteza da eficiência da identificação de jatos (JetID) em azul [24]. . . . . . . . . . . . . . . . . . . . . . 76

4.13 Medida final da seção de choque da produção inclusiva de jatos [83] . . . . 77

4.14 Razão entre a medida da seção de choque da produção inclusiva de jatos e a previsão teórica [83]. . . . . . . . . . . . . . . . .

5.1 Dependência da energia depositada no calorímetro com relação à luminosidade instantânea $\left(L_{\text {inst }}\left[10^{30} \mathrm{~cm}^{-2} \mathrm{~s}^{-1}\right]\right)$. . . . . . . . . . . . . . . . .

5.2 Distribuições das variáveis dos jatos mostrando boa concordância entre dados (JT_125TT) e simulação (PYT). . . . . . . . . . . . . . . . .

5.3 Perfil da luminosidade instantânea para os dados (JT_125TT) e para simulação (PYT) nas unidades $10^{30} \mathrm{~cm}^{-2} \mathrm{~s}^{-1}$. . . . . . . . . . . . . . 85

5.4 Ilustração de como é calculado o limiar $E_{l}^{M C}$. Considere binc $=\operatorname{bin}_{M C} . \quad$. $\quad 86$

5.5 Constantes de calibração $(\alpha)$ encontradas para o teste de consistência através do método explicado na subseção 5.2.2 para células da amostra de dados reais.

5.6 Constantes de calibração $(\alpha)$ encontradas para o teste de consistência através do método explicado na subseção 5.2.2 para células da amostra de simulação. . . . . . . . . . . . . . . . . . . .

5.7 Fatores de correção relativa $(\alpha)$ da resposta do calorímetro simulado para o calorímetro real.

5.8 Fatores de correção relativa $(\alpha)$ da resposta do calorímetro simulado obtida após a correção para o calorímetro real. . . . . . . . . . . . . .

5.9 Frações da energia transversa contida em cada camada dos calorímetros EM e FH antes da correção. Os histogramas de linha vermelha representam a simulação e, os pontos, os dados reais.

5.10 Frações da energia transversa contida em cada camada dos calorímetros EM e FH depois da correção. Os histogramas de linha vermelha representam a simulação e, os pontos, os dados reais. . . . . . . . . . . . . . .

6.1 Perfil da luminosidade instantânea de todas as amostras usadas comparado com o perfil almejado (distribuição tracejada). As distribuições estão normalizadas para possuírem área igual a um. . . . . . . . . . . . . .

6.2 Número de eventos após a seleção explicada na seção 6.2 para três diferentes triggers. . . . . . . . . . . . . . . . . . . . . . . 98

6.3 Razão entre o número de eventos dos dados e o número de eventos simulados após a normalização explicada no texto. . . . . . . . . . . . . . 
Figura

Página

6.4 Variáveis dos dois jatos mais energéticos para eventos NDF simulados e dados reais: momentum trasnverso $\left(p_{T}^{j 1, j 2}\right)$, rapidez $\left(y^{j 1, j 2}\right)$, massa invariante do sistema de dijatos $\left(M_{j j}\right)$ e a diferença entre seus ângulos azimutais $(\Delta \varphi) . \quad 99$

6.5 Variável da energia fora do sistema de dijato para dados simulados não difrativos e dados reais. . . . . . . . . . . . . . . . . . . . . 102

6.6 Variável da energia fora do sistema de dijato para todas amostras de simulação. As distribuições estão normalizadas pela área. ......... 102

6.7 Comparação entre a distribuição de LL e de ll, como explicado no texto. 104

6.8 Frações das energias transversas (FRACTION) em cada camada do calorímetro norte para ieta maior que 30. As camadas $(L A Y E R) 1,2,3$ e 4 representam o calorímetro EM e as camadas 5, 6, 7 e 8 o calorímetro FH. . . . . . . . 106

6.9 Frações das energias transversas (FRACTION) em cada camada do calorímetro sul para ieta maior que 30. As camadas ( $L A Y E R)$ 1, 2, 3 e 4 representam o calorímetro EM e as camadas 5, 6, 7 e 8 o calorímetro FH. . . . . . . . . 107

6.10 Frações das energias transversas (FRACTION) em cada camada do calorímetro norte para ieta $=(20,30]$. As camadas $(L A Y E R) 1,2,3$ e 4 representam o calorímetro EM e as camadas 5, 6, 7 e 8 o calorímetro FH. . . . . . . . . 108

6.11 Frações das energias transversas (FRACTION) em cada camada do calorímetro sul para ieta $=(20,30]$. As camadas $(L A Y E R) 1,2,3$ e 4 representam o calorímetro EM e as camadas 5, 6, 7 e 8 o calorímetro FH. . . . . . . . . . 109

6.12 Distribuição das variáveis definidas na equação 6.9 . . . . . . . . . . . . . 110

6.13 Distribuição das variáveis definidas na equação 6.9 . . . . . . . . . . . . . 111

6.14 Distribuição das variáveis definidas na equação 6.9 . . . . . . . . . . . . . 112

6.15 Distribuição das variáveis definidas na equação 6.9 para todos os modos de produção simulados. . . . . . . . . . . . . . . . . . . . 113

6.16 Distribuição das variáveis definidas na equação 6.9 para todos os modos de produção simulados. . . . . . . . . . . . . . . . . . . . 114

6.17 Distribuição das variáveis definidas na equação 6.9 para todos os modos de produção simulados. . . . . . . . . . . . . . . . . . . 115

6.18 Distribuições do discriminante construído pelo método multivariável de verossimilhança para as quatro produções difrativas e a distribuição $R_{j j}$ depois do corte $l l(e d p / n d f)>0,95$. Apenas dados reais e a simulação NDF são mostrados. . . . . . . . . . . . . . . . . . . . . . . . 117

6.19 Distribuições do discriminante construído pelo método multivariável de verossimilhança para as quatro produções difrativas e a distribuição $R_{j j}$ depois do corte $l l(e d p / n d f)>0,95$.

6.20 Variável da energia fora do sistema de dijato para dados reais e simulação, considerando todas as produções, exceto a EDP.

6.21 Distribuição do discriminante construído pelo método multivariável de verossimilhança considerando NDF, SDN, SDS e IDP como ruídos (BKG), e EDP como sinal, sendo esse normalizado pela seção de choque do modelo KMR. 121

A.1 Distância mínima entre a reta formada por uma tira do detector CPS e o centro do cone do jato . . . . . . . . . . . . . . . . . . . 125

A.2 Ajuste da função $f_{C P S}$ para eventos simulados de fóton+jato com jatos reconstruídos com cone $\Delta R=0,5$. 
Figura

Página

A.3 Melhoria na resolução da energia do jato para eventos simulados de fóton+jato com jatos reconstruídos com cone $\Delta R=0,5\left(E^{\prime}=E_{p t c l}\right) . \quad$. . . 127

A.4 Ajuste da função $f_{C P S}$ para eventos simulados de fóton+jato com jatos reconstruídos com cone $\Delta R=0,5$ usando $E^{\prime}$ ao invés de $E_{p t c l}$. . . . . 128

A.5 Melhoria na resolução da energia do jato para eventos simulados de fóton+jato com jatos reconstruídos com cone $\Delta R=0,5$. . . . . . . . . 128

A.6 Ajuste da função $f_{C P S}$ para eventos reais de fóton+jato com jatos reconstruídos com cone $\Delta R=0,5$. . . . . . . . . . . . . . . . . . . 128

A.7 Melhoria na resolução da energia do jato para eventos reais de fóton+jato com jatos reconstruídos com cone $\Delta R=0,5$.

A.8 Comparação das funções $f_{C P S}$ para eventos simulados de fóton+jato e produção de Higgs para jatos centrais reconstruídos com cone $\Delta R=0,5$.

A.9 Comparação das funções $f_{C P S}$ para eventos simulados de dijato e de produção de dois quarks b para jatos centrais reconstruídos com cone $\Delta R=$

A.10 Comparação das funções $f_{C P S}$ para eventos simulados de dijato e produção de dois quarks b para jatos centrais reconstruídos com cone $\Delta R=0,7$.

A.11 Ajuste da função $f_{C P S}$ para eventos simulados de dijato com jatos reconstruídos com cone $\Delta R=0,5$. . . . . . . . . . . . . . . . . . . . 132

A.12 Ajuste da função $f_{C P S}$ para eventos simulados de dijato com jatos reconstruídos com cone $\Delta R=0,7$.

A.13 Ajuste da função $f_{C P S}$ para eventos reais de dijato com jatos reconstruídos com cone $\Delta R=0,5$.

A.14 Ajuste da função $f_{C P S}$ para eventos reais de dijato com jatos reconstruídos com cone $\Delta R=0,7 \ldots \ldots \ldots \ldots \ldots \ldots$

A.15 Melhoria da resolução da energia do jato para eventos simulados de dijato com jatos reconstruídos com cone $\Delta R=0,5$.

A.16 Melhoria da resolução da energia do jato para eventos simulados de dijato com jatos reconstruídos com cone $\Delta R=0,7$.

A.17 Melhoria da resolução da energia do jato para eventos reais de dijato com jatos reconstruídos com cone $\Delta R=0,5$.

A.18 Melhoria da resolução da energia do jato para eventos reais de dijato com jatos reconstruídos com cone $\Delta R=0,7$.

A.19 Comparação da função $f_{C P S}$ para eventos reais de dijato entre as amostras p17 e p20 com jatos reconstruídos com cone $\Delta R=0,5$. . . . . . . . 135

B.1 Distribuições de energia de células problemáticas (vermelho) de células normais (linha preta pontilhada). . . . . . . . . . . . . . . . 139

B.2 Ocupação das células do anel de $\varphi(7,10)$ no período 6 . . . . . . . . . . . . 140

B.3 Ocupação das células do anel de $\varphi(1,-3)$ no período 2 . . . . . . . . . . . . 141

B.4 Distribuições de energia para células problemáticas (vermelho) e células normais (linha preta pontilhada). . . . . . . . . . . . . . . 142

B.5 Ocupação das células do anel de $\varphi(7,16)$ para o período 1 . . . . . . . . . . 143

B.6 Ocupação das células do anel de $\varphi(11,11)$ para o período $1 . \quad$. . . . . . . . . . 144

B.7 Distribuições de energia de células problemáticas (vermelho) e células normais (linha preta pontilhada). . . . . . . . . . . . . . . 145

B.8 Ocupação das células do anel de $\varphi(14,23)$ para o período $2 . \quad$. . . . . . . . 146 
B.9 Ocupação das células do anel de $\varphi(14,-14)$ para o período $9 . \quad$. . . . . . . 147 


\section{Capítulo 1}

\section{Introdução}

Os fenômenos discutidos e estudados nesta tese são de natureza quântica e relativística. Mais especificamente, a teoria da cromodinâmica quântica (QCD) é credidata ser a teoria fundamental da fenomenologia que será estudada.

De fato, a QCD vem a ser uma teoria de grande sucesso na predição e descrição de fenômenos envolvendo a interação forte, no entanto, esse sucesso é limitado ao regime perturbativo, i.e, no limite em que os quarks e glúons são considerados partículas livres. No espalhamento elástico ou difração de hádrons, faz-se necessário o uso de modelos fenomenológicos, já que as interações entre os constituintes dos hádrons têm que ser consideradas.

Há aproximadamente 20 anos, foi observada em processos difrativos, a produção de partículas de alto momentum transverso $\left(\mathrm{p}_{\mathrm{T}}\right)$, indicando a existência de uma escala dura em um processo não perturbativo. Esse fato incentivou a construção de modelos difrativos baseados em QCD a nível partônico.

O colisor de elétron-próton HERA tornou-se percursor na observação da estrutura partônica do próton, medindo, assim, as funções de distribuição de pártons (pdfs). Conseqüentemente, as pdfs diffrativas também podem ser acessadas nesse tipo de colisão quando o próton é difratado. Essas medidas elevaram a importância da física difrativa dentro da comunidade de física de partículas, considerando o fato de que, aproximadamente, $10 \%$ dos eventos em colisões de elétron-próton são difrativos

Um dos modelos de difração dura de maior sucesso é baseado na fatoração entre o processo que dá origem à produção de alto $\mathrm{p}_{\mathrm{T}}$ e à fenomenologia que proporciona a difração. Isso possibilita a comparação direta de resultados entre colisores do tipo lépton-hádron e hádron-hádron. No entanto, foi observada uma quebra dessa fatoração no Tevatron. Uma forma de explicar esse resultado é acrescentar uma constante na seção de choque em colisores de hádron-hádron, que provém da probabilidade de pártons espectatores interagirem entre si e, dessa forma, a difração ficar mascarada.

Considerando o modelo de fatoração, um processo difrativo muito interessante em colisores hádron-hádron seria quando ambos os hádrons sofrem um processo difrativo e 
uma produção central de alto $\mathrm{p}_{\mathrm{T}}$ é observada. Pode-se imaginar que essa produção central carregue apenas parte da energia perdida pelos hádrons ou, em um caso extremo, toda essa energia. Nesse último caso, a produção é considerada exclusiva e contém, dessa forma, alta correlação entre o regime não perturbativo e o perturbativo da QCD. Além do aspecto importante de estar acessando a fundo a correlação desses regimes, medindo-se a cinemática dos hádrons difratados, pode-se medir a massa central produzida, tornandose, portanto, um canal importante para descoberta de física nova no LHC com o uso detectores frontais de prótons.

Nesta tese, uma busca por eventos produzidos pelo processo difrativo exclusivo no experimento D $\varnothing$ é apresentada. A presença de dois jatos é requerida para garantir a presença da escala dura. Os eventos são provenientes de dados tomados pela colaboração D no acelerador Tevatron. No espaço de fase, no qual os eventos obtidos foram procurados, nenhuma observação foi possível, porém, um limite para a produção desse processo foi estabelecido e modelos fenomenológicos excluídos.

No capítulo 2, a teoria que envolve a física de partículas é revisada e os modelos fenomenológicos para a difração são discutidos. No capítulo 3, o acelerador Tevatron e o experimento DØ são descritos. A descrição de jatos no experimento D $\varnothing$ encontra-se no capítulo 4. Métodos utilizados para garantir a qualidade da calorimetria do detector DØ são descritos no capítulo 5. Finalmente, no capítulo 6, a análise é apresentada e seus resultados discutidos. Conclusões sobre os resultados são expressas no capítulo 7 . No final desta tese, um glossário com diversos termos técnicos utilizados ao longo do texto é apresentado.

Nota-se que, parte do trabalho desenvolvido durante o período de doutoramento não encontra-se documentado neste manuscrito. Expressiva parte das minhas contribuições para o experimento $\mathrm{D} \varnothing$ foram realizadas no sistema de detectores de prótons frontais: comissão dos detectores de tempo (TDC), operação deste sistema, colaboração no alinhamento e na medida de eficiência dos triggers, e estudos da reconstrução do momentum dos prótons. 


\section{Capítulo 2}

\section{Teoria}

Há mais de dois mil anos, o homem já discutia a existência e interação de partículas elementares, tal como Leucipo e Demócrito, que foram os primeiros a proporem a teoria atômica. Atualmente, o conhecimento humano alcançou notável sabedoria sobre a estrutura da matéria, porém, há ainda muitas perguntas sem respostas.

A física das partículas elementares fundamenta-se na teoria quântica de campos, a qual descreve com muito sucesso diversos resultados experimentais. Na seção 2.1, uma introdução ao modelo padrão é apresentada. Na seção 2.2, a teoria das interações fortes é brevemente revista. Na seção 2.3, o fenômeno de difração hadrônica é abordado. Na seção 2.4, a produção de dijatos no Tevatron é discutida e, finalmente, na seção 2.5, o processo estudado nesta tese é descrito.

\subsection{Modelo Padrão}

Todas as interações conhecidas na natureza podem ser explicadas através de quatro forças fundamentais: forte, fraca, eletromagnética e gravitacional (ver tabela 2.1). O modelo padrão é uma teoria que incorpora três das quatro interações fundamentais, deixando de fora apenas a gravitação, teoria ainda não entendida no nível quântico. Por outro lado, a força gravitacional tem intensidade desprezível no regime de energia de validade das três outras forças. Inúmeros resultados experimentais sugeriram que apenas uma teoria poderia explicar diversos fenômenos e, com o uso da teoria quântica de campos, foi possível construir o modelo padrão, considerado a teoria mais abrangente e bem sucedida do ponto de vista experimental.

O modelo padrão é uma teoria de calibre renormalizável e invariante sobre transformações locais de calibre, representado pelo grupo de simetria $\mathrm{SU}(3)_{C} \mathrm{xSU}(2)_{L} \mathrm{xU}(1)_{Y}$ $[1,2,3,4,5]$. Supõe-se que existam doze férmions elementares e 12 bósons de calibre, os quais intermediam as interações fundamentais (tabela 2.2). Os férmions dividem-se em léptons e quarks, os quais são classificados em três gerações, devido aos números quânticos associados a esses. Todas as interações possuem seus mediadores, sendo o fóton o medi- 


\begin{tabular}{|c|c|c|}
\hline Interação & Intensidade Relativa & Alcance \\
\hline Forte & 1 & $\approx 10^{-15} \mathrm{~m}$ \\
Eletromagnética & $10^{-2}$ & $\infty$ \\
Fraca & $10^{-15}$ & $\ll 10^{-15} \mathrm{~m}$ \\
Gravitacional & $10^{-41}$ & $\infty$ \\
\hline
\end{tabular}

Tabela 2.1: As 4 interações fundamentais e suas respectivas intensidades (considerando a força forte de intensidade unitária) e alcances. [4]

ador da interação eletromagnética; os bósons $W^{ \pm}$e $Z^{0}$ mediadores da interação fraca; e os glúons mediadores da força forte.

\begin{tabular}{|c|ccc|}
\hline & \multicolumn{3}{|c|}{ Gerações } \\
& $\mathrm{I}$ & $\mathrm{II}$ & $\mathrm{III}$ \\
\hline \multirow{2}{*}{ léptons } & $\nu_{e}(1953)$ & $\nu_{\mu}(1962)$ & $\nu_{\tau}(2000)$ \\
& $e(1897)$ & $\mu(1936)$ & $\tau(1975)$ \\
\hline \multirow{2}{*}{ quarks } & $\mathrm{u}(1968)$ & $\mathrm{c}(1974)$ & $\mathrm{t}(1995)$ \\
& $\mathrm{d}(1968)$ & $\mathrm{s}(1964)$ & $\mathrm{b}(1977)$ \\
\hline \hline \multirow{2}{*}{ bósons de calibre } & \multicolumn{3}{|c}{$\mathrm{g} 1 \ldots \mathrm{g} 8(1979)$} \\
& \multicolumn{3}{|c|}{$W^{ \pm}, Z^{0}(1900)$} \\
\hline
\end{tabular}

Tabela 2.2: Partículas elementares da natureza até o presente momento. Entre parênteses estão os anos de suas respectivas observações $[1,2,6,8]$

As interações eletromagnéticas são descritas pela eletrodinâmica quântica (QED). O número quântico que a caracteriza é a tão conhecida carga elétrica. Excluindo o fóton, mediador da QED, as únicas partículas elementares que possuem carga elétrica nula são os glúons, os neutrinos e o $Z^{0}$. As interações eletromagnéticas são responsáveis pelas ligações atômicas e moleculares.

A cromodinâmica quântica (QCD) é a teoria das interações fortes. Sendo uma teoria de calibre de simetria $\mathrm{SU}(3)_{c}$, há três graus de liberdade correspondendo a números quânticos, comumente denominados cores (verde, vermelho e azul). Os léptons não carregam cor, não participando das interações fortes [9]. Já os glúons, por carregarem cor, podem interagir entre si, produzindo os efeitos de confinamento e liberdade assintótica: a força forte aumenta quanto maior a separção entre as partículas e diminui com a aproximação destas. Dessa forma, a interação forte é responsável pela formação de estados ligados: núcleos atômicos e hádrons.

A interação fraca é a única das quatro interações fundamentais que não produz estados ligados, que atua em todos os férmions fundamentais e que distingue as gerações e a quiralidade. Há dois tipos de interação fraca: carregada, mediada pelo $W^{ \pm}$e neutra, mediada pelo $Z^{0}$. Através da troca de $W^{ \pm}$; os quarks podem mudar de sabor (e.g., 
$u \rightarrow d$, inclusive para outro fora de sua geração (e.g, $u \rightarrow s$ ), originando a matriz de Cabibbo-Kobayashi-Maskawa (CKM) [4].

O modelo padrão, até o presente momento, não inclui as massas das partículas elementares em sua Lagrangiana, pois tal termo viola a invariância de calibre. O mecanismo de Higgs de quebra espontânea de simetria [10], no entanto, permite a introdução de termos associados com as massas dos bósons $W^{ \pm}$e $Z^{0}$, permitindo também a adição da massa dos férmions como acoplamentos de Yukawa entre esses e o campo de Higgs. Os glúons e o fóton possuem massa nula, portanto não se acoplam com o Higgs. Atualmente, há uma grande movimentação no meio científico para a descoberta do bóson de Higgs, incluindo a construção do grande acelerador LHC [11].

Nesta tese, a fenomenologia a ser discutida está relacionada à interação forte. Portanto, descrever-se-á com mais detalhes essa última, não nos aprofundando nas outras duas, as quais ainda podem ser unificadas utilizando-se a teoria de Glashow-Weinberg-Salam [5].

\subsection{QCD}

Nos anos 50, muitos experimentos detectavam partículas pesadas denominadas hádrons, que apresentavam interação forte as quais se supunham ser fundamentais. Primeiramente, foram classificadas por suas cargas elétricas e spins. Entretanto, devido ao aumento do número de hádrons observados e da complexidade das regras que regiam seus decaimentos, os hádrons, já divididos em bárions (pesados) e mésons (massas intermediárias), foram organizados em padrões geométricos. Enfim, Gell-Mann e Zweig propuseram o modelo de quarks, o qual explica os padrões descobertos, supondo que os hádrons não são de fato fundamentais, mas constituídos por outras partículas mais fundamentais, chamadas de quark [12]. As propriedades dos quarks estão expostas na tabela 2.2.

\begin{tabular}{|c|c|c|c|c|}
\hline Quark & Carga & Massa & Número Bariônico & Isospin \\
\hline $\mathrm{u}$ & $+2 / 3$ & $\lesssim 4 \mathrm{MeV}$ & $1 / 3$ & $+1 / 2$ \\
\hline $\mathrm{d}$ & $-1 / 3$ & $\lesssim 7 \mathrm{MeV}$ & $1 / 3$ & $-1 / 2$ \\
\hline $\mathrm{c}$ & $+2 / 3$ & $\sim 1,3 \mathrm{GeV}$ & $1 / 3$ & 0 \\
\hline $\mathrm{s}$ & $-1 / 3$ & $\sim 95 \mathrm{MeV}$ & $1 / 3$ & 0 \\
\hline $\mathrm{t}$ & $+2 / 3$ & $\sim 172 \mathrm{GeV}$ & $1 / 3$ & 0 \\
\hline $\mathrm{b}$ & $-1 / 3$ & $\sim 5 \mathrm{GeV}$ & $1 / 3$ & 0 \\
\hline
\end{tabular}

Tabela 2.3: Propriedades dos quarks [15].

A introdução do grau de liberdade cor foi necessária a fim de resolver o problema de os quarks estarem no mesmo estado quântico, e.g. em bárions de spin $\frac{3}{2}$. Sem a cor, os quarks não poderiam obedecer à estatística de Fermi-Dirac [13]. Com o objetivo de explicar a não existência de milhares de hádrons, o requerimento de apenas existirem singletos de cor (cor nula) foi imposto. 
A QCD nasceu do advento do modelo de quarks, verificado através de diversos resultados experimentais na década de 70 [2]; e do uso de técnicas de perturbação da teoria quântica de campos para explicar resultados experimentais, e.g. a evidência de eventos com três jatos no laborátorio PETRA [14]. .

Como os quarks são coloridos, os glúons necessitam carregar duas cores, fato já determinado pela simetria da QCD. Poderiam existir, de fato, nove glúons, oito octetos de cor e um singleto de cor, podendo esse último interagir como partícula livre. É conhecido experimentalmente, porém, que a interação forte é de curto alcance, e a existência de um glúon como singleto de cor resultaria numa interação de longo alcance nunca observada.

Uma forma muito utilizada para representar a interação de duas partículas em teorias quânticas de campo é o gráfico de Feynman. De fato, os gráficos de Feynman correspondem à termos de uma série perturbativa para cálculos de interações entre campos quânticos, onde o acoplamento entre esses é pequeno. O gráfico consiste em três partes:

- as linhas externas, representando as funções de onda das partículas iniciais e finais;

- as linhas internas, descrevendo os propagadores da interação;

- os vértices, que representam o acoplamento entre as partículas.

O espalhamento de um quark $(q)$ e um antiquark $(\bar{q})$, através da troca de um glúon, seria representado pelo diagrama 2.1a. Note que a linha temporal no diagrama, decorre da esquerda para a direita. A fusão $q \bar{q}$ em um glúon seria representada pelo diagrama 2.1b. Os gráficos de Feynman estão sujeitos a regras, para que os cálculos respeitem a teoria. Tais regras estão descritas em [1, 2, 4, 13].

Os gráficos de Feynman da figura 2.1 representam a primeira aproximação (ou primeira ordem ou LO) para o espalhamento $q q \rightarrow q q$. Para o cálculo exato de seções de choque e decaimentos seria necessário considerar as infinitas possibilidades de interações entre cada campo. No entanto, quando o fator de escala da interação (e.g., energia dos quarks interagentes) é muito grande, a soma dos primeiros termos da série perturbativa é uma boa aproximação.

A QCD é uma teoria de grande sucesso, pois muitas de suas implicações experimentais podem ser calculadas de forma perturbativa, ou seja, no regime em que quarks são partículas livres. No entanto, existem fenômenos de natureza hadrônica, como a formação de estados ligados, nos quais a aplicação da QCD perturbativa é bastante limitada, sendo necessária a criação de modelos fenomenológicos e fatorações.

Cálculos perturbativos em QCD conseguem descrever muito bem fenômenos como:

- correções devido à radiação de glúons na seção de choque hadrônica na aniquilação de um par elétron-pósitron;

- evolução da estrutura partônica do próton; 


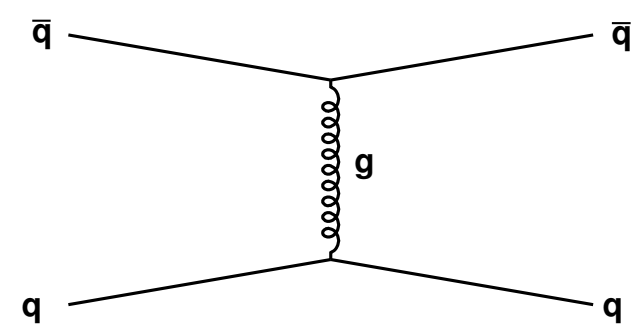

(a) Diagrama de Feynman representando o espalhamento entre um quark e um antiquark, com troca de um glúon.

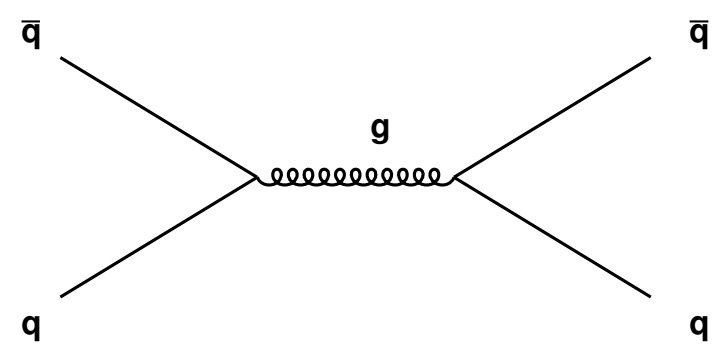

(b) Diagrama de Feynman representando a fusão de um quark e antiquark em um glúon.

Figura 2.1: Diagramas de Feynman de primeira ordem para o espalhamento elástico de quarks e fusão de quarks.

- cálculos perturbativos para seções de choque de jatos em colisores hadrônicos.

Porém, fenômenos não menos importantes ainda não apresentam uma descrição adequada, tais como:

- difração hadrônica;

- hadronização de quarks e glúons;

- estrutura partônica dos hádrons.

Um breve resumo sobre o uso de fatoração em QCD é apresentado na seção 2.2.1. Na seção 2.2.2, o conceito de jatos é abordado.

\subsubsection{Fatoração em QCD}

Como discutido da seções 2.1 e 2.2, os hádrons não são partículas fundamentais, mas sim uma mistura de quarks e glúons. Os principais blocos dos hádrons são seus quarks de valência, i.e., os que definem suas propriedades quânticas, porém, pode haver criação e aniquilação de outras partículas dentro do hádron.

Evidentemente, os constituintes do hádron, além de conterem números quânticos, possuem também um 4-vector associados a eles. Dessa forma, quando se calcula a seção de 
choque do espalhamento inelástico $e+p \rightarrow e+X$ mediado por um fóton virtual, em que $\mathrm{X}$ denota qualquer estado final, é natural usar uma convolução da probabilidade de achar um quark de determinado sabor com determinada fração de momentum do hádron, com a amplitude do espalhamento $e+q \rightarrow e+X$, como definida na equação 2.1 .

$$
\sigma_{e p}\left(x, Q^{2}\right)=\Sigma_{a} \int_{x}^{1} d \xi f_{a / p}(\xi) \hat{\sigma}\left(x / \xi, Q^{2}\right),
$$

onde, $Q^{2}$ é o 4-momentum ao quadrado do fóton virtual, $f_{a / p}(\xi)$ é a probabilidade do fóton virtual interagir com um quark livre do sabor a e que carrega uma fração $\xi$ do momentum longitudinal do próton, e $x$ é conhecida a variável de Bjorken, definida como:

$$
x=\frac{Q^{2}}{2 P \cdot q}
$$

sendo $P$, o 4-momemtum do próton e $q$ o 4-momentum do fóton virtual.

Note que a fatoração apresentada na equação 2.1 é válida somente no caso em que os quarks podem ser considerados livres, ou seja, no limite $Q^{2}, P \cdot q \rightarrow \infty$, chamado de espalhamento profundamente inelástico (DIS).

Em colisores hadrônicos, o uso da fatoração é amplamente usado em fenômenos de alto $\mathrm{p}_{\mathrm{T}}$. Nesses casos, os constituentes são considerados partículas livres e descritos pelo modelo partônico conforme ilustrado na figura 2.2. Dessa forma, a seção de choque pode ser escrita da forma:

$$
\sigma\left(P_{1}, P_{2}\right)=\Sigma_{i, j} \int d x_{1} d x_{2} f_{i}\left(x_{1}, \mu^{2}\right) f_{j}\left(x_{2}, \mu^{2}\right) \hat{\sigma}_{i j}\left(x_{1} P_{1}, x_{2} P_{2}, \alpha_{s}\left(\mu^{2}\right), Q^{2} / \mu^{2}\right)
$$

onde $P_{1}$ e $P_{2}$ são os 4-momentum iniciais dos hádrons; $\mu$ é a escala de renormalização da teoria; $x_{1}$ e $x_{2}$ a fração do 4-momentum carregado pelos pártons de seus respectivos hádrons; $f_{i}\left(x_{1}, \mu^{2}\right)$ a função distribuição do párton i dentro do hádron; $Q^{2}$ é a escala da espalhamento duro; e $\hat{\sigma}_{i j}\left(p_{1}, p_{2}, \alpha_{s}\left(\mu^{2}\right), Q^{2} / \mu^{2}\right)$ a seção de choque do processo duro, calculada usando-se a teoria de perturbação.

O uso da fatoração consiste na capacidade de separar um processo mole (não perturbativo, i.e., constante de acoplamento grande ou interação de longo alcance) de um processo duro (perturbativo). Essa dicotomia de ignorância e conhecimento corresponde à falta de habilidade de calcular perturbativamente fenômenos de longa de distância, apesar de possuir notória compreensão à pequenas distâncias. A fatoração é usada para explicar outros fenômenos , e.g., difração hadrônica.

\subsubsection{Jatos}

Devido ao fato de os glúons possuírem massa nula, quando se calcula um observável usando os cálculos de Feynman, divergências ultravioletas são encontradas. Para remover essas 


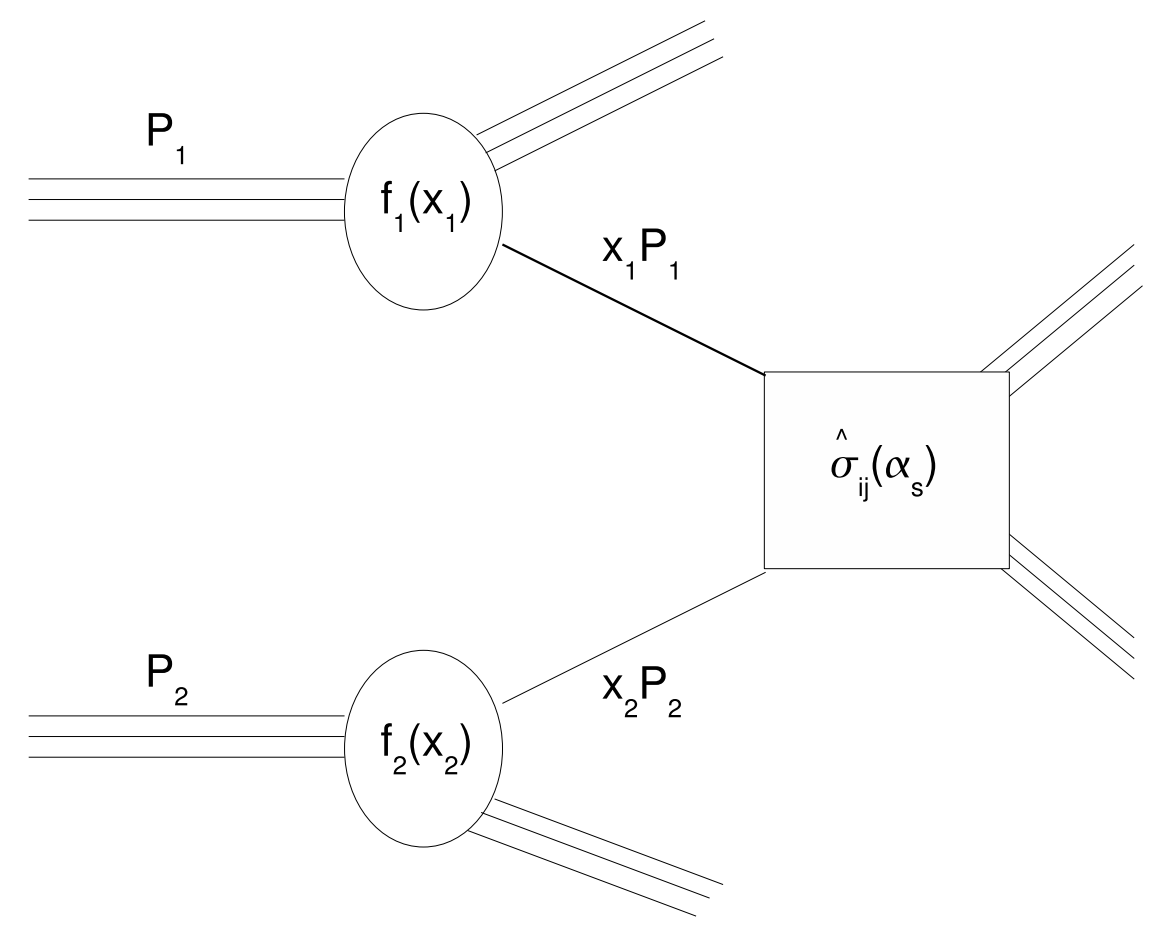

Figura 2.2: Representação da colisão de dois hádrons com produção de partículas de alto $\mathrm{p}_{\mathrm{T}}$.

divergências, é necessário aplicar técnicas de renormalização, introduzindo uma escala de massa $\mu$. Dessa forma, os observáveis dependem não apenas da escala de energia da interação $Q$, mas também da razão $\frac{Q^{2}}{\mu^{2}}$. Portanto, quando o espalhamento quark-quark (figura 2.1a) é calculado em ordens superiores, incluindo os gráficos do tipo representado na figura 2.3, o acoplamento efetivo entre esses dois quarks é:

$$
\alpha_{s}\left(Q^{2}\right)=\frac{\alpha_{s}\left(\mu^{2}\right)}{1+\left(\alpha_{s}\left(\mu^{2}\right) /(12 \pi)(11 n-2 f) \log \left(Q^{2} / \mu^{2}\right)\right.},
$$

onde $n$ é o número de cores $(=3)$ e $f$ o número de sabores $(=6)$, resultando em um fenônemo chamado liberdade assintótica. Ou seja, quanto menor a distância entre os quarks maior o $Q^{2}$ e menor o acoplamento entre eles. Conseqüentemente, os quarks e glúons podem ser considerados partículas livres se $Q^{2} \rightarrow \infty$, como observado na seção 2.2.1.

A liberdade assintótica e o postulado de que apenas partículas sem cor podem existir, fazem com que não observemos diretamente os quarks e glúons como partículas livres, mas sim como aglomerados de hádrons e seus decaimentos, chamados jatos. Jatos foram observados, primeiramente, em colisores de elétron-pósitron [16], e esses são quase onipresentes em colisores hadrônicos ou de íons pesados 


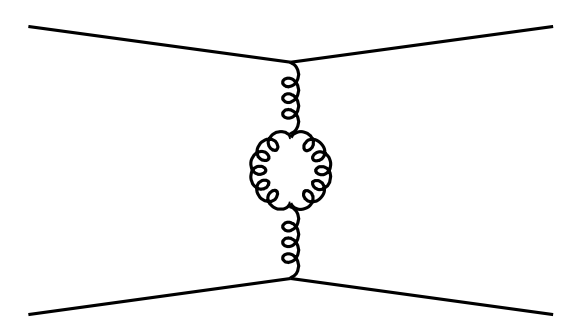

Figura 2.3: Exemplo de um diagrama de Feynman de ordem seguinte à dominante para o espalhamento elástico entre dois quarks.

\section{Simulação de Jatos}

O fenômeno de fragmentação e hadronização dos quarks e glúons (pártons) é de origem não perturbativa, pois involve interações de longo alcance. Para a comparação de dados experimentais com a teoria, faz-se necessário o uso de programas de simulação, como o PYTHIA [17] e o HERWIG [18].

De uma forma geral, o primeiro passo da simulação é fragmentar os pártons do estado final em outros pártons irradiados, utilizando uma probabilidade de o párton dividir-se em outros de menor energia, através do uso da QCD perturbativa. A probabilidade de não emissão de um párton é dada por:

$$
\mathcal{S}\left(Q^{2}\right)=\exp \left(-\int_{Q_{0}^{2}}^{Q^{2}} \frac{d q^{2}}{q^{2}} \int d z \frac{\alpha_{s}}{2 \pi} P(z)\right)
$$

onde $Q_{0}$ é o 4-momentum mínimo permitido, a fim de evitar divergências chamadas de infravermelhas; $Q^{2}$ é o 4-momentum do párton a ser dividido; e $P(z)$ é uma função probabilidade calculada em QCD perturbativa [21]. A probabilidade $\mathcal{S}\left(Q^{2}\right)$ é chamada de fator de forma de Sudakov [13].

O segundo passo é agrupar os pártons em hádrons, fenômeno chamado de hadronização, para o qual a QCD perturbativa não pode ser aplicada.

O HERWIG e o PYTHIA utilizam modelos de fragmentação e hadronização diferentes. Enquanto o HERWIG usa um modelo para a fragmentação descrito em [20], o PYTHIA usa o modelo de Lund [19]. Ambos os modelos funcionam de forma que apenas os quarks sejam agrupados na hadronização. Após a fragmentação, o HERWIG faz o agrupamento de objetos sem cor, que decaem em hádrons. O PYTHIA utiliza um módelo no qual sistemas de dois quarks são criados.

Os parâmetros são sempre ajustados para concordarem com dados experimentais. Em alguns casos, um prediz melhor do que o outro, mas nenhum dos dois possui lugar privilegiado na comunidade científica. 


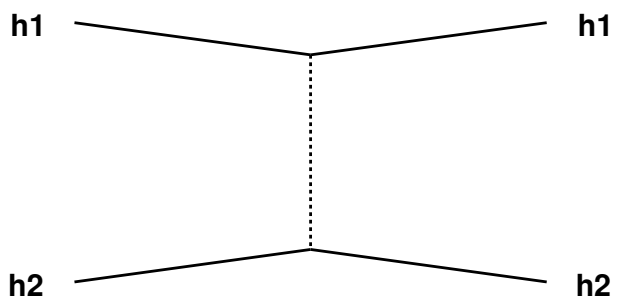

(a)

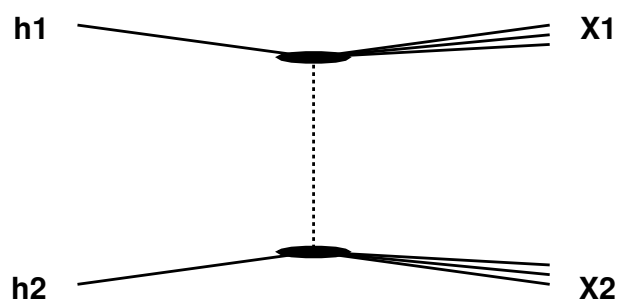

(c)

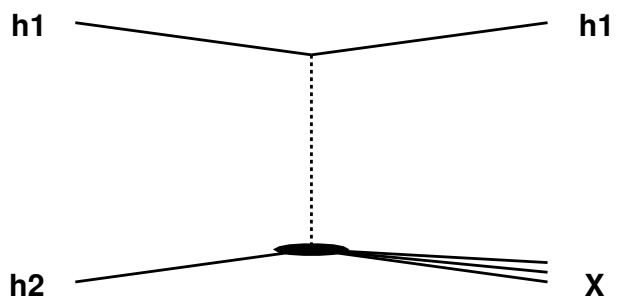

(b)

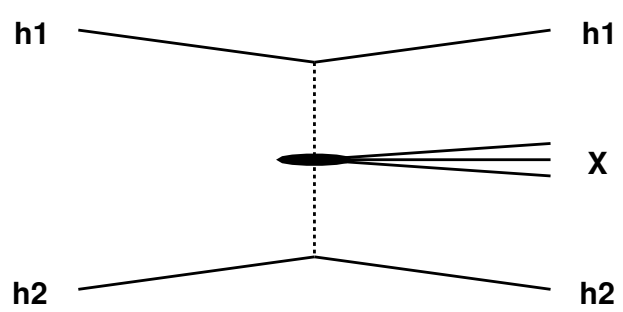

(d)

Figura 2.4: Os quatro tipos de difração hadrônica que podem ocorrer em um colisor de hádron-hádron.

\subsection{Difração}

De uma forma geral, o fenômeno de difração hadrônica é caracterizado pela falta de troca de cor, i.e., troca de um singleto de cor pelo hádron difratado. Em particular, toda reação na qual um hádron inicial permanece intacto é chamada difração hadrônica. Entretanto, é possível ocorrer troca de um singleto de cor e o hádron se dissociar.

Nos anos 60, as predições de Good e Walker [25] para os fenômenos de difração hadrônica foram confirmadas em colisores de hádrons. Nesse tipo de fenômeno, os constituintes dos hádrons não podem ser considerados partículas livres, já que sua escala de energia é pequena. Depois que a QCD tornou-se concretamente a teoria das interações fortes, passou a haver uma busca intensa para se entender a difração hadrônica com o uso de fundamentos básicos da QCD [26, 27].

Na figura 2.4, são mostrados os tipos de difração hadrônica em colisores hadrônicos. A figura 2.4a mostra o clássico espalhamento elástico. A figura 2.4b representa a difração simples, em que apenas um dos hádrons é difratado. O fenômeno de difração dupla é representado na figura $2.4 \mathrm{c}$, na qual os dois hádrons são difratados, porém, dissociam-se ou produzem ressonâncias. Na figura 2.4d, o fenômeno chamado de dupla troca de pomeron é ilustrado, no qual ambos os hádrons trocam o singleto de cor e, como conseqüência da colisão desses singletos de cor, partículas são produzidas. 


\subsubsection{Teoria de Regge}

Enquanto a difração hadrônica não é completamente entendida por fundamentos básicos da QCD, outras teorias são usados para explicar e predizer esses fenômenos. Uma das teorias mais aceitas e usadas é a teoria de Regge [28], apesar de se basear em espalhamento de potenciais não relativísticos. O principal resultado dessa teoria é que a amplitude de espalhamento, no limite $s \rightarrow \infty$, é descrita como

$$
A(s, t) \sim s^{\alpha(t)}
$$

onde $s$ e $t$ são as variáveis de Mandelstam [1,2], e $\alpha(t)$ representa a trajetória de Regge originada pelos pólos que são formados pela amplitude de ondas parciais da teoria de matriz S [26]. A trajetória de Regge mais usada em difração hadrônica é o pomeron, cujos números quânticos são os mesmos do vácuo.

Donnachie e Landshoff descreveram com grande sucesso as seções de choque totais [29] para os espalhamentos $p p, p \bar{p}, K^{ \pm} p, \pi^{ \pm} p$ e $\gamma p$, usando uma expressão baseada na teoria de Regge:

$$
\sigma_{T O T} \sim \Sigma_{i} A_{i} s^{\alpha_{i}(0)-1}=X s^{0,0808}+Y s^{-0,4525},
$$

onde X e Y são parâmetros dependentes dos estados iniciais da colisão. O segundo termo é explicado pela troca de reggeons, trajetórias identificadas por mésons como o $\rho$ e $\omega$. O primeiro termo é associado à troca de um pomeron, ressonância ainda não observada, supostamente formada de glúons (bola de glúons).

Supondo que $\alpha(t)$ possa ser expandido em uma série de potências, se t é pequeno, então:

$$
\alpha(t)=\alpha(0)+\alpha^{\prime} t
$$

onde $\alpha(0)$ é conhecido como a interseção da trajetória de Regge, e $\alpha^{\prime}$ sua inclinação. Dessa forma, usando o primeiro termo da equação 2.7, a interseção do pomeron é

$$
\alpha(0) \simeq 1,08
$$

O pomeron com $\alpha(0) \simeq 1,08$ é geralmente classificado como pomeron mole, já que esse parâmetro provém de um fenômeno exclusivamente não perturbativo. Quando uma escala dura está presente na difração hadrônica, o valor da interseção do pomeron modifica-se levemente, fato que ainda permanece sem explicação.

Outros modelos fenomenológicos são utilizados na procura de uma forma de entender a difração aos olhos da QCD perturbativa [34], o que enriquece muito essa área da física das partículas elementares. 


\subsubsection{Lacunas de Rapidez}

Uma característica muito usada para identificar a difração hadrônica são as chamadas lacunas de rapidez, ou seja, intervalos de rapidez (ver subseção 3.2.1 para definição de rapidez) em que nenhuma partícula é produzida. As lacunas de rapidez acontecem entre o hádron difratado e a produção central.

No caso da difração simples representada na figura 2.4b, supondo que o hádron difratado tenha massa $m$ e rapidez positiva, e trabalhando no limite em que o momentum longitudinal é muito grande, pode-se calcular que o valor mínimo da rapidez do hádron h1 é:

$$
\left(y_{h 1}\right)_{M I N} \simeq \log \frac{\sqrt{s}}{m}
$$

Também é possível calcular o valor máximo de rapidez para uma partícula de massa $m$ pertencente ao sistema $\mathrm{X}$

$$
\left(y_{X}\right)_{M A X} \simeq \log \frac{m \sqrt{s}}{M^{2}},
$$

onde $M$ é a massa do sistema X. Dessa forma, nenhuma partícula é produzida no intervalo de rapidez

$$
\Delta y \simeq \log \frac{s}{M^{2}}
$$

o que origina uma lacuna de rapidez entre o hádron difratado e a produção de partículas no sistema $X$.

O mesmo cálculo é válido para o caso da dupla troca de pomeron, portanto duas lacunas frontais de rapidez são produzidas. Já no caso de difração dupla, a lacuna de rapidez é entre o sistema de partículas $X 1$ e o sistema de partículas $X 2$.

\subsubsection{Difração Dura}

O fenômeno de difração dura foi sugerido por Ingelman e Schlein em 1985 [30]. Ambos sugeriram estudar a produção difrativa de jatos de alto momentum transverso para investigar a estrutura partônica do pomeron [31].

Em 1988, a colaboração UA8 observou eventos com jatos e grandes lacunas de rapidez [32] na colisão próton-antipróton, sendo o primeiro resultado experimental de que em eventos difrativos, pode existir uma escala dura associada. A existência dessa escala dura implica na possibilidade de usar a QCD perturbativa para explicar esse fenômeno e predizer outros semelhantes.

Supondo que exista um fluxo de pomeron e que esse possua uma estrutura partônica similar à dos hádrons, pode-se aplicar a fatoração discutida na seção 2.2.1. Portanto, a seção de choque da difração simples com produção de estado final com alto momentum transverso pode ser escrita como:

$$
d \sigma \sim f_{\mathbb{P} / h 1}(\xi, t) f_{a / \mathbb{P}}\left(\beta, Q^{2}\right) f_{b / h 2}\left(x, Q^{2}\right) d \hat{\sigma}_{a+b \rightarrow X}
$$


onde $f_{\mathbb{P} / h 1}(\xi, t)$ é a probabilidade do hádron h1 emitir um pomerom com 4-momentum ao quadrado t e fração de momentum $\xi$ do hádron; $f_{a / \mathbb{P}}\left(\beta, Q^{2}\right)$ é a probabilidade de achar um párton do sabor a dentro do pomeron com fração da energia e momentum $\beta$ e que colida produzindo um estado final de 4-momentum $Q ; f_{b / h 2}\left(x, Q^{2}\right)$ a probabilidade de achar um párton do sabor b dentro do hádron h2 com fração de energia $x$ e que colida produzindo um estado final de 4-momentum $Q$; e $d \hat{\sigma}_{a b \rightarrow X}$ é a seção de choque diferencial do processo duro $a+b \rightarrow X$ similar à apresentada na equação 2.3.

Em 1994, as colaborações ZEUS e H1 também observaram a difração dura de prótons em colisões elétron-próton [33]. A taxa da produção difrativa foi estimada em $10 \%$ dos eventos, uma surpresa para a comunidade científica, visto se tratar de um índice maior do que o esperado para esse tipo de produção. Nesses tipos de eventos é possível medir uma função de estrutura difrativa do próton similar à função da equação 2.1, só que medida em eventos difrativos. Supondo a fatoração entre o fluxo do pomeron e o processo duro, a função de estrutura difrativa pode ser escrita como:

$$
F^{D}\left(Q^{2}, \xi, t\right)=f_{\mathbb{P} / h 1}(\xi, t) f_{b / \mathbb{P}}\left(\beta, Q^{2}\right)
$$

Assim como a função de estrutura não difrativa calculada em experimentos do tipo elétron-próton podem ser usadas em experimentos hadrônicos, é natural acreditar que o mesmo acontece para a função de estrutura difrativa. A colaboração CDF, porém, mediu a função de estrutura difrativa no Tevatron, colisor próton-antipróton, e verificou uma discrepância de uma ordem de grandeza em relação a medida no HERA. Essa discrepância não é ainda bem explicada, mas acredita-se que há essa quebra da fatoração devido às interações entre pártons espectadores dos hádrons, as quais não existem em colisões elétron-próton. Essas interações resultariam numa normalização do fluxo do pomeron $f_{\mathbb{P} / h 1}(\xi, t)$, usualmente chamada de probabilidade de sobrevivência da lacuna de rapidez.

\subsection{Produção de Dijatos no Tevatron}

Muitos estados finais estudados no Tevatron contém jatos, e.g., produção de Higgs. Nesta tese, o estado final estudado é a produção de dois jatos (dijatos), a qual em ordem dominante da QCD perturbativa é calculada com os diagramas do tipo representado pela figura 2.1 [22]. Cálculos em ordem seguinte à dominante (ou NLO) [23] incluem correções de radiação de estado final (proveniente dos pártons finais) e de estado inicial (proveniente dos pártons iniciais), e interações entre os campos (ver figura 2.5).

O estado final dijatos pode ser produzido através de um espalhamento completamente inelástico (figura 2.2), de difração simples (figura 2.4b) e troca dupla de pomeron (figura $2.4 \mathrm{~d})$. 


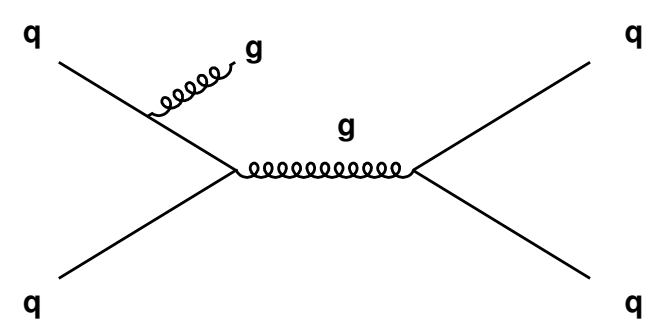

(a)

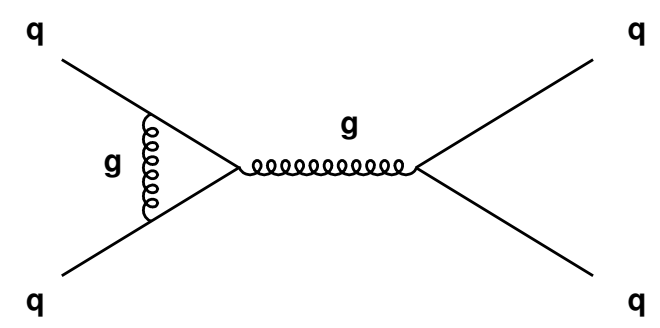

(c)

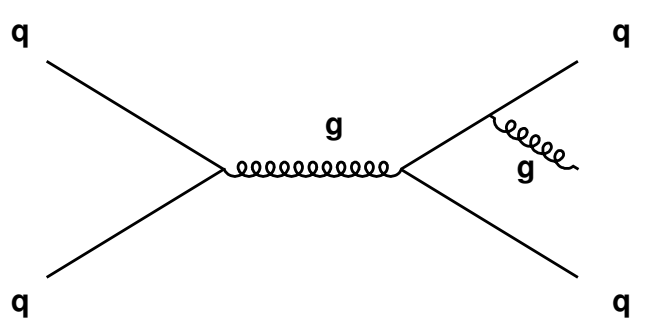

(b)

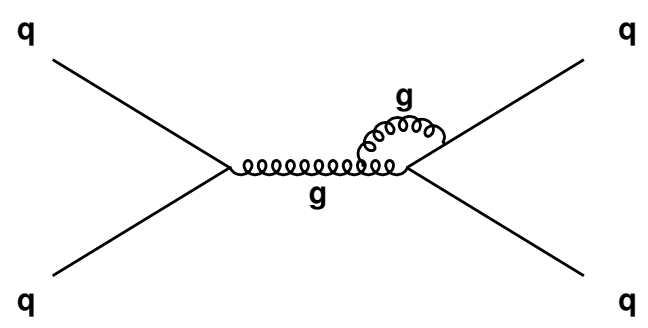

(d)

Figura 2.5: Alguns diagramas de Feynman de ordem seguinte à dominante para o espalhamento de dois quarks. O diagrama (a) inclui correção devido radiação do estado inicial. O diagrama (b) leva em conta radiação do estado final. Os diagramas (c) e (d) consideram interações entre os campos.

\subsubsection{Espalhamento Inelástico}

A produção de dijatos de alto momentum transverso indica que a interação entre os pártons ocorreu num espaço de tempo muito curto, portanto, a probabilidade do hádron tornar-se instável e quebrar é alta. Dessa forma, a seção de choque da produção de dijatos é muito maior em espalhamento inelástico do que em difração hadrônica (figura 2.2). Portanto, a seção de choque pode ser descrita pela equação 2.3 , em que $\hat{\sigma}_{i j}$ é a seção de choque da produção de dijatos.

Esse espalhamento é muito utilizado para testar cálculos de QCD perturbativa de ordem superior à dominante, já que sua seção de choque é consideravelmente alta, sendo também fonte de ruído para outros canais. Também pode-se acessar a função de estrutura do (anti)próton para altos valores de $x$ (fração do momentum carregado pelo párton).

Como discutido na seção 2.2.1, a fatoração funciona bem para espalhamentos hadrônicos inelásticos, sendo correto usar funções de estruturas medidas no HERA. Para isso, usam-se equações da QCD perturbativa para evolução da estrutura partônica (DGLAP) [21]. Na figura 2.6 pode-se ver a probabilidade de um párton possuir fração de momentum do (anti)próton $x$, na escala de energia $Q^{2}=10 \mathrm{GeV}^{2}$, ajustada pelas colaborações $\mathrm{H} 1$, ZEUS e CTEQ.

Convoluindo a seção de choque dura $\hat{\sigma}_{i j}$ com a probabilidade de achar certo sabor de párton, pode-se achar diferentes combinações de pártons iniciais, com suas respectivas 
probabilidades, como mostrado na figura 2.7.

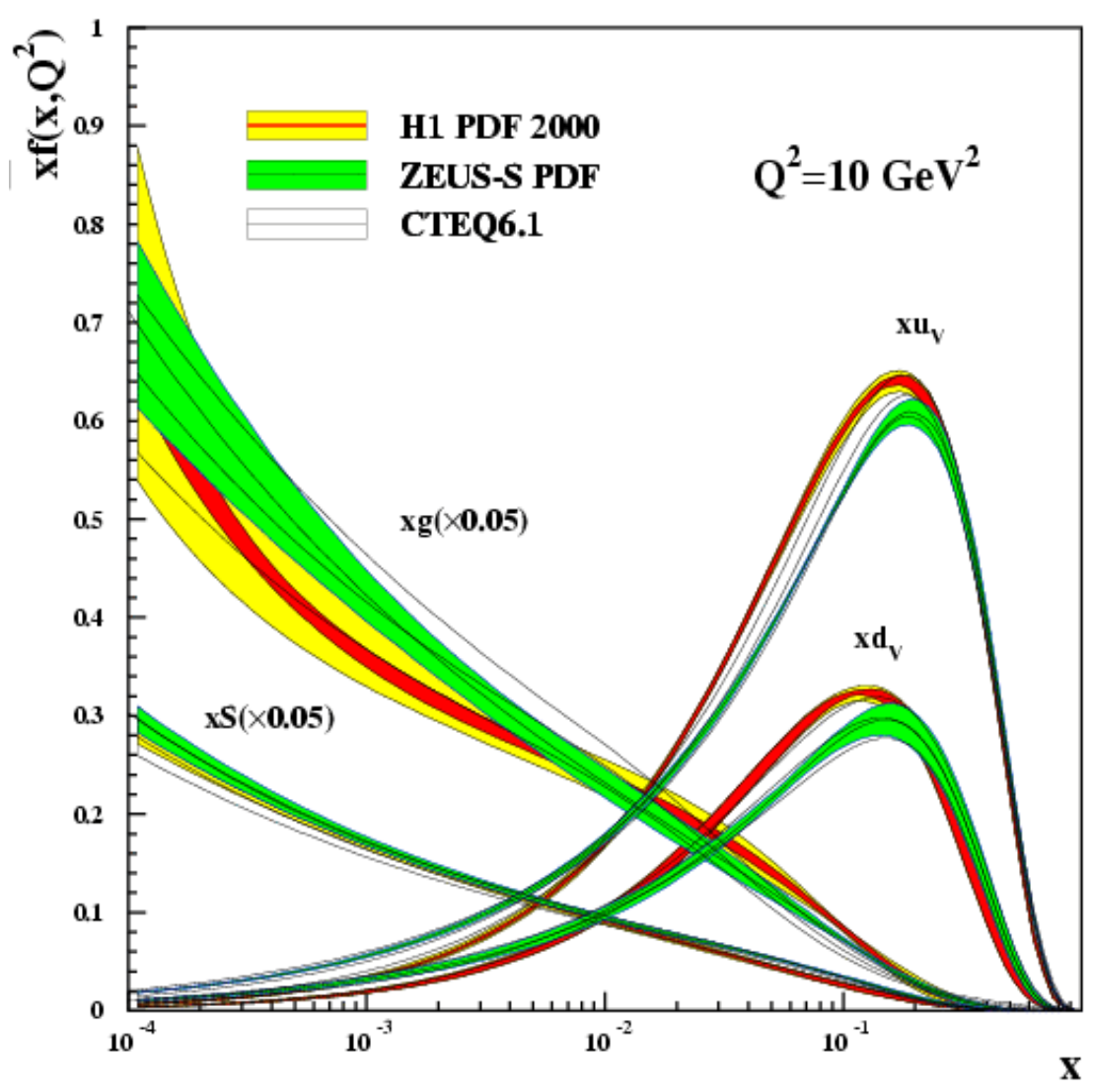

Figura 2.6: Distribuição de probabilidades $x f\left(x, Q^{2}\right)$ de um párton com fração de momentum do (anti)próton $x$, na escala de energia $Q^{2}=10 \mathrm{GeV}^{2}$ ajustadas pelas colaborações H1, ZEUS e CTEQ [24]. A função $S$ representa o quark estranho s; a função $g$, os glúons; a função $u_{v}$, os quarks de valência $\mathrm{u}$; e a função $d_{v}$, os quarks de valência d.

\subsubsection{Difração Simples}

A produção de dijatos por difração simples pode ser representada pela proposta de Ingelman e Schlein [30] e ilustrada pela figura 2.8, em que $X_{\mathbb{P}}$ representa os remanecentes da fragmentação do pomeron. Portanto, a seção de choque dessa produção pode ser escrita no mesmo espírito da equação 2.13 , substituindo $h 1$ pelo próton e $h 2$ pelo antipróton (ou vice-versa).

$$
\frac{d \sigma_{D S}^{j j}}{d \xi d t d Q^{2}}=\int d \beta f_{\mathbb{P} / \bar{p}}(\xi, t) f_{b / \mathbb{P}}\left(\beta, Q^{2}\right) f_{a / p}\left(x, Q^{2}\right) d \hat{\sigma}_{a+b \rightarrow \text { dijet }}
$$




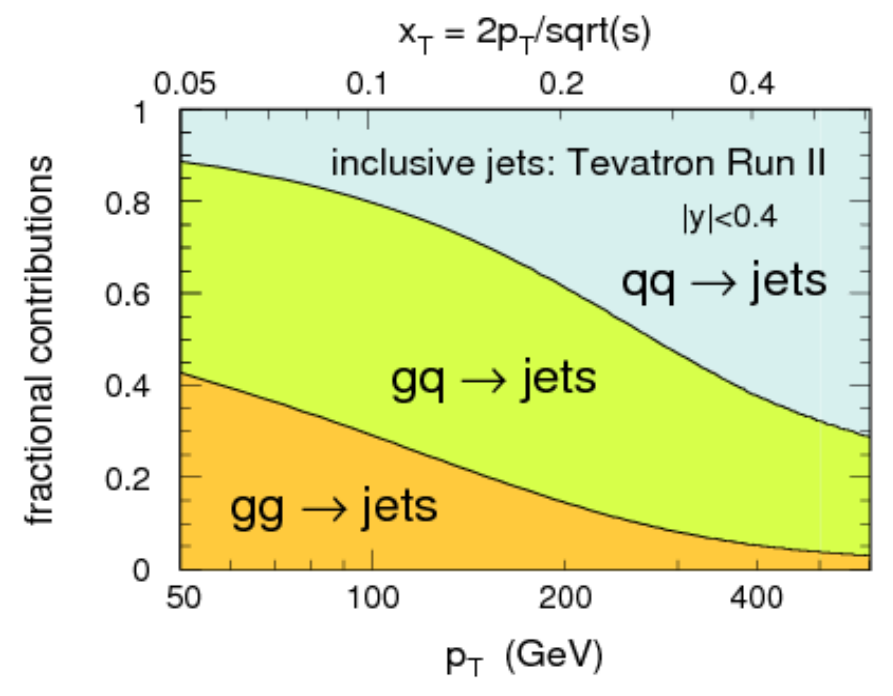

Figura 2.7: Contribuição fracional de diferentes combinações de pártons para a produção de jatos centrais no Tevatron com relação ao $\mathrm{p}_{\mathrm{T}}$ dos jatos produzidos [24].

Nota-se que, se as funções $f_{\mathbb{P} / \bar{p}}(\xi, t)$ e $f_{b / \mathbb{P}}\left(\beta, Q^{2}\right)$ são medidas no HERA, necessita-se aplicar ainda um fator de normalização na equação 2.15 .

\subsubsection{Dupla Troca de Pomeron}

Com a possibilidade de se produzir o bóson de Higgs na fusão de dois pomerons, o processo no qual ocorre dupla troca de pomeron tornou-se muito popular no meio difrativo. Há dois tipos distintos de produção por dupla troca de pomeron:

- Dupla Troca de Pomeron Inclusiva (IDP) $\rightarrow$ quando há presença de radiação proveniente do pomeron (figura 2.9);

- Dupla Troca de Pomeron Exclusiva $(E D P) \rightarrow$ sem a presença de radiação, ou seja, toda a energia da colisão dos pomerons é usada na produção do Dijato (figura 2.10).

Nesta subseção apenas descreve-se a IDP, deixando a EDP para a seção 2.5, onde mais detalhes serão apresentados.

\section{Dupla Troca de Pomeron Inclusiva}

Há dois modelos diferentes para a produção de dijatos com dupla troca de pomeron inclusiva, porém, os dois resultam na mesma formulação fenomenológica. Um modelo 


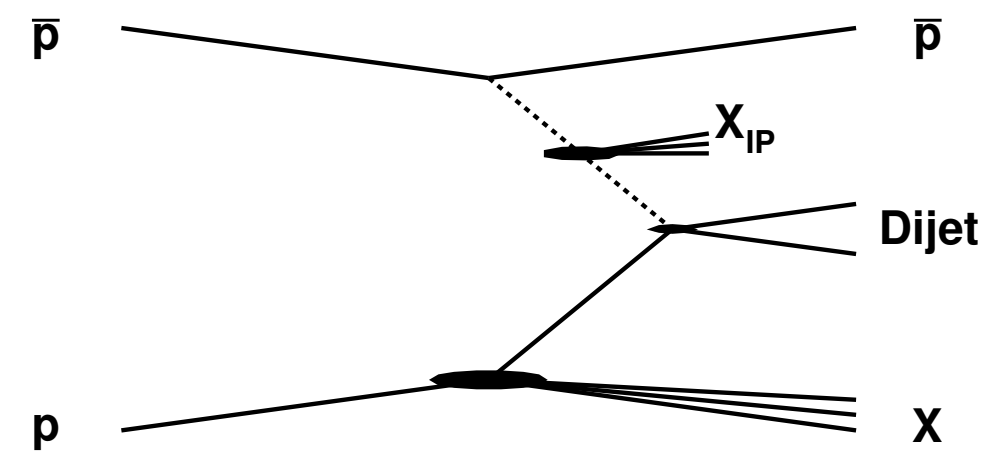

Figura 2.8: Produção de dijatos em um evento de difração simples, no qual o antipróton foi difratado.

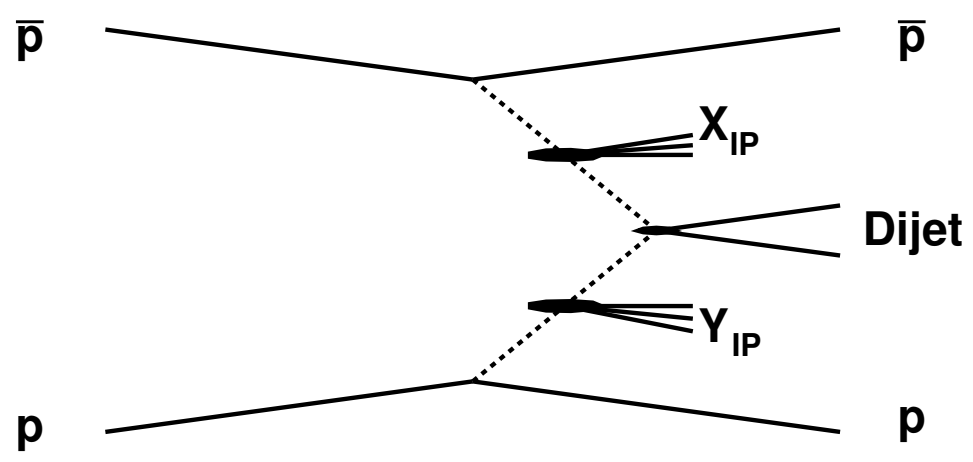

Figura 2.9: Produção de dijatos em um evento de dupla troca de pomeron inclusiva.

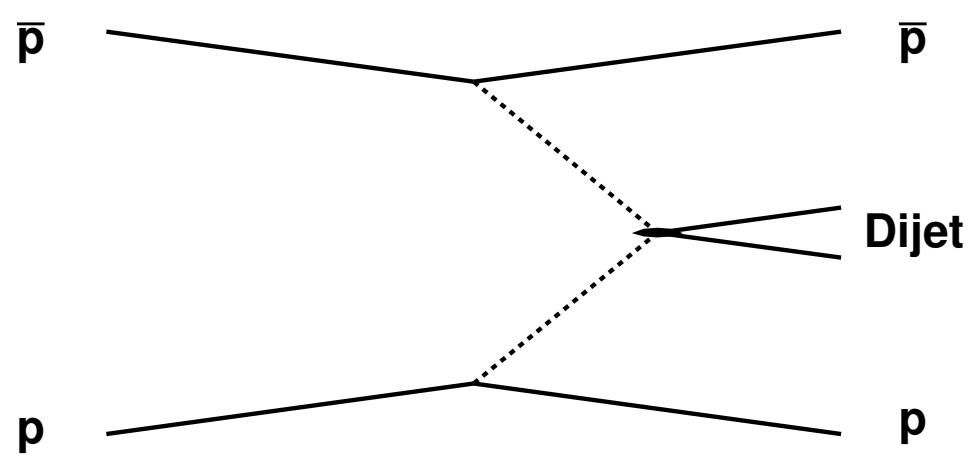

Figura 2.10: Produção de dijatos em um evento de dupla troca de pomeron exclusiva. 
foi sugerido por Boonekamp, Peschanski e Royon (BPR) [37] e outro por Cox, Forshaw e Heinemann (CFH) [38]. Ambos os modelos usam o resultado do CDF [39] para a normalização do fluxo do pomeron.

O modelo BPR [37] usa como princípio um modelo de EDP, formulado por BialasLandshoff (BL) [43]. No de BL, dois glúons não perturbativos do modelo de LandshoffNachtmann [40] são trocados entre os hádrons e esses não irradiam. O de BPR expandiu esse modelo, permitindo que haja radiação dos glúons trocados. Dessa forma, a seção de choque fica sendo

$$
\begin{aligned}
\frac{d \sigma_{I D P}^{j j}}{d \xi_{p} d \xi_{\bar{p}} d t_{p} d_{t_{\bar{p}}} d Q^{2}}= & C_{j j} \int d \beta_{1} d \beta_{2}\left(\frac{\beta_{1} \beta_{2} s}{M_{j j}^{2}}\right)^{2 \epsilon} \\
& \prod_{i=p, \bar{p}}\left\{d \xi_{i} d^{2} v_{i} \xi_{i}^{2 \alpha^{\prime} v_{i}^{2}} \exp \left(-2 v_{i}^{2} \lambda\right)\right\} \times \\
& \left\{\hat{\sigma_{j j}} G_{\mathbb{P}}\left(\beta_{1}, Q^{2}\right) G_{\mathbb{P}}\left(\beta_{2}, Q^{2}\right)\right\}
\end{aligned}
$$

onde $C_{j j}$ é uma constante de normalização arbitrária; $\beta_{i}$ a fração do momentum carregada pelos glúons interagentes; $M_{j j}^{2}$ a massa do dijato; $v_{i}^{2}=t /\left(1-\xi_{i}\right) \hat{\sigma_{j j}}$ a seção de choque dura da produção de dijato; $\alpha^{\prime}, \lambda$ e $\epsilon$ são parâmetros do modelo explicados na próxima seção; $G_{\mathbb{P}}\left(\beta_{i}, Q^{2}\right)$ representa a função de estrutura partônica do pomeron.

Nota-se que $C_{j j}$ é normalizada com os dados do CDF [39] e que pela forma como é construído o modelo, pode-se fatorar o fluxo de pomeron com a estrutura partônica desse.

Por outro lado, o modelo CFH já parte do princípio da fatoração sugerido por Ingelman e Schlein. Portanto, a seção de choque é escrita como:

$$
\frac{d \sigma_{I D P}^{j j}}{d \xi_{p} d \xi_{\bar{p}} d t_{p} d_{t_{\bar{p}}} d Q^{2}}=N \underset{f_{\mathbb{P} / p}\left(\xi_{p}, t_{p}\right) f_{a / \mathbb{P}}\left(\beta_{2}, Q^{2}\right) d \hat{\sigma}_{a+b \rightarrow j j}}{N}
$$

onde $N$ é uma constante de normalização calculada com os dados do CDF [39]. Nesse caso, $N=0,1$ [38], compatível com valores calculados teoricamente para a probabilidade de sobrevivência da lacuna de rapidez [41].

Em geral, $f_{\mathbb{P} / h}\left(\xi_{h}, t_{h}\right)$ é ajustado com os dados do HERA, utilizando a seguinte função:

$$
f_{\mathbb{P} / h}\left(\xi_{h}, t_{h}\right)=\frac{\exp ^{-\beta\left|t_{h}\right|}}{\xi^{2 \alpha_{\mathbb{P}(|t|)-1}}}
$$

Dessa forma, as equações 2.16 e 2.17 ficam similares, já que $M_{j j}^{2} \sim s \xi_{p} \xi_{\bar{p}} \beta_{1} \beta_{2}$. 


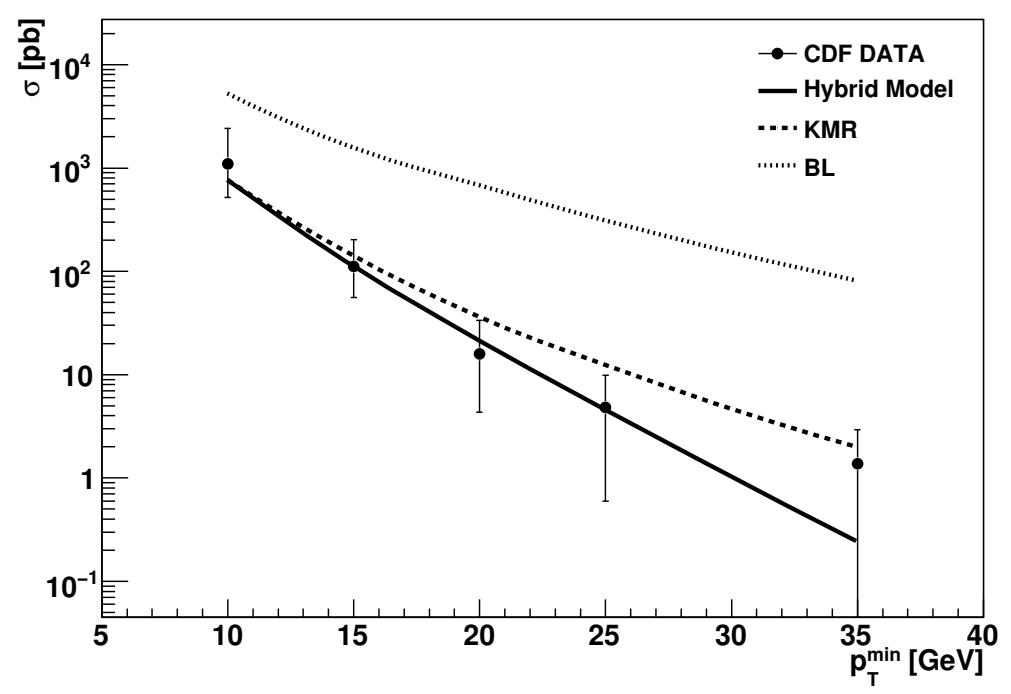

Figura 2.11: Comparação do resultado do CDF [42] com três modelos de EDP.

\subsection{Dupla Troca Pomeron Exclusiva}

Como discutido na seção anterior, o processo difrativo de dupla troca de pomeron exclusiva ocorre quando toda energia trocada pelos hádrons é usada na produção dura. Há uma grande atração teórica e experimental por esse canal, já que é um processo em que se tem acesso direto aos parâmetros teóricos e, por ser também um processo muito limpo, facilita a descoberta de partículas, como o bóson de Higgs. O maior problema experimental é a baixa seção de choque dessa produção, e, portanto, outros processos contaminam uma possível seleção desses eventos.

A colaboração CDF acredita ter observado esse tipo de produção no Tevatron [42], já que nenhuma outra fonte de ruído explica a distribuição de energia fora do sistema dijato. Por outro lado, um dos motivos maiores de provar a existência desses eventos é a produção do bóson de Higgs no LHC.

Há três modelos, atualmente, que são usados para a predição e comparação com resultados experimentais de EDP ([43], [44] e [45]). De fato um dos modelos - o sugerido por Bialas e Landshoff - não concorda com o resultado do CDF [46], enquanto os outros dois modelos sugeridos por Khoze, Martin e Ryskin (KMR) e por Peschanski, Rangel e Royon (Híbrido) ajustam-se bem a esse resultado (ver figura 2.11).

\subsubsection{Modelo de Bialas-Landshoff}

Landshoff e Natchmann propuseram um modelo de vácuo quântico para explicar a troca de pomeron entre hádrons, em particular, para o espalhamento elástico [40]. A idéia principal é a de que o espalhamento se dá pela interação de um dos quarks de cada 


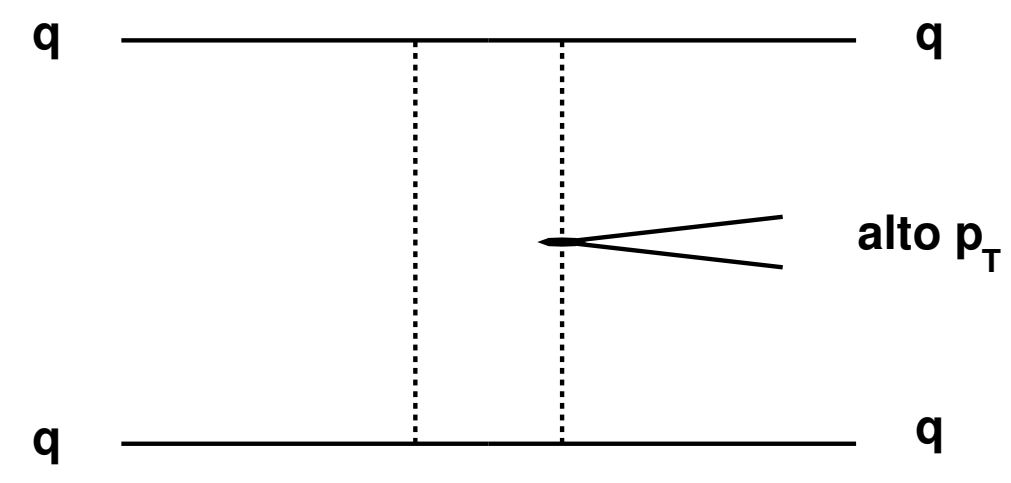

Figura 2.12: Diagrama para a produção de um objeto de alto $\mathrm{p}_{\mathrm{T}}$ em EDP no modelo de Bialas-Landshoff.

hádron e esses trocam dois glúons não perturbativos e abelianos que se acoplam com o hádron de forma similar a um fóton isoescalar. A seção de choque elástica pode ser escrita como:

$$
\frac{d \sigma_{\text {elas }}}{d t}=\frac{1}{4 \pi}\left|\frac{\left(G^{4} D_{N P}^{2} b^{2}\right)}{8 \pi} e^{\left(-|t| / 2 b^{2}\right)}\right|^{2}
$$

onde $G$ é a constante de acoplamento entre o glúon não perturbativo e o hádron; $D_{N P} e^{\left(-|t| / b^{2}\right)}$ é o propagador desse glúon.

Comparando a equação 2.19 com a seção de choque calculada pela troca de um pomeron [29] , pode-se calcular os parâmetros desse modelo como:

$$
G^{2} D_{N P} \simeq 300 \quad \text { e } \quad b^{2}=0,1
$$

Observa-se que não há como extrair o valor de $G^{2}$ separadamente, portanto, não se sabe ao certo qual o valor da constante de acoplamento entre o glúon não perturbativo e o quark.

A idéia de Bialas e Landshoff foi supor que em um dos glúons perturbativos poderia introduzir-se um processo duro (ver figura 2.12). Dessa forma, o cálculo da seção de choque desse processo é similar ao da equação 2.19, só que com a introdução de um processo duro de alto momentum transverso.

Um problema desse modelo é a falta de conhecimento de como o glúon não perturbativo se acopla com o processo duro. Também há um outro fator de discussão, já que seção de choque do processo exclusivo depende diretamente de $G^{2}$, valor que não pode ser medido. O valor usado atualmente é $G^{2} \sim 4 \pi$, aumentando a incerteza desse modelo. Há ainda o fato desse modelo não impor que o glúon não perturbativo não emita radiação, mas isso poderia ser contornável para o caso da produção dura de objetos leves (massas menores que $10 \mathrm{GeV}$ ), já que o glúon é não perturbativo. 
Mesmo com todos esses pontos contra o modelo, ele não prediz um valor muito incoerente a baixo $\mathrm{p}_{\mathrm{T}}$, como mostrado na figura 2.11. Portanto, acredita-se que esse modelo pode ser usado para a produção de objetos de baixa massa como o méson $\chi_{c_{0}}$.

\section{Produção do Méson $\chi_{c_{0}}$}

Baseados em um resultado do CDF, foi realizado um estudo para elucidar o potencial de observar a produção exclusiva do méson $\chi_{c_{0}}[47]$ no experimento D $\varnothing$, já que a colaboração CDF reportou um resultado preliminar do limite superior da seção de choque desse processo [48] no tradicional decaimento do $\chi_{c_{0}}$ em $J / \psi+\gamma$ :

$$
\sigma_{\text {exc }}(p \bar{p} \rightarrow p+J / \psi+\gamma+\bar{p})<49 \pm 18(\text { stat }) \pm 39(\text { sys }) p b .
$$

Nesse estudo, foi usado o modelo de Bialas-Landshof, já que esse não apresenta restrições para produção de baixas massas. Dessa forma, a seção de choque usada é similar à equação 2.16:

$$
\begin{aligned}
d \sigma_{\chi}^{e x c}(s)= & C_{\chi}\left(\frac{s}{M_{\chi}^{2}}\right)^{2 \epsilon} \delta\left[\frac{M_{\chi}^{2}}{s}-\frac{M_{d i f}^{2}}{s}\right] \\
& \prod_{i=1,2}\left\{d^{2} v_{i} \frac{d \xi_{i}}{1-\xi_{i}} \xi_{i}^{2 \alpha^{\prime} v_{i}^{2}} \exp \left(-2 \lambda_{\chi} v_{i}^{2}\right)\right\} .
\end{aligned}
$$

Para um predição correta desses eventos, um cálculo específico para cinemática de baixas massas foi realizado, já que a aproximação usual $M_{d i f} \sim \xi_{p} \xi_{\bar{p}} s$ apenas é válida no limite em que a massa difratada é muito maior que o 4-momentum transverso trocado pelos hádrons $M_{d i f}^{2} \gg|t|$.

Utilizando conservação do 4-momentum sem usar a aproximação $M_{d i f}^{2} \gg|t|$, obtém-se:

$$
M_{d i f f}^{2}=s \times\left(1+\frac{\left(1-\xi_{1}\right)\left(1-\xi_{2}\right)}{2 \cos \theta_{1} \cos \theta_{2}}(1-\Omega)-\left(\frac{1-\xi_{1}}{\cos \theta_{1}}+\frac{1-\xi_{2}}{\cos \theta_{2}}\right)\right),
$$

onde $\Omega=-\cos \theta_{1} \cos \theta_{2}+\sin \theta_{1} \sin \theta_{2}\left(\cos \varphi_{1} \cos \varphi_{2}+\sin \varphi_{1} \sin \varphi_{2}\right), \theta$ é o ângulo de espalhamento e $\varphi$ o ângulo polar. Como em geral, as variáveis cinemáticas usadas são a fração do momentum $\xi$ e o quadrado dos 4-momentum transferido $t$, pode-se substitiuir o ângulo de espalhamento segundo a equação 2.24.

$$
\sin ^{2} \theta_{1,2} \sim \theta_{1,2}^{2}=\frac{\left|t_{1,2}\right|}{\left(1-\xi_{1,2}\right)(s / 4)} .
$$

Para a simulação dos eventos, o gerador DPEMC [49] foi utilizado com a cinemática correta acima. O resultado a nível de gerador, ou seja, sem simulação de detector é compatível com o resultado do CDF: 


$$
\sigma_{e x c}\left(p \bar{p} \rightarrow p+\chi_{c_{0}}(\rightarrow J / \psi \gamma)+\bar{p}\right)=61 p b
$$

Para certificar-se de que nesse canal de baixa massa a produção de dupla troca de pomeron inclusiva não contamina a seleção de eventos exclusivos, o fator $(1-\beta)^{\nu}$ foi multiplicado pela densidade de glúons medida no HERA, onde $\beta$ é a fração de momentum carregado pelo párton interagente e $\nu$ é estimado em $0,0 \pm 0,6$. Percebe-se que se $\nu=-1$, a densidade de glúons é a mais alta possível.

Também foi feito um estudo de como a seção de choque varia com o corte na variável $F_{M}$, onde $F_{M}$ é a fração da massa do evento contida no processo duro, nesse caso a massa do $\chi_{c_{0}}$, já que o CDF usa esse corte na seleção de eventos com $F_{M} \geq 0,85$. Os resultados desse estudo estão mostrados na tabela 2.4 .

\begin{tabular}{|c|c|c|c|c|c|}
\hline Corte $\mathrm{em} F_{M}$ & $\nu=0$ & $\nu=-1$ & $\nu=-0.5$ & $\nu=0.5$ & $\nu=1$ \\
\hline$\geq 0.75$ & 14.33 & 194.94 & 52.28 & 3.88 & 0.84 \\
$\geq 0.8$ & 5.4 & 118.87 & 27.15 & 0.84 & 0.17 \\
$\geq 0.85$ & 2.02 & 61.89 & 11.13 & 0.17 & 0 \\
$\geq 0.9$ & 0.34 & 28.43 & 2.87 & 0 & 0 \\
$\geq 0.95$ & 0.08 & 19.48 & 0.84 & 0 & 0 \\
\hline
\end{tabular}

Tabela 2.4: Seção de choque de IDP para diferentes cortes de $F_{M}$ e diferentes densidades de glúon como explicado no texto.

Analisando a tabela 2.4, conclui-se que a seção de choque exclusiva pode ser explicada pela falta de conhecimento da função de estrutura do pomeron, especialmente se um corte fraco na variável $F_{M}$ é realizado.

Também foi proposta a possibilidade da seleção desses eventos com o uso dos detectores de prótons frontais do experimento D $\varnothing$. Dessa forma, conhece-se $M_{\text {dif }}$ diretamente da medida dos prótons (ver equação 2.23). O gerador de eventos DPEMC foi acoplado ao código de propagação do ponto de interação aos detectores de prótons frontais [51] com o objetivo de estimar em quantos eventos os (anti)prótons difratados atingiriam os detectores. Porém, para uma luminosidade integrada $100 \mathrm{pb}^{-1}$, a detecção de ambos os hádrons é muito ineficiente, devido à aceitação geométrica dos detectores (tabela 2.5).

Dessa forma, para se realizar essa medida no detector $\mathrm{D} \varnothing$, seria preciso ter uma grande quantidade de dados com os detectores de prótons frontais, o que é impossível, já que esses são inseridos apenas quando a luminosidade instantânea é baixa em cada tomada de dados. Outra hipótese seria detectar um hádron de um lado e uma lacuna de rapidez do outro, porém, neste caso, teria se que realizar um corte muito restrito na fração de massa $F_{M}$, similar à medida do CDF. Com isso, o número de eventos é praticamente nulo devido à necessidade do corte forte em $F_{M}$.

Partindo do resultado desses estudos, foi decidido analisar a produção de dijatos, já 


\begin{tabular}{|c|c|c|c|c|}
\hline \multicolumn{5}{|c|}{ Tevatron - L $=100 \mathrm{pb}^{-1}$} \\
\hline Cenário & $\mathrm{A}$ & $\mathrm{B}$ & $\mathrm{C}$ & $\mathrm{D}$ \\
\hline 0 & $1.2 \times 10^{8}$ & $2.6 \times 10^{6}$ & $4.8 \times 10^{6}$ & $2.9 \times 10^{5}$ \\
DØ selection & $1.8 \times 10^{2}$ & $2.7 \times 10^{1}$ & $3.0 \times 10^{1}$ & 1.5 \\
\hline
\end{tabular}

Tabela 2.5: Número de eventos exclusivos com produção de $\chi_{c_{0}}$ (erro estatístico da simulação é menor que 10\%) no Tevatron. O cenário 0 representa todos os canais de decaimento sem cortes de seleção. As colunas representam o número de eventos: A - todos (sem detecção dos hádrons difratados); B - com detecção do próton; C - com detecção do antipróton; D - com detecção de ambos hádrons difratados.

que essa possui uma seção de choque maior e os objetos são de maior massa e momentum transverso, sendo mais fáceis de se detectar no D .

\subsubsection{Modelo KMR}

O modelo para a produção exclusiva de dijatos proposto por Khoze, Martin e Ryskin é uma tentativa de explicar o fenômeno chamado de dupla troca de pomeron exclusiva através de cálculos de QCD perturbativa [44]. Como primeiro passo, supõe-se uma fatoração entre o processo duro e uma luminosidade efetiva, tal como:

$$
\sigma^{e x c}=\mathcal{L}^{e x c}\left(M^{2}, y\right) \hat{\sigma}\left(M^{2}\right)
$$

onde $M$ é a massa do sistema produzido; $y$, a rapidez desse sistema; $\hat{\sigma}\left(M^{2}\right)$, a seção de choque do processo duro; $\mathcal{L}^{\text {exc }}\left(M^{2}, y\right)$, a luminosidade efetiva do fenômeno.

Devido ao espalhamento dos constituintes espectadores dos hádrons, ou da chamada probabilidade de sobrevivência da lacuna de rapidez, insere-se um fator $\hat{S}$, de forma que ele possa depender de $M$ e $y$ (equação 2.27).

$$
M^{2} \frac{d \mathcal{L}^{e x c}}{d y d M^{2}}=\hat{S}^{2} L^{e x c}
$$

Considerando a produção ilustrada na figura $2.13, L^{e x c}$ é escrita como:

$$
L^{e x c}=\frac{\pi}{\left(N_{C}^{2}-1\right) b} \int \frac{d p_{T}^{2}}{p_{T}^{4}} f_{g}\left(x_{1}, x_{1}^{\prime}, p_{T}^{2}\right) f_{g}\left(x_{2}, x_{2}^{\prime}, p_{T}^{2}\right),
$$

onde $N_{C}$ é o número de cores $(=3) ; b(=4)$ é conseqüência do fator de forma do próton; $f_{g}\left(x, x^{\prime}, p_{T}^{2}\right)$ são as densidades de glúon não integradas.

Note que a constante $b$ representa a parte não perturbativa do modelo, em que é considerada dependência em $|t|$ da colisão, de tal forma que a seção de choque tenha a seguinte dependência:

$$
\frac{d^{2} \sigma}{d t_{\bar{p}} d t_{p}} \propto e^{-b\left(\left|t_{\bar{p}}\right|+\left|t_{p}\right|\right)}
$$




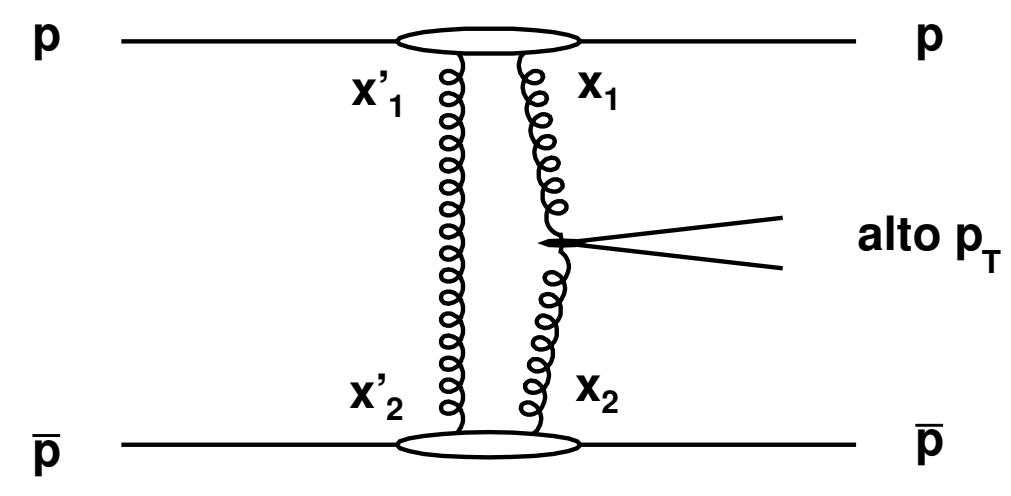

Figura 2.13: Diagrama representativo para a produção de um objeto de alto $\mathrm{p}_{\mathrm{T}}$ no modelo KMR de EDP.

As funções $f_{g}\left(x, x^{\prime}, p_{T}^{2}\right)$ representam a probabilidade de achar dois glúons no (anti)próton, um com fração de momentum $x$ e outro $x^{\prime}$, sendo que $x^{\prime} \ll x$. Nessa função também levase em conta a probabilidade de não emissão de um glúon $T\left(p_{T}\right)$ similar à da equação 2.5 . Apesar de ser uma função difícil de se calcular, usa-se uma forma simplificada dela [52]:

$$
f_{g}\left(x, x^{\prime}, p_{T}^{2}\right)=R_{g}\left(x, x^{\prime}, p_{T}^{2}\right) \frac{\partial}{\partial \ln \left(p_{T}^{2}\right)}\left(\sqrt{T\left(p_{T}\right)} x g\left(x, p_{T}^{2}\right)\right),
$$

onde $g\left(x, p_{T}^{2}\right)$ é a função de glúons tradicional do próton e $R_{g}$ é o fator que leva em conta a existência do segundo glúon. No limite $x^{\prime} \ll x$, para as energias do Tevatron, $R_{g}=1,4$.

O sucesso do modelo KMR deve-se ao fato de descrever os dados do CDF (ver figura 2.11) e ao mesmo tempo ter como base cálculos de QCD perturbativa.

\subsubsection{Modelo Híbrido}

O modelo híbrido [45] foi desenvolvido dentro do projeto desta tese. A fim de apresentar um modelo baseado na fenomenologia de troca de pomeron mais realista do que o modelo de Bialas-Landshoff. O modelo de pomeron híbrido para produção exclusiva foi proposto por Peschanski, Rangel e Royon.

Como ponto de partida, adota-se a proposta do modelo BL, com troca de dois glúons efetivos, porém, diferentes propagadores e constantes de acoplamento são introduzidas. De fato, o glúon que possui o papel de manter a característica difrativa do processo permanece idêntico ao modelo BL, mas o glúon que participa do processo duro é modificado (ver figura 2.14).

De certa forma, a fatoração entre a parte dura e a parte mole do pomeron é proposta. A parte mole do pomeron é determinada através dos dados do espalhamento elástico próton-próton. A parte dura do pomeron é extraída de dados da produção de mésons vetoriais no HERA. 


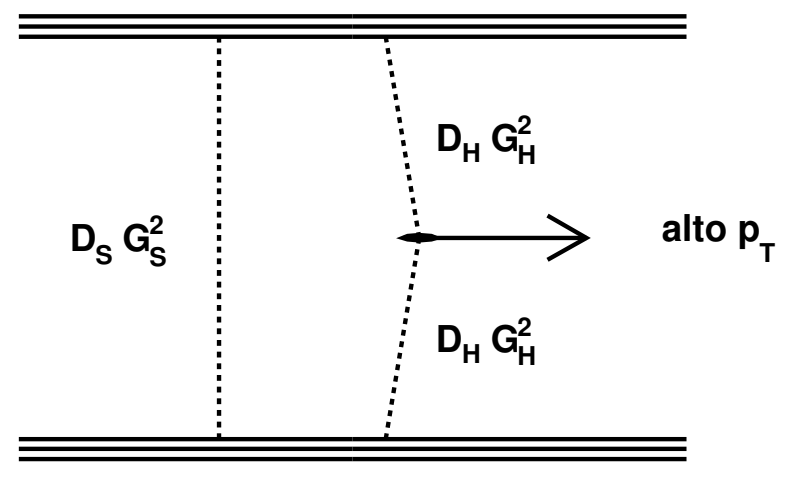

Figura 2.14: Diagrama para produção de um objeto massivo no modelo de pomeron híbrido.

O propagador do glúon não perturbativo é calculado seguindo a proposta de LandshoffNatchmann [40], representando o espalhamento elástico pela troca de dois glúons, como explicado na subseção 2.5.1. Dessa forma, pode-se escrever:

$$
\left.\left[G_{S}^{2} D_{S}^{(0}\right)\right]^{2}=8 \beta^{2} s^{2 \epsilon} \exp \left(4 b+2 \alpha^{\prime} \log s\right),
$$

onde, os parâmetros $\beta, b, \alpha^{\prime}$ e $\epsilon$ são extraídos dos dados do espalhamento elástico prótonpróton (ver tabela 2.6), $s$ é a energia do centro de momentum da colisão.

No caso da parte dura do pomeron, foi usado o espalhamento elástico entre um dipolo (dois quarks) e um próton (ver figura 2.15). Esse tipo de espalhamento é observado no HERA através da produção exclusiva de mésons vetoriais [53]. Nesse caso, não se faz necessária a supressão da radiação de glúons, já que o propagador efetivo do glúon originase de eventos com esse efeito suprimido. Nota-se que o modelo usado para ajustar-se com os dados do HERA introduz a possibilidade de efeitos de saturação, apesar de esses não serem relevantes na discussão do modelo.

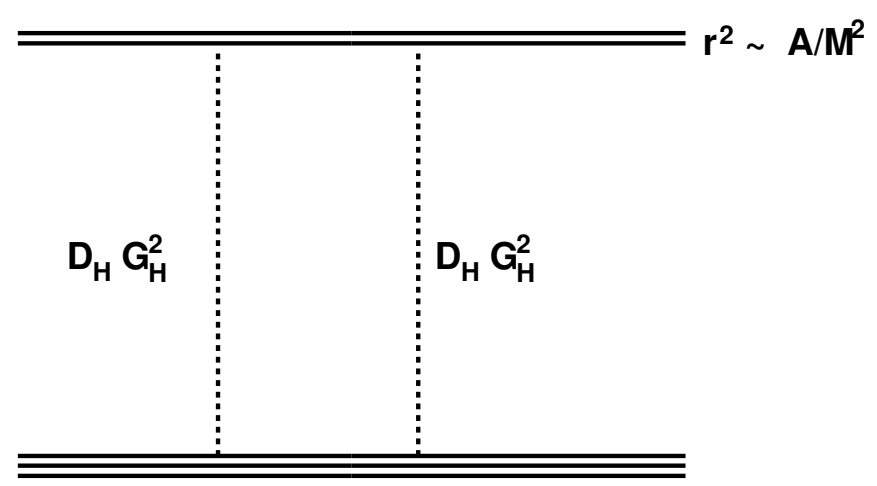

Figura 2.15: Diagrama do espalhamento elástico dipolo-próton.

O glúon que participa da produção do objeto massivo é proveniente de um modelo 
baseado em QCD perturbativa, já que os cálculos iniciam-se com as equações BalitskyFadin-Kuraev-Lipatov (BFKL) [53]. Calcula-se que seu propagador seja [45]:

$$
\begin{aligned}
{\left[G_{H}^{2} D_{H}^{(0)}\right]^{2} } & =\frac{8 \pi}{6 \mu_{H}^{2}} \times 2 \pi R_{p}^{2} N_{0} \times r^{-2} \times\left(P_{H}\right)^{\gamma_{C}} \exp \left(\frac{\log ^{2}\left(P_{H}\right)}{2 \kappa \lambda \log (\xi)}\right) \\
\mu_{H} & =0.5
\end{aligned}
$$

Os parâmetros usados estão expostos na tabela 2.6.

\begin{tabular}{|c||c||c|c|}
\hline \multicolumn{1}{|c||}{ Parâmetros } & Valores centrais & $\begin{array}{c}\text { Intervalos } \\
\text { de variação }\end{array}$ & Quark c incluído \\
\hline \hline $\begin{array}{c}\text { Parâmetros } \\
\text { da parte dura do pomeron }\end{array}$ & & & \\
\hline \hline$N_{0}$ & 0,7 & - & 0,7 \\
$Q_{0}$ & $0,254 \mathrm{GeV}$ & $0,243-0,263$ & 0,298 \\
$R_{p}$ & $3,277 \mathrm{GeV}^{-1}$ & $3,233-3,321$ & 3,344 \\
$\gamma_{C}$ & 0.6194 & $0,6103-0,6285$ & 0,7376 \\
$\kappa$ & 9,9 & - & 9,9 \\
$\lambda$ & 0,2545 & $0,2494-0,2596$ & 0,2197 \\
$B$ & 2 & - & 2 \\
$\mu_{H}$ & 0,5 & - & 0,5 \\
\hline Parâmetros & & & \\
\hline \hline da parte mole do pomeron & & - & 1,08 \\
$\alpha^{\prime}$ & 1.08 & - & 0,06 \\
$\beta$ & 0.06 & $3-5$ & 4 \\
$\epsilon$ & 4 & - & - \\
\hline
\end{tabular}

Tabela 2.6: Lista de parâmetros usados no modelo híbrido. A segunda coluna apresenta os valores padrões, a terceira coluna mostra os limites inferiores e superiores de cada parâmetro devido às suas incertezas. A quarta coluna apresenta os valores para o modelo do espalhamento dipolo-próton quando o quark $c$ é considerado.

Finalmente, pode-se escrever a matriz amplitude da produção como:

$$
|M|^{2}=\left(D_{S} G_{S}^{2}\right)^{2}\left(\left[D_{H} G_{H}^{2}\right]_{1}\right)^{2}\left(\left[D_{H} G_{H}^{2}\right]_{2}\right)^{2}\left|M_{\hat{\sigma}}\right|^{2}
$$

onde $M_{\hat{\sigma}}$ é a amplitude do espalhamento duro.

A notação $\left[D_{H} G_{H}^{2}\right]_{i}, i=1,2$ é usada para distinguir o glúon de cada vértice (ver figura 
2.14). Em paralelo com o método usado na referência [43], obtém-se a seção de choque:

$$
\begin{aligned}
& \sigma=81 \frac{2 s}{(2 \pi)^{5}}\left[G_{S}^{2} D_{S}^{(0)}\right]^{2} \int d^{4} p_{1} d^{4} p_{2} \delta\left(p_{1}^{2}\right) \delta\left(p_{2}^{2}\right) \delta\left(\left(p_{a}+p_{b}-p_{1}-p_{2}\right)^{2}-M^{2}\right) \\
& \times\left(\frac{s}{s_{1}}\right)^{2 \alpha(t 1)-2}\left(\frac{s}{s_{2}}\right)^{2 \alpha(t 2)-2} e^{2 b t_{1}} e^{2 b t 2}\left[G_{H}^{2} D_{H}^{(0)}\right]_{1}^{2}\left[G_{H}^{2} D_{H}^{(0)}\right]_{2}^{2}\left|M_{\hat{\sigma}}\right|^{2}
\end{aligned}
$$

Usando a relação [54]

$$
\int d^{4} p_{i} \delta\left(p_{i}^{2}\right)=-\frac{1}{2} \int d \xi_{i} d^{2} \overrightarrow{v_{i}} ; \quad \frac{s}{s_{i}}=\frac{1}{\xi_{i}}
$$

onde $\overrightarrow{v_{i}}$ é o momentum transverso dos prótons difratados e mudando a variável $v_{i}$ para $\left|t_{i}\right|$ usando $\left|\overrightarrow{v_{i}}\right|^{2}=\left(1-\xi_{1}\right)\left|t_{i}\right|$, encontra-se:

$$
\begin{aligned}
\sigma= & \frac{81}{2(2 \pi)^{3}} \times\left[G_{S}^{2} D_{S}^{(0)}\right]^{2} \times \\
& \prod_{i=1,2}\left(\iint d \xi_{i} d\left|t_{i}\right| \frac{1-\xi_{i}}{\xi_{i}^{2 \epsilon}} \exp \left(-\left(2 b+2 \alpha^{\prime} \log \left(\frac{1}{\xi_{i}}\right)\left|t_{i}\right|\right)\right)\left[G_{H}^{2} D_{H}^{(0)}\right]_{i}^{2}\left|M_{\hat{\sigma}}\right|\right) .
\end{aligned}
$$

Esse modelo foi implementado no gerador de eventos DPEMC [49] e então comparado com os dados do CDF [42]. Nota-se que o modelo não possui normalização fixa, portanto, optou-se por normalizá-lo de acordo com os dados do CDF. A normalização foi determinada em $3.85 \times 10^{-4} \pm 1.89 \times 10^{-4}$ com $\chi^{2}=0.67$ e cinco pontos usados (a incerteza vem dos dados do CDF).

Na figura 2.11, observa-se a boa concordância do modelo com os dados do CDF, sendo esse um candidato na predição de eventos exclusivos no LHC. Nota-se que o modelo possui uma dependência mais forte com a massa produzida, porém com os dados do CDF, nada pode-se afirmar sobre qual modelo descreve melhor os dados.

Mais ainda, foi verificado que os resultados são estáveis com a relação às incertezas dos parâmetros do glúon $\left[D_{H} G_{H}^{2}\right]$ (ver figuras 2.16, 2.17 e 2.18). 


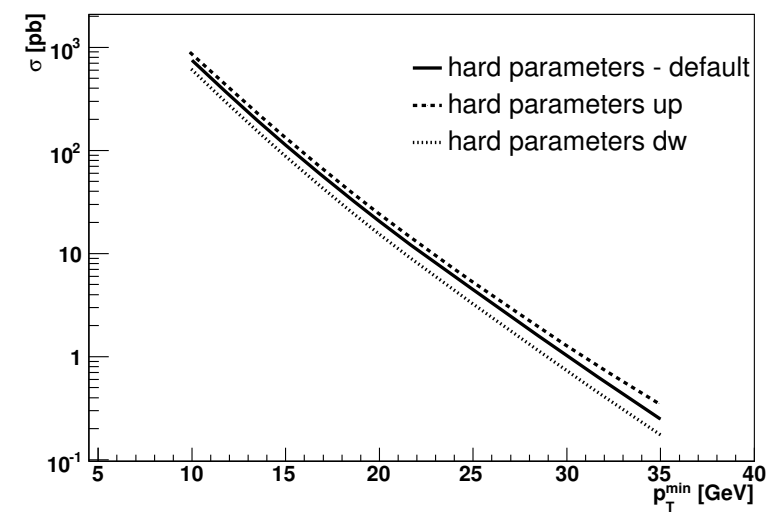

Figura 2.16: Variação do modelo devido às incertezas dos parâmetros determinados para a parte dura do pomeron (hard parameter).

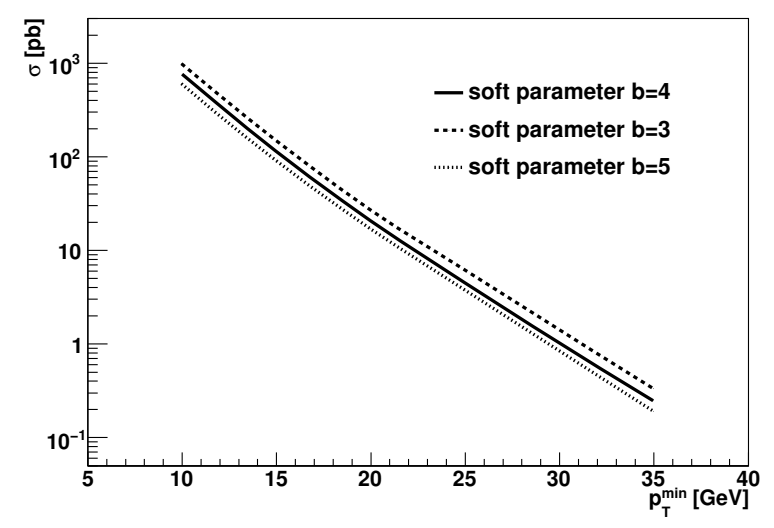

Figura 2.17: Variação do modelo devido às incertezas dos parâmetros determinados para a parte mole do pomeron (soft parameter).

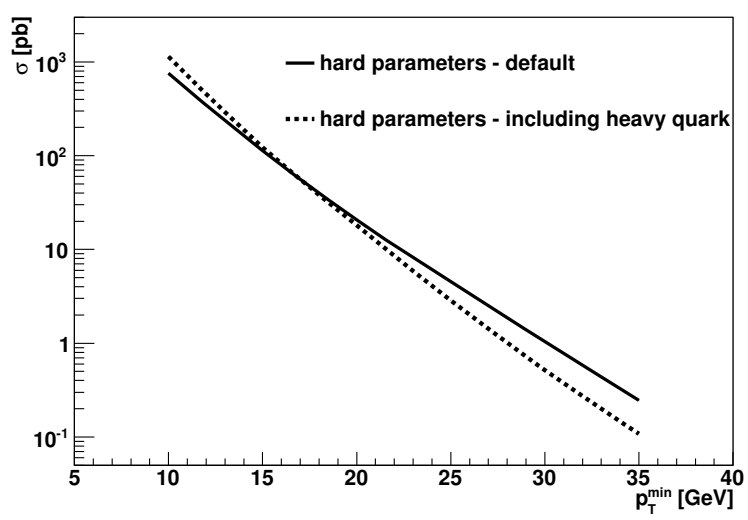

Figura 2.18: Variação do modelo devido à inclusão da contribuição do quark $c$ na determinação dos parâmetros da parte dura do pomeron (including heavy quark). 


\subsection{Observações}

Observa-se que a física de difração hadrônica possui um grande potencial de entender mais profundamente como os hádrons comportam-se em interações não perturbativas. Mais especificadamente para o caso da EDP, a produção de objetos massivos, incluindo partículas ainda não descobertas, pode ocorrer em eventos muito limpos, i.e., sem adição de radiação.

Porém, a produção de eventos por EDP permanece elusiva, havendo apenas um resultado experimental para a produção de dijatos relativamente leves $(M \lesssim 100 \mathrm{GeV})$. A fim de elucidar a possibilidade desses eventos existirem na produção de objetos pesados $(M \gtrsim 100 \mathrm{GeV})$, a análise apresentada nesta tese é baseada na busca desses eventos com produção de dijatos no experimento $\mathrm{D} \varnothing$. 


\section{Capítulo 3}

\section{O Experimento DØ}

O Experimento DØ está localizado no acelerador de prótons e antiprótons Tevatron, onde colisões entre essas duas partículas acontecem a uma energia de centro de massa de 1,96 $\mathrm{TeV}$ a cada 396 nanosegundos. Esse capítulo tem como objetivo realizar uma breve descrição do complexo de aceleradores Tevatron e do experimento DØ .

\subsection{O Tevatron}

O complexo de aceleradores Tevatron pertence ao Fermi National Accelerator Laboratory (Fermilab), localizado nos Estados Unidos da América, na cidade de Batavia no estado de Illinois. O Fermilab, cujo nome é uma homenagem ao físico ganhador do Prêmio Nobel de 1938, Enrico Fermi, foi projetado em 1967 com o objetivo de estudar a física das partículas fundamentais da natureza [55]. De fato, três delas foram descobertas no Fermilab, o quark bottom em 1977 [56], quark top em 1995 [6] e o neutrino do $\tau$ em 2000 [7].

Atualmente, o Tevatron fornece colisões entre prótons e antiprótons com energia de centro de massa de $1960 \mathrm{GeV}$ (bilhões de eletrovolts) a cada 396 nanosegundos. Para isso, é necessário operar com 36 pacotes de prótons e antiprótons, que realizam uma volta completa no anel em poucos pico segundos. As colisões ocorrem em duas localidades, onde se situam os experimentos D $\varnothing$ e CDF. A tomada de dados dessas colisões iniciou-se em 2002 e a denominamos de Run II.

O complexo de aceleradores é composto por 8 aceleradores no total (ver figura 3.1) [57]: Cockcroft-Walton, Linac, Booster, Debuncher, Accumulator, Main Injector, Recycler e o Tevatron.

Os 3 primeiros são responsáveis pela fonte de prótons ao acelerador principal. Íons $H^{-}$são pré-acelerados no Cockcroft-Walton a uma energia de $750 \mathrm{KeV}$. Esses íons são então acelerados no acelerador linear Linac a uma energia de $400 \mathrm{MeV}$ até o Booster com o uso de cavidades de rádio frequiência. Os íons $H^{-}$, após passarem por uma folha de carbono, perdem os elétrons e são transformados em íons $H^{+}$, ou, simplesmente, prótons. 


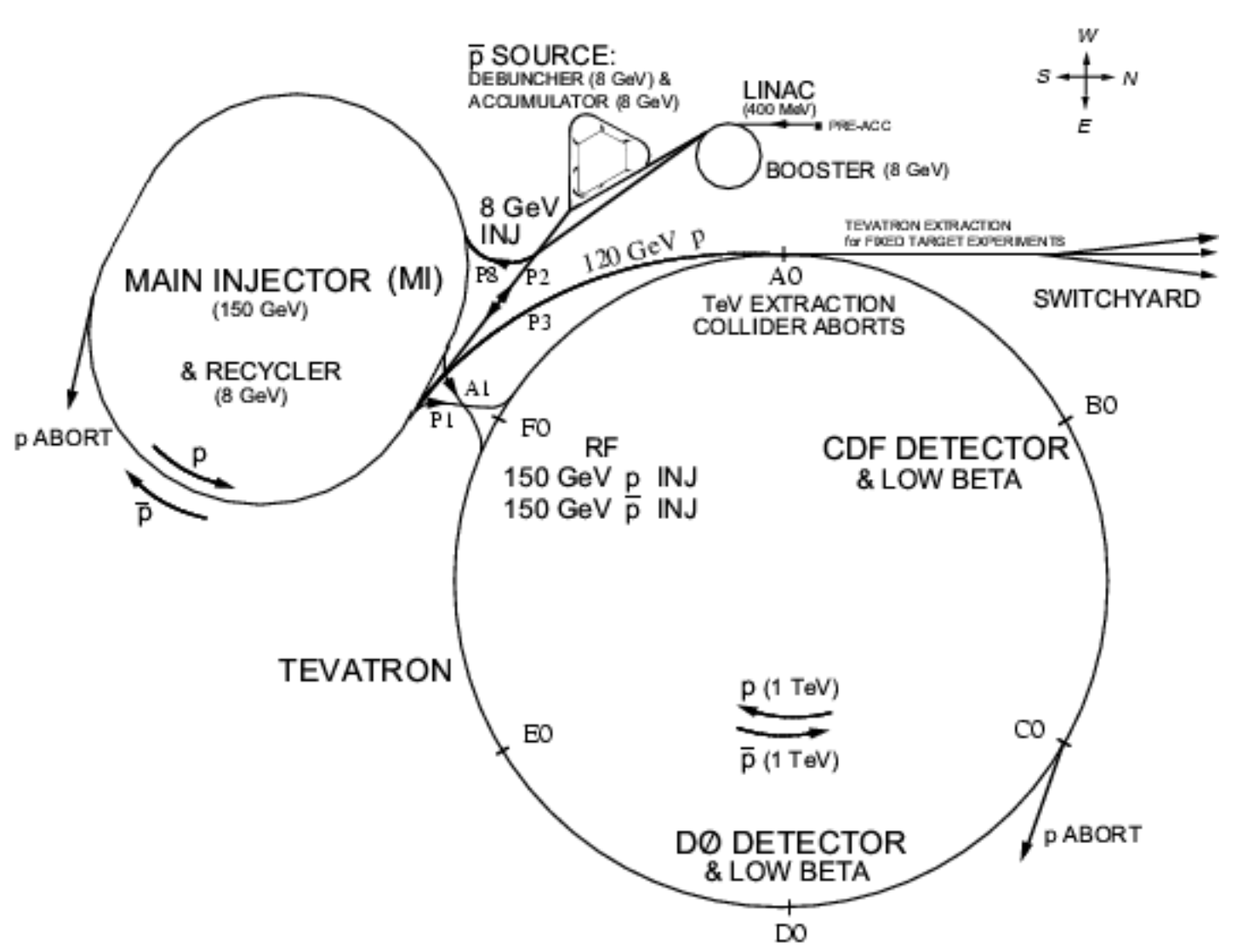

Figura 3.1: Visão esquemática do complexo de aceleradores Tevatron 3.1.

Esses últimos são injetados no Booster, primeiro síncrotron da cadeia com 475 metros de circunferência, que os acelera a uma energia de $8 \mathrm{GeV}$.

Os prótons de $8 \mathrm{GeV}$ provenientes do Booster e antiprótons de $8 \mathrm{GeV}$ provenientes do Accumulator são injetados no Main Injector, que os acelera uma energia de $150 \mathrm{GeV}$. O Recycler, que funciona no mesmo túnel do Main Injector, serve para a reciclagem de antiprótons após o fim de uma tomada de dados no Tevatron, ou pode também funcionar como um segundo Accumulator. O principal objetivo do Recycler é, portanto, garantir a maior luminosidade possível.

Os antiprótons são produzidos através da colisão de um feixe de prótons de $120 \mathrm{GeV}$, provenientes do Main Injector com uma folha de níquel de $7 \mathrm{~cm}$. Precisa-se de aproximadamente um milhão de prótons para a criação de 20 antiprótons. Os antiprótons criados possuem um espectro de energia com dispersão muito alta, então, são enviados para o Debuncher que, através do uso de cavidades de rádio-freqüência, diminui a dispersão de energia dos antiprótons. Logo após essa fase, os antiprótons são enviados ao Accumulator, que tem como função acumulá-los até que o estoque de antiprótons seja o suficiente para o início de colisões.

Finalmente, o Tevatron acelera prótons e antiprótons a uma energia de $980 \mathrm{GeV}$ e focaliza os dois feixes onde se encontram os detectores CDF e D $\varnothing$, de forma que colisões 
de próton e antipróton sejam produzidas com a maior freqüência possível. Sendo um síncontron com aproximadamente $1 \mathrm{~km}$ de raio, o Tevatron é o maior acelerador do mundo em funcionamento.

Apesar da produção de prótons ser mais simples que a de antiprótons, há vantagens de colidir prótons com antiprótons, ao invés de prótons com prótons. Um colisor de próton-próton necessitaria de 2 tubos de feixe e 2 campos magnéticos no mesmo anel, já que se tratam de 2 partículas de mesma carga elétrica. Esse fato simplifica-se no caso de um colisor de próton-antipróton. Há também processos físicos que possuem maior seção de choque em colisores de próton-antipróton devido às funções de estruturas desses dois hádrons. Em energias de centro massa superiores a $3 \mathrm{TeV}$, as funções de estrutura são dominadas por glúons, portanto, não há diferenças entre colisões de próton-antipróton ou próton-próton.

\subsection{O Detector DØ}

O Detector DØ foi proposto em 1983 para estudar o resultado de colisões próton-antipróton com energia de centro de massa 1,8 TeV, o que ocorreu no período de 1992-1996 com grande sucesso, chamado de RunI. Em 2001, após a atualização do acelerador, o Run II iniciou-se com colisões de centro de massa de 1,96 TeV e colisões sucessivas a uma freqüência de 1,7 MHz. O detector DØ também foi atualizado para suportar as novas condições das colisões [58].

O detector DØ é um detector de propósito geral, sendo construído e desenvolvido para identificar e medir com grande precisão a energia e o momentum de partículas altamente energéticas. Para tanto, o detector possui 3 grandes seções (ver figura 3.2a):

- detectores de traços centrais;

- calorímetros de urânio e argônio líquido;

- espectrômetros de múons.

Em adição a esses 3 principais sistemas de detectores, o detector $\mathrm{D} \varnothing$ possui detectores suplementares, para medidas mais específicas ou para compensar falhas dos detectores citados. Desses, destacam-se os detectores intercriostato, localizados entre os criostatos do calorímetro (ICD); os detectores chamados de pré-chuveiro (CPS e FPS), que servem para melhor a identificação de elétrons; o monitor de luminosidade (LM), usado para as medidas de luminosidade; e o detector de prótons frontais (FPD), construído para detecção de prótons difratados.

É importante ressaltar que o tubo onde o feixe está confinado, na região do detector, é feito de berílio. Apesar de ser um material leve, essencialmente transparente às partículas produzidas na colisão, é também muito duro, podendo, dessa forma, suportar as pressões 


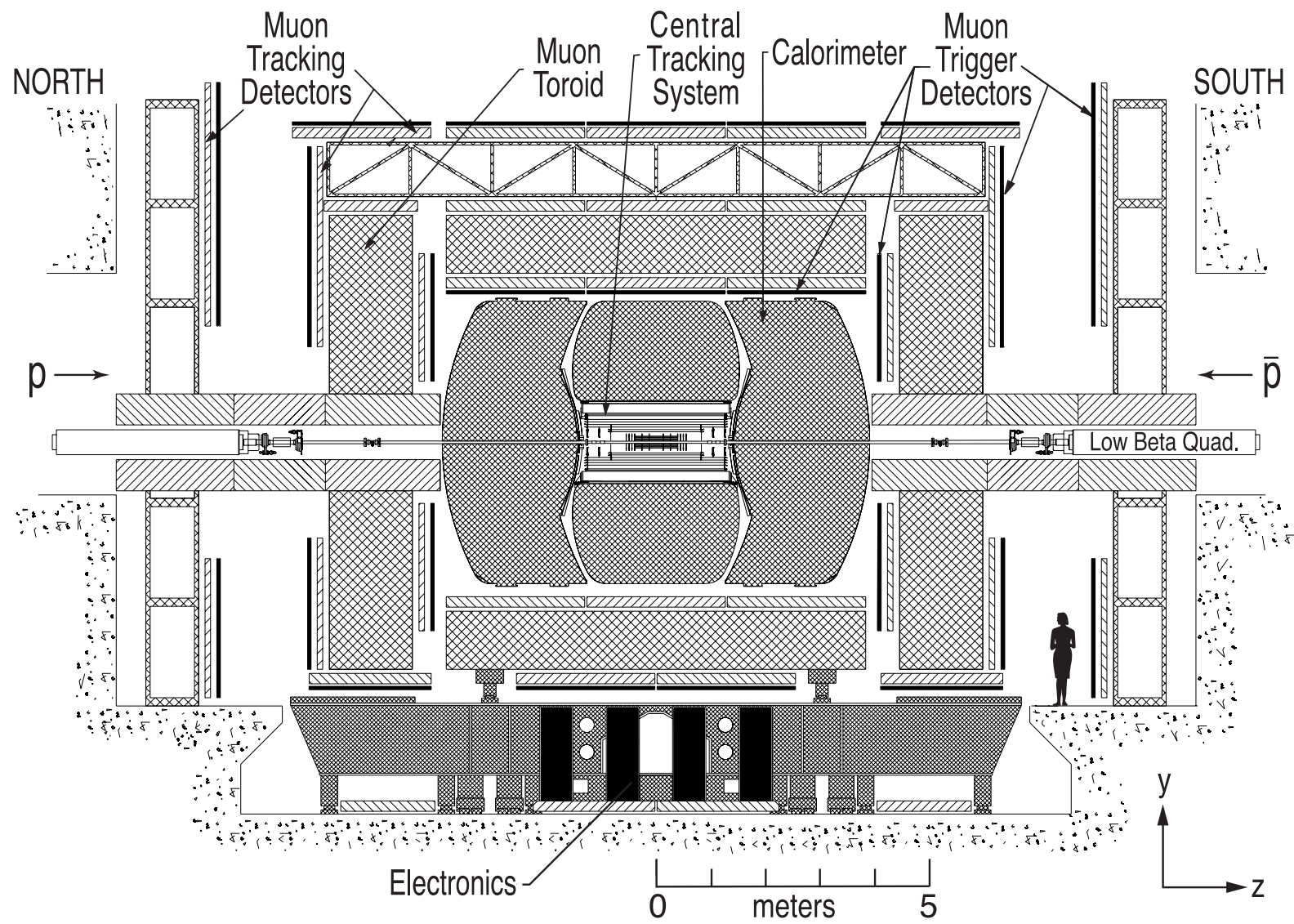

(a) Seção transversal completa do detector. O detector de prótons frontais não está ilustrado.

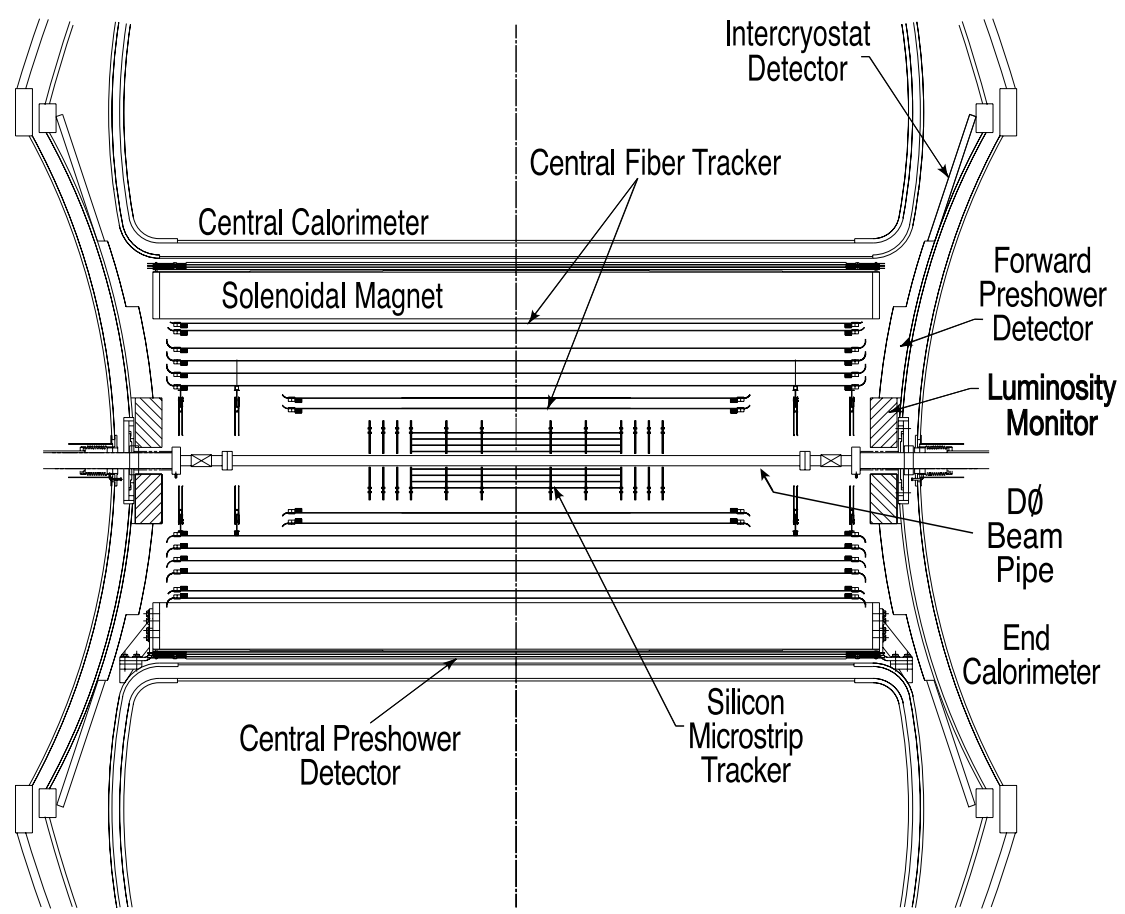

(b) Seção transversal da parte central do detector.

Figura 3.2: Ilustrações do detector D . 

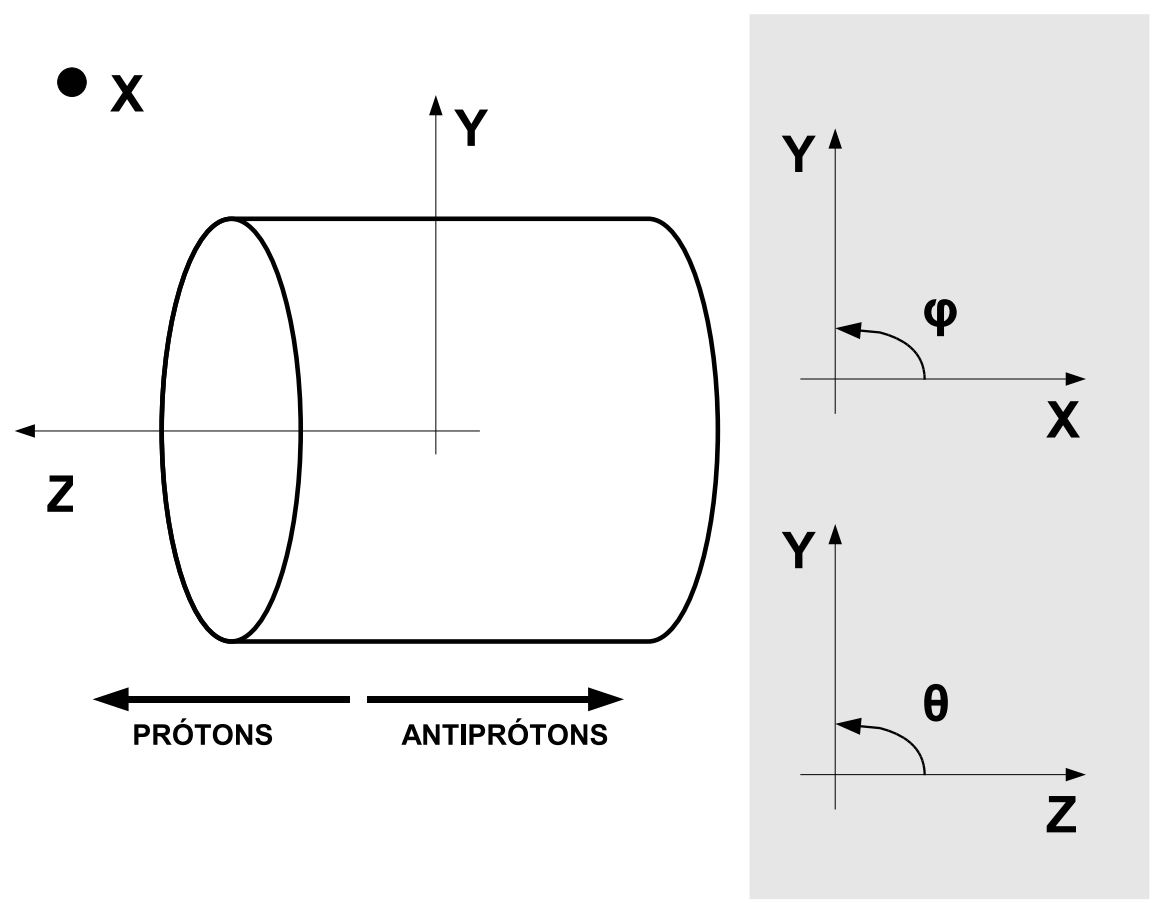

Figura 3.3: Sistema de coordenadas.

provenientes do material que o rodeia. A parede do tubo possui 0,508 milímetros de espessura, um diâmetro externo de 38,1 milímetros e 2,37 metros de comprimento.

\subsubsection{Sistema de Coordenadas}

Diferentes sistemas de coordenadas podem ser usados para descrever o detector D $\varnothing$, incluindo o cartesiano $(x, y, z)$ e o esférico $(r, \varphi, \theta)$. As coordenadas angulares $\varphi$ e $\theta$ são os ângulos polares azimutais, respectivamente, definidos como:

$$
\varphi=\arctan \frac{y}{x} \quad \text { e } \quad \theta=\arccos \frac{z}{r}
$$

O sistema cartesiano padrão obedece à regra da mão direita e por definição, o eixo positivo da coordenada $z$ possui a mesma direção do fluxo dos prótons, e o eixo positivo da coordenada $y$ é vertical à superfície terrestre com direção para cima, como ilustrado na figura 3.3. Dessa forma, o eixo $x$ aponta para fora do acelerador.

Os outros sistemas de coordenadas são então baseados no sistema cartesiano padrão descrito acima. Para cada tipo de situação, um sistema de coordenadas adequa-se melhor que o outro para a descrição de uma partícula. Porém, o sistema que se ajusta à maioria dos casos é o que mistura as coordenadas $(z, y, \varphi)$, onde $y$ é a rapidez da partícula definida como: 


$$
y=\frac{1}{2} \ln \left(\frac{E+p_{z}}{E-p_{z}}\right)
$$

onde $E$ é a energia da partícula e $p_{z}$ a componente longitudinal (eixo $z$ ) do seu momentum.

A coordenada z determina a localização do vértice primário com relação ao centro do detector. O uso do ângulo $\varphi$, que é perpendicular ao eixo z, é conveniente devido à simetria azimutal do detector. E a rapidez $y$, que substitui o ângulo $\theta$, mede a inclinação da partícula com relação ao eixo z. A vantagem da rapidez sobre o ângulo polar, é que as diferenças de rapidez permanecem iguais sobre transformações de Lorentz.

No caso do Tevatron, as partículas que são criadas devido à colisão dos constituintes dos (anti)prótons são altamente energéticas, o que torna suas massas desprezíveis $\left(p^{2} \gg\right.$ $\left.m^{2}\right)$. Portanto, a aproximação:

$$
E^{2}=p^{2} \quad \Rightarrow \quad p_{z}=p \cos \theta=E \cos \theta
$$

é válida, então podemos reescrever a rapidez como:

$$
y=\frac{1}{2} \ln \left(\frac{E(1+\cos \theta)}{E(1-\cos \theta)}\right)=-\ln \left(\frac{1-\cos \theta}{1+\cos \theta}\right)^{1 / 2}=-\ln \left(\tan \frac{\theta}{2}\right) \equiv \eta
$$

que é a definição de pseudorapidez, e será usada com maior freqüência por simplicidade.

É importante ressaltar que, além das variáveis citadas acima, o momentum transverso $\left(\mathrm{p}_{\mathrm{T}}\right)$ e a energia transversa $\left(\mathrm{E}_{T}\right)$ são bastante utilizados.

$$
E_{T}=E \operatorname{sen} \theta \text { e } p_{T}=p \operatorname{sen} \theta
$$

Nota-se que a energia é uma grandeza escalar, porém, por conveniência, é usada em partículas relativísticas, já que para $p^{2} \gg m^{2}$, tem-se:

$$
E_{T}=p_{T}
$$

A projeção do momentum transversa ao feixe é especial, pois, no caso do Tevatron, muitas partículas resultantes das colisões não são detectadas, pois são produzidas na direção do feixe $(|\eta| \sim \infty)$, ou seja, possuem altos momenta longitudinais $\left(p_{z}\right)$. Porém, essas partículas praticamente não possuem momentum transverso ao feixe, então, podem ser desprezadas, e.g., se um balanço do momentum transverso total é medido para a inferir a existência de neutrinos no evento. Devido ao fato dos pártons interagentes dos (anti)prótons possuírem componentes do momentum longitudinal dos hádrons iniciais, torna-se impossível saber o momentum longitudinal inicial da colisão a priori, restando apenas trabalhar com a conservação de momentum na região transversal ao feixe. Adicionalmente, as partículas detectadas possuem massa desprezível, portanto, quanto maior seu momentum transverso, maior é a energia disponível na interação. 


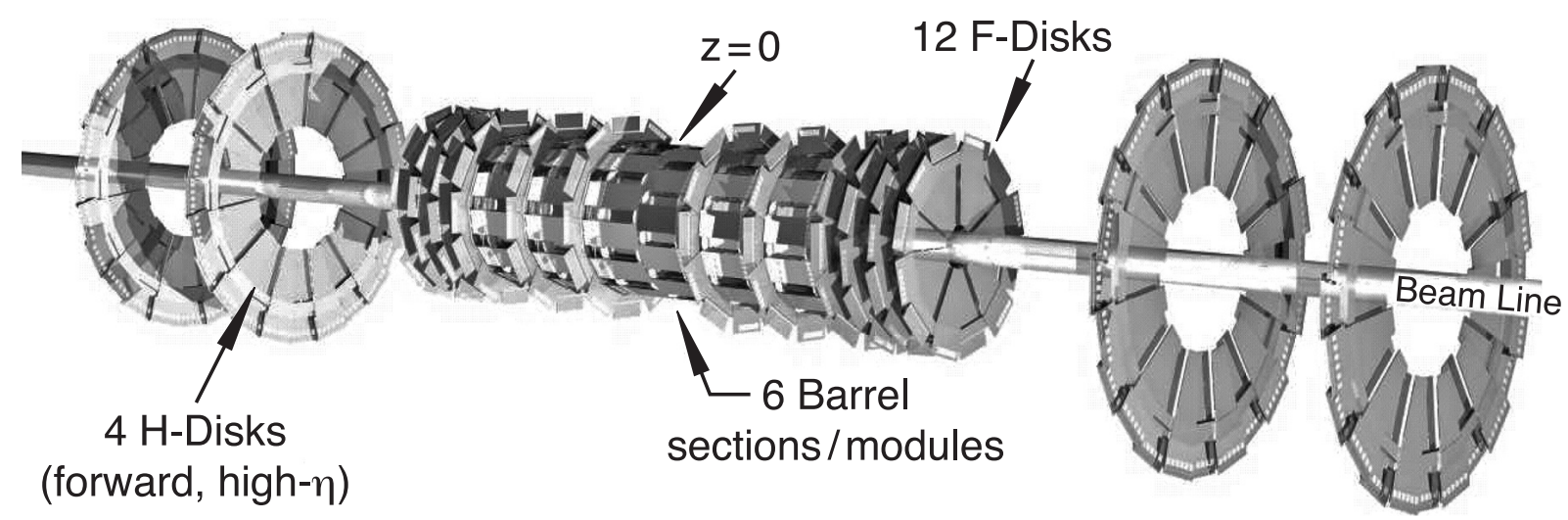

Figura 3.4: Ilustração do detector SMT.

\subsubsection{Sistema de Traços Centrais}

O sistema de detectores de traços centrais é o núcleo do detector D $\varnothing$, ou seja, é o se que encontra mais perto das colisões. O seu objetivo principal é reconstruir trajetórias de partículas carregadas sob a ação de um campo magnético, e, conseqüentemente, identificar vértices primários com uma precisão de aproximadamente $35 \mu \mathrm{m}$ ao longo da linha do feixe. O sistema é composto por detectores de micro tiras de silício (SMT) e fibras cintiladoras (CFT) que são rodeados por um solenóide supercondutor como mostrado na figura $3.2 \mathrm{~b}$.

O campo magnético produzido pelo solenóide é de cerca de dois Tesla e possui campo aproximadamente uniforme paralelo à linha do feixe. Dessa forma, o momentum transverso de uma partícula carregada pode ser medido usando seu raio de curvatura $r$ através da equação

$$
p_{T}[G e V]=0,3 \times r[m] \times B[T] .
$$

\section{SMT}

SMT é o detector mais interno do D $\varnothing$ e é capaz de reconstruir traços e identificar vértices, cobrindo um intervalo de pseudorapidez $|\eta| \lesssim 2,5$. Devido ao fato da região de interação ter uma dispersão ao longo do eixo $z$ de aproximadamente $25 \mathrm{~cm}$, as direções das partículas não são, em geral, perpendiculares às superfícies do detector, portanto, o SMT é composto de módulos do tipo barril e disco entrecortados na parte central e um conjunto de discos na parte frontal, como representado na figura 3.4. Dessa forma, os barris medem as coordenadas $r-\varphi$ das partículas, e os discos, as coordenadas $r-z-\varphi$. Para as partículas mais centrais, são usados os detectores do tipo barril e também o CFT, e para as partículas mais frontais, os discos reconstroem suas trajetórias em três dimensões.

O SMT possui seis detectores do tipo barril na região central, que possuem quatro camadas de silício cada. Cada camada possui um número de módulos de silício instalados 


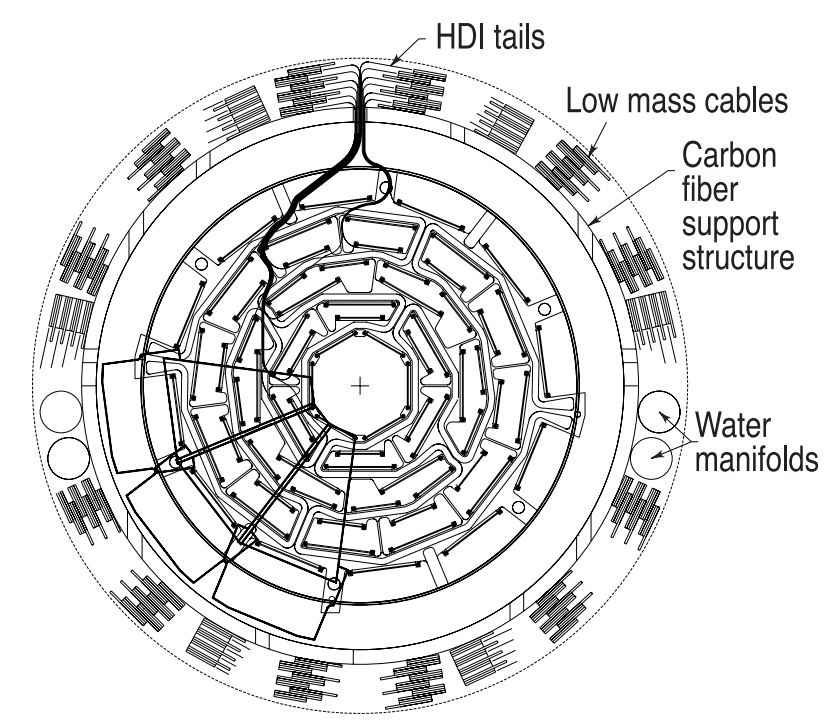

Figura 3.5: Ilustração da seção transversa do SMT.

que usam o chip de leitura SVXIIe [60]. Cada barril contém 432 módulos de silício. Nas extremidades de cada barril encontram-se os discos com doze detectores de dois lados, chamados "F-disk". Ao final do sistema entrecortado de barril e "F-disks", há uma unidade de 3 "F-disks" nos lados sul e norte. Nas regiões mais frontais, ou seja, mais longígüas do centro do detector, encontram-se dois discos de maior diâmetro, chamados "H-disk". Os "H-disks" localizam-se à $|z|=100,4$ e 121,0 cm e os "F-disks" à $|z|=[12,5 ; 25,3 ; 38,2$; 43,$2 ; 48,1$ e 53,1] cm. Os centros dos barris estão localizados à $|z|=[6,2 ; 19,0$ e 31,8] cm.

Devido à complexidade do SMT, seu projeto e construção foram um desafio. Havia pouco espaço para a montagem de peças, passagem de cabos de leitura e sistema de resfriamento (ver figura 3.5). Para isso, os módulos de silício devem ser leves, bem alinhados e com uma boa performance térmica, portanto, montados sobre estruturas de berílio e juntas de fibras de carbono-boro. A estrutura de sustentação é feita de fibra de carbono e o resfriamento é provido por uma mistura de 30\% de água e $70 \%$ de etilenoglicol a uma temperatura de $-10^{\circ} \mathrm{C}$. Deve-se ainda ressaltar que os dados de cada módulo de silício são transmitidos através de cabos e conexões especiais, chamadas de HDI (High Density Interconnect). A tabela 3.1 mostra as especificações gerais do SMT [59].

\begin{tabular}{|c|c|c|c|}
\hline & Barris & "F-Disks" & "H-Disks" \\
\hline Número de canais & 387072 & 258048 & 147456 \\
Número de módulos de Si & 432 & 144 & 96 pares \\
Área de Si m & 1,3 & 0,4 & 1,3 \\
Raio interno cm & 2.7 & 2.6 & 9.5 \\
Raio externo cm & 9.4 & 10.5 & 26 \\
\hline
\end{tabular}

Tabela 3.1: Especificações do SMT 


\section{CFT}

O CFT é composto de fibras cintiladoras dipostas em cilindros concêntricos como ilustrado na figura 3.2b. Para acomodar os "H-Disks"do SMT, os dois cilindros mais internos têm 1,66 m de comprimento ao longo do eixo $z$; os cilindros mais externos possuem 2,52 m de comprimento. Cada cilindro comporta duas camadas de fibras, uma orientada ao longo da direção do feixe $(z)$ e a outra que cruza a primeira com um ângulo estéreo de $+3^{\circ}$ $(u)$ ou $-3^{\circ}(v)$, dependendo da camada. Do cilindro mais interno para o mais externo, a orientação das camadas é: $z u-z v-z u-z v-z u-z v-z u-z v$.

O diâmetro das fibras cintiladoras é de $835 \mu m$ e essas estão conectadas à guias de luz. Ao todo, o CFT usa em torno de $200 \mathrm{~km}$ de fibras cintiladoras e $800 \mathrm{~km}$ de guias de luz.

A produção de luz nas fibras é um processo que ocorre em várias etapas. A fibra é feita basicamente de poliestireno misturado com um material orgânico paraterfenil que se excita na passagem de uma partícula carregada. O paraterfenil excitado decai rapidamente emitindo fótons de comprimento de onda de aproximadamente $340 \mathrm{~nm}$. Como o livre caminho médio da luz no poliestireno, nesse comprimento de onda, é muito curto (centenas de $\mu m$ ), o material 3-hidroflaxfone é adicionado na fibra em baixa concentração, absorvendo radiação de comprimento de onda de $340 \mathrm{~nm}$ e reemitindo-a a um comprimento de onda de $530 \mathrm{~nm}$, o qual é bem transmitido pelo poliestireno.

Após o sinal luminoso ser retirado do detector por guias de luz, ele é convertido em sinal elétrico por contadores de luz visível (VLPC). Os VLPCs operam a uma temperatura de $9 \mathrm{~K}$, para isso, estão situados imersos em hélio líquido. Eles têm uma resposta rápida, excelente eficiência quântica $(\geq 75 \%)$, alto ganho, baixa dispersão e capacidade de trabalhar em ambientes ruidosos; sendo capazes de detectar um único fóton [61], gerando entre 30 a 60 mil elétrons.

\section{Solenóide}

O eletroimã soleinodal supercondutor foi proposto para otimizar a resolução do momentum reconstruído pelos detectores SMT e CFT e, dessa forma, melhorar a identificação de partículas por esses detectores. O tamanho do solenóide e a intensidade do seu campo foram limitados pelo espaço disponível pela espessura do criostato e o suporte cilíndrico. Ele possui comprimento de 2,73 m e diâmetro de 1,42 m, como ilustrado na figura 3.6, sendo capaz de induzir um campo magnético de 2 Tesla.

O solenóide tem ainda cinco características relevantes:

- ser estável e seguro em cada polaridade;

- ter um campo magnético uniforme em grande parte do seu volume;

- ser o mais fino possível para aumentar o volume do sistema de detecção de traços; 


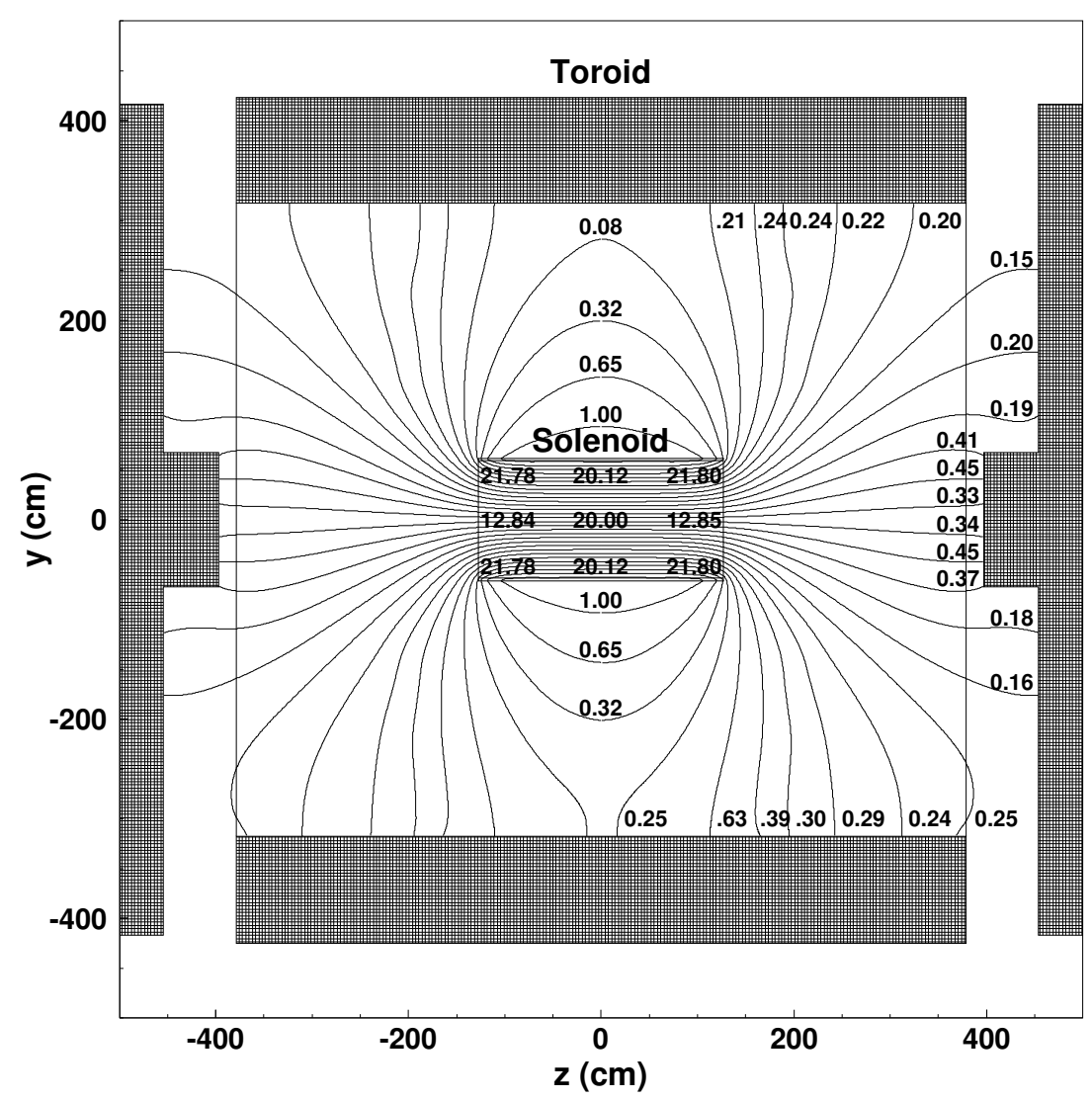

Figura 3.6: Visão do campo magnético (em $\mathrm{kG}$ ) do solenóide no eixo $y-z$.

- possuir um comprimento de radiação de aproximadamente $1 X_{0}$ na parte central, com a finalidade de otimizar a performance do CPS, situado do lado externo do solenóide;

- desligar de forma estável se o feixe de (anti)prótons for interrompido bruscamente.

O solenóide possui duas camadas de cabos supercondutores com múltiplos filamentos, nesse caso, Cu:NbTi a uma razão de 1,34:1, estabilizados com alumínio puro. A corrente de operação é de aproximadamente $5 \mathrm{kA}$, possuindo uma energia armazenada de 5,3 MJ operando a uma temperatura de $10 \mathrm{~K}$.

O alinhamento relativo entre o solenóide e o toróide é conhecido com uma precisão de 0,5 a $1 \mathrm{~cm}$. Se o solenóide estiver deslocado um centímetro na direção do feixe, a variação do momentum reconstruído pode chegar 0,1 \% nas direções frontais; se o deslocamento for transversal à direção do feixe, a variação é de aproximadamente $0,01 \%$.

\subsubsection{Calorímetro}

Calorímetros são detectores designados para medir a energia de elétrons, fótons e jatos, também auxiliando na identificação desses e de múons. Outro objetivo do calorímetro é 
medir o balanço de energia dos eventos, podendo-se induzir a existência de neutrinos de alto momentum transverso.

O calorímetro do DØ está ilustrado na figura 3.7, em que pode-se ver as três subdivisões desse detector: central (CC), frontal sul (ECS) e frontal norte (ECN). O CC cobre a região de pseudorapidez $|\eta| \lesssim 1$, e o ECN e o ECS estendem a cobertura do calorímetro até $|\eta| \sim 4$, como ilustrado na figura 3.8. Cada subdivisão do calorímetro está localizada em um criostato, que mantém a temperatura do detector a aproximadamente $90 \mathrm{~K}$. Para compensar a falta de calorímetro entre os criostatos, uma camada de células calorimétricas é adicionada (Vão de células), além dos cintiladores intercriostatos discutidos a seguir.

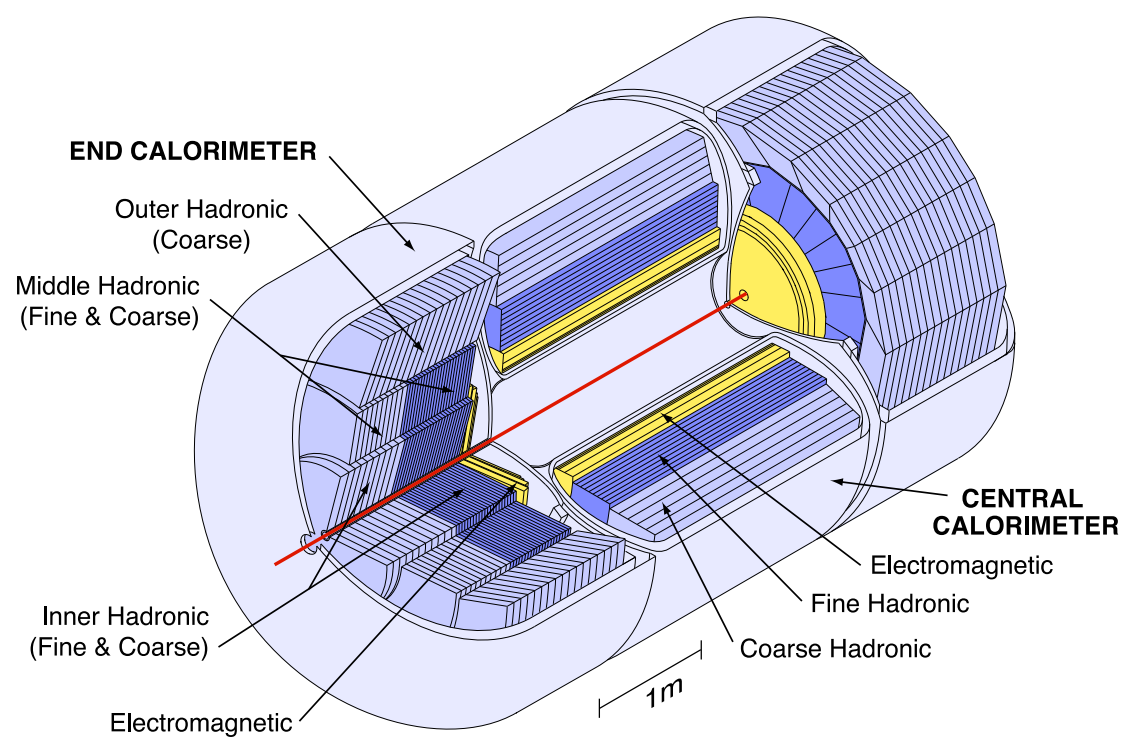

Figura 3.7: Calorímetro central e frontal ilustrados.

Nota-se que as células são construídas de forma que seus centros estejam sobre raios projetados do centro do detector, sendo chamadas de pseudo-projetivas (veja figura 3.8). Isso resulta em uma segmentação de $\Delta \varphi \times \Delta \eta=0,1 \times 0,1$, apropriada ao tamanho transversal típico de chuveiros: aproximadamente $2 \mathrm{~cm}$ para chuveiros eletromagnéticos e aproximadamente $10 \mathrm{~cm}$ para chuveiros hadrônicos.

Pode-se perceber na figura 3.7 que o calorímetro possui 3 agrupamentos de camadas: eletromagnética (EM), mais perto do feixe; hadrônica fina $(\mathrm{FH})$; e hadrônica grossa $(\mathrm{CH})$. O nome deve-se ao fato de que partículas cuja interação dominante é a eletromagnética são absorvidas nas primeiras camadas do calorímetro, e.g., fótons e elétrons. Os hádrons penetram mais no detector, interagindo nas camadas mais distantes do ponto de interação. A primeira parte do calorímetro hadrônico é mais segmentada com a segunda parte menos segmentada, com células maiores.

O meio ativo usado em todo calorímetro é argônio líquido. Como placas absorventes, usa-se o urânio empobrecido $\left(\mathrm{U}^{238}\right)$ de espessura aproximada de quatro milímetros na camada EM. Na camada FH, placas de urânio quase puro de espessura 6 milímetros 


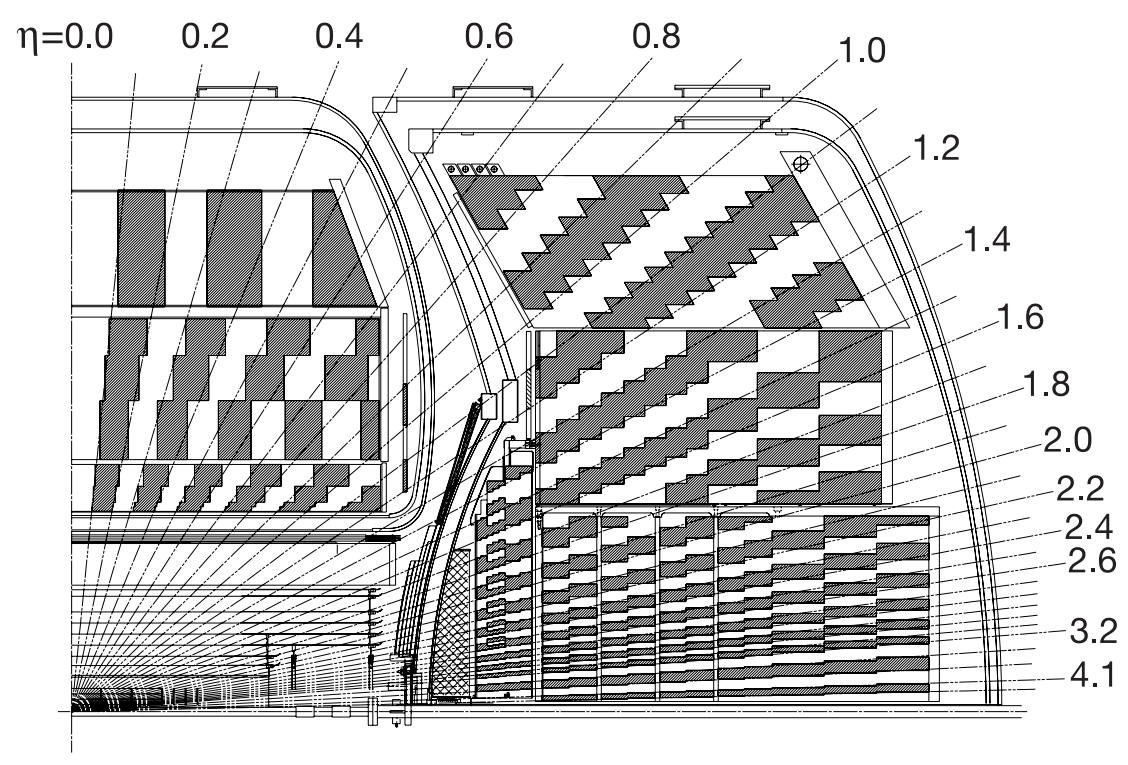

Figura 3.8: Ilustração das células pseudo-projetivas do calorímetro.

são usadas e, na camada CH, elas são de cobre (CC) e aço inoxidável (ECN e ECS) de espessura 46,5 milímetros.

Uma típica célula calorimétrica é ilustrada na figura 3.9. A diferença de potencial típica entre as placas absorventes é de $2,0 \mathrm{kV}$. Dessa forma, o tempo de vôo de um elétron entre as placas absorventes atravessando a região preenchida de argônio líquido é de 450 nanosegundos (2,3 milímetros de vão). Observa-se que as interações no Tevatron ocorrem a cada 396 nanosegundos, o que vai resultar em perda de parte do sinal devido ao tempo curto de integração disponível. Esse fato será discutido nas próximas seções, já que a simulação do detector não leva em conta esse tempo curto de integração.

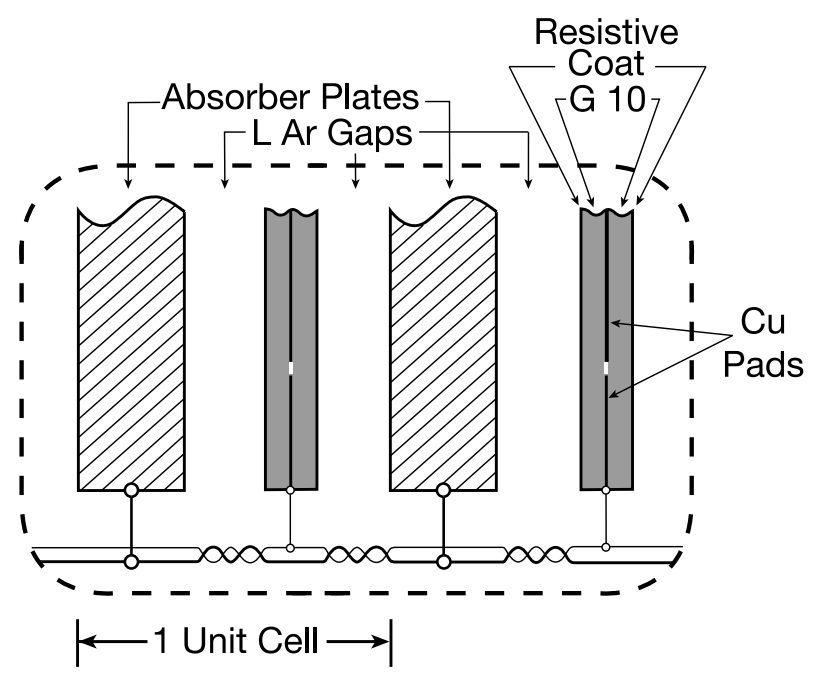

Figura 3.9: Esquema de uma típica célula calorimétrica [58]. 


\section{Geometria do Calorímetro}

Cada célula calorimétrica é identificada por três valores: ieta, iphi e ilayer. O valor ilayer determina a qual camada a célula pertence (ver tabela 3.2). O valor ieta informa a posição relativa à pseudorapidez da célula nas coordenadas de detector (ver tabela 3.3 e figura 3.10). O valor iphi determina a posição da célula com relação ao ângulo azimutal, variando de 1 a 64 .

\begin{tabular}{|c|c|}
\hline ilayer & Camada \\
\hline $1-7$ & EM \\
$8-10$ & ICD e Vão de células \\
$11-14$ & FH \\
$15-16$ & CH \\
\hline
\end{tabular}

Tabela 3.2: Relação das camadas de cada célula com relação a ilayer.

\begin{tabular}{|c|c|}
\hline ieta & região de $\eta_{D E T}$ \\
\hline 1 & $0-0,1$ \\
2 & $0,1-0,2$ \\
.. &.. \\
32 & $3,1-3,2$ \\
33 & $3,2-3,42$ \\
34 & $3,42-3,7$ \\
35 & $3,7-4,1$ \\
36 & $4,1-4,45$ \\
37 & $4,45-5,2$ \\
\hline
\end{tabular}

Tabela 3.3: Relação da pseudorapidez de cada célula com relação a ieta.

\section{ICD}

Devido ao fato de o calorímetro estar contido em criostatos, esse não cobre a região de pseudorapidez $0,8<|\eta|<1,4$ (veja figura 3.8). Além disso, há uma quantidade grande de obstáculos para as partículas nessa região, o que causa ineficiência e degradação da energia. A fim de resolver esse problema, foram instalados cintiladores localizados entre os criostatos do calorímetro, cobrindo a região $1,1<|\eta|<1,4$.

\section{Detectores Pré-chuveiros}

Devido à presença de materiais (e.g., cabos, suportes, solenóide) entre o calorímetro e o ponto de interação, existem perdas de energia imensuráveis pelo detector. Para amenizar 


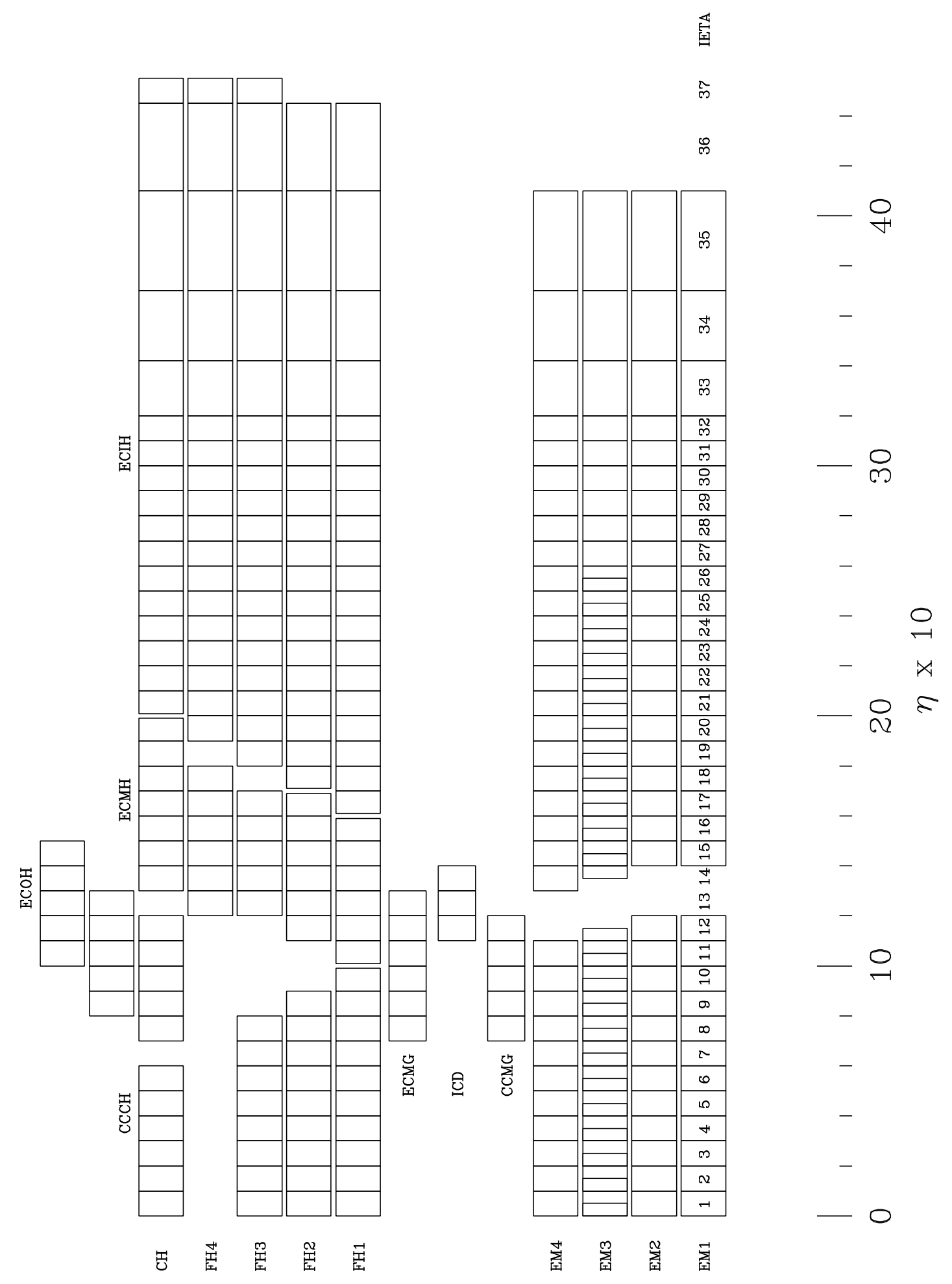

Figura 3.10: Ilustração da geometria das células calorimétricas no plano [58]. 
esse problema, detectores chamados de pré-chuveiros foram instalados, permitindo correções de energia, melhora na identificação de objetos físicos (fótons e elétrons) e rejeição de ruídos.

Há três detectores pré-chuveiro, um central (CPS) e dois frontais (FPS). O CPS cobre a região $|\eta|<1,3$, localizando-se entre o solenóide e o calorímetro. Os dois detectores FPS estão localizados junto aos calorímetros frontais, cobrindo a região $1,5<|\eta|<2,5$.

Os detectores pré-chuveiro usam tiras de cintiladores triangulares, não ocorrendo espaço morto entre as tiras, resultando numa boa resolução espacial. No meio das tiras cintiladoras, há fibras que carregam luz até o final do detector para a leitura do sinal em VLPCs.

A geometria das tiras do CPS e do FPS seguem o mesmo princípio. No caso do CPS, há três camadas de tiras de cintiladores arranjadas em $x-u-v$ (ver figura 3.11). A camada $x$ é axial ao feixe, a camada $u$ possui um ângulo de $23,774^{\circ} \mathrm{com}$ o eixo axial e a camada $v$ um ângulo de $24,016^{\circ}$.

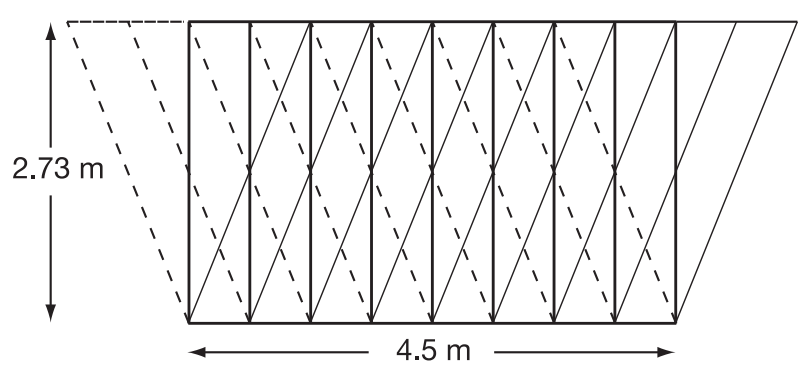

Figura 3.11: Geometria das tiras do detector CPS [58].

\subsubsection{Espectrômetros de Múons}

Para a detecção de múons, usam-se câmaras proporcionais (PDTs), cintiladores e eletroimã toroidal para a região central $(|\eta|<1,0)$ e mini câmaras proporcionais (MDTs) para região a frontal $(1,0<|\eta|<2,0)$.

Os eletroimãs toroidais [62] permitem uma rejeição de partículas de baixo $\mathrm{p}_{\mathrm{T}}$ no primeiro nível de trigger do evento (ver seção 3.2.7 para definição trigger), uma melhor identificação de múons utilizando traços centrais, rejeição de múons provenientes de decaimentos de píons e káons e melhor resolução de $\mathrm{p}_{\mathrm{T}}$ para múons de alto momentum transverso. Para acesso fácil ao detector, os eletroimãs são dispostos em três seções: uma central, localizada na base do detector, servindo de suporte para o sistema central de traços e calorímetros; e outras duas em forma de C, que podem ser movidas perpendicularmente ao centro do feixe. Os eletroimãs operam com uma corrente de $1500 \mathrm{~A}$. 


\section{Sistema Central de Múons}

O sistema de detecção de múons centrais utiliza os eletroimãs toroidais, câmaras de múons e cintiladores.

As PDTs [62] são dividas em três camadas, uma localizada entre o ponto de interação e o eletroimã toroidal (camada A) e duas localizadas após o eletroimã toroidal (ver figura 3.12 ), cobrindo a região central $|\eta| \lesssim 1,0$.

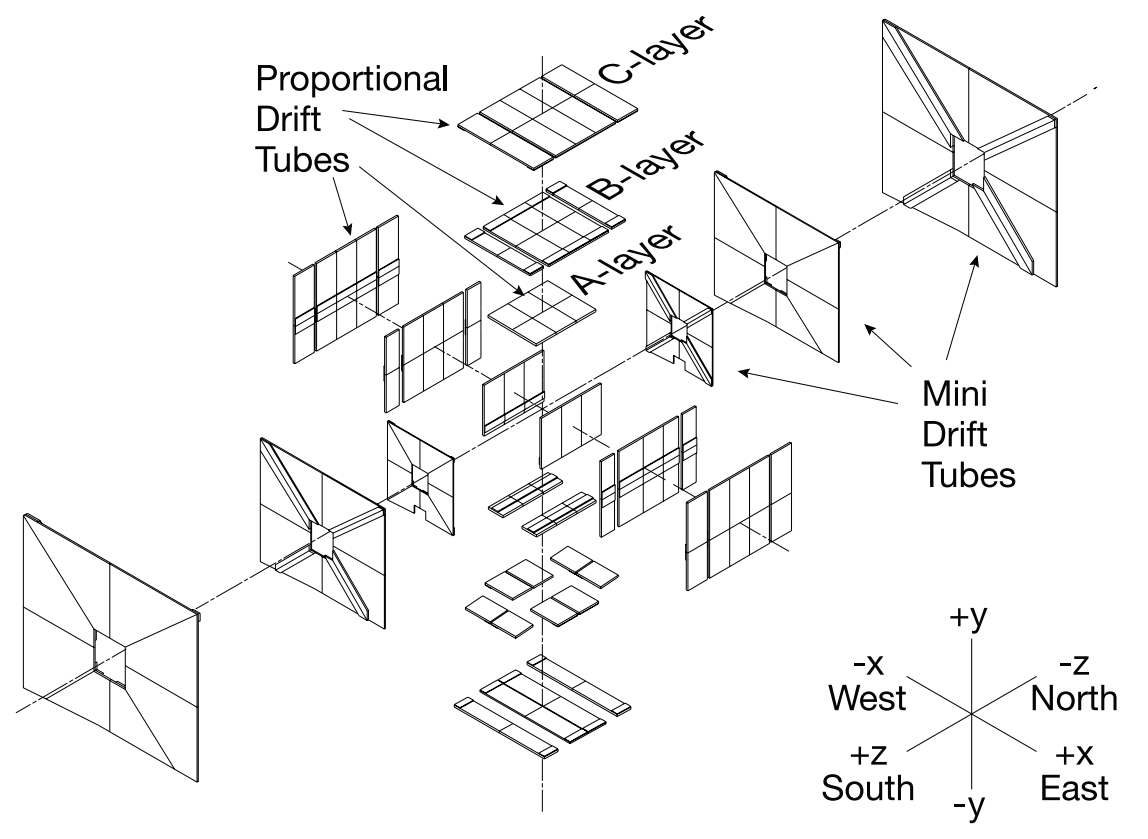

Figura 3.12: Imagem ilustrativa do sistema de detecção de múons [58].

Cintiladores localizados na parte superior e inferior do detector servem para o veto de múons côsmicos [63] (ver figura 3.13).

Outra camada de cintiladores localizada entre o calorímetro e o toróide $(A-\varphi)$, permite maior velocidade para o trigger de eventos, identificação de múons e rejeição de múons frontais espalhados para a parte central do detector. (ver figura 3.13).

\section{Sistema Frontal de Múons}

Para múons frontais, há três camadas de MDTs para reconstrução e três camadas de cintiladores para o trigger de eventos.

MDTs foram escolhidas pela boa resolução espacial combinada com resistência à radiação, já que essa cresce com a pseudorapidez. Assim como no sistema central de múons, a camada A situa-se entre o ponto de interação e o toróide, e as camadas B e C, após o toróide. As MDTs cobrem a região $1 \lesssim|\eta| \lesssim 2$ (ver figura 3.12).

Os cintiladores para trigger de eventos também dividem-se em três camadas (A, B e C) (ver figura 3.13). Eles foram construídos para possuir uma ótima resolução temporal 


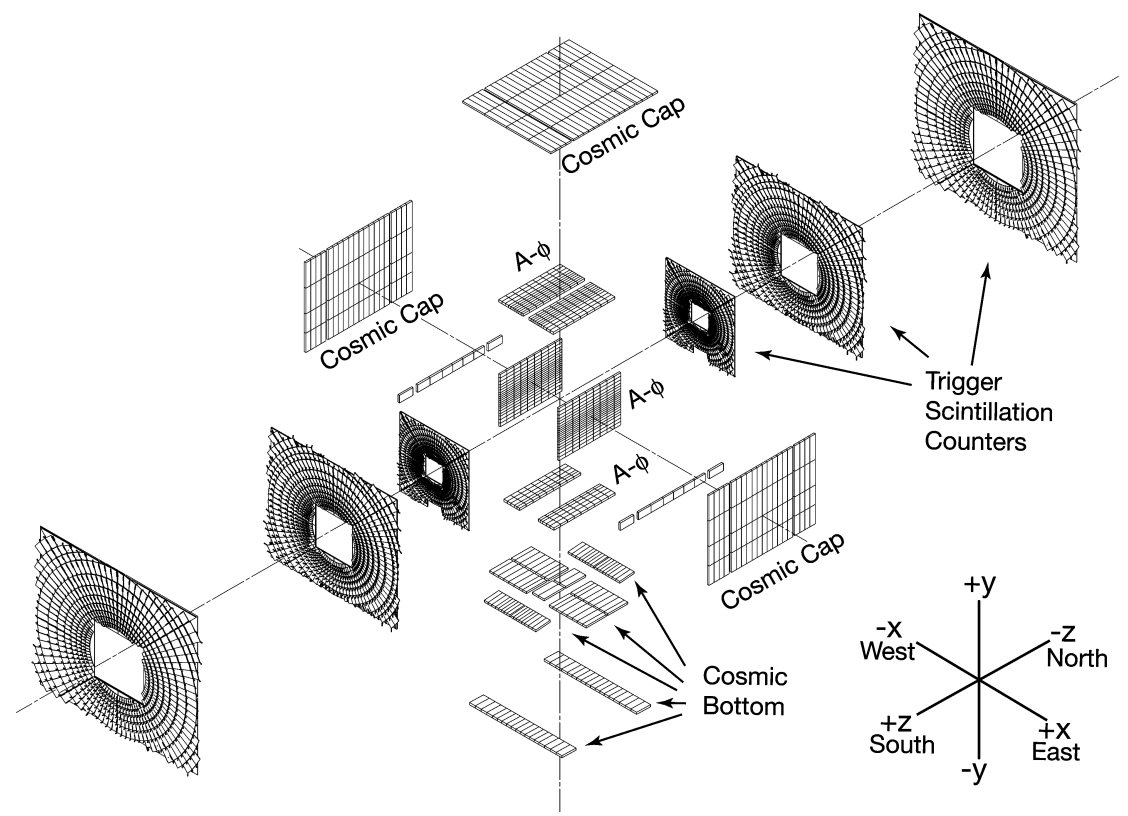

Figura 3.13: Ilustração da posição dos cintiladores de múons [58].

e espacial, sendo as camadas bastante segmentadas (aproximadamente 0,1 em pseudorapidez). Para isso, cerca de 5000 cintiladores são utilizados, dando forma à parte mais bonita, visualmente, do detector $\mathrm{D} \varnothing$.

\subsubsection{Detector de Prótons Frontais}

O sistema de detectores de prótons frontais (FPD) é constituído por um grupo de espectômetros para medir os momenta de prótons difratados, que viajam dentro do tubo do feixe, do ponto de interação até os detectores [64]. Os detectores precisam operar próximo ao feixe e em pressão atmosférica e, para isso, eles são instalados em compartimentos mantidos à mesma condição de vácuo extremo do tubo do feixe que podem ser movidos para perto (somente em condições estáveis) ou longe do centro do feixe (e.g, durante a injeção de prótons e término do feixe), chamados de Roman Pots (RPs) [65]. Os RPs ficam localizados em castelos, no total de seis (ver figura 3.14), não interferindo no funcionamento do acelerador.

No total, o FPD possui nove espectrômetros e dezoito detectores. Cada espectrômetro necessita de dois detectores de posição, pois os campos magnéticos aos quais os (anti)prótons difratados estão sujeitos são não-lineares. Os detectores estão dispostos a aproximadamente 20/30 metros do ponto de interação para oito dos espectômetros (quadrupolos) e 60 metros para apenas um (dipolo), como mostrado na figura 3.14.

Nos detectores de posição, utilizam-se fibras cintiladoras, dispostas em três planos (ver figura 3.15), permitindo uma boa resolução espacial. Os planos são divididos em três $(u-v-x)$, sendo que os planos $u(v)$ estão orientados a um ângulo de $+(-) 45^{\circ}$ com o 


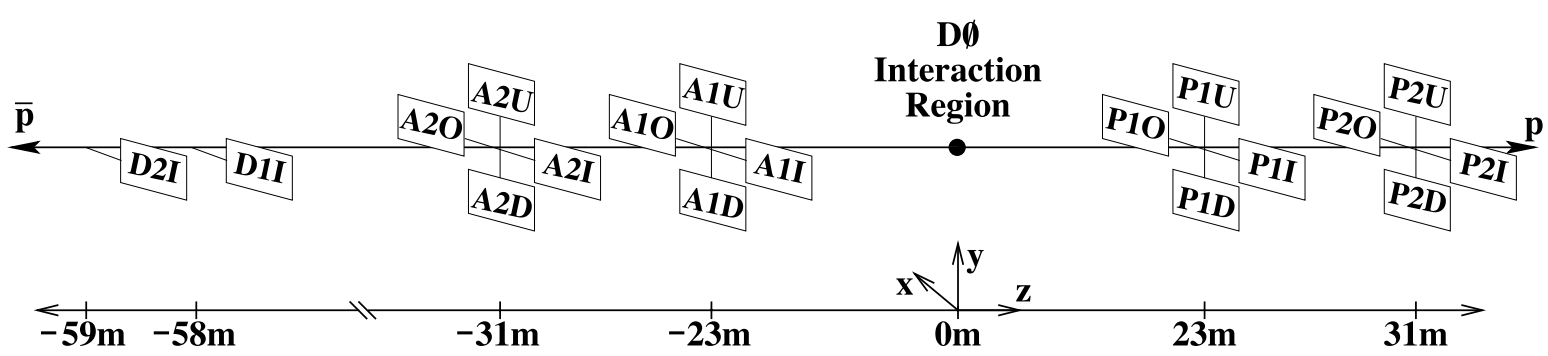

Figura 3.14: Localizações dos detectores de prótons frontais com relação à região de interação (DØ Interation Region) [58].

plano $x$. O plano $x$ está sempre orientado paralelo ao movimento de inserção dos RPs. Cada plano possui duas camadas deslocadas entre si para que o detector não possua áreas mortas (ver figura 3.15).

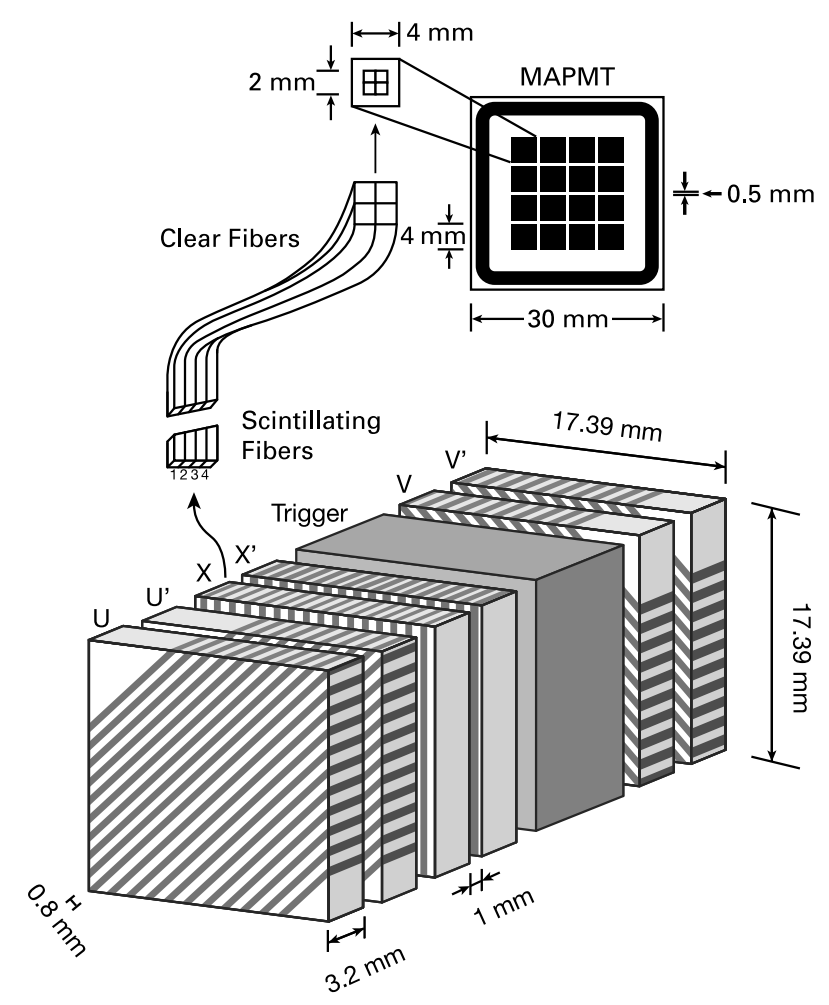

Figura 3.15: Ilustração do tipo de detector usado no FPD [58].

\subsubsection{Monitor de Luminosidade}

O principal objetivo do monitor de luminosidade (LM) é medir com acurácia a luminosidade das colisões ocorridas na região de interação do DØ . Dessa forma, o detector é designado para contar o número de colisões inelásticas em colisões próton-antipróton. O LM também tem a capacidade de medir taxas de halo e de reconstruir vértices, utilizando 


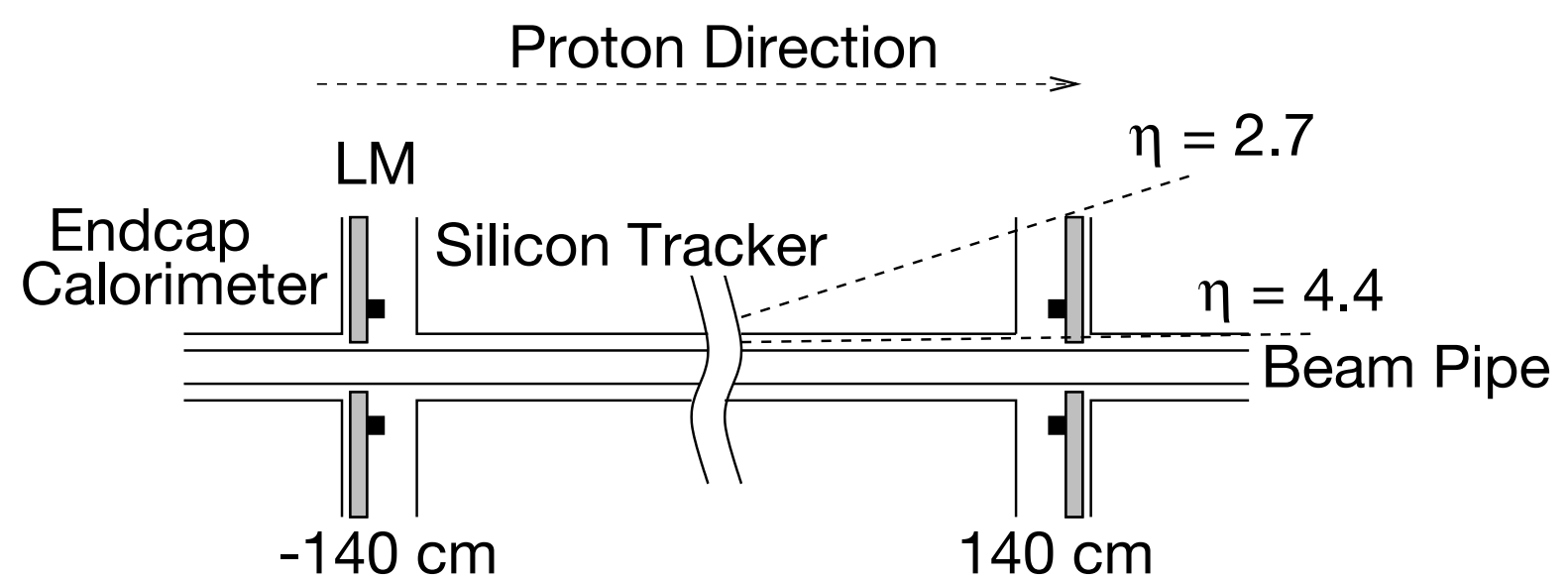

Figura 3.16: Disposição dos detectores de luminosidade do dØ [58].

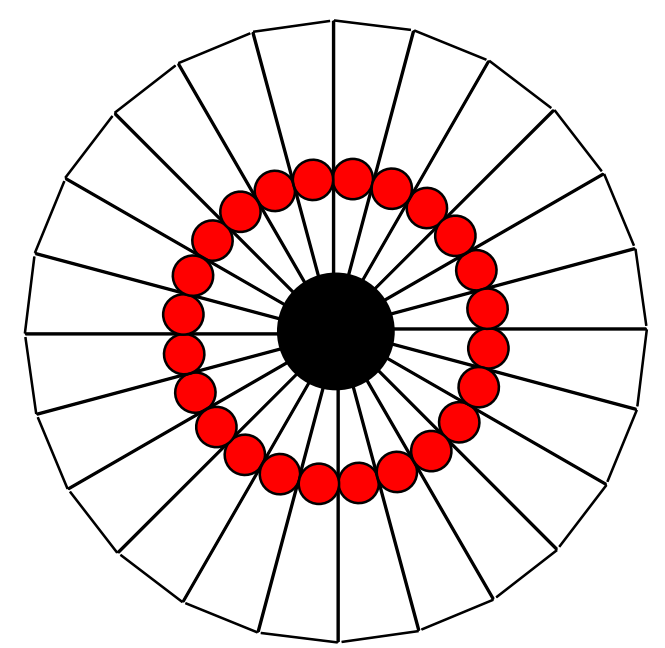

Figura 3.17: Visão esquemática dos cintiladores do LM [58].

a informação de tempo de vôo das partículas [66].

O detector LM consiste em dois sistemas de vinte e quatro cintiladores plásticos localizados a $140 \mathrm{~cm}$ do centro do detector, sendo um no lado sul e outro no lado norte (figuras 3.16 e 3.17). Eles se encontram na frente do calorímetro frontal longitudinalmente e radialmente entre o FPS e o tubo do feixe (figura 3.2b). Os cintiladores possuem $15 \mathrm{~cm}$ de comprimento, cobrindo a região de pseudorapidez $(\eta)$ do detector de 2,7 a 4,4.

A luz proveniente dos dectetores é transformada em sinal elétrico através do uso de fotomultiplicadoras (PMTs). As PMTs, por estarem sujeitas a um campo de um Tesla devido ao solenóide, possuem ganho menor em trinta vezes [67]. A resolução da medida de tempo é de 0,3 ns. Como os detectores estão muito perto do feixe, eles recebem uma alta dose de radiação (25 Krad/fb-1), porém, devido ao uso de quartzo nas PMTs, é esperado que a eficiência apenas decresça de $10 \%$ após $3 \mathrm{fb}^{-} 1$. De fato, esses detectores já foram trocados em 2006. 


\section{Medida da Luminosidade Instantânena}

Luminosidade instantânea (L) é a medida do número de colisões inelásticas por unidade de tempo e por unidade de seção de choque. Através de L, pode-se medir a luminosidade integrada (levando-se em conta as colisões elásticas) sobre um período de tempo $(\mathcal{L})$, sendo, desse modo, possível medir a seção de choque de qualquer processo físico detectado pelo D .

Calcula-se L através da equação

$$
L=\frac{f \times \bar{N}}{\epsilon \times A \times \sigma_{\text {inel }}},
$$

onde $f$ é a freqüência do cruzamento de feixe, $\bar{N}$ é o número médio de colisões por cruzamento de feixe medido pelo LM, $\sigma_{\text {inel }}$ a seção de choque inelástica medida a priori, $\epsilon$ a eficiência do LM e $A$ a aceptância do LM para colisões inelásticas.

Geralmente, há mais de uma colisão entre prótons e antiprótons em cada cruzamento de feixe. Para levar em conta mútiplas interações na medida de $\bar{N}$, uma contagem de número de cruzamentos de feixe sem nenhuma colisão é realizada e, usando estatística de Poisson, determina-se $\bar{N}$.

Para distingüir partículas provenientes da quebra de (anti)prótons de partículas que viajam ao redor do feixe (halo) são necessárias medidas precisas de tempo entre as partículas que atingem o LM no lado norte e no lado sul (figura 3.18). Os momenta transverso das partículas que atingem o LM podem ser desprezados e a velocidade dessas é, aproximadamente, a velocidade da luz $(c)$, então, a coordenada $z$ de uma colisão pode ser medida através da diferença do tempo de vôo de partículas produzidas nessa interação:

$$
z_{v}=\frac{c}{2}\left(t_{-}-t_{+}\right)
$$

onde $t_{-}$é o tempo de vôo medido por partículas no LM do lado norte e $t_{+}$do lado sul. Dessa forma, apenas colisões com $\left|z_{v}\right|<100 \mathrm{~cm}$ são consideradas, eliminando a possibilidade de contar falsas interações quando halos do feixe atingem o LM, pois esses produzem $\left|z_{v}\right| \sim 140 \mathrm{~cm}$. O corte $\left|z_{v}\right|<100 \mathrm{~cm}$ possui eficiência próxima de $100 \%$, já que $\sigma\left(z_{v}\right) \sim 30 \mathrm{~cm}$.

Para calcular a luminosidade integrada $(\mathcal{L})$, o experimento D $\varnothing$ utiliza unidades de tempo chamadas de blocos de luminosidade (LBN). Requer-se que o tempo de duração do LBN seja curto (menor que $60 \mathrm{~s}$ ), já que para cada LBN um valor de luminosidade instantânea é associado, usando a equação 3.8. Dessa forma, todos os requerimentos de qualidade de dados são baseados nos LBNs, e a luminosidade integrada de uma amostra é a soma da luminosidade instantânea de cada LBN presente nessa. 


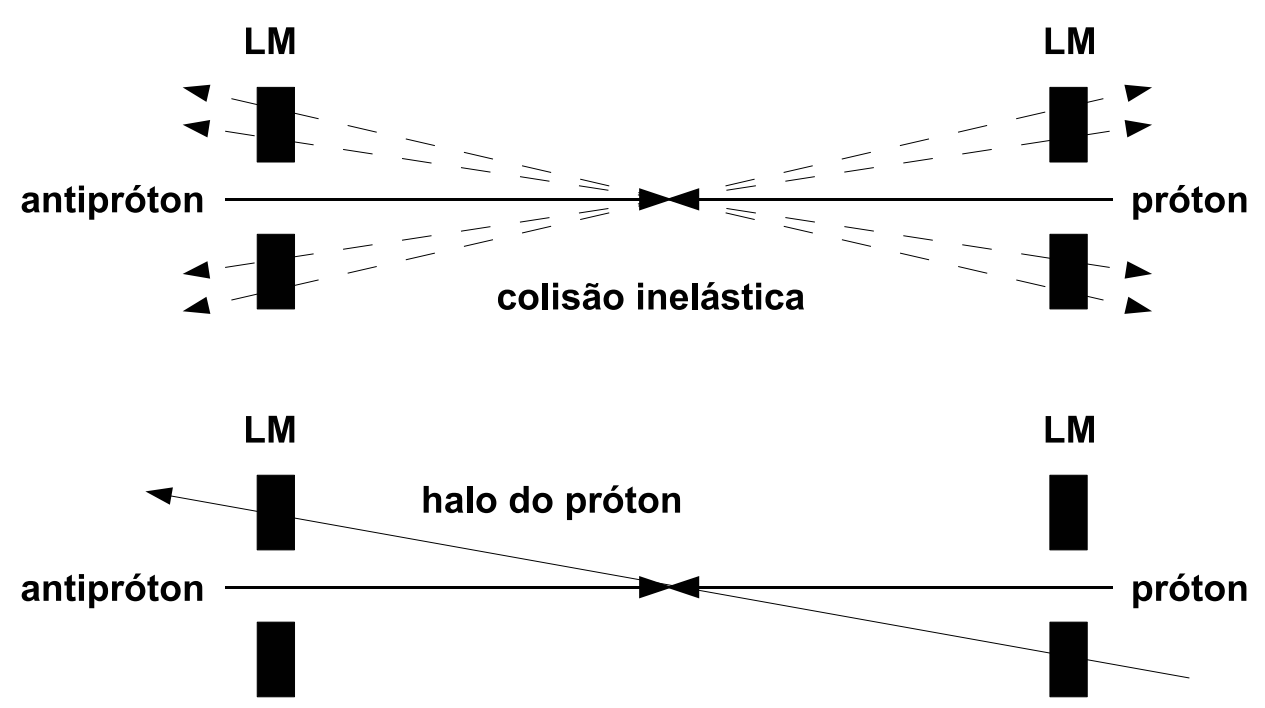

Figura 3.18: Ilustração de uma interação inelástica e de um halo detectados pelo LM.

\subsubsection{Seleção de Eventos em Tempo Real}

A taxa de eventos produzidos no Tevatron $(\sim 2,5 \mathrm{MHz})$ é muito maior do que o experimento DØ pode gravar em disco $(\sim 50 \mathrm{~Hz})$ e, de certa forma, muitos desses eventos são de pouco interesse. Portanto, é necessário o uso de uma seleção de eventos em tempo real ou trigger [68].

O sistema de triggers do DØ possui três níveis (L1, L2 e L3). O L1 é a seleção mais simples, com algorítmos rápidos, que suporta uma taxa de aproximadamente $2 \mathrm{kHz}$. Já o L2 tem algorítmos mais complicados, podendo processar eventos com uma taxa de $1 \mathrm{kHz}$. O L3 é o último requerimento para o evento ser gravado em disco, com um algorítmo mais apurado, processando eventos a uma taxa de $50 \mathrm{~Hz}$.

Após a seleção em tempo real, uma taxa de eventos que passam pelos critérios do trigger é rejeitada aleatoriamente, já que alguns triggers aceitam mais eventos do que o sistema consegue processar. Dessa forma, define-se uma taxa de aceitação do trigger, a qual varia aproximadamente entre 1, para triggers muito restritivos, e $10^{6}$, para triggers pouco restritivos.

O sistema de triggers é parte essencial do sistema de aquisição de dados do experimento DØ . Essa aquisição é realizada sempre que o Tevatron fornece colisões no Tevatron, sendo necessário que os colaboradores façam plantões para garantir a qualidade da coleta de dados. Quinhentas e quatro horas de plantão, com a responsabilidade sobre o sistema de aquisição de dados, foram realizadas como parte do trabalho desta tese e requerimento para ter acesso aos dados do experimento. 


\subsubsection{Reconstrução de Eventos no DØ}

O experimento DØ possui uma coleção de algorítmos ( truir os eventos adquiridos pelo detector D $\varnothing$ [69]. Essa coleção processa uma quantidade enorme de informação e define objetos físicos essenciais para as análises, assim como: vértices primários, elétrons, fótons, múons e jatos.

A reconstrução é ajustada para ter a maior eficiência e menor suscetibilidade a ruído possíveis. Os métodos de reconstrução são similares aos explicados em [68]. De fato, todos os resultados experimentais publicados pela colaboração D $\varnothing$ suportam o fato de que $d \varnothing$ reco funciona apropriadamente.

\subsection{Observações}

Observa-se que o Tevatron oferece condições únicas para realizar estudos da física de difração hadrônica. Em adição, o detector D $\varnothing$ possui todos os requerimentos necessários para tais estudos.

Pode-se usar o FPD para medir prótons difratados e o calorímetro para medir a diferença da topologia entre os eventos difrativos e não difrativos. Apesar do potencial do FPD, esse não possui dados acumulados com luminosidade integrada suficiente para identificar os eventos que são procurados nesta tese. 


\section{Capítulo 4}

\section{Jatos no DØ}

Devido ao confinamento de cor, discutido na seção 2.2.2, quarks e glúons fragmentam-se em jatos de partículas sem cor. Esses jatos podem ser reconstruídos e identificados no detector $\mathrm{D} \emptyset$ com o uso do calorímetro. Este capítulo é dedicado à descrição de como jatos são caracterizados pelo experimento D $\varnothing$.

Na seção 4.1, a reconstrução de jatos no DØ é revista. Na seção 4.2, os requerimentos para identificação de jatos são expostos. A correção da energia dos jatos é discutida na seção 4.3. E, finalmente, a seção 4.5 trata da resolução da energia dos jatos.

\subsection{Reconstrução de Jatos}

Seguindo a evolução temporal de formação dos jatos, pode-se estender o conceito de jatos a três níveis: jatos de pártons, jatos de partículas e jatos calorimétricos (ver figura 4.1). Através do calorímetro do D $\varnothing$, descrito na subseção 3.2.3, pode-se reconstruir os jatos calorimétricos de cada evento.

A reconstrução de jatos no DØ é realizada com o uso de um algorítmo de cone [71], preenchendo necessidades teóricas para a comparação de medidas experimentais com a teoria [72]. O algorítmo apresenta as seguintes características:

- insensível à divergência infravermelha, discutida na subseção 2.2.2, ou seja, insensível à radiações de glúons de baixo momentum transverso;

- insensível à radiações colineares ao jato, podendo tornar ineficiente a reconstrução do jato;

- invariante sobre transformações de coordenada;

- tempo de computação finito.

O algorítmo é baseado no agrupamento de torres, as quais são formadas pelas células do calorímetro. Cada torre representa uma região de $\eta$ e $\varphi$ do calorímetro. Tratando as células como objetos sem massa, o 4-momentum de cada torre é definido como: 


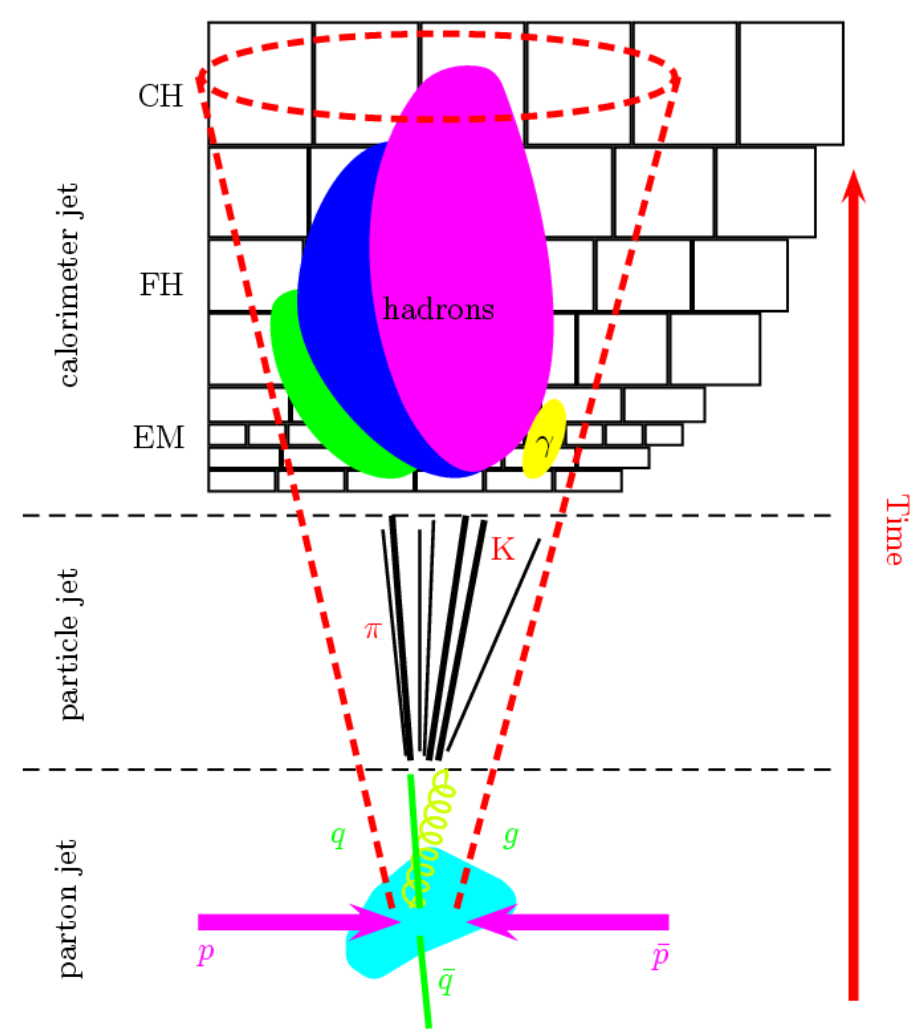

Figura 4.1: Esquema da evolução temporal da formação dos jatos, passando pela fragmentação em pártons (parton jet), depois pela formação de partículas sem cor (particle jet) e, finalmente, pela observação dessas pelo conjunto de detectores (calorimeter jet) $[70]$.

$$
P^{\text {torre }}=\Sigma_{i=\text { células da torre }}\left(E^{i}, p_{x}^{i}, p_{y}^{i}, p_{z}^{i}\right)
$$

O primeiro passo da reconstrução é agrupar as torres em protojatos. Cortes específicos são aplicados para evitar ruído [71]. Começando pela torre de maior momentum transverso, os protojatos são formados por torres pertencentes a um cone no espaço $(y, \varphi)$, tal que

$$
\text { torre i } \subset \text { protojato }: \Delta R=\sqrt{\left(Y_{p}-Y_{i}\right)^{2}+\left(\varphi_{p}-\varphi_{i}\right)^{2}}<0.3 \text {, }
$$

onde $Y_{i}$ e $\varphi_{i}$ são a rapidez e o ângulo azimutal da iésima torre, respectivamente; e $Y_{p}$ e $\varphi_{p}$ a rapidez e o ângulo azimutal do protojato, respectivamente.

Uma vez que essa lista de pratojatos está formada, o segundo passo é encontrar candidatos a jatos. Nesse passo, usa-se a distância principal do tamanho do jato $R_{\text {cone }}$, dentro da qual definem-se as torres pertencentes a esse. Para cada protojato, inclui-se as torres dentro de um raio de cone menor que $R_{\text {cone }}$. Testes de estabilidade são realizados para evitar sensibilidade à divergência infravermelha de QCD, já que o algorítmo é iniciado 
através de sementes (torre de maior momentum transverso).

Após o segundo passo, algumas torres podem estar contidas em mais de um jato candidato. Para evitar dupla contagem de energia, um terceiro passo de separação e combinação dos jatos candidatos é realizado. Se dois jatos candidatos dividem torres, e essas possuem mais da metade do $\mathrm{p}_{\mathrm{T}}$ de um dos jatos candidatos, esses dois são combinados em um único, caso contrário, as torres são divididas entre os dois jatos candidatos com base na distância $\Delta R$ dessas com o centro do jato, o qual é recalculado.

Como passo final na reconstrução de jatos no $\mathrm{D} \varnothing$, um corte no $\mathrm{p}_{\mathrm{T}}$ do jato é aplicado, para evitar a presença de jatos sem significado físico. O corte usado é de $\mathrm{p}_{\mathrm{T}}$ maior que 6,0 GeV.

Antes de atingirem o calorímetro, muitas partículas perdem energia interagindo com materiais do detector anteriores a esse, e, além disso, o calorímetro não é completamente eficiente. Juntando esses dois fatores, a reconstrução dos jatos apresenta uma ineficiência, especialmente para jatos de baixo $\mathrm{p}_{\mathrm{T}}$. Na seção 4.4, as eficiências de reconstrução são apresentadas.

\subsection{Identificação de Jatos}

Uma vez reconstruídos, os jatos passam por uma etapa de identificação para evitar ruídos instrumentais e falsos jatos [73]. Pode-se classificar os critérios de identificação a partir de três variáveis:

- fração máxima no $\mathrm{CH}$;

- fração mínima e máxima no EM;

- confirmação no L1.

\subsubsection{Fração Máxima no $\mathrm{CH}$}

Um corte na fração de energia do jato no calorímetro $\mathrm{CH}(\mathrm{CHF})$ remove jatos reconstruídos devido à presença de ruído nesta camada do calorímetro, conhecida por apresentar ruído significativo. Cada região de $\eta$ do detector necessita de um corte diferente e, através de uma série de estudos, os seguintes cortes foram definidos [73]:

- $(C H F<0,4)$ ou;

- $\left(C H F<0,6\right.$ para $0,85<\left|\eta_{D E T}\right|<1,25$ e $\left.n 90<20\right)$ ou;

- $(C H F<0,44$ para $|\eta|<0,8)$ ou;

- $(C H F<0,46$ para $1,5<|\eta|<2,5)$; 
onde $n 90$ é o número de torres que contém $90 \%$ da energia do jato, $\eta_{D E T}$ a pseudorapidez do jato calculada no referencial do detector e $\eta$ a pseudorapidez do jato calculado no referencial do centro de massa (considerando a posição do vértice da colisão).

\subsubsection{Fração Mínima e Máxima no EM}

Aplicar um corte de limite inferior na fração da energia do jato no calorímetro EM $(E M F)$ remove ruído hadrônico, e de limite superior, falsos jatos reconstruídos pela passagem de um fóton ou elétron no calorímetro do DØ. Os requerimentos aplicados são [73]:

- $(E M F>0,05)$ ou;

- $\left(1,3>\left(|| \eta_{D E T}|-1,25|+\operatorname{Max}\left(0,40 \times\left(\sigma_{\eta}-0,1\right)\right)\right)\right)$ ou;

- $\left(E M F>0,03\right.$ e $\left.1,1<\left|\eta_{D E T}\right|<1,4\right)$ ou;

- $(E M F>0,04$ e $|\eta|>2,5)$;

onde $\sigma_{\eta}$ é a largura do jato no eixo da pseudorapidez. Nota-se que se o requerimento que envolve $\sigma_{\eta}$ for verdadeiro, a pureza do jato é garantida sem a necessidade de um corte sobre EMF [73].

É preciso aplicar um limite superior para $E M F$, já que se o jato possui grande parte de seu momentum transverso no calorímetro eletromagnético, há grande probabilidade de ser um falso jato reconstruído pela passagem de um fóton ou elétron. O limite superior aceito para $E M F$ é de 0,95 .

\subsubsection{Confirmação no L1}

Para evitar outras fontes de ruídos instrumentais, aplica-se uma confirmação do nível 1 do sistema de trigger do DØ [74]. Usa-se, portanto, a razão entre a energia do jato reconstruído e a energia das torres do nível 1 do sistema de trigger que se encontram dentro do cone do jato correspondente $\left(\Delta R<R_{\text {cone }}\right)(L 1 R)$. Os requerimentos aplicados são os seguintes:

- $(L 1 R>0,5)$ ou;

- $\left(L 1 R>0,35\right.$ e $p_{T}<15 \mathrm{GeV}$ e $\left.|\eta|>1,4\right)$ ou;

- $\left(L 1 R>0,1\right.$ e $p_{T}<15 G e V$ e $\left.|\eta|>3,0\right)$ ou;

- $\left(L 1 R>0,2\right.$ e $p_{T} \geq 15 G e V$ e $\left.|\eta|>3,0\right)$.

Os cortes de identificação de jatos exercem o papel de remover jatos falsos, porém, parte dos jatos verdadeiros são removidos nesse processo. Na seção 4.4, a eficiência da identificação de jatos é apresentada. 


\subsection{Correção da Energia dos Jatos}

Os jatos calorimétricos reconstruídos são objetos suscetíveis à atenuação instrumental na energia e eficiências dos detectores, tendo, portanto, uma energia menor do que a energia dos jatos de partículas. Outro fator que modifica a energia do jato calorimétrico é a presença de partículas dentro do cone do jato, que não pertencem ao jato, mas sim a: i) interações secundárias presentes no mesmo cruzamento do feixe, ii) energia remanescente de colisões anteriores ou iii) energia proveniente de produtos do decaimento do Urânio. Outro fator importante é a dissipação da energia das partículas durante a formação do chuveiro. Nesse caso, a energia reconstruída dos jatos calorimétricos não é comparável com teoria e, portanto, precisa ser corrigida. Em geral, a energia dos jatos calorimétricos é corrigida ao nível dos jatos de partículas através da seguinte fórmula:

$$
E_{\text {part }}=\frac{E_{\text {calo }}-\mathcal{O}}{\mathcal{R} \times \mathcal{S}}
$$

onde $\mathcal{O}$ é a correção do deslocamento da energia devido ao ruído eletrônico, múltiplas interações, etc; $\mathcal{R}$ a correção devida à resposta do calorímetro; e $\mathcal{S}$ a correção devida às dissipações de energia fora do cone.

O calorímetro do DØ não possui uma simulação satisfatória para utilizar fatores de correção derivados de eventos simulados, aqueles nos quais se conhece a energia dos jatos de partículas. Uma forma de contornar esse fato é usar métodos independentes da simulação, os quais são, de fato, confiáveis.

O método utilizado no experimento D $\varnothing$ é baseado em eventos com o estado final contendo fóton + jato. Utilizando o balanceamento do momentum transverso, tem-se que:

$$
E_{\text {jato }}=p_{T}^{\gamma} \times \cosh \left(\eta_{j a t o}\right)
$$

O momentum transverso do fóton $\left(p_{T}^{\gamma}\right)$ é medido com precisão muito boa e, portanto, pode ser usado para corrigir o momentum do jato.

No caso do estado final contendo dijato, é necessário realizar correções adicionais devido à diferença de composição de pártons nas amostras de dijatos e de fóton + jato [75]. Uma das correções mais importantes é o deslocamento da rapidez dos jatos reconstruídos com relação aos jatos de partículas (ver figura 4.2). Nota-se que, devido ao fato de o detector ICD possuir maiores fontes de ruído, as correções são maiores na região de pseudorapidez $1<|\eta|<2$.

Essas correções não são triviais e apresentam grandes incertezas, sendo uma das maiores fontes de erros sistemáticos das análises do DØ. Uma análise em que se pode visualizar isso é a da medida da seção de choque diferencial da produção de jatos apresentada na seção 4.6 . 


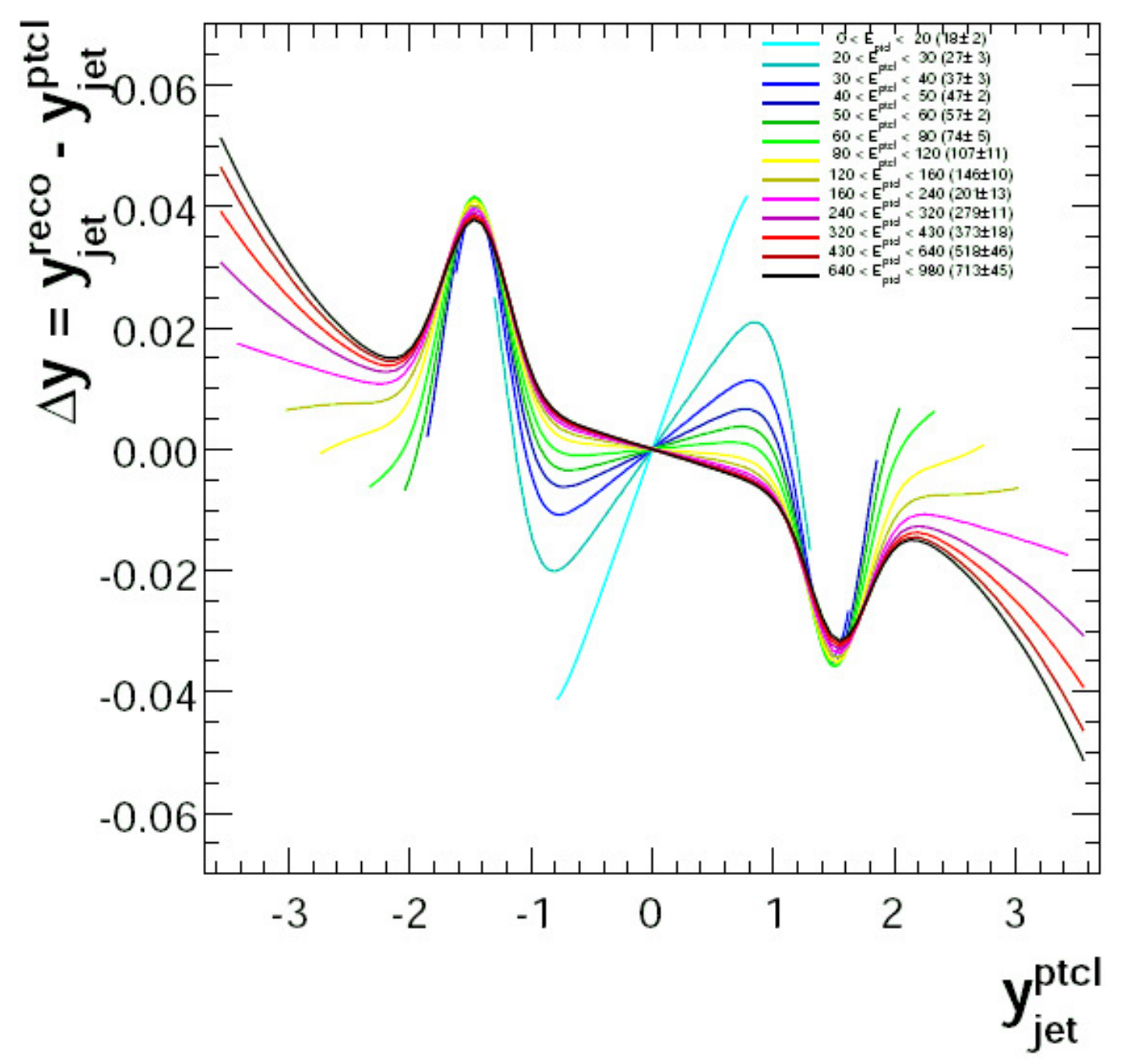

Figura 4.2: Deslocamento de rapidez dos jatos reconstruídos $\left(y_{j e t}^{r e c o}\right)$ com relação aos jatos de partículas $\left(y_{j e t}^{p t c l}\right)$ em vários intervalos de energia dos jatos de partículas $\left(E_{p t c l}\right)$ [75].

\subsection{Eficiência da Reconstrução e Identificação de Jatos}

A reconstrução e identificação de jatos não é $100 \%$ eficiente. Todas as análises do experimento $\mathrm{D} \varnothing$ precisam, portanto, levar em conta essas ineficiências, que precisam ser calculadas de forma independente, tanto na simulação, quanto nos dados. Parte do trabalho desta tese foi calcular a eficiência combinada da reconstrução e identificação de jatos no $\mathrm{D} \varnothing[76]$.

O método utilizado baseou-se na seleção de eventos, a qual rotula a existência de um jato em uma certa região do espaço de fase. Desse modo, ao verificar se o jato foi reconstruído e identificado, pode-se medir as eficiências de reconstrução e de identificação [77]. Nesse estudo, pode-se usar eventos com estado final de fóton + jato ou de dijatos. A amostra de dijatos foi escolhida, pois essa possui um maior número de eventos. No entanto, estes resultados foram comparados com a amostra de fóton + jato, bem como 
com resultados de um método independente [78], apresentando sempre boa concordância.

A amostra de dijatos foi selecionada utilizando os seguintes requerimentos:

- um dos seguintes triggers terem sido satisfeitos (apenas para dados): JT_125TT JT_95TT JT_65TT JT_45TT JT_25TT_NG JT_15TT JT_8TT.

- um vértice primário com, pelo menos, três traços associados e posição longitudinal $\left|Z_{P . V .}\right|<50 \mathrm{~cm}$.

- critérios de qualidade sugeridos pelo experimento DØ satisfeitos;

- $\mathbb{E}_{T} / \mathrm{p}_{\mathrm{T}}<0,7$, para evitar o ruído de raios cósmicos (ver figura 4.3), onde $\mathbb{E}_{T}$ é a energia transversa invisível para detector.

A rotulagem realizada para os jatos baseou-se nos seguintes requerimentos:

- um jato reconstruído e que passe os requerimentos dos cortes de identificação;

- o jato de maior $\mathrm{p}_{\mathrm{T}}$ (chamado de jato rótulo) ser confirmado pelos três níveis do trigger de jatos, removendo a influência do trigger na existência de qualquer outro jato no evento;

- $E_{T} / p_{T}^{j 1}<0,7$, para evitar o ruído de raios cósmicos (ver figura 4.3).

- um jato reconstruído somente por traços do CFT e SMT (trackjet) que seja oposto em $\varphi$ ao jato rótulo, i.e., $\Delta \varphi_{j 1, \text { trackjet }}>3,0$.

O algorítmo de reconstrução de jatos, usando-se apenas traços do CFT e SMT, é aproximadamente $100 \%$ eficiente, pois é otimizado para esse fim, sendo, entretanto, inútil para medidas de momentum, pois a resolução da medida do momentum de traços muito energéticos $\left(\mathrm{p}_{\mathrm{T}}>20 \mathrm{GeV}\right)$ é muito pobre. De fato, os jatos de traços reforçam a rotulagem do evento, indicando que um jato no calorímetro deve ser reconstruído na mesma região do espaço de fase.

Nota-se que, a confirmação de que o jato rótulo seja o responsável pelo trigger é fundamental, pois a seleção de eventos, da qual o trigger faz parte, não pode influenciar na condição de existência do jato a ser testado.

Após rotular a presença de um jato no evento, pode-se definir a eficiência de reconstrução como:

$$
\epsilon_{\text {reco }}=\frac{N_{\text {rot }}-N_{\text {semjato }}}{N_{\text {rot }}} \pm \sqrt{\frac{\epsilon_{\text {reco }}\left(1-\epsilon_{\text {reco }}\right)}{N_{\text {rot }}}},
$$

onde, $N_{\text {rot }}$ é o número de eventos rotulados e $N_{\text {semjato }}$ é o número de eventos sem jato reconstruído pelo calorímetro na região esperada do espaço de fase. 


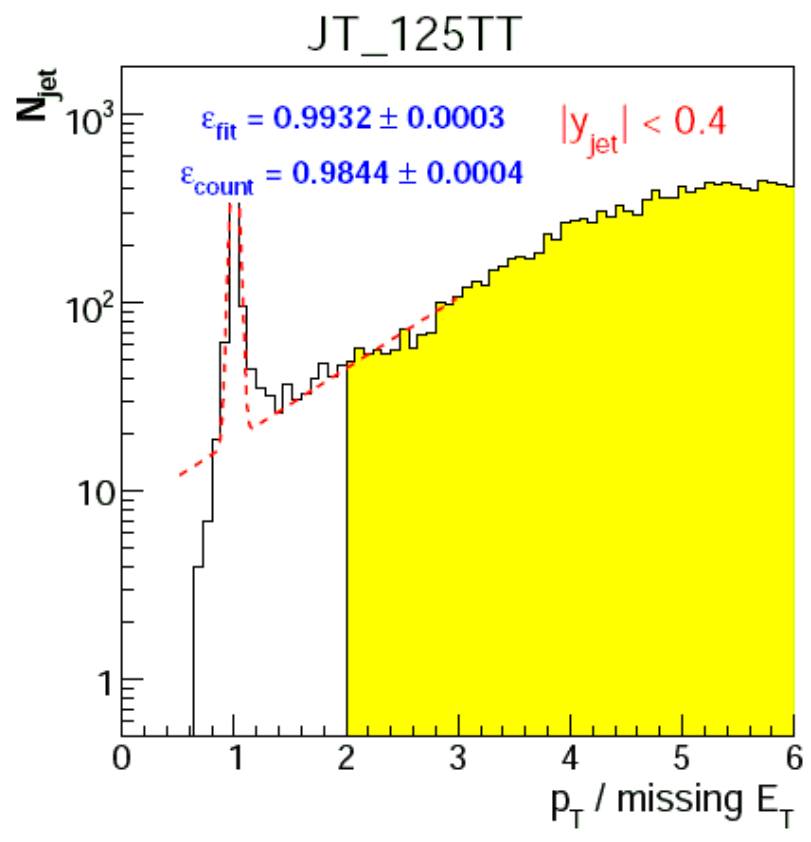

Figura 4.3: Pico na distribuição $\mathrm{p}_{\mathrm{T}} / E_{T}$ devido ao ruído cósmico poder imitar um evento de dijato. A região sombreada mostra os jatos que passam pelo condição $\mathbb{E}_{T} / \mathrm{p}_{\mathrm{T}}<0,7$ $[24]$.

A eficiência da reconstrução é apresentada na Fig. 4.4. Pode-se ver que, para $\mathrm{p}_{\mathrm{T}} \gtrsim$ $50 \mathrm{GeV}$, a eficiência atinge o plateau de $100 \%$.

A eficiência da identificação pode ser calculada quando se inclui na rotulagem do evento a condição do jato estar reconstruído. Dessa forma, pode-se escrever:

$$
\epsilon_{i d}=\frac{N_{\text {rotreco }}-N_{\text {semid }}}{N_{\text {rotreco }}} \pm \sqrt{\frac{\epsilon_{i d}\left(1-\epsilon_{i d}\right)}{N_{\text {rotreco }}}},
$$

onde $N_{\text {rotreco }}$ é o número de eventos rotulados e com jato reconstruído e $N_{\text {semid }}$ é o número de eventos em que o jato não passou pelos cortes de identificação.

O principal objetivo é encontrar diferenças entre a eficiência da simulação e dos dados, utilizando fatores de escala, i.e., a divisão da eficiência nos dados pela da simulação.

É esperado que essas diferenças apenas dependam do momentum do jato e da região de pseudorapidez em que ele se encontra. Porém, foi testada a existência da dependência dos fatores de escala com relação a posição longitudinal do vértice primário $\left(Z_{P V}\right)$, como mostra a Fig. 4.5. Nota-se que não há nenhuma dependência que necessite de correção.

Com relação ao momentum do jato, foi medida e eficiência para diferentes regiões de pseudorapidez nas coordenadas do detector com relação ao $\mathrm{p}_{\mathrm{T}}$ do jato, como mostra a Fig. 4.6. Fatores de escala foram calculados para cada região (ver Fig. 4.7).

Nota-se que a dependência com relação ao $\mathrm{p}_{\mathrm{T}}$ do jato é aproximadamente constante, sendo a diferença maior na região em pseudorapidez na qual o jato se encontra. Dessa 

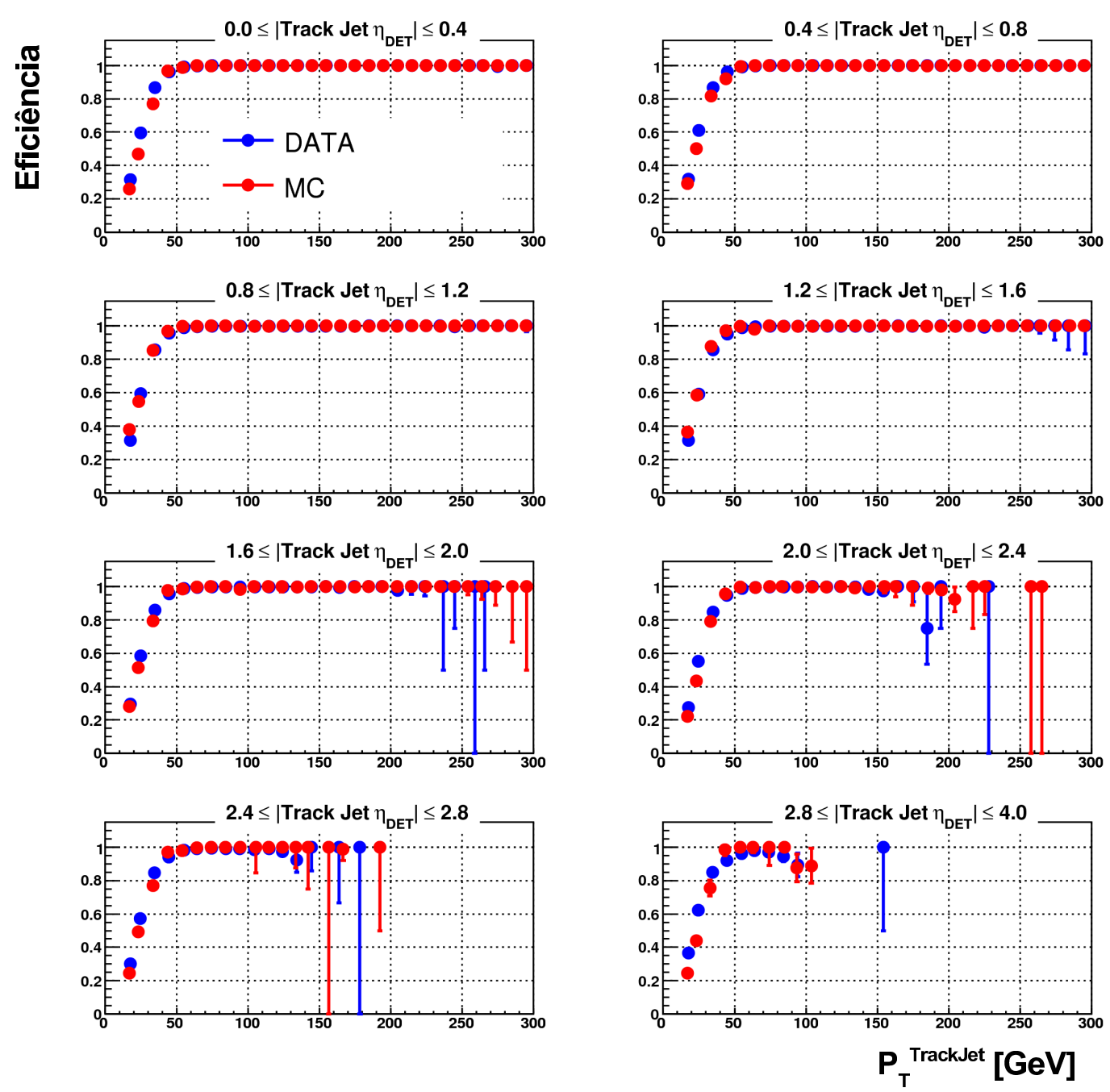

Figura 4.4: Eficiência da reconstrução de jatos em relação ao $\mathrm{p}_{\mathrm{T}}$ do jato de traços $\left(p_{T}^{\text {TrackJet }}\right)$ para diferentes regiões de pseudorapidez do jato de traços (Track Jet $\left.\eta_{D E T}\right)$.

forma, uma constante foi ajustada para cada distribuição de fator de escala nas diferentes regiões de pseudorapidez (ver Fig. 4.8). Essas constantes ficam sendo os fatores de correção da simulação para os dados.

Com o objetivo de entender qual a origem da falta de concordância entre simulação e dados na região do detector ICD (ver subseção 3.2.3), os cortes da identificação de jatos foram analisados um a um, como mostra a Fig. 4.9. Nota-se que todos os cortes contribuem para essa diferença, excluindo o corte no limite máximo na $E M F$.

Fatores de escala extraídos do gráfico da Fig. 4.8 foram aplicados para a correção da simulação, e confirmou-se que, após a correção, nenhuma diferença remanecente existe entre a simulação e os dados com relação à eficiência da reconstrução e identificação de jatos(ver Fig. 4.10).

Os fatores de escala medidos nesta tese são usados pela colaboração D $\varnothing$ com a finalidade de melhorar a concordância entre a simulação e os dados coletados. Já as medidas 
de eficiência servem para corrigir medidas de espectrometria (ver seção 4.6).

\subsection{Resolução da Energia dos Jatos}

A resolução da energia dos jatos medida pelo detector D $\varnothing$ é muito importante para medidas de precisão e buscas por física nova. A resolução típica em função do momentum transverso dos jatos é ilustrada na Fig. 4.11.

Parte do trabalho desta tese foi investigar a possibilidade de melhorar a resolução da energia dos jatos utilizando o detector CPS [80]. O objetivo principal desse projeto foi aumentar a sensibilidade na busca pelo bóson de Higgs em seu decaimento no canal $b \bar{b}$.

A metodologia usada e resultados preliminares encontram-se no apêndice A. Observase que uma melhoria entre 5 e $10 \%$ foi alcançada. Espera-se que o uso desse método nas análises de busca pelo bóson de Higgs comece em breve.

\subsection{Medida do Espectro da Seção de Choque da Pro- dução Inclusiva de Jatos}

As eficiências devido aos cortes de identificação de jatos, calculadas nesta tese, são usadas em todas as análises realizadas pela colaboração DØ que envolvem jatos, e.g., a evidência da produção eletrofraca do quark top [82]. A medida do espectro da seção de choque da produção inclusiva de jatos só foi possível com os resultados apresentados na seção 4.2.

Essa medida tem por finalidade testar os cálculos NLO da QCD e as funções de estrutura do próton [83]. Pode-se ver, na figura 4.12, a contribuição das incertezas devido às eficiências calculadas na seção 4.2 e, nas figuras 4.13 e 4.14, a boa concordância entre a medida e a previsão teórica.

\subsection{Observações}

Neste capítulo, o conceito de jatos no experimento D $\varnothing$ foi estudado detalhadamente. Foram medidas as eficiências da reconstrução e identificação de jatos para dados reais e simulados, estabelecendo fatores de escala entre essas medidas; e um projeto para melhorar a resolução da energia dos jatos foi desenvolvido e concluído.

De fato, jatos são objetos físicos, cujas características são bem conhecidas. Apesar das medidas apresentadas neste capítulo não serem diretamente usadas na análise desta tese, elas influenciaram nas escolhas realizadas durante o desenvolvimento da análise. 

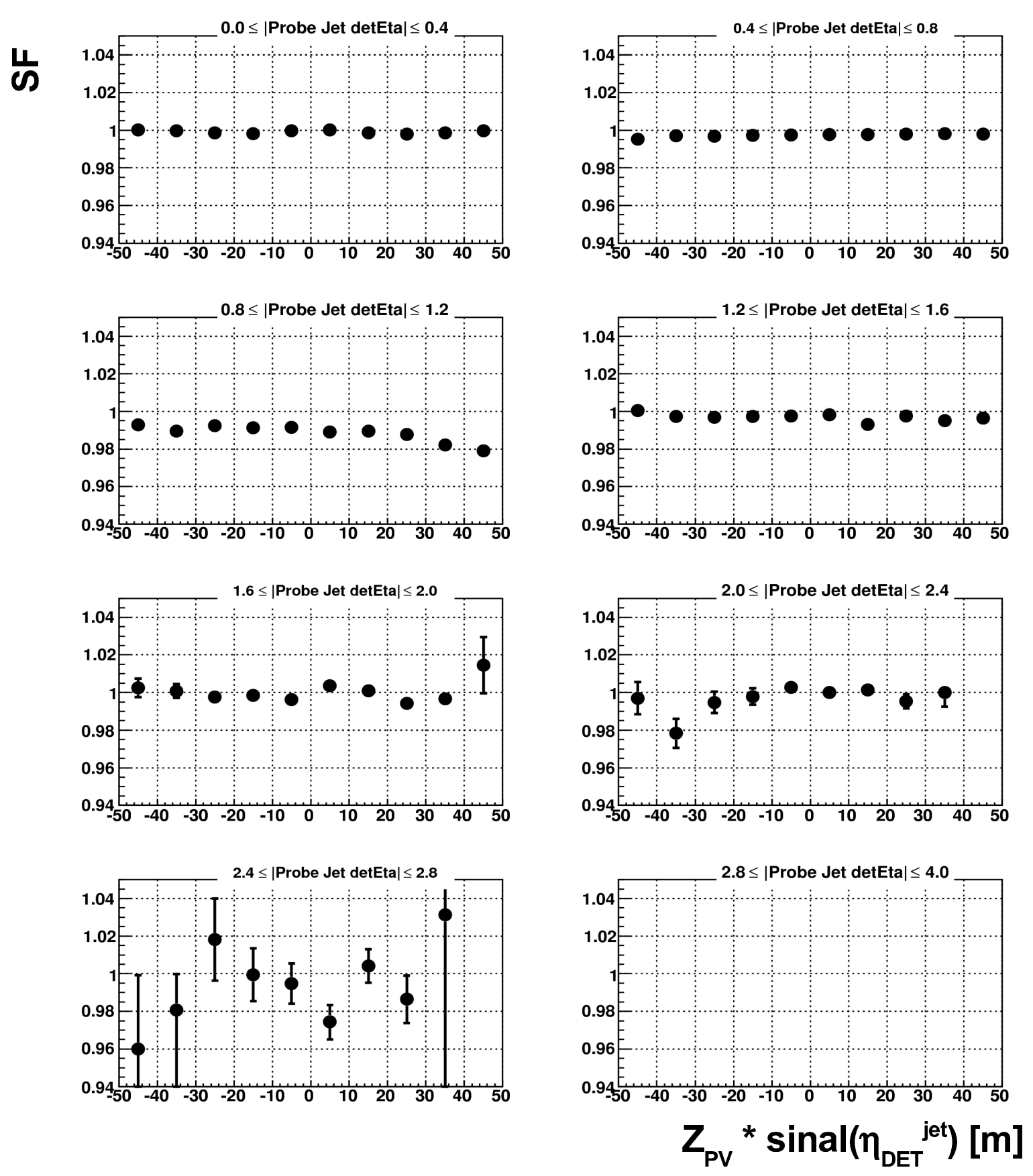

Figura 4.5: Fatores de escala (SF) da eficiência da identificação de jatos com relação à $Z_{P V}$ multiplicada pelo sinal da pseudorapidez do jato nas coordenadas do detector em diferentes regiões de pseudorapidez nas coordenadas do detector (Probe Jet detEta). Nota-se que na região mais frontal não há estatística para essa medida. 

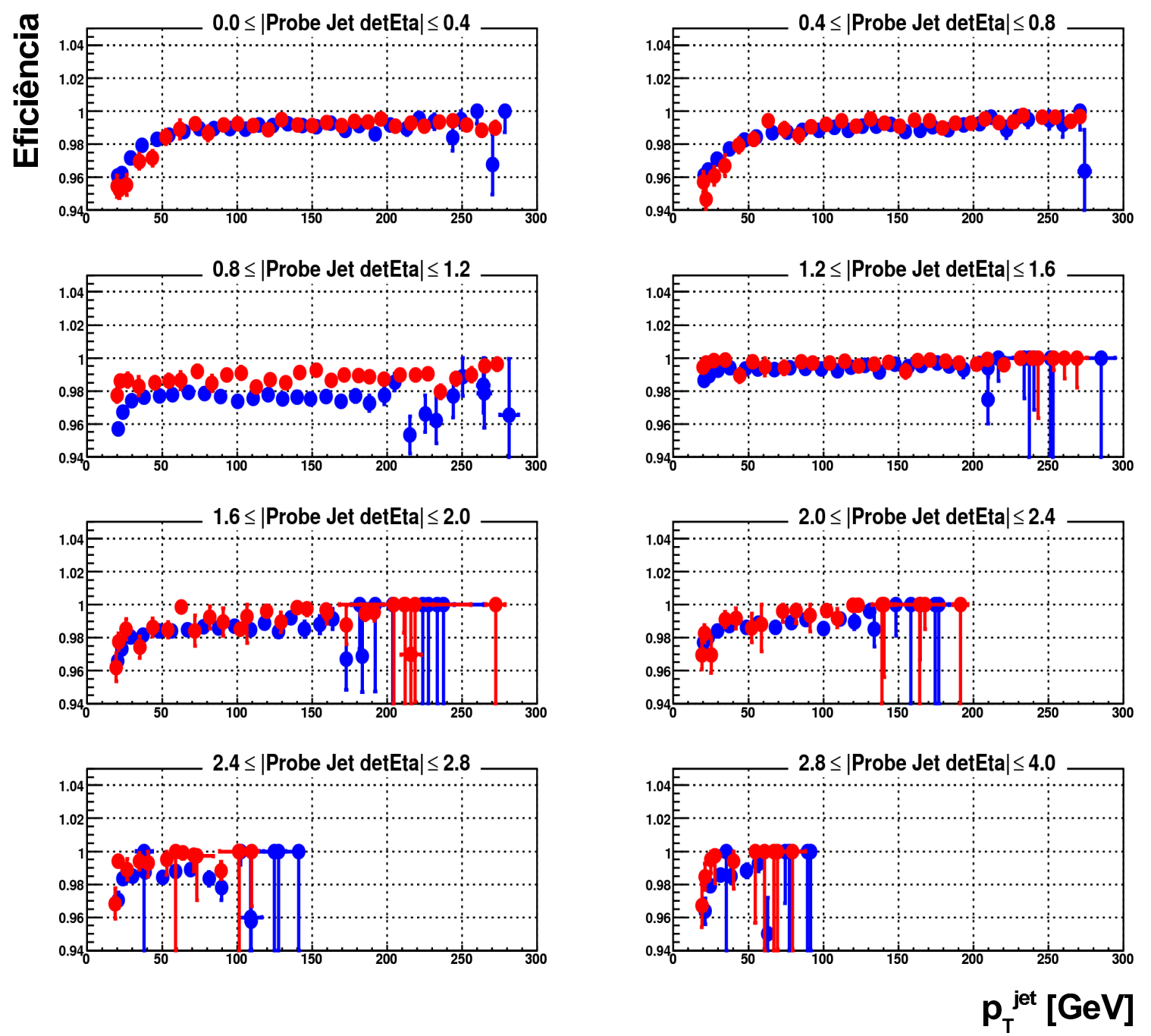

Figura 4.6: Eficiência da identificação de jatos com relação ao $\mathrm{p}_{\mathrm{T}}$ do jato em diferentes regiões de pseudorapidez nas coordenadas do detector (Probe Jet detEta) para dados reais (azul) e simulação (vermelho). 

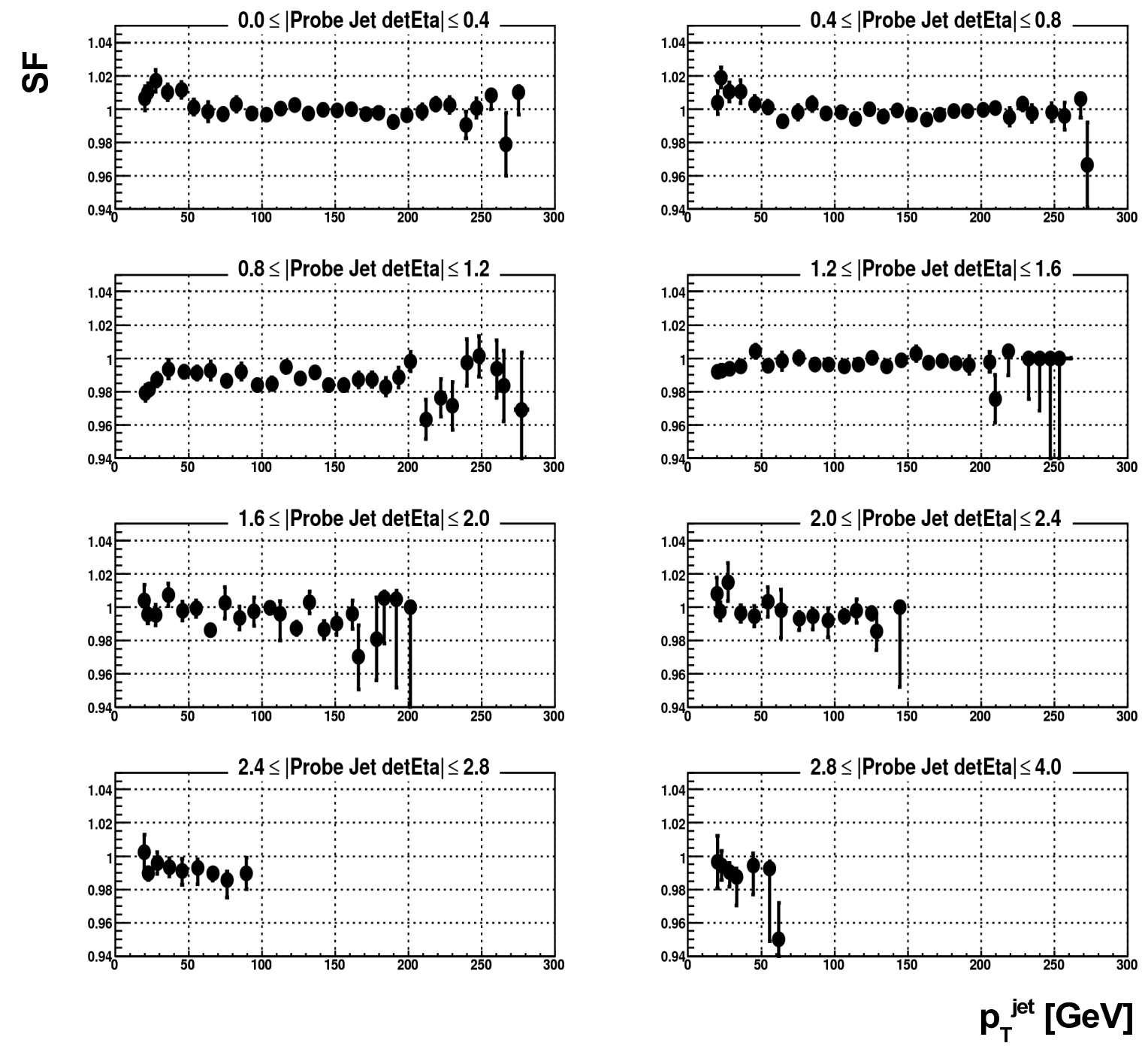

Figura 4.7: Fatores de escala (SF) da eficiência da identificação de jatos com relação ao $\mathrm{p}_{\mathrm{T}}$ do jato em diferentes regiões de pseudorapidez nas coordenadas do detector (Probe Jet detEta). 


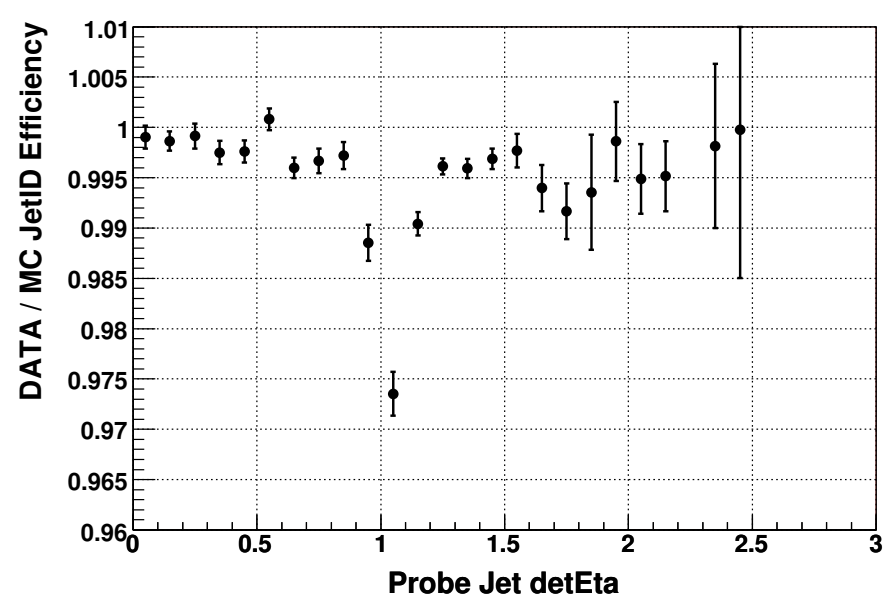

Figura 4.8: Fatores de escala da eficiência da identificação de jatos com relação à pseudorapidez do jato nas coordenadas do detector (Probe Jet detEta).

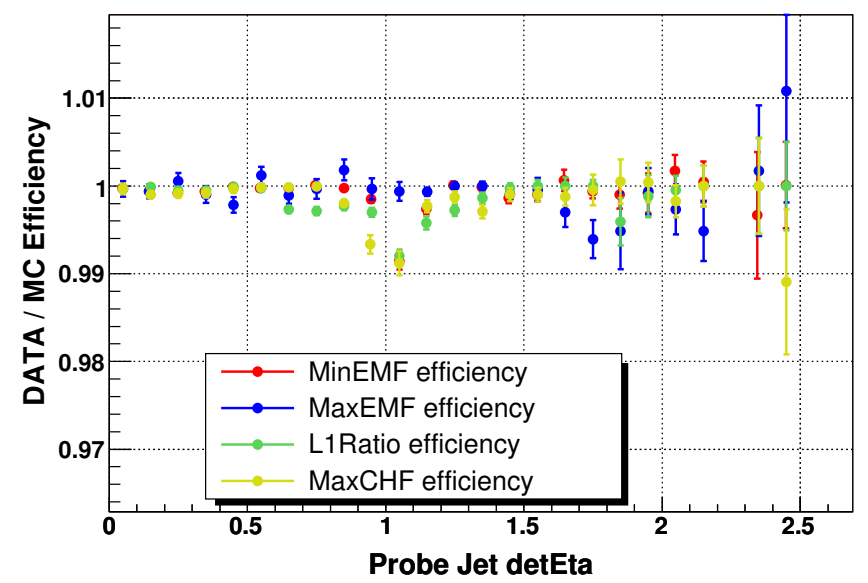

Figura 4.9: Fatores de escala da eficiência da identificação de jatos com relação à pseudorapidez do jato nas coordenadas do detector (Probe Jet detEta) para cada corte da identificação de jatos. 


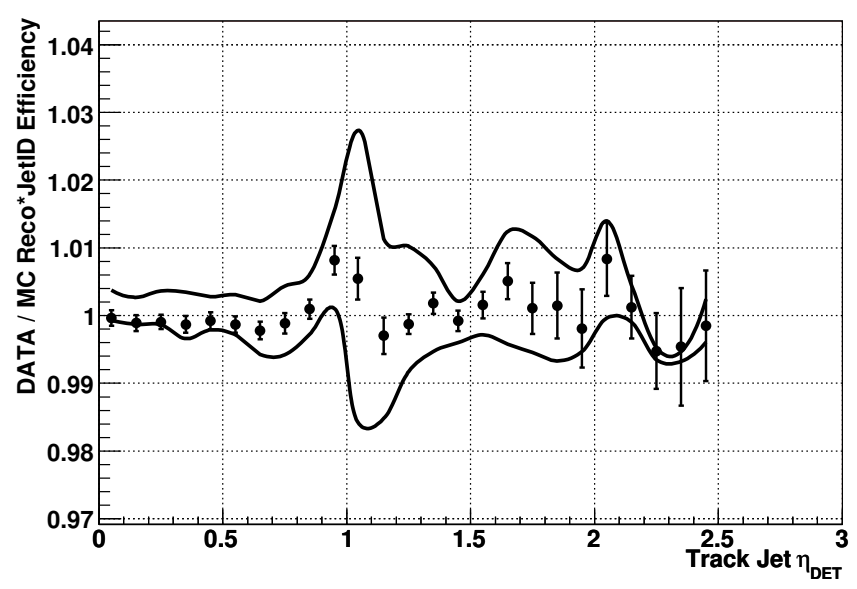

Figura 4.10: Fatores de escala da eficiência da reconstrução e identificação de jatos com relação à pseudorapidez do jato de traços nas coordenadas do detector (Track Jet $\eta_{D E T}$ ) após a correção da simulação como explicada no texto. As curvas sólidas representam o erro sistemático.

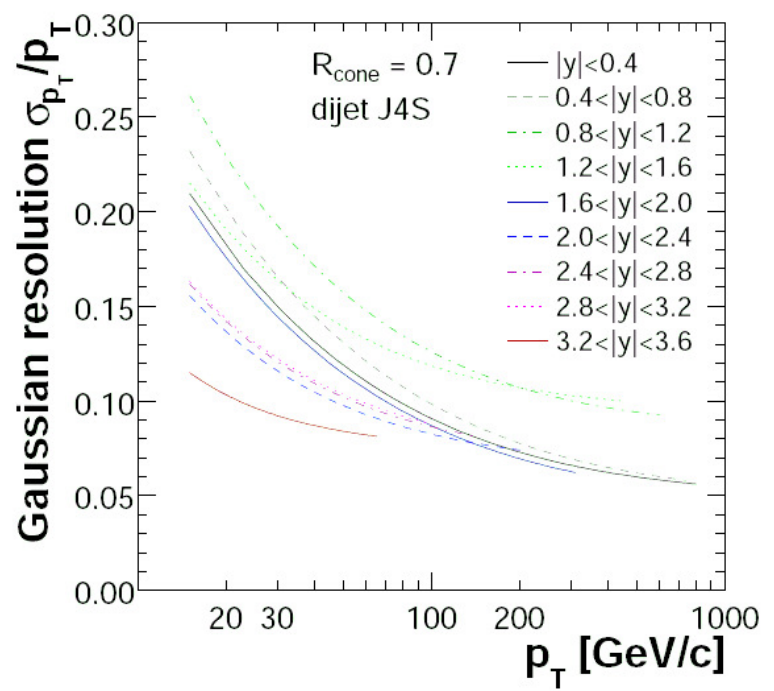

Figura 4.11: Resolução típica de jatos no DØ [79]. 

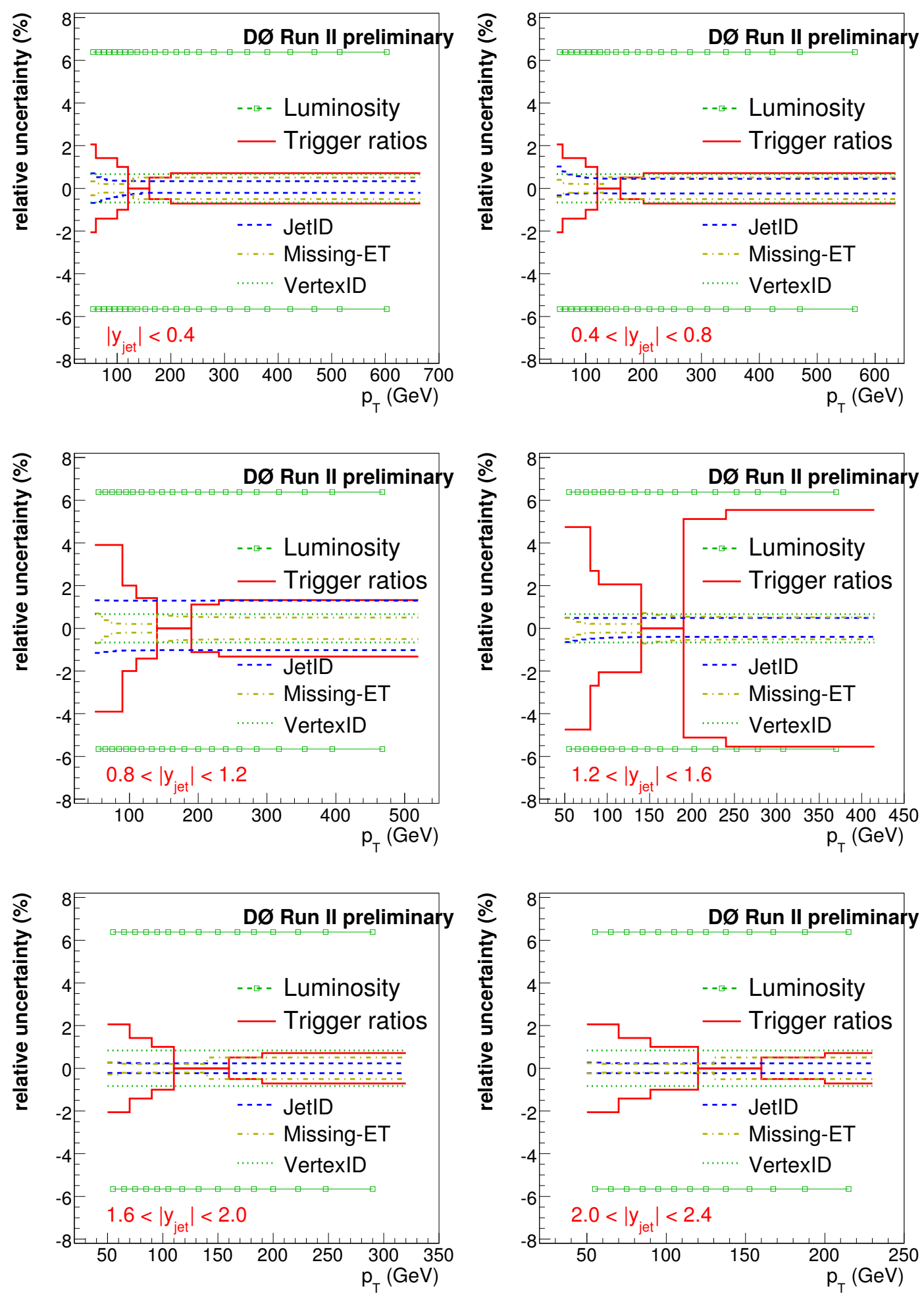

Figura 4.12: Incertezas da medida do espectro da seção de choque da produção inclusiva de jatos, incluindo a incerteza da eficiência da identificação de jatos (Jet-ID) em azul [24]. 


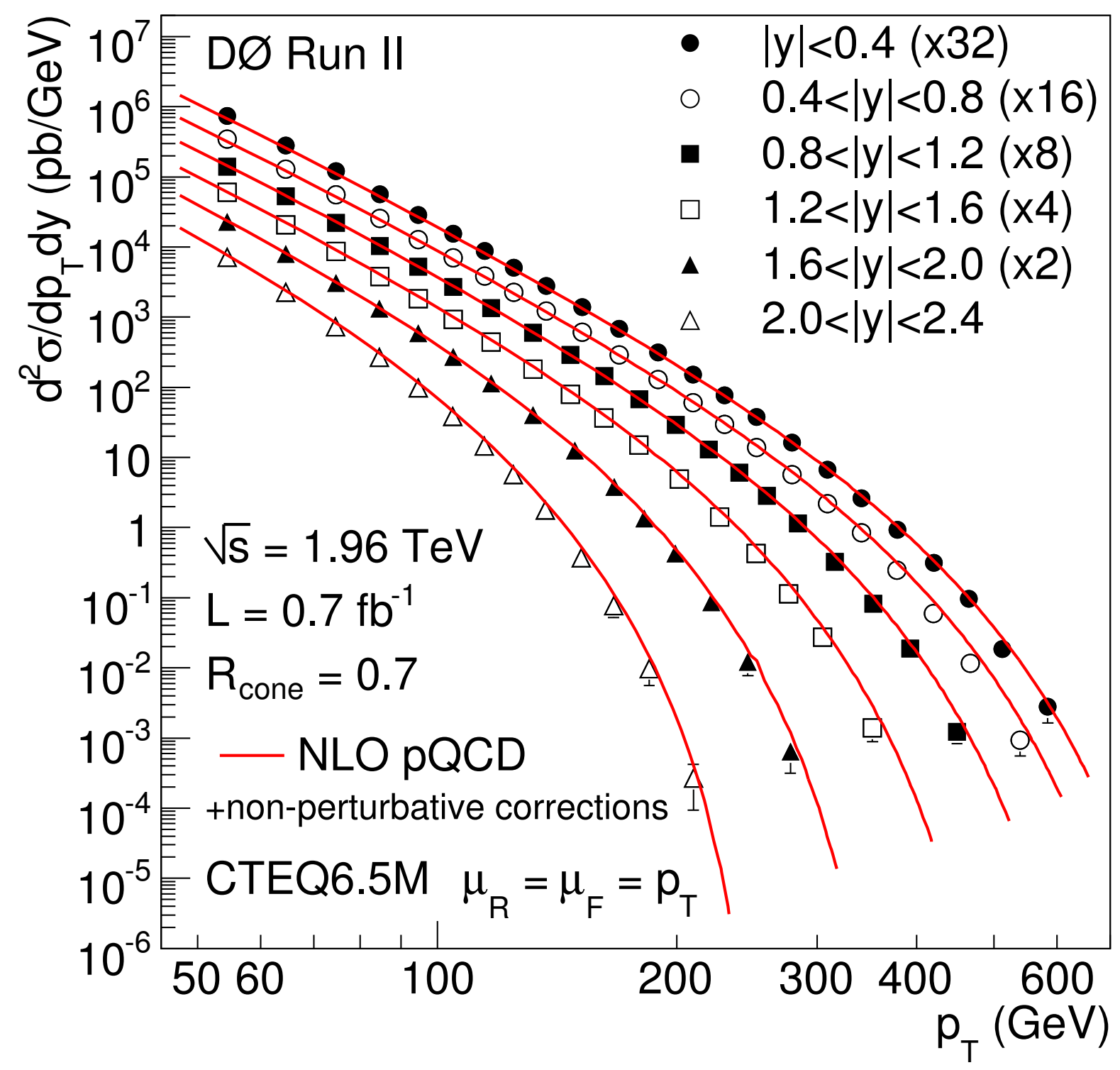

Figura 4.13: Medida final da seção de choque da produção inclusiva de jatos [83]. 


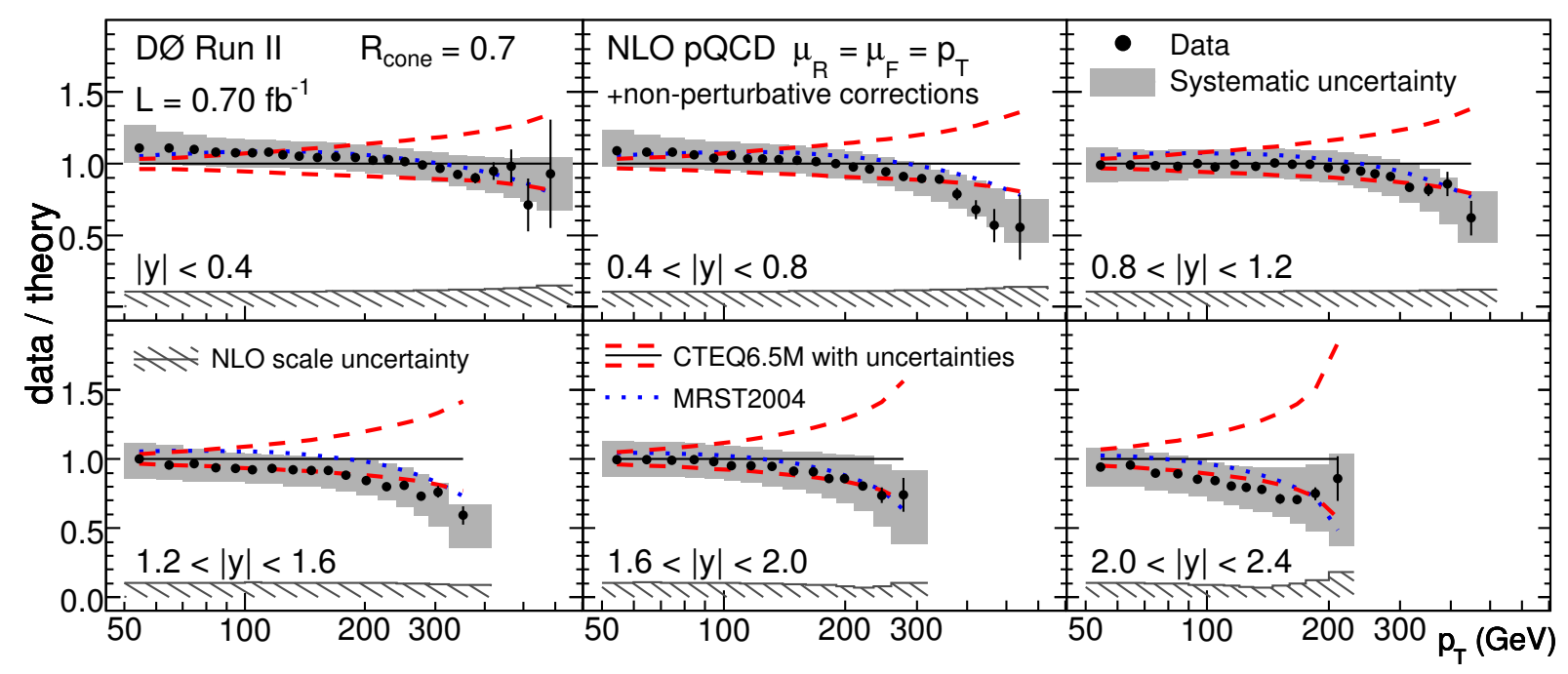

Figura 4.14: Razão entre a medida da seção de choque da produção inclusiva de jatos e a previsão teórica [83]. 


\section{Capítulo 5}

\section{Calorimetria no DØ}

Em eventos de dupla troca de pomeron exclusiva, nenhuma outra partícula é produzida fora do sistema de dijatos como discutido na seção 2.5 do capítulo 2, portanto, o detector mais indicado para identificar eventos exclusivos separando-os de outros tipos, tais como, não difrativos, é o calorímetro. É necessário, dessa forma, garantir a qualidade dos dados obtidos por esse detector.

Com o objetivo de eliminar células calorimétricas problemáticas, uma lista dessas células foi determinada, como é descrito na seção 5.1. A calibração relativa das células do calorímetro simulado para o real é discutida na seção 5.2.

\subsection{Lista de Células Problemáticas}

Mesmo após cortes padrões adotados pela colaboração D $\varnothing[84,85]$, outras análises encontraram regiões problemáticas do calorímetro [86, 87]. Em particular, para a análise desenvolvida nesta tese, os dados obtidos pelo calorímetro são usados ao nível das células, algo não comum dentro da colaboração D $\varnothing$, visto ser uma necessidade específica desta análise. É necessário, portanto, assegurar que células problemáticas sejam removidas.

Nota-se que apenas células que apresentam problemas com certa persistência podem ser identificadas, já que é necessária boa estatística de eventos. Em geral, as fontes dos problemas são provenientes de calibrações mal realizadas e ruídos instrumentais (decaimento radiaotivo, ruído eletrônico, etc.).

Parte do trabalho desta tese foi identificar células problemáticas [88]. Na subseção 5.1.1, a seleção de eventos é descrita. Na subseção 5.1.2, o método utilizado para determinar se a célula é problemática ou não é discutido.

\subsubsection{Seleção de Eventos}

As fontes de problemas das células podem ser diversas e, para ocorrerem, dependem do espectro da energia depositada nas células. A fim de aumentar a sensibilidade para todos 
os tipos de problemas, três conjunto de dados foram usados:

- ZBMB, composta de eventos gravados pelos triggers $Z B$ e $M B$;

- QCD, composta de eventos gravados pelos triggers de jato inclusivo;

- EMInclusive, composta por eventos gravados por triggers que usam torres do calorímetro eletromagnético.

O conjunto de dados ZBMB possui a vantagem de não possuir nenhum tipo de influência do calorímetro na sua seleção, pois os triggers são independentes desse detector. No entanto, o conjunto apresenta poucos eventos, já que é um trigger com baixa taxa de aceitação (porcentagem dos eventos gravados em disco que passam pelos critérios do trigger).

O conjunto de dados QCD tem a influência do calorímetro na sua seleção, o que pode causar flutuações indesejadas para as células que possuem o mesmo ângulo azimutal (mesmo anel de $\varphi$ ). Por outro lado, o conjunto QCD tem mais eventos por célula, particularmente, para células hadrônicas. A mesma afirmação pode ser feita sobre o conjunto de dados EMInclusive, sendo que esse é mais sensível às células eletromagnéticas.

A seleção de dados inclui critérios de qualidade de dados especificados pela colaboração DØ . Na análise desta tese, apenas células do calorímetro EM e FH foram usadas (ver figura 3.10), enquanto as outras partes do calorímetro foram desconsideradas por apresentarem alta taxa de ruído.

\subsubsection{Método}

O método usado é similar ao realizado para objetos eletromagnéticos [87]. A célula é considerada problemática se a sua ocupação é significantemente diferente das células vizinhas no mesmo anel de $\varphi$.

O primeiro passo é calcular o valor médio da ocupação e seu desvio padrão, usando apenas células vizinhas do mesmo anel de $\varphi$ a uma dada célula j:

$$
\begin{gathered}
<n>_{j}=\frac{\sum_{i \neq j} n_{i}}{N_{j}} \\
<n^{2}>_{j}=\frac{\sum_{i \neq j} n_{i}^{2}}{N_{j}} \\
\sigma_{j}=\sqrt{<n^{2}>_{j}-<n>_{j}^{2}} ;
\end{gathered}
$$

onde $n$ define ocupação, $N_{j}$ é o número de células vizinhas a uma dada célula j, e a soma em i corresponde a todas as células com diferentes ângulos azimutais na mesma camada.

O segundo passo é medir o quão longe a ocupação da célula j $\left(n_{j}\right)$ está de $<n>_{j}$ em unidades de desvio padrão, o que é chamado de significância (S). 


$$
S_{j}=\frac{n_{j}-<n>_{j}}{\sigma_{j}}
$$

Para diminuir a sensibilidade do método à flutuações estatísticas, apenas células com ocupação maior que 50 e anéis de $\varphi$ com, pelo menos, 30 células foram usados.

De fato, em um mesmo anel de $\varphi$, podem existir mais de uma célula com problemas. Dessa forma, as células com $S_{j}>50$ são eliminadas primeiramente, depois $S_{j}$ é recalculado e as que possuem $S_{j}>20$ são eliminadas. Finalmente, $S_{j}$ é recalculado uma terceira vez e as células que têm $S_{j}>10$ são eliminadas.

O Run IIa foi dividido em dez períodos (ver tabela 5.1), com o objetivo de identificar células problemáticas presentes em menores períodos de tempo.

A fim de detalhar a identificação de células com problemas, a ocupação para diferentes regiões de energia foi calculada. Nota-se que ocupação é definida como:

$$
n=\int_{E \min }^{E \max } f(E) d E
$$

onde $f(E)$ é a distribuição da energia de cada célula. Desta forma, quatro regiões de energia foram usadas: $(\operatorname{Emin}, E \max )=(1, \infty),(1,2),(2,3)$ e $(3, \infty) \mathrm{GeV}$.

\begin{tabular}{|c|c|c|}
\hline Período & Store Inicial & Store Final \\
\hline 1 & 1216 & 2694 \\
2 & 2702 & 3103 \\
3 & 3108 & 3249 \\
4 & 3252 & 3475 \\
5 & 3477 & 3665 \\
6 & 3671 & 3950 \\
7 & 3952 & 4072 \\
8 & 4073 & 4178 \\
9 & 4179 & 4319 \\
10 & 4320 & 4666 \\
\hline
\end{tabular}

Tabela 5.1: Divisão em períodos de tempo para o Run IIa, usando o número da Store como unidade de tempo.

Como três conjuntos de dados diferentes foram usados, a lista de células problemáticas foi formada por qualquer célula significantemente diferente de suas vizinhas em qualquer um dos conjuntos usados (ver apêndice B). É importante ressaltar que foram verificados casos em que uma célula com problema foi identificada em um conjunto de dados e não em outro conjunto. Explicações para esse fato encontram-se no apêndice B. 


\subsection{Calibração Relativa das Células Calorimétricas}

A simulação do calorímetro do DØ não é precisa o suficiente para a comparação direta com o calorímetro real [89]. No caso de objetos reconstruídos, como jatos, há formas de calibrar suas energias independentemente da simulação. Entretanto, para o caso da análise desta tese, a simulação necessita estar de acordo com os dados. Dessa forma, fatores de correção das células da simulação do calorímetro para o real precisam ser calculados.

Parte do trabalho desta tese foi calcular esses fatores discutidos acima [90]. A seleção de eventos está descrita na subseção 5.2.1. Na subseção 5.2.2, o método utilizado é descrito. Na subseção 5.2.3, testes de consistência realizados são apresentados, e, na subseção 5.2.4, os resultados obtidos são expostos.

\subsubsection{Seleção de Eventos}

O método para a obtenção da correção da resposta do calorímetro simulado necessita de uma amostra com um processo físico conhecido e bem entendido, tanto do ponto de vista teórico quanto experimental. Além disso, esse processo deve possuir uma boa relação entre estatística e pureza. A produção de dijatos preenche tais requerimentos, sendo, portanto, utilizado nesse estudo.

A seleção de eventos baseou-se nos seguintes critérios:

- eventos gravados pelo trigger JT_125TT (torres que possuam a soma de energia transversa maior que $125 \mathrm{GeV}$ ) no caso de dados reais;

- luminosidade instantânea (L) precisa ser bem definida, portanto, optou-se por utilizar apenas eventos na região $\mathrm{L}=[5-100] \times 10^{30} \mathrm{~cm}^{-2} \mathrm{~s}^{-1}$;

- pelo menos um vértice primário reconstruído pelo programa de reconstrução $d \varnothing$ reco com, pelo menos, três traços e posição longitudinal $\left|Z_{P V}\right|<50[\mathrm{~cm}]$;

- critérios da qualidade de dados satisfeitos;

- dois jatos considerados bons pelos critérios de identificação de jatos [73];

- os dois jatos de maior $\mathrm{p}_{\mathrm{T}}$ centrais com $|\eta|<0.8$;

- o jato de maior $\mathrm{p}_{\mathrm{T}}$ possuir $p_{T}^{j 1}>250[\mathrm{GeV}]$;

- o segundo jato de maior $\mathrm{p}_{\mathrm{T}}$ ter $p_{T}^{j 2}>50[\mathrm{GeV}]$.

Como os jatos são centrais $(|\eta|<0.8)$ e $\mathrm{p}_{\mathrm{T}} p_{T}^{j 1}>250 \mathrm{GeV}$, não é preciso se preocupar com as eficiências de trigger, já que o jato de maior $\mathrm{p}_{\mathrm{T}}$ preenche os critérios para o trigger ser disparado [91]. 
A luminosidade instantânea é bastante importante neste estudo, já que ela influencia na energia do calorímetro, devido às múltiplas interações. Desta forma, é necessário ponderar a simulação, a fim de que essa tenha o mesmo perfil de luminosidade que os dados. Pode-se ver a dependência da energia depositada no calorímetro em função da luminosidade na distribuição da figura 5.1.

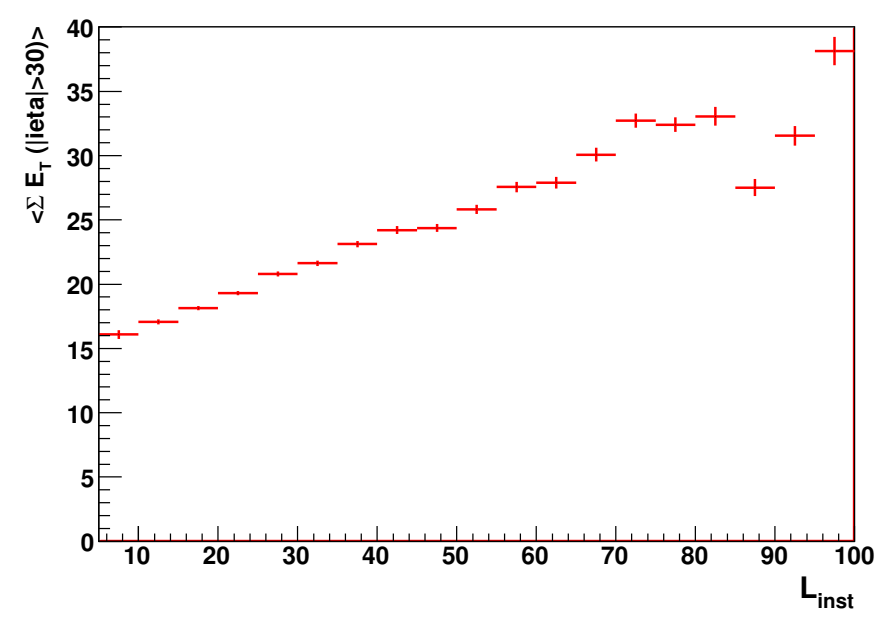

Figura 5.1: Dependência da energia depositada no calorímetro com relação à luminosidade instantânea $\left(L_{\text {inst }}\left[10^{30} \mathrm{~cm}^{-2} \mathrm{~s}^{-1}\right]\right)$.

A fim de ilustrar que a seleção foi corretamente realizada, distribuições de controle foram produzidas com algumas variáveis dos jatos (ver figura 5.2). Nota-se que a simulação foi normalizada a fim de obter o mesmo número de eventos que os dados reais possuem. Pode-se ver, na figura 5.3, que o perfil da luminosidade instantânea está bem representado na simulação.

Percebe-se que apenas as células das camadas EM e FH do calorímetro foram consideradas neste estudo, já que elas servirão para esta análise. Também é importante relatar que apenas células consideradas normais pelos cortes padrões do experimento D $\varnothing$ [84] foram usadas e, as problemáticas, removidas (ver lista apresentada nas tabelas B.1 e B.2).

\subsubsection{Método}

O método usado para determinar os fatores de correção é similar ao usado na calibração entre as células de mesmo anel de $\varphi$ [92]. Assume-se que a ocupação de uma célula apresenta o seguinte comportamento:

$$
\int_{E_{l}}^{\infty} f(E) d E=\int_{\alpha \times E_{l}}^{\infty} f(\alpha \times E) d E
$$

onde $f(E)$ é a densidade de probabilidade da energia de uma célula, $E_{l}$ é um dado limiar inferior e $\alpha$ é uma constante de calibração. 


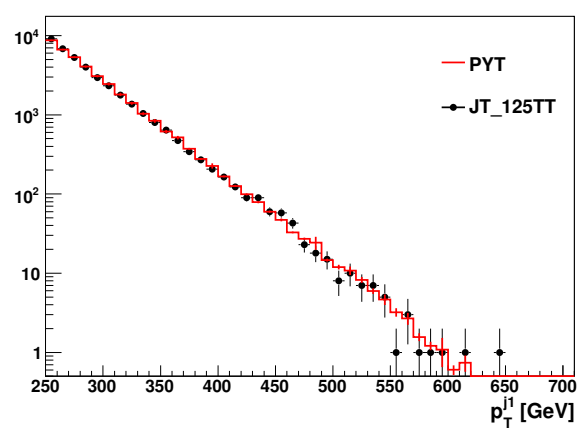

(a) $p_{T}^{j 1}$.

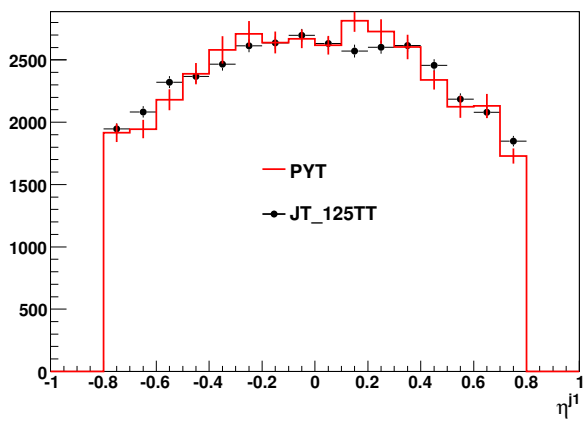

(c) $\eta^{j 1}$.

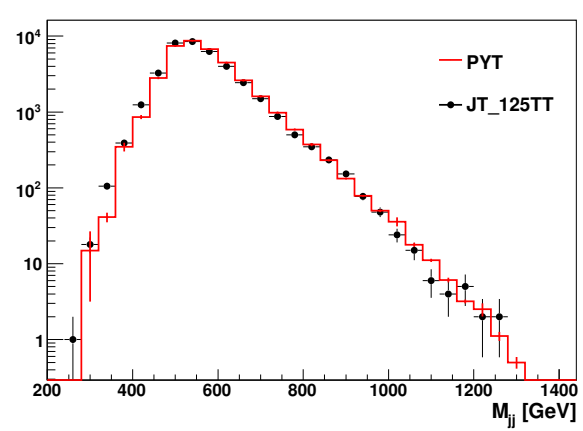

(e) Massa invariante do dijato.

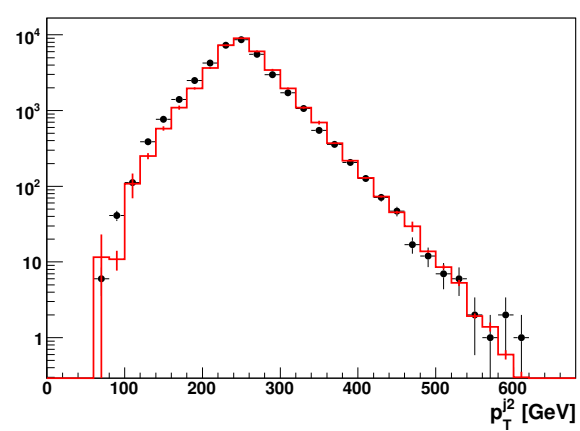

(b) $p_{T}^{j 2}$.

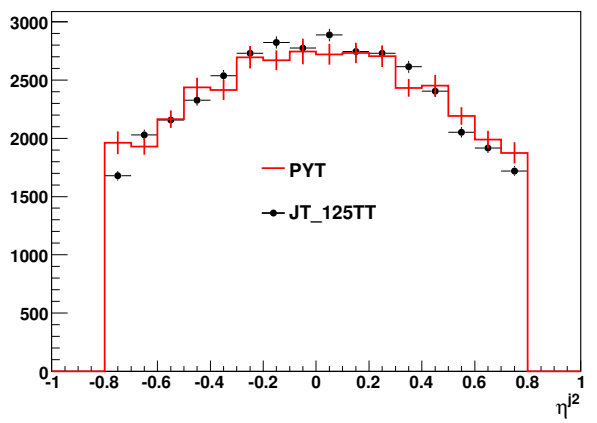

(d) $\eta^{j 2}$.

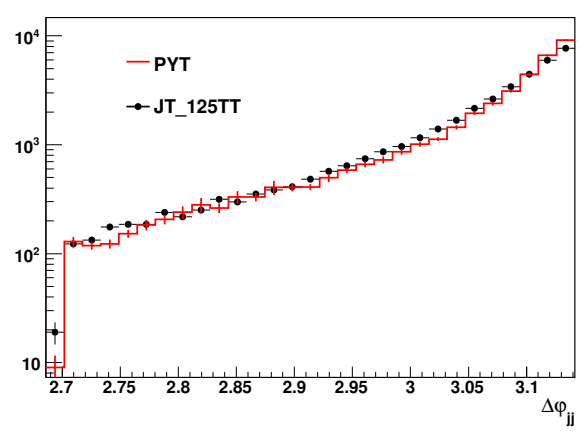

(f) $\Delta \varphi_{j j}$

Figura 5.2: Distribuições das variáveis dos jatos mostrando boa concordância entre dados (JT_125TT) e simulação (PYT).

A fim de simplificar o método, supõe-se que os fatores de correção são constantes, portanto, esses podem ser definidos como:

$$
C=\frac{E_{l}^{D}}{E_{l}^{M C}},
$$

onde $E_{l}^{M C}$ é o limiar para a função $f_{M C}(E)$, que reproduz a mesma ocupação que o limiar $E_{l}^{D}$ dos dados para a função $f_{D}(E) . f_{M C}(E)$ é a densidade de probabilidade da energia para simulação e $f_{D}(E)$ para os dados.

Na prática, as funções $f(E)$ são representadas por histogramas, os quais possuem bin 


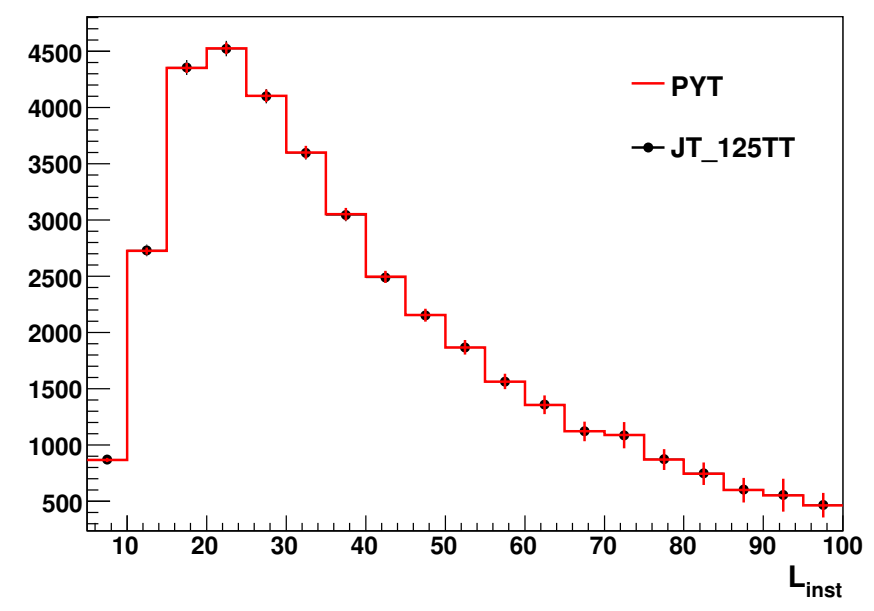

Figura 5.3: Perfil da luminosidade instantânea para os dados (JT_125TT) e para simulação (PYT) nas unidades $10^{30} \mathrm{~cm}^{-2} \mathrm{~s}^{-1}$.

de tamanho $0,1 \mathrm{GeV}$. O limiar padrão para os dados foi escolhido como $E_{l}^{D}=0,4 \mathrm{GeV}$, que corresponde ao bin 5 , portanto:

$$
O_{D}=\sum_{b i n \geq 5} f_{D}(\text { bin })
$$

onde $O_{D}$ é a ocupação da célula com limiar inferior igual a $E_{l}^{D}=0,4 \mathrm{GeV}$.

Dessa forma, o bin $\operatorname{bin}_{M C}$ para a distribuição $f_{M C}(E)$ é procurado tal que:

$$
O_{D}>\sum_{b i n \geq b i n_{M C}+1} f_{M C}(b i n) \text { e } O_{D} \leq \sum_{b i n \geq b i n_{M C}} f_{M C}(\text { bin })
$$

Para levar em conta a continuidade da distribuição, os valores de $E_{l}^{M C}$ para os bins $\operatorname{bin}_{M C}$ e $\operatorname{bin}_{M C}+1$ são interpolados (ver figura 5.4). Desse modo, tem-se que:

$$
E_{l}^{M C}=E_{l}^{b i n_{M C}}+\frac{E_{l}^{b i n_{M C}+1}-E_{l}^{b i n_{M C}}}{O_{b i n_{M C}}-O_{b i n_{M C}+1}}\left(O_{b i n_{M C}}-O_{D}\right)
$$

Finalmente, a constante de calibração é calculada como:

$$
C=\frac{0.4}{E_{l}^{M C}}
$$

O erro de $E_{l}^{M C}$ é estimado devido aos erros estatísticos das ocupações envolvidas em seu cálculo.

De fato, para reduzir o erro estatístico, o procedimento da calibração pode ser realizado integrando-se as células no mesmo anel de $\varphi$, já que essas possuem o mesmo tamanho e, portanto, devem possuir a mesma constante de calibração. De qualquer modo, as células no mesmo anel de $\varphi$ são previamente calibradas a fim de que possuam a mesma resposta. 


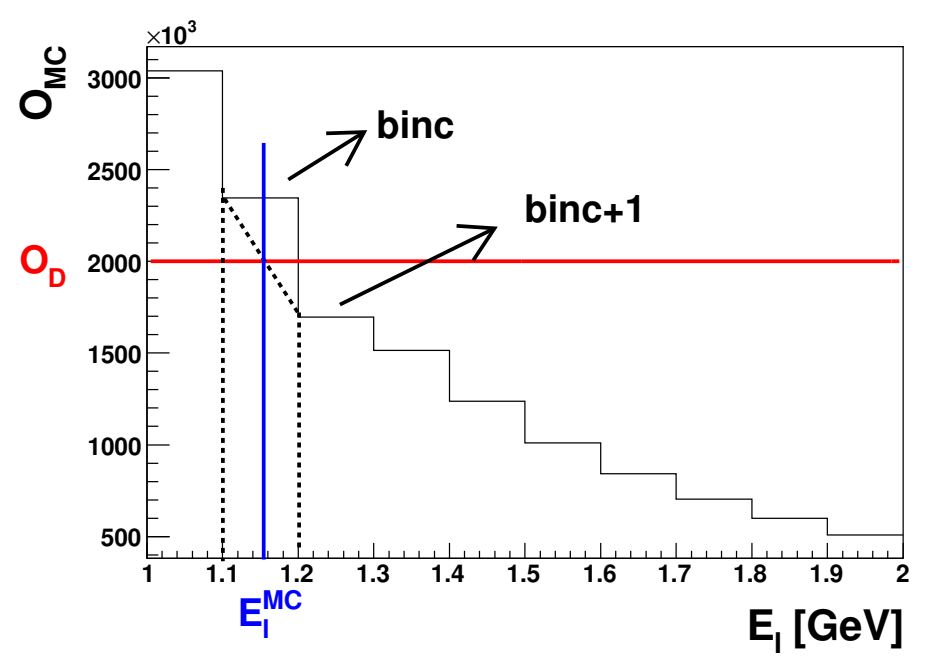

Figura 5.4: Ilustração de como é calculado o limiar $E_{l}^{M C}$. Considere binc $=\operatorname{bin}_{M C}$.

\subsubsection{Testes de Consistência}

Para confirmar se o método funciona, um teste foi realizado com amostras nas quais as constantes de calibração são conhecidas. Para isso, a energia das células foi multiplicada por três fatores de calibração $(0,2 ; 0,5 ; 0,8)$ em cada uma das amostras (simulação e dados). O método explicado na subseção 5.2 .2 é, então, utilizado para encontrar as constantes de calibração.

Pode-se observar nas figuras 5.5 e 5.6 que o método funciona tanto para os dados quanto para a simulação, e para todas as camadas (ilayer) e pseudorapidez.

\subsubsection{Resultados}

As constantes de calibração encontradas pelo método discutido na subseção 5.2.2 para cada ilayer e ieta do calorímetro, são apresentadas na figura 5.7.

A fim de validar o método, o mesmo foi utilizado para encontrar as constantes de calibração após o calorímetro simulado ser corrigido pelo resultado apresentado acima. Pode-se ver que as constantes achadas são compatíveis com o valor 1, portanto, pôde-se comprovar que a resposta do calorímetro simulado corresponde à resposta do calorímetro real.

Pode-se observar, nas figuras 5.9 e 5.10, que as variáveis a serem utilizadas na análise desta tese são melhores representadas pela simulação após a correção da resposta do calorímetro.

Nota-se que as constantes de calibração devem apresentar dependência em relação à luminosidade instantânea, pois espera-se que a energia depositada pelas múltiplas interações influencie na calibração. Dessa forma, o uso da calibração deve ser realizado respeitando o perfil da luminosidade instantânea da figura 5.3. 

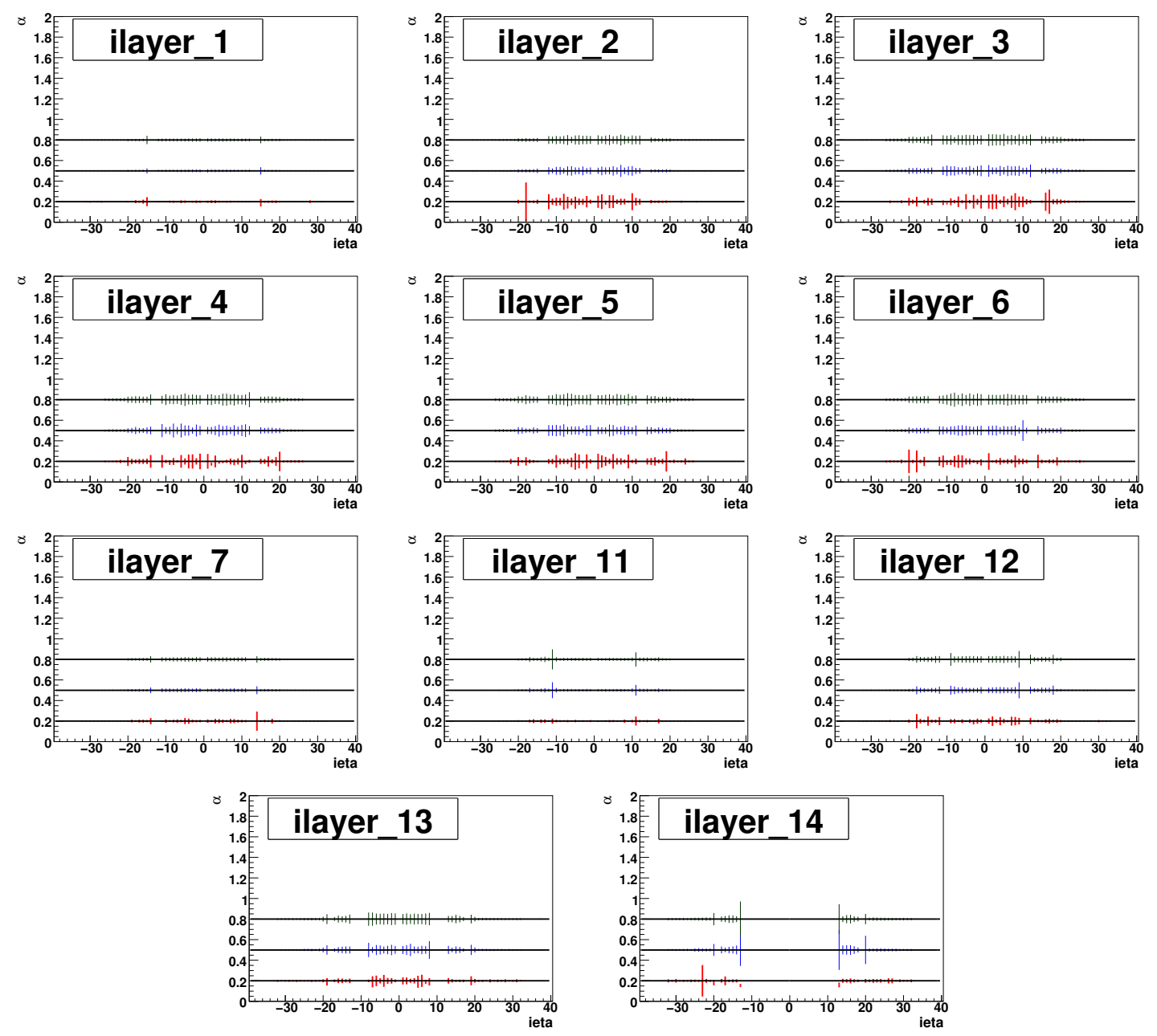

Figura 5.5: Constantes de calibração $(\alpha)$ encontradas para o teste de consistência através do método explicado na subseção 5.2.2 para células da amostra de dados reais. 

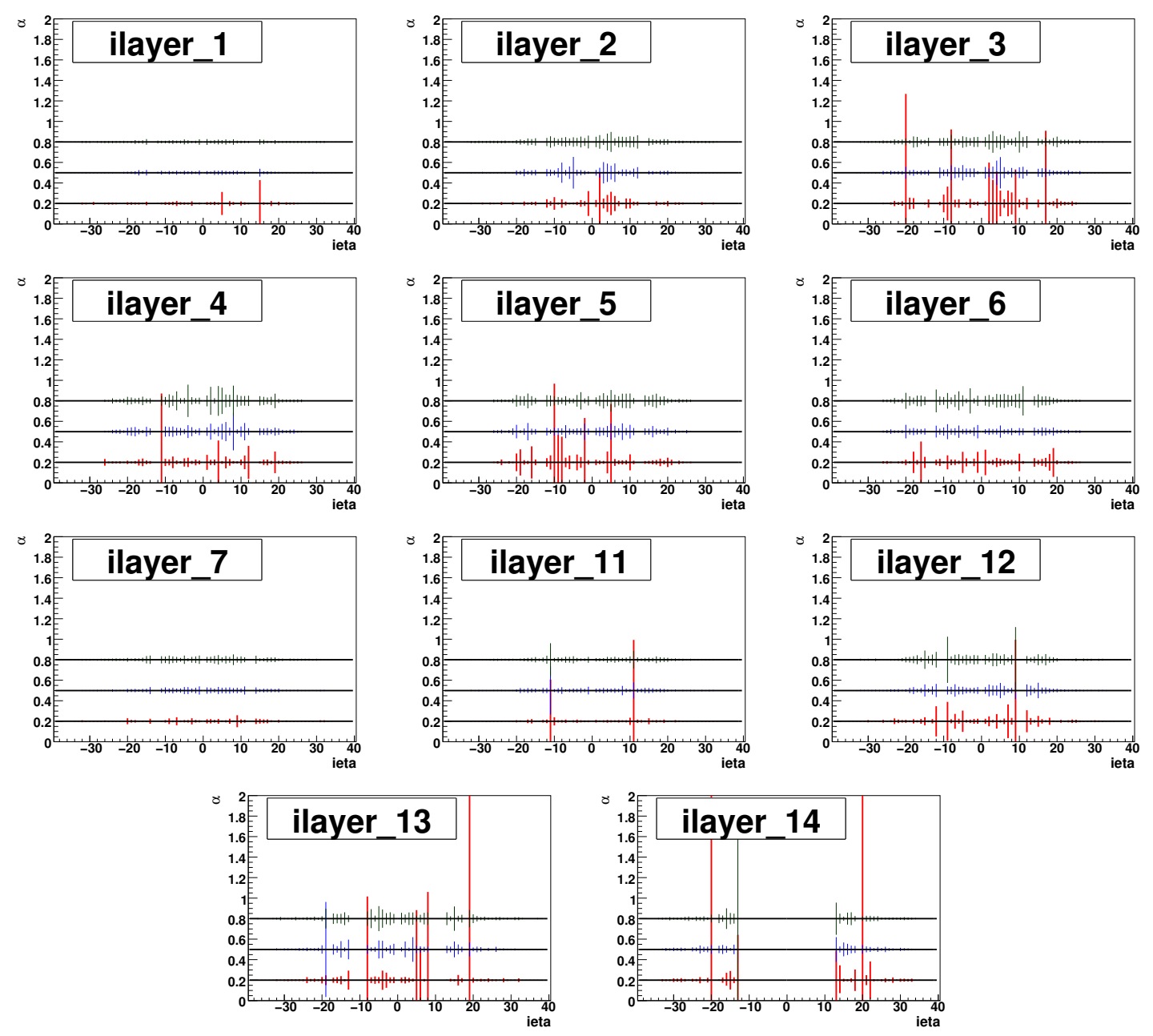

Figura 5.6: Constantes de calibração $(\alpha)$ encontradas para o teste de consistência através do método explicado na subseção 5.2.2 para células da amostra de simulação. 

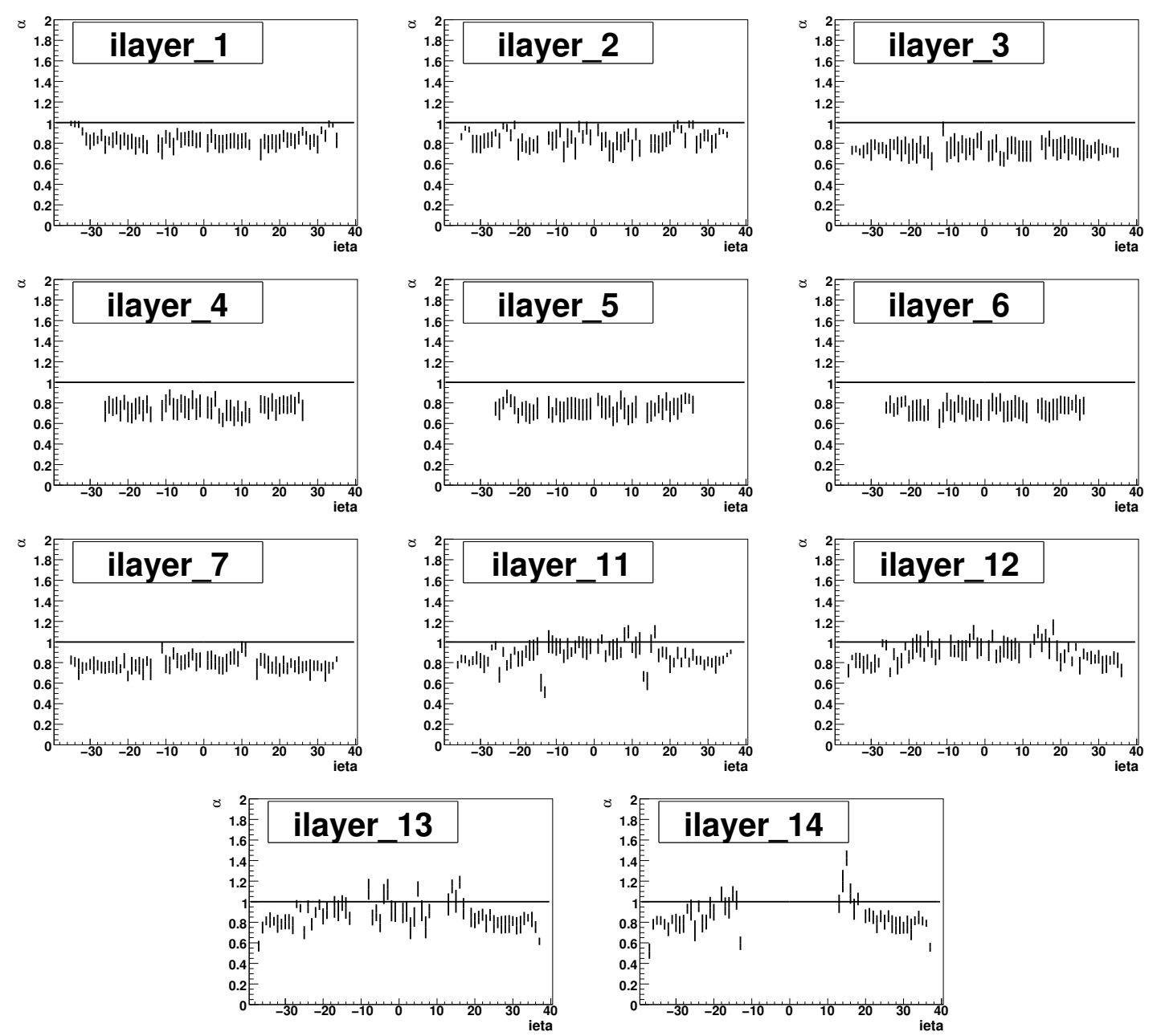

Figura 5.7: Fatores de correção relativa $(\alpha)$ da resposta do calorímetro simulado para o calorímetro real. 

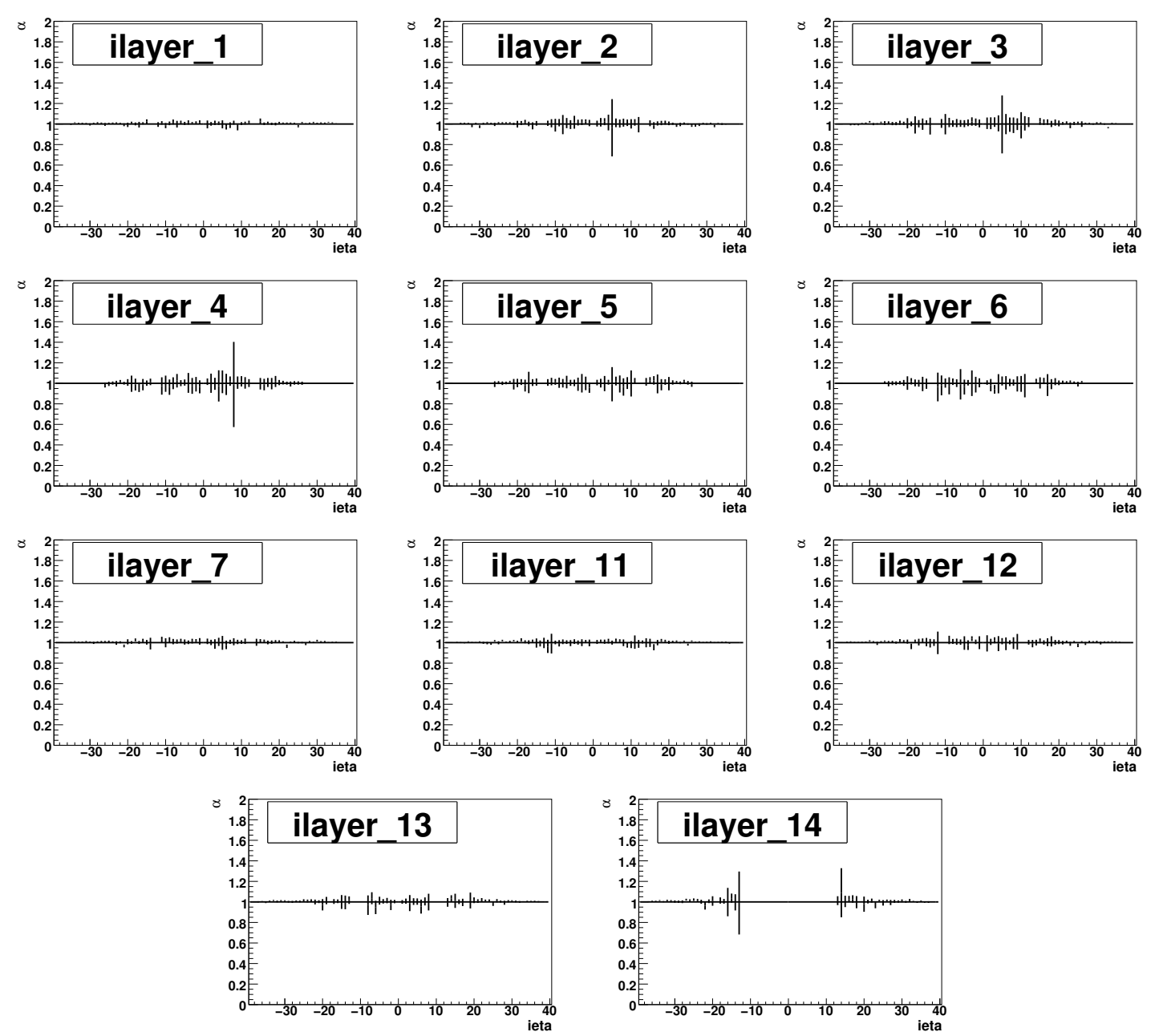

Figura 5.8: Fatores de correção relativa $(\alpha)$ da resposta do calorímetro simulado obtida após a correção para o calorímetro real. 

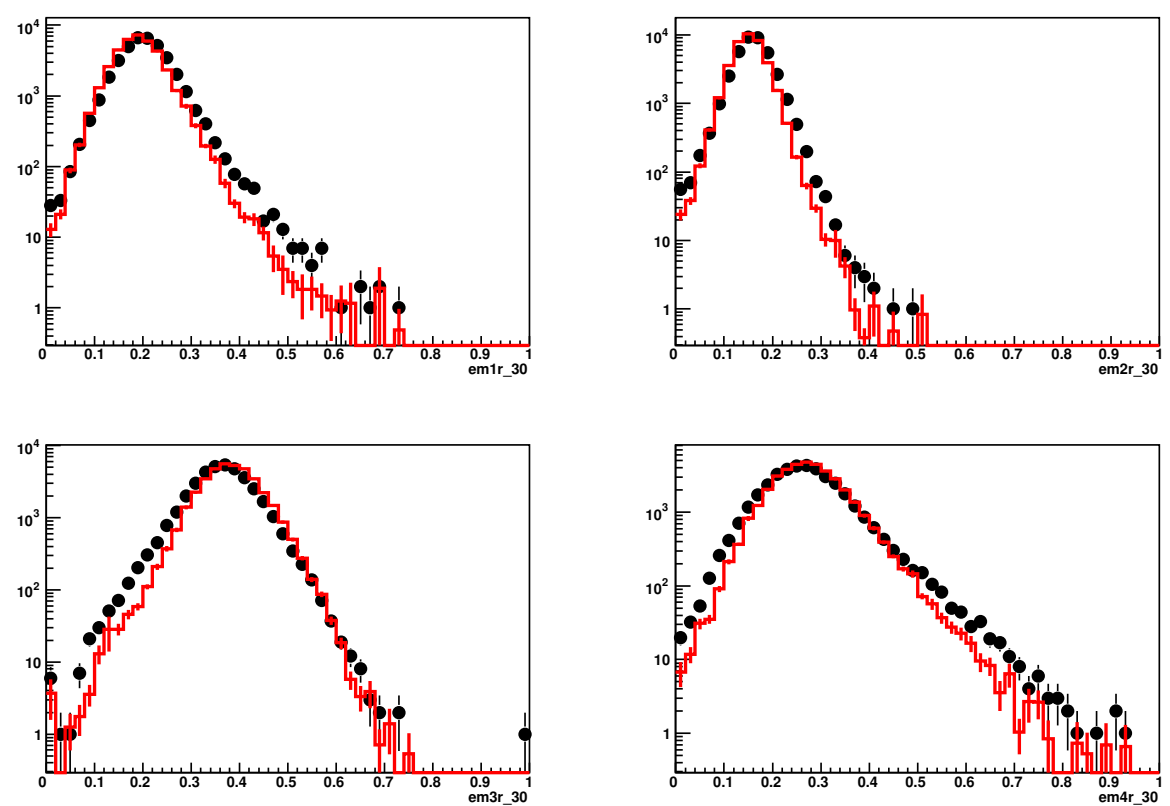

(a) Frações da energia transversa das camadas do calorímetro EM antes da correção.
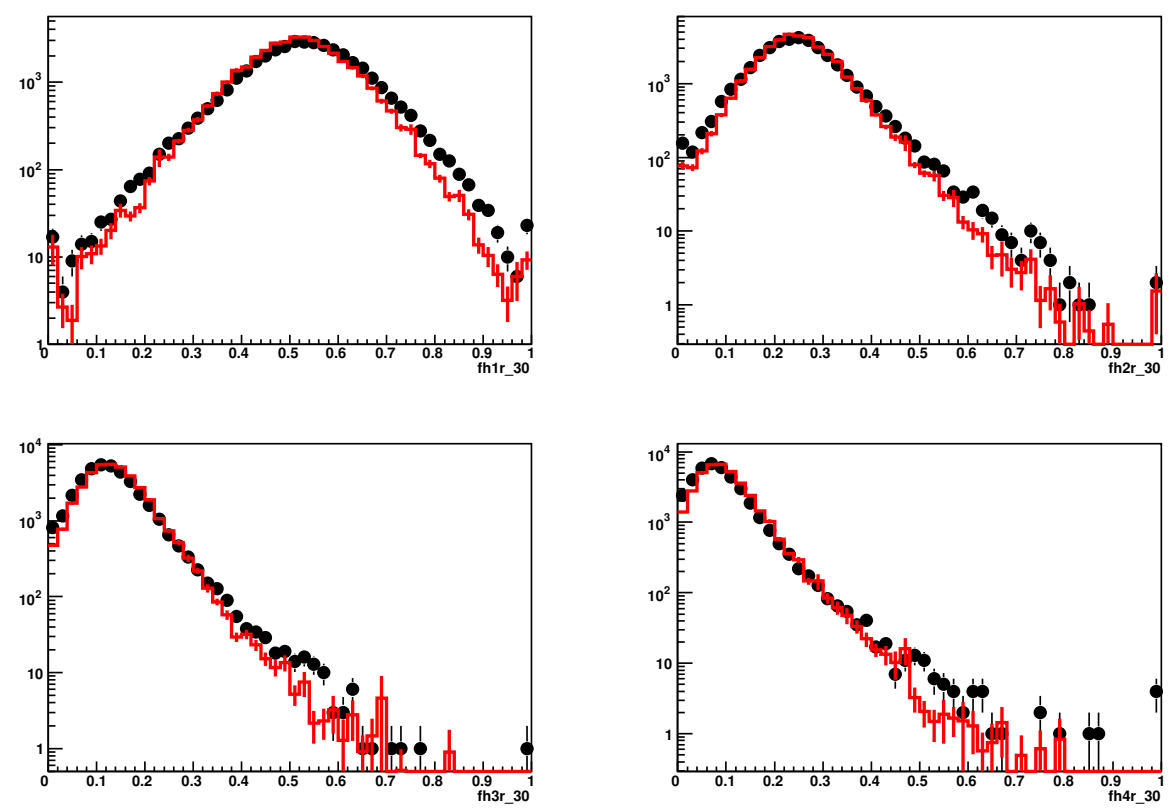

(b) Frações da energia transversa das camadas do calorímetro FH antes da correção.

Figura 5.9: Frações da energia transversa contida em cada camada dos calorímetros EM e FH antes da correção. Os histogramas de linha vermelha representam a simulação e, os pontos, os dados reais. 

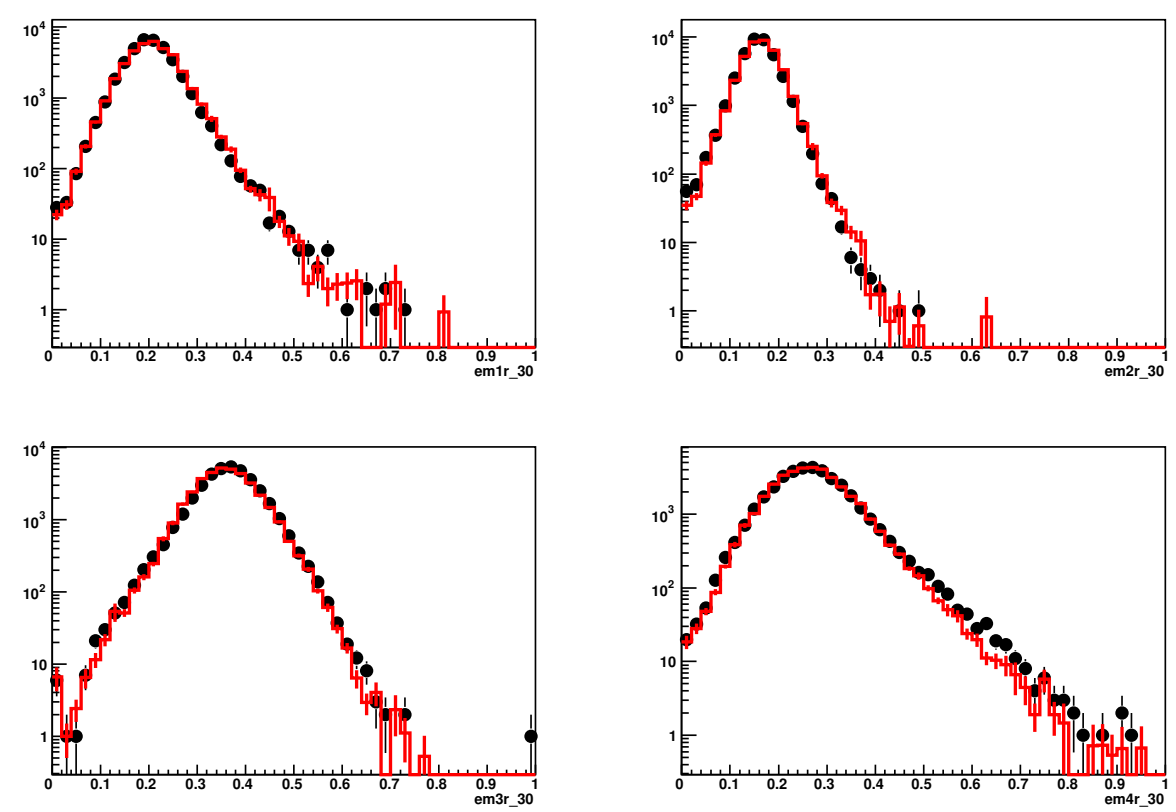

(a) Frações da energia transversa das camadas do calorímetro EM após da correção.
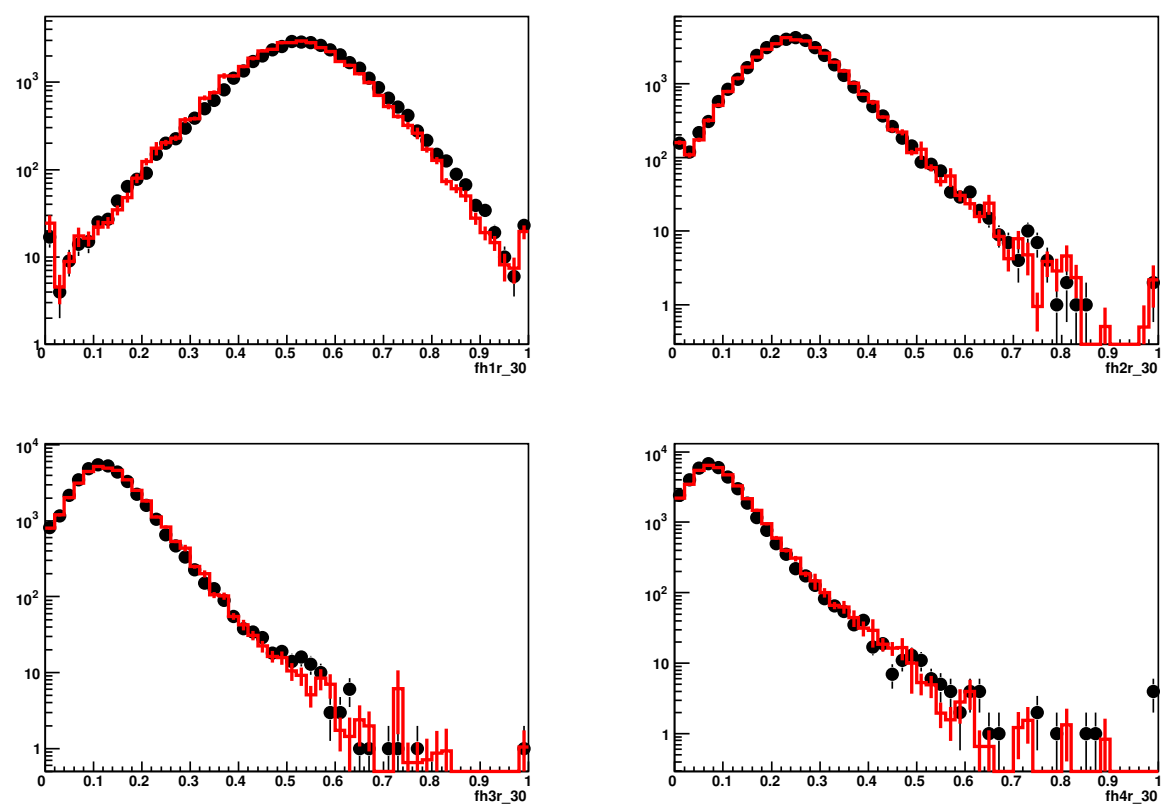

(b) Frações da energia transversa das camadas do calorímetro FH após da correção.

Figura 5.10: Frações da energia transversa contida em cada camada dos calorímetros EM e FH depois da correção. Os histogramas de linha vermelha representam a simulação e, os pontos, os dados reais. 


\subsection{Observações}

O calorímetro do D $\varnothing$ foi estudado em detalhes neste capítulo. Observou-se que células calorimétricas problemáticas permaneciam presentes nos dados, mesmo após aplicar cortes padrões da colaboração D $\varnothing$. Adicionalmente, uma calibração relativa do calorímetro simulado para o real foi realizada.

Ambos os estudos apresentados são inéditos dentro da experimento D $\varnothing$, e fundamentais para análise desenvolvida nesta tese. Espera-se, portanto, que esses estudos possam auxiliar análises similares no futuro. 


\section{Capítulo 6}

\section{Análise dos Dados Obtidos}

Neste capítulo, é apresentada a busca pela produção de jatos exclusivos, utilizando-se o detector $\mathrm{D} \varnothing$, descrito no capítulo 3; jatos reconstruídos e identificados como discutido no capítulo 4; e o calorímetro estável e calibrado do DØ, exposto no capítulo 5.

\subsection{Amostras de Eventos Simulados}

Cinco amostras de simulação de eventos precisam ser usadas a fim de representar todos os modos de produção de dijato possíveis:

- Produção não difrativa (inelástica) de dijatos (NDF);

- Produção de dijatos por difração simples do próton (SDS);

- Produção de dijatos por difração simples do antipróton (SDN);

- Produção inclusiva de dijatos por dupla troca de pomeron (IDP)

- Produção exclusiva de dijatos por dupla troca de pomeron (EDP)

O gerador PYTHIA [17] foi usado para o caso NDF, com jatos partônicos gerados com momentum transverso maior que $40 \mathrm{GeV}\left(\hat{p}_{T}>40 \mathrm{GeV}\right)$. De fato, a geração é feita em passos de $\hat{p}_{T}$ como mostrado na tabela 6.1.

Nota-se que a luminosidade integrada respectiva à região de $\hat{p}_{T}$ 40-80 é aproximadamente $0,5 p b^{-1}$, ou seja, bem menor do que a luminosidade integrada dos dados. Como o objetivo da análise é observar eventos de energia muito baixa fora do sistema de dijatos, eventos com um corte ao nível do gerador foram produzidos. O corte usado foi de $E_{p t c l}<100 \mathrm{GeV}$, em que $E_{p t c l}$ é a soma da energia de partículas com rapidez maior que 3. Esse corte seleciona 512 dos 552186 eventos gerados na região de $\hat{p}_{T} 40-80$. Foram gerados mais de 100.000 eventos, sendo que 6.008 sobrevivem aos cortes de jatos, aumentando em 10 vezes a luminosidade integrada na região de baixa energia. A estatística da simulação 


\begin{tabular}{|l|c|c|}
\hline$\hat{p}_{T}$ & $\sigma_{L O}[\mathrm{pb}]$ & Número de eventos \\
\hline $40-80$ & $1.3 \times 10^{6}$ & 552186 \\
$80-160$ & $3.8 \times 10^{4}$ & 1111952 \\
$160-320$ & $6.5 \times 10^{2}$ & 1212818 \\
$320-980$ & 3.2 & 737693 \\
\hline
\end{tabular}

Tabela 6.1: Número de eventos gerados com o gerador PYTHIA para produção não difrativa de dijatos para diferentes regiões de $\hat{p}_{T}$ e suas respectivas seções de choque em LO.

\begin{tabular}{|l|c|}
\hline Modo de produção difrativo & Número de Eventos \\
\hline SDS & 176113 \\
SDN & 176113 \\
IDP & 23405 \\
EDP & 14292 \\
\hline
\end{tabular}

Tabela 6.2: Número de eventos gerados para cada modo de produção difrativo

não é a ideal, porém, a seguir, será mostrado que o erro estatístico dos dados é dominante nesta análise.

O gerador de eventos POMWIG [93] foi utilizado para gerar SDS e SDN com $\hat{p}_{T}>43$ GeV. De fato, somente o modo SDN está implementado no POMWIG, mas supondo que SDS e SDN sejam simétricos, a amostra SDS é obtida pela inversão do calorímetro da amostra SDN.

Para IDP e EDP, foi o usado o gerador DPEMC [49] com o corte $\hat{p}_{T}>40 \mathrm{GeV}$. Para EDP, há três modelos fenomenológicos que tentam explicar essa produção: BL [43], KMR [44] e o do pomeron híbrido [45]. Como discutido no capítulo 2, o modelo KMR descreve melhor os dados do CDF [42], e esse é o escolhido na geração dos eventos. Não são esperadas diferenças entre esses modelos com relação às distribuições utilizadas na seleção de eventos exclusivos, uma vez que essas dependem apenas do ruído no calorímetro para esses eventos, como será explicado a seguir.

A tabela 6.2 mostra o número de eventos gerados para cada modo de produção difrativa.

Nota-se que todas as amostras passaram por uma simulação completa do detector, utilizando os programas de simulação da colaboração. Eventos do trigger ZB são também superpostos em todas as amostras para emular efeitos instrumentais e múltiplas interações presentes nos dados reais. A reconstrução dos eventos simulados é exatamente igual a dos eventos reais. 


\subsection{Seleção de Eventos}

A seleção de eventos é a mesma para os eventos simulados e reais, excetuando o critério do trigger necessário nos dados reais.

Os eventos reais foram obtidos com os critérios do trigger JT_45TT, i.e., existência de torres calorimétricas com energia transversa maior que $45 \mathrm{GeV}$. Esse requerimento não é completamente eficiente para eventos com jatos de $p_{T} \lesssim 100 \mathrm{GeV}$, então, os eventos precisam ser corrigidos, como explicado na seção 6.4 .

O primeiro corte realizado é sobre a luminosidade instantânea $(\mathrm{L})$, devido à alta sensibilidade desta análise com relação ao perfil da mesma. Apenas eventos na região de L $=[5-100] \times 10^{30} \mathrm{~cm}^{-2} \mathrm{~s}^{-1}$ foram selecionados. Observa-se que, para os eventos simulados, a luminosidade instantânea é proveniente dos eventos do trigger ZB superpostos. Dessa forma, esse corte é aplicado ao nível de gerador para as amostras simuladas.

Os eventos devem possuir, pelo menos, um vértice primário com, pelo menos, três traços associados a esse. O vértice primário, identificado com o espalhamento duro, não deve estar muito longe do centro geométrico do D $\varnothing$, portanto, sua posição longitudinal é mantida na região entre -50 e $50 \mathrm{~cm}$.

Os eventos devem possuir também dois jatos reconstruídos usando o algorítmo de cone [71] com tamanho $\Delta R=0,7$. Apenas jatos que passaram nos critérios de identificação de jatos [73] são considerados. Os 4-momenta dos jatos são corrigidos ao nível dos jatos de partículas [75]. Para selecionar eventos com dijatos de massa invariante $\gtrsim 100 \mathrm{GeV}$ (ver figura 6.4), os seguintes cortes foram aplicados nos dois jatos de maior $p_{T}$ :

- $p_{T}^{j 1}>50 \mathrm{GeV}$;

- $p_{T}^{j 2}>40 \mathrm{GeV}$;

- $\left|y^{j 1, j 2}\right|<0,8$

onde $j 1$ corresponde ao jato de maior $\mathrm{p}_{\mathrm{T}}$ e $j 2$ ao segundo jato de maior $\mathrm{p}_{\mathrm{T}}$.

Para suprimir a radiação de estado final dos jatos, os dois jatos de maior $\mathrm{p}_{\mathrm{T}}$ devem estar opostos em relação ao ângulo azimutal, portanto, o corte $\Delta \varphi>2,7$ é usado.

Ruído de raios cósmicos são rejeitados pelo requerimento de que a energia tranversa invisível deve ser menor do que $70 \%$ do $\mathrm{p}_{\mathrm{T}}$ não corrigido do jato de maior $\mathrm{p}_{\mathrm{T}}$ [24].

\subsection{Luminosidade Instantânea}

O primeiro passo é ponderar os eventos para que o perfil de luminosidade de todas as amostras seja o mesmo usado na determinação das constantes de calibração do calorímetro (ver seção 5.2).

Na figura 6.1, pode-se ver que o perfil de luminosidade de todas amostras concordam com o almejado. 


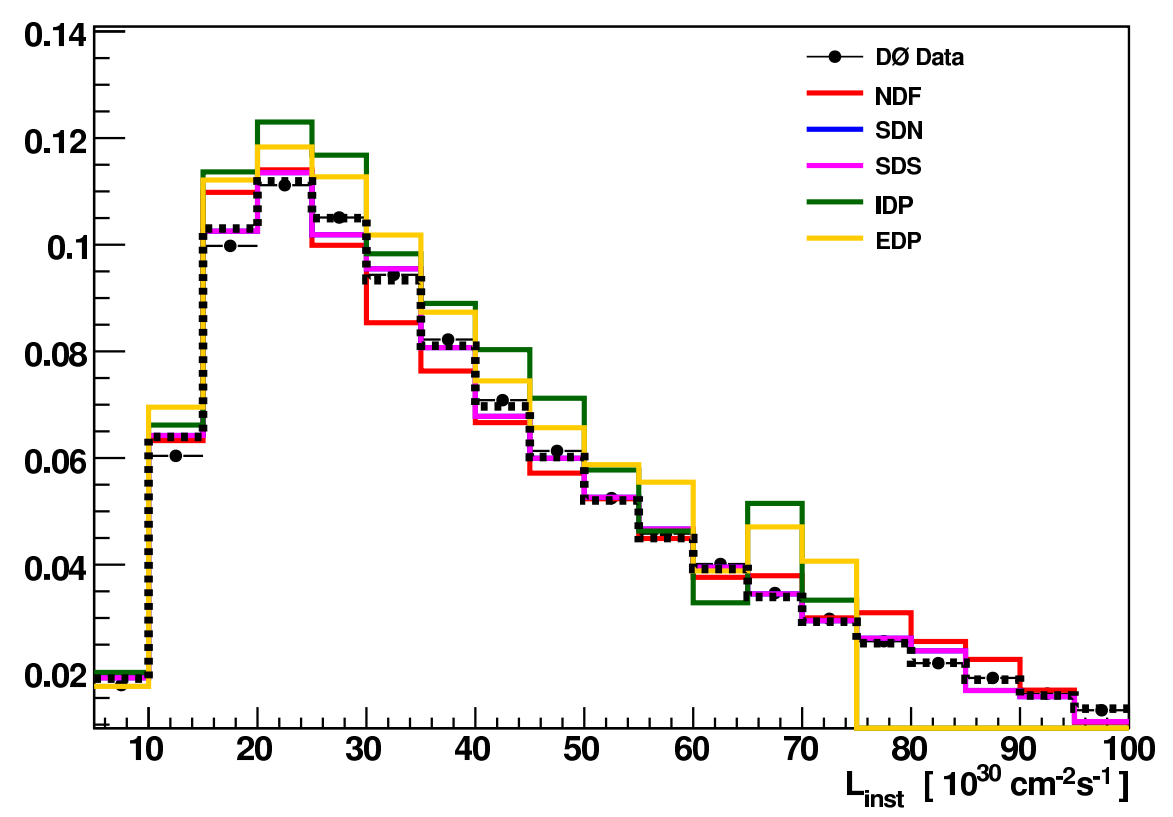

Figura 6.1: Perfil da luminosidade instantânea de todas as amostras usadas comparado com o perfil almejado (distribuição tracejada). As distribuições estão normalizadas para possuírem área igual a um.

\subsection{Correção da Eficiência do trigger}

Apesar de não ser um trigger dedicado à difração, um trigger de jato foi usado nessa análise, já que ele é muito bem entendido. Quanto menor o limiar do trigger, menor sua taxa de aceitação (porcentagem dos eventos gravados em disco que passam pelos requerimentos do trigger). O trigger que apresenta maior quantidade de eventos para a seleção, como explicado na seção 6.2, é o JT_45TT, como mostra a figura 6.2. De fato, apesar de o trigger JT_45TT possuir baixa eficiência na região de menor $\mathrm{p}_{\mathrm{T}}$, sua taxa de aceitação é bem maior do que a dos outros triggers.

Os critérios do trigger JT_45TT possuem eficiência máxima para $p_{T}^{j 1} \gtrsim 80 \mathrm{GeV}$ [91]. Portanto, devem-se corrigir os dados reais devido à ineficiência do trigger para $\mathrm{p}_{\mathrm{T}}$ entre 50 e $100 \mathrm{GeV}$. Para isso, eventos foram divididos em regiões de $p_{T}^{j 1}, p_{T}^{j 2}$ e $y^{j 1}$, e o coeficiente de correção provém da divisão do número de eventos da amostra JT_15TT com o número de eventos da amostra JT_45TT, propriamente ponderados pela luminosidade integrada de ambas as amostras.

\subsection{Contribuição não difrativa}

Supõe-se que a fração de eventos NDF na amostra de dados é de 100\%, já que as contribuições difrativas são menores que 1\%. Primeiramente, os eventos NDF simulados são ponderados de acordo com a seção de choque em LO (ver tabela 6.1), então, esses são 


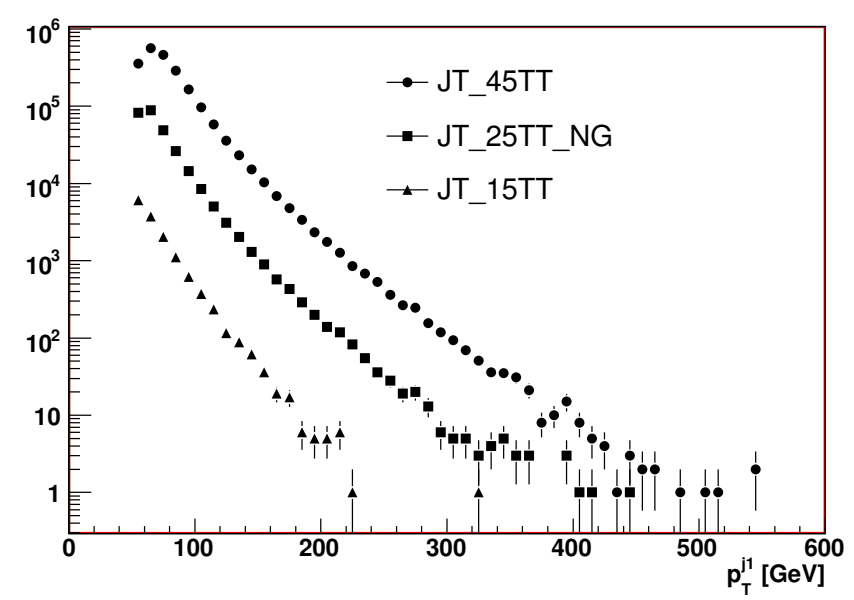

Figura 6.2: Número de eventos após a seleção explicada na seção 6.2 para três diferentes triggers.

normalizados para corresponderem ao mesmo número de eventos dos dados reais. O peso determinado é:

$$
w_{N D F}=67,79 \pm 0,87
$$

De fato, $w_{N D F}$ depende do $\mathrm{p}_{\mathrm{T}}$ do jato mais energético devido a efeitos não simulados corretamente. Pode-se ver, na figura 6.3, essa dependência com a variação do corte mínimo no $\mathrm{p}_{\mathrm{T}}$ do jato mais energético. Por simplicidade, o peso é mantido constante e um erro sistemático de $20 \%$ é associado a esse.

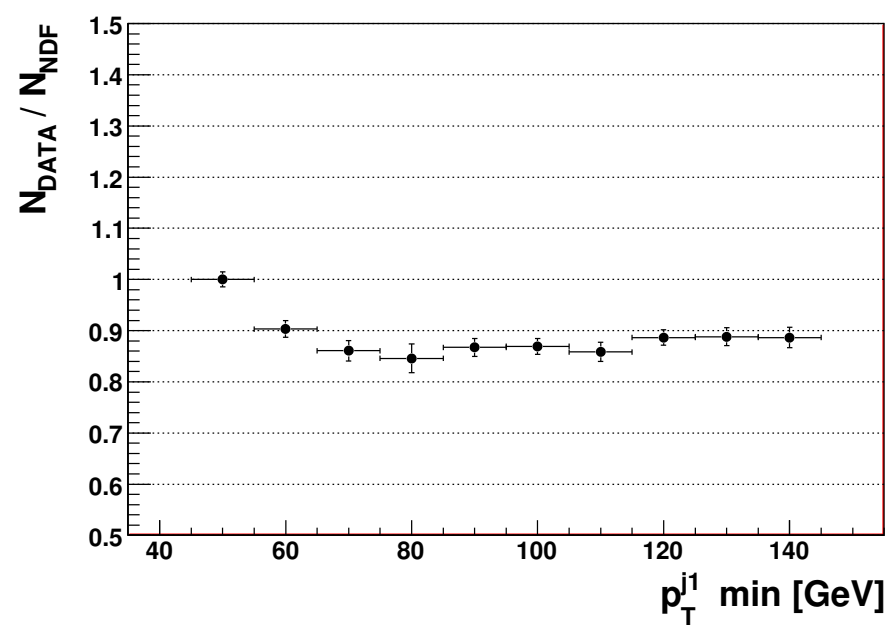

Figura 6.3: Razão entre o número de eventos dos dados e o número de eventos simulados após a normalização explicada no texto.

Pode-se ver, pela comparação com os dados reais, que o peso $w_{N D F}$ é, de fato, correto 
(ver figura 6.4), e também que a correção dos eventos reais com relação a eficiência do trigger foi propriamente realizada.
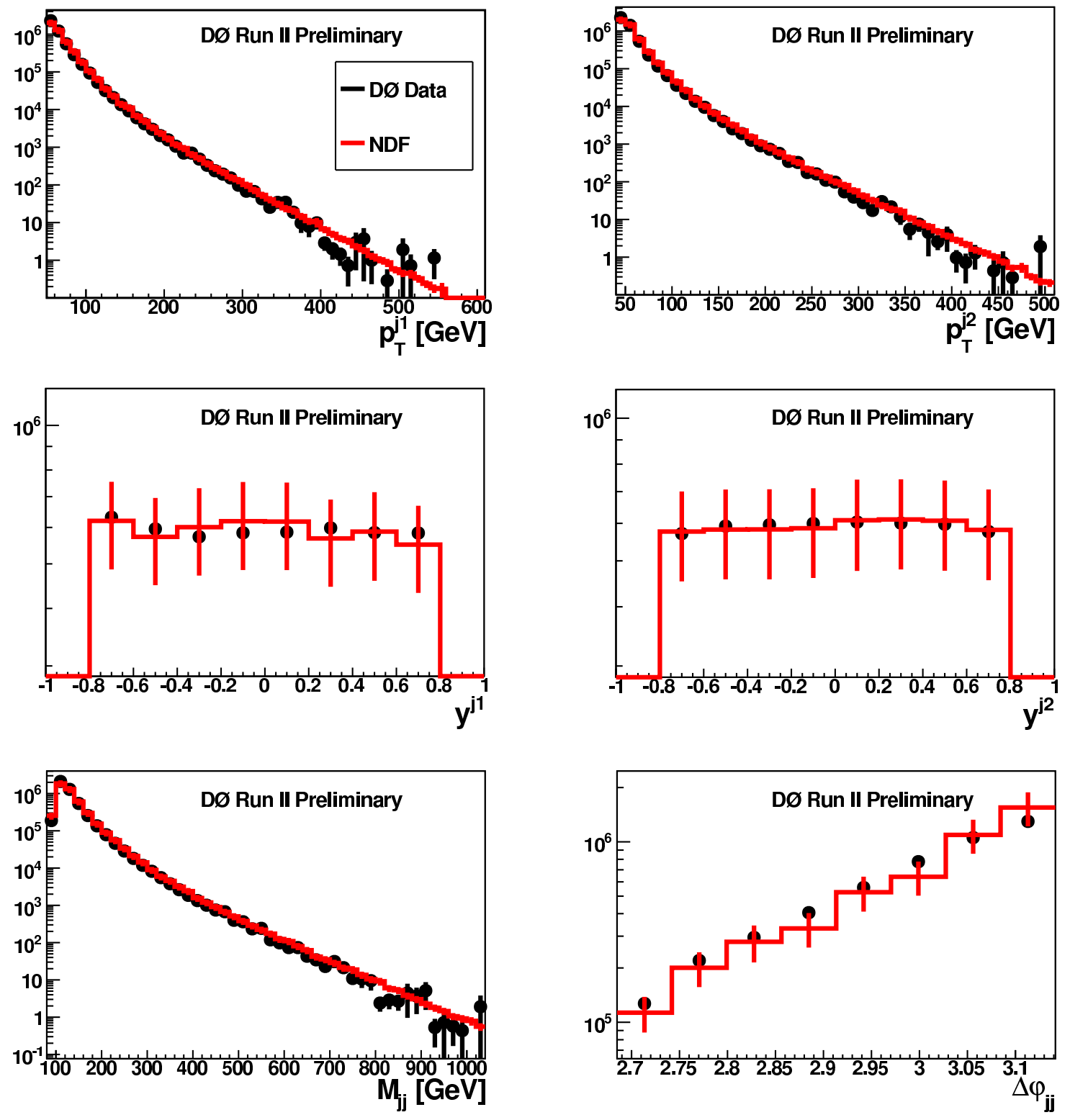

Figura 6.4: Variáveis dos dois jatos mais energéticos para eventos NDF simulados e dados reais: momentum trasnverso $\left(p_{T}^{j 1, j 2}\right)$, rapidez $\left(y^{j 1, j 2}\right)$, massa invariante do sistema de dijatos $\left(M_{j j}\right)$ e a diferença entre seus ângulos azimutais $(\Delta \varphi)$.

\subsection{Contribuições difrativas}

As razões do número de eventos do tipo SDN, SDS, IDP e EDP com relação ao número de eventos NDF não são bem conhecidas teoricamente. De qualquer modo, valores esperados para essas razões podem ser calculados usando as seções de choque em LO multiplicados 
pela eficiência da seleção de eventos. ${ }^{1}$ A correção das seções de choque do processo duro em LO para NLO são constantes, sendo canceladas no cálculo da razão. Os valores esperados para essas razões são apresentados na tabela 6.3.

\begin{tabular}{|l|c|c|c|}
\hline Produção & $\sigma_{L O}(\mathrm{pb})$ & $\begin{array}{c}\text { Eficiência da } \\
\text { Seleção de Eventos (\%) }\end{array}$ & $\begin{array}{c}\text { Razão (\%) } \\
\text { Prevista }\end{array}$ \\
\hline NDF & $1.2 \times 10^{6}$ & 4.1 & 100 \\
SDN & 4261 & 4.0 & 0.35 \\
SDS & 4261 & 4.0 & 0.35 \\
IDP & 140.5 & 13.2 & 0.04 \\
EDP KMR & 9 & 10.5 & 0.002 \\
EDP BL & 202 & 10.5 & 0.04 \\
EDP Híbrido & 0.6 & 10.5 & 0.0001 \\
\hline
\end{tabular}

Tabela 6.3: Razões teóricas entre o número de eventos de cada produção difrativa e número de eventos da produção não difrativa.

De forma a reduzir a dependência da análise das previsões teóricas, adotou-se a estratégia de medir as razões para todos os modos difrativos independentemente das previsões teóricas, apenas supondo que as formas das distribuições estejam corretas.

Uma forma de medir as contribuições difrativas é construir variáveis sensíveis a cada modo de produção difrativo. Cortes nessas variáveis apareceriam como excessos dos dados reais em relação à simulação NDF. Verifica-se que, em geral, os excessos encontrados conterão eventos de todos os modos de produção difrativa, portanto, para cada excesso, escreve-se:

$N_{D A T A}^{i}-N_{N D F}^{i} \times w_{N D F}=w_{S D N} \times N_{S D N}^{i}+w_{S D S} \times N_{S D S}^{i}+w_{I D P} \times N_{I D P}^{i}+w_{E D P} \times N_{E D P}^{i}$,

onde $N_{k}^{i}$ é o número de eventos para o iésimo corte, $k$ representa a amostra em questão e $w_{k}$ é o peso para cada amostra de simulação.

Observa-se que $w_{S D N}, w_{S D S}, w_{I D P}$ e $w_{E D P}$ são parâmetros livres. Pode-se determinar pontos para $\mathrm{N}$ diferentes cortes de forma que, minimizando uma distribuição de $\chi^{2}$, determina-se os parâmetros livres.

Os excessos $N_{D A T A}^{i}-N_{N D F}^{i} \times w_{N D F}$ são medidos com a ajuda de um discriminante construído através de um método multivariável, como discutido na seção 6.8 .

\footnotetext{
${ }^{1}$ Nesse caso, a eficiência da seleção de eventos é definida como a fração dos eventos gerados que, após a simulação completa, passam pelos critérios da seleção.
} 


\subsection{Análise Linear}

Primeiramente, explora-se a possibilidade de encontrar eventos com dijatos produzidos por dupla troca de pomeron exclusiva através da energia fora do sistema de dijato. Como explicado na seção 6.2, os jatos são selecionados na região central do detector. Dessa forma, definem-se as células calorimétricas fora do sistema de dijato, células que possuem ieta maior que 20 ( ou $\eta_{D E T}>2$ ). Para o maior detalhamento da energia fora do sistema de dijato, dividem-se as células com ieta maior que 20 em duas regiões de ieta: $20<$ $\mid$ ieta $\mid \leq 30$ e ieta $>30$. Todas as células consideradas problemáticas (ver seção 5.1) são removidas e a calibração discutida na seção 5.2 é usada.

A variável que se relevou mais sensível à energia fora do sistema do dijato é:

$$
V A R_{E}=0,5 \times\left(\exp \left(-\sum_{20<i \text { et } a \leq 30} E\right)+\exp \left(-\sum_{\text {ieta }>30} E\right)\right)
$$

onde $E$ é a energia das células.

Pode-se ver, na figura 6.5, que a produção de dijatos não difrativa não explica eventos que possuam pouca energia fora do sistema de dijato, ou seja, eventos com $V A R_{E}>0,8$. Porém, na figura 6.6, observa-se que não apenas eventos EDP povoam esta região de baixa energia, mas as outras produções difrativas também.

De fato, a determinação da contribuição de cada produção difrativa é necessária para que a busca por eventos de dupla troca de pomeron exclusiva seja realizada corretamente. 


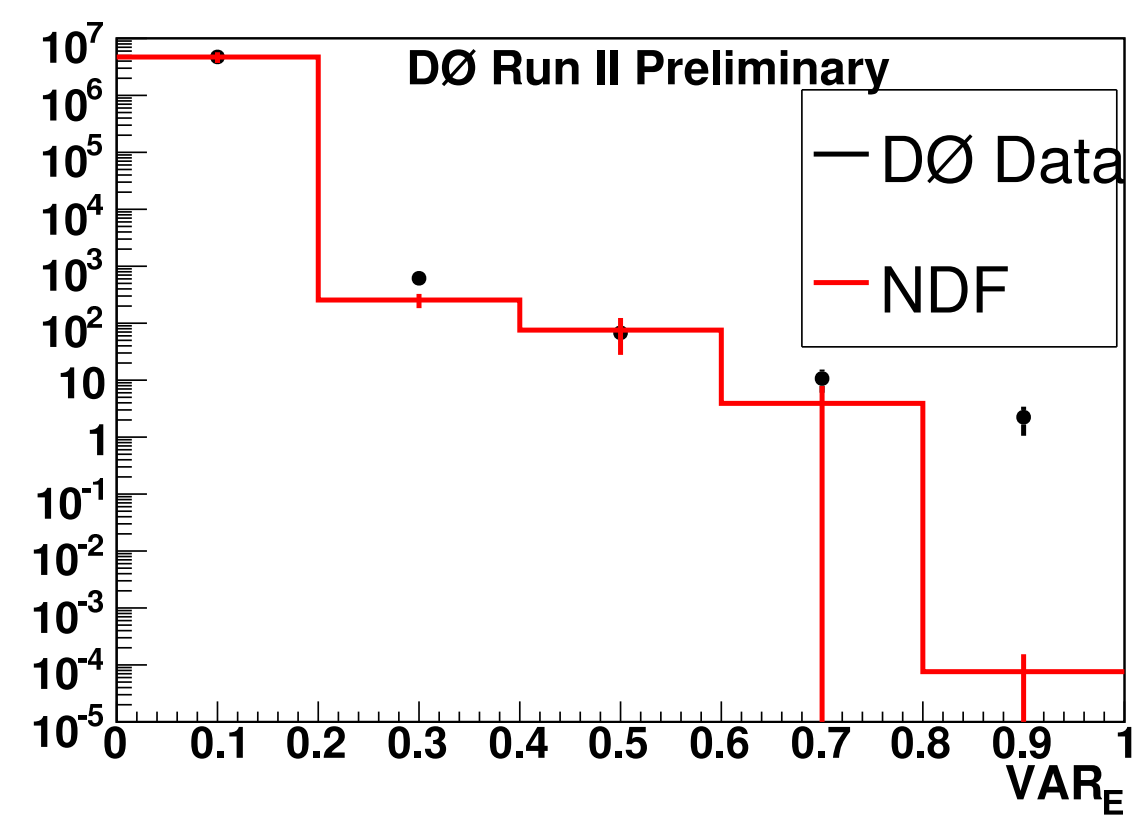

Figura 6.5: Variável da energia fora do sistema de dijato para dados simulados não difrat

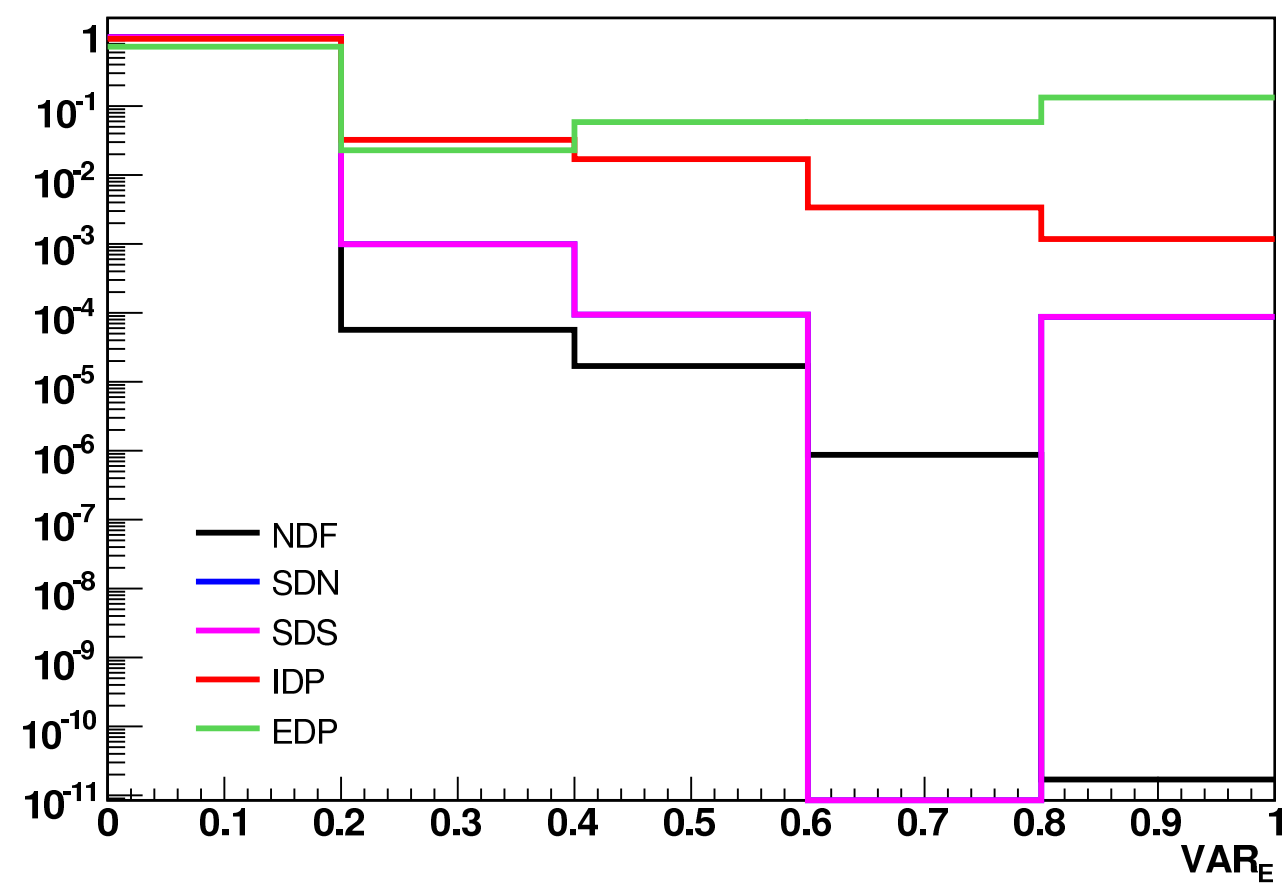

Figura 6.6: Variável da energia fora do sistema de dijato para todas amostras de simulação. As distribuições estão normalizadas pela área. 


\subsection{Método Multivariável de Verossimilhança}

Para determinar a contribuição de cada modo de produção difrativo, usa-se um método multivariável de verossimilhança, o que fornece uma variável discriminante entre uma amostra ruído (bkg) e outra de sinal (sig), definida para cada evento como:

$$
L L=\frac{P_{s i g}}{P_{b k g}+P_{s i g}}
$$

onde $P_{s i g}$ e $P_{b k g}$ são as probabilidades do evento pertencer à amostra de sinal e de ruído respectivamente.

O cálculo das probabilidades é realizado utilizando-se um número $N$ de variáveis, e, sendo essas não correlacionadas, pode-se escrever:

$$
P_{b k g}=\prod_{v=1}^{v<N} P_{b k g}^{(v)}
$$

e

$$
P_{s i g}=\prod_{v=1}^{v<N} P_{s i g}^{(v)},
$$

onde $P_{s i g, b k g}^{v}$ é a função densidade de probabilidade.

Nota-se que $P_{\text {sig,bkg }}^{v}$ pode ser representado por um histograma da variável $v$ sendo, portanto, uma função densidade de probabilidade discreta.

Para evitar extremos na distribuição de $L L$, uma transformação de variável é realizada. definindo-se:

$$
l l(\operatorname{sig} / b k g)=\log \left(\frac{1}{L L}-1\right) .
$$

Nota-se que, para fins práticos, LL nunca é nulo para evitar divergências, sendo substituído por $\epsilon=10^{-15}$, caso seja menor que esse valor. Também deseja-se que ll( $\mathrm{sig} / \mathrm{bkg}$ ) varie entre os valores 0 e 1, portanto, a equação 6.7 é substituída pela seguinte equação:

$$
l l(\operatorname{sig} / b k g)=\frac{\log (1 / \epsilon-1)-\log (1 / L L-1)}{2 \log (1 / \epsilon-1)} .
$$

A fim de ilustrar as diferenças entre LL e ll, foram comparadas as distribuições para LL(edp/bkg) e ll(edp/bkg) (ver figura 6.7), em que bkg é a soma dos ruídos para a produção exclusiva, como explicado na subseção 6.9.1. Os eventos EDP são normalizados de acordo com a seção de choque do modelo KMR e, os ruídos, de acordo com as medidas mostradas na seção 6.9. De fato, a distribuição de $11(\mathrm{edp} / \mathrm{bkg})$ não apresenta as regiões de extremo presentes na distribuição de $\mathrm{LL}(\mathrm{edp} / \mathrm{bkg})$, melhorando a visualização da separação entre ruído e sinal. 

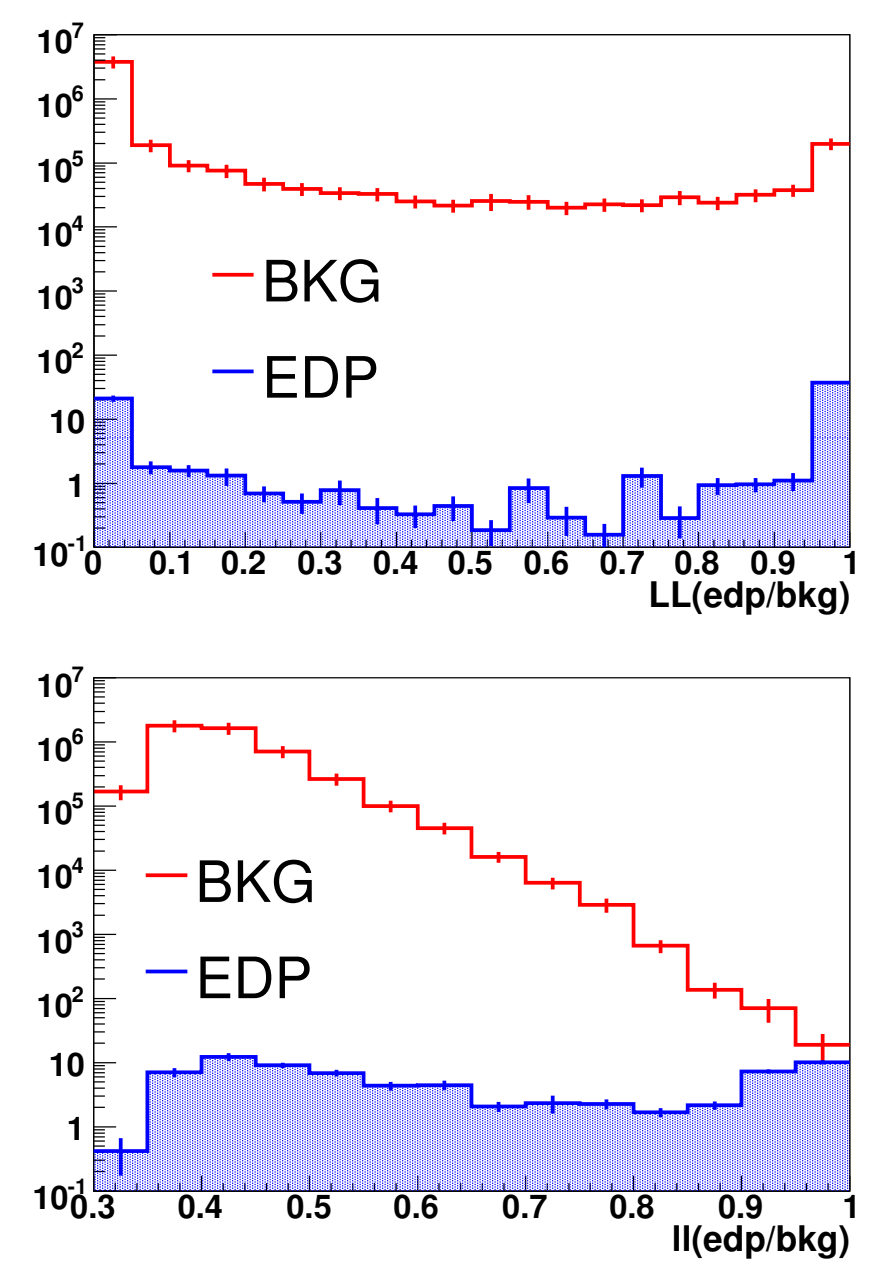

Figura 6.7: Comparação entre a distribuição de LL e de ll, como explicado no texto.

\subsubsection{Variáveis de entrada}

Para discriminar eventos difrativos de não difrativos, variáveis calorimétricas foram usadas. Oito regiões do calorímetro foram definidas para o maior detalhamento da topologia dos eventos:

- EM1S: $20<$ ieta $<30$, ilayer $\leq 7$

- EM1N: $-20>$ ieta $>-30$, ilayer $\leq 7$

- EM2S: ieta $\geq 30$, ilayer $\leq 7$

- EM2N: ieta $\leq-30$, ilayer $\leq 7$

- FH1S: $20<$ ieta $<30,11 \leq$ ilayer $\leq 14$

- FH1N: $-20>$ ieta $>-30,11 \leq$ ilayer $\leq 14$

- FH2S: ieta $\geq 30,11 \leq$ ilayer $\leq 14$ 
- FH2N: ieta $\leq-30,11 \leq$ ilayer $\leq 14$

Cada região é dividida em quatro camadas constituídas de diferentes ilayers. Para o calorímetro EM, os pares (camada;ilayer) são: $(1 ; 1),(2 ; 2),(3 ; 3,4,5$ e 6$)$ e $(4 ; 7)$. Para o calorímetro FH, os pares são: $(1 ; 11),(2 ; 12),(3 ; 13)$ e $(4 ; 14)$.

As frações da energia transversa em cada camada das regiões do calorímetro são usadas como entrada para o método multivariável de verossimilhança. A idéia básica é usar as correlações entre estas variáveis a fim de caracterizar a passagem de partículas pelo calorímetro (ver figuras 6.8, 6.9, 6.10 e 6.11), o que é o principal fator de diferença entre eventos difrativos e não difrativos.

Nota-se que o discriminante é melhor construído se as variáveis não possuírem nenhuma correlação entre si. A segunda e a terceira camadas são bastante descorrelacionadas para todas as regiões (ver matriz de correlação entre as variáveis no apêndice D e as figuras 6.8-6.11), portanto, essas são escolhidas como as variáveis de entrada para o método multivariável.

Dessa forma, as seguintes variáveis são usadas:

$$
\begin{aligned}
& \mathbf{V A R} 1=F(E M 1 N)(2) \text { VAR2 }=\quad F(E M 1 S)(2) \\
& \mathbf{V A R 3}=F(E M 2 N)(2) \mathbf{V A R} 4=F(E M 2 S)(2) \\
& \text { VAR5 }=F(F H 1 N)(2) \text { VAR6 }=F(F H 1 S)(2) \\
& \mathbf{V A R 7}=F(F H 2 N)(2) \mathbf{V A R} 8=F(F H 2 S)(2) \\
& \mathbf{V A R 9}=F(E M 1 N)(3) \text { VAR10 }=F(E M 1 S)(3) \\
& \mathbf{V A R 1 1}=F(E M 2 N)(3) \text { VAR12 }=F(E M 2 S)(3) \\
& \mathbf{V A R 1 3}=F(F H 1 N)(3) \text { VAR14 }=F(F H 1 S)(3) \\
& \mathbf{V A R} 15=F(F H 2 N)(3) \text { VAR16 }=F(F H 2 S)(3) \\
& \text { VAR17 }=\frac{\sum_{c e l}^{\text {part }=E M 1 S, F H 1 S} E_{T}}{\sum_{c e l}^{\text {part }=E M 1 S, F H 1 S, E M 2 S, F H 2 S} E_{T}} \\
& \text { VAR18 }=\frac{\sum_{c e l}^{p a r t=E M 1 N, F H 1 N} E_{T}}{\sum_{c e l}^{p a r t=E M 1 N, F H 1 N, E M 2 N, F H 2 N} E_{T}},
\end{aligned}
$$

onde, $F(i)(l)=\frac{\sum_{c e l}^{c a m a d a=l, r e g=i} E_{T}}{\sum_{c e l}^{r e g=i} E_{T}}$, i.e., a fração da energia transversa contida em uma dada camada $l$ da região $i$ com relação à energia transversa contida em toda região.

Observa-se que a simulação dos eventos NDF estão de acordo com os dados reais para todas as variáveis escolhidas (ver figuras 6.12, 6.13 e 6.14). De fato, apenas uma análise multivariável poderá discriminar os eventos difrativos dos não difrativos.

Nas figuras 6.15, 6.16 e 6.17, pode-se ver a comparação entre os diferentes modos de produção simulados. 

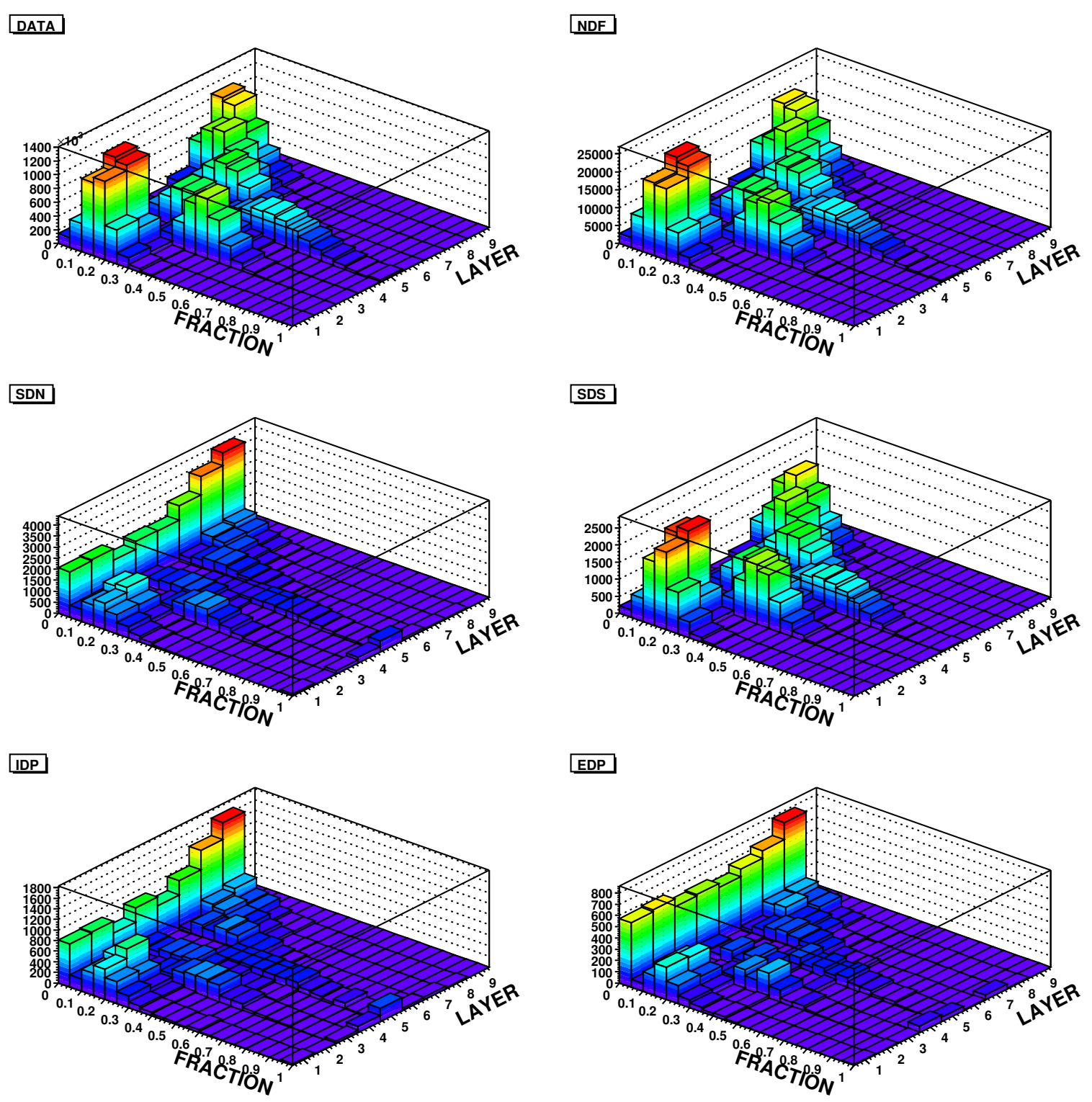

Figura 6.8: Frações das energias transversas (FRACTION) em cada camada do calorímetro norte para ieta maior que 30. As camadas $(L A Y E R)$ 1, 2, 3 e 4 representam o calorímetro EM e as camadas $5,6,7$ e 8 o calorímetro $\mathrm{FH}$. 

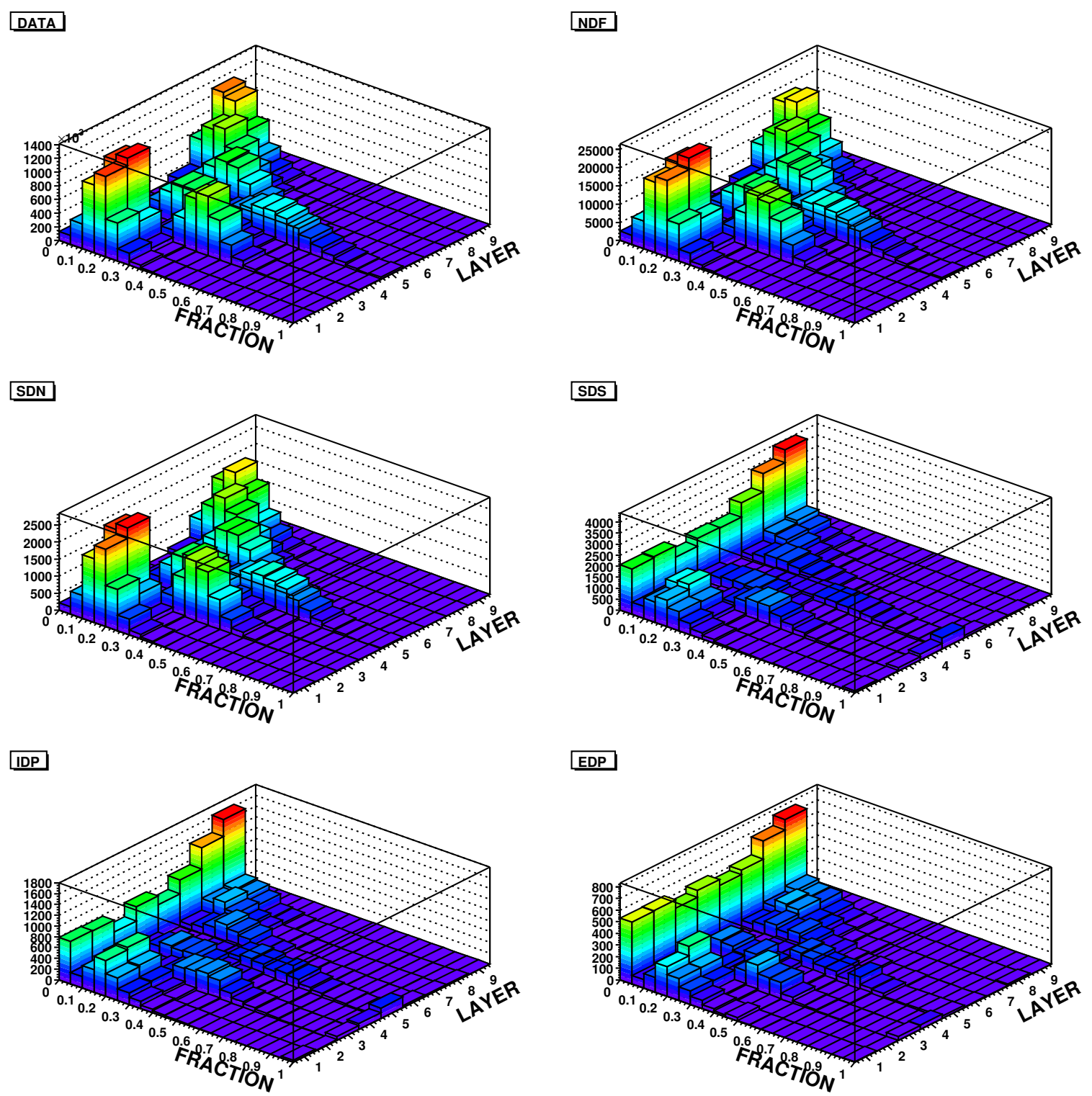

Figura 6.9: Frações das energias transversas (FRACTION) em cada camada do calorímetro sul para ieta maior que 30. As camadas $(L A Y E R)$ 1, 2, 3 e 4 representam o calorímetro EM e as camadas 5, 6, 7 e 8 o calorímetro $\mathrm{FH}$. 

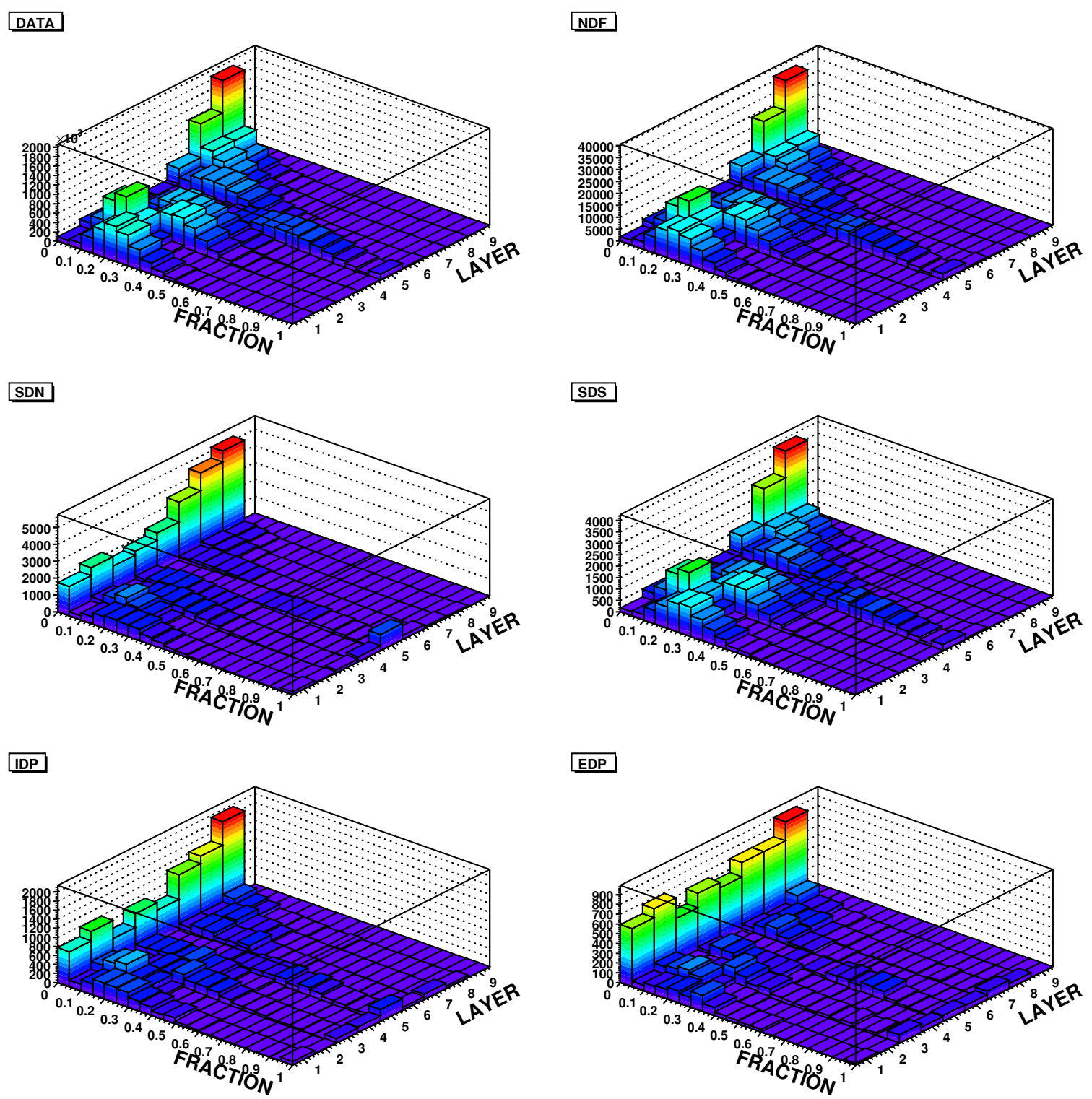

Figura 6.10: Frações das energias transversas (FRACTION) em cada camada do calorímetro norte para ieta $=(20,30]$. As camadas $(L A Y E R) 1,2,3$ e 4 representam o calorímetro EM e as camadas 5, 6, 7 e 8 o calorímetro FH. 

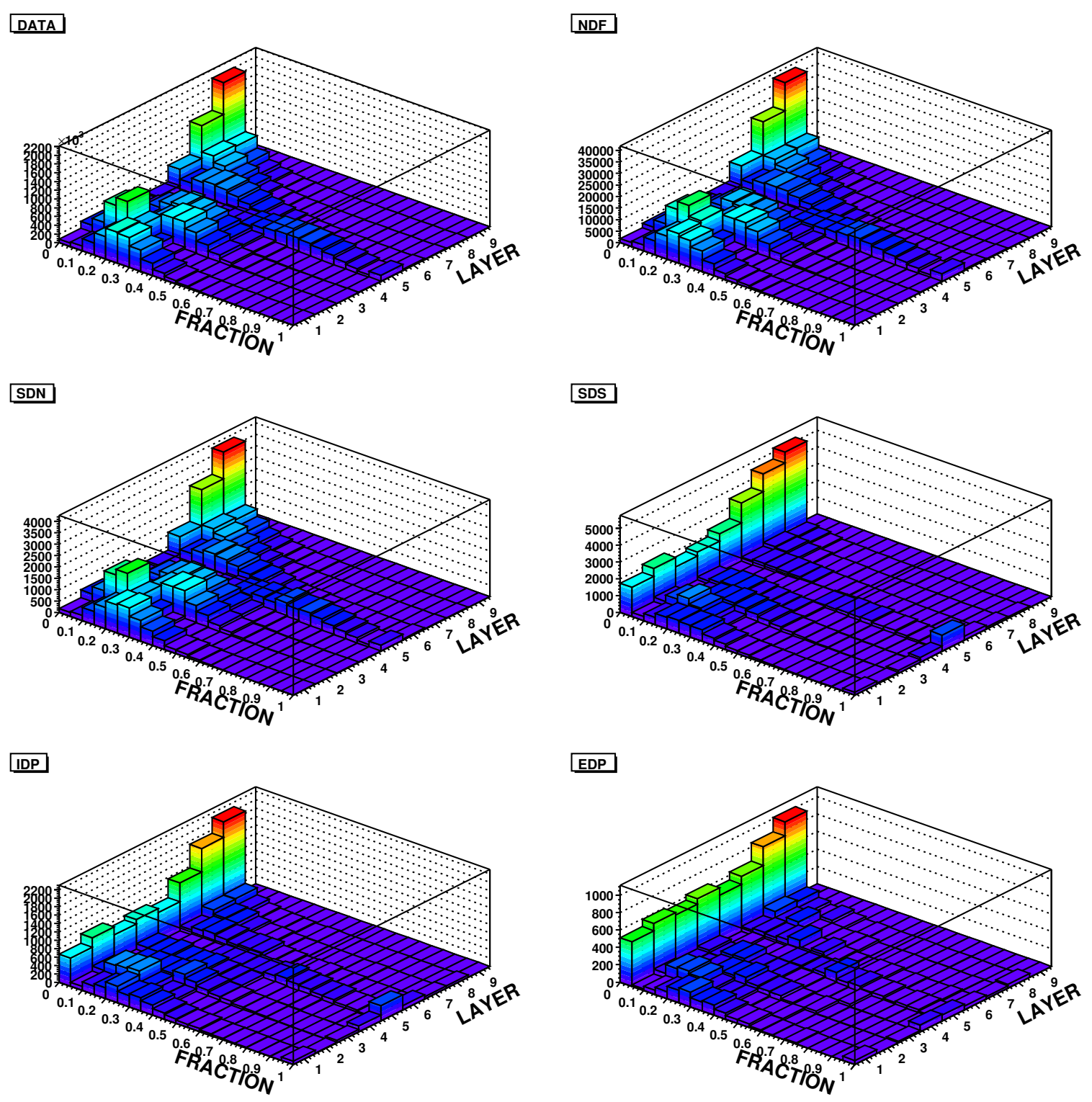

Figura 6.11: Frações das energias transversas (FRACTION) em cada camada do calorímetro sul para ieta $=(20,30]$. As camadas $(L A Y E R) 1,2,3$ e 4 representam o calorímetro EM e as camadas 5, 6, 7 e 8 o calorímetro FH. 

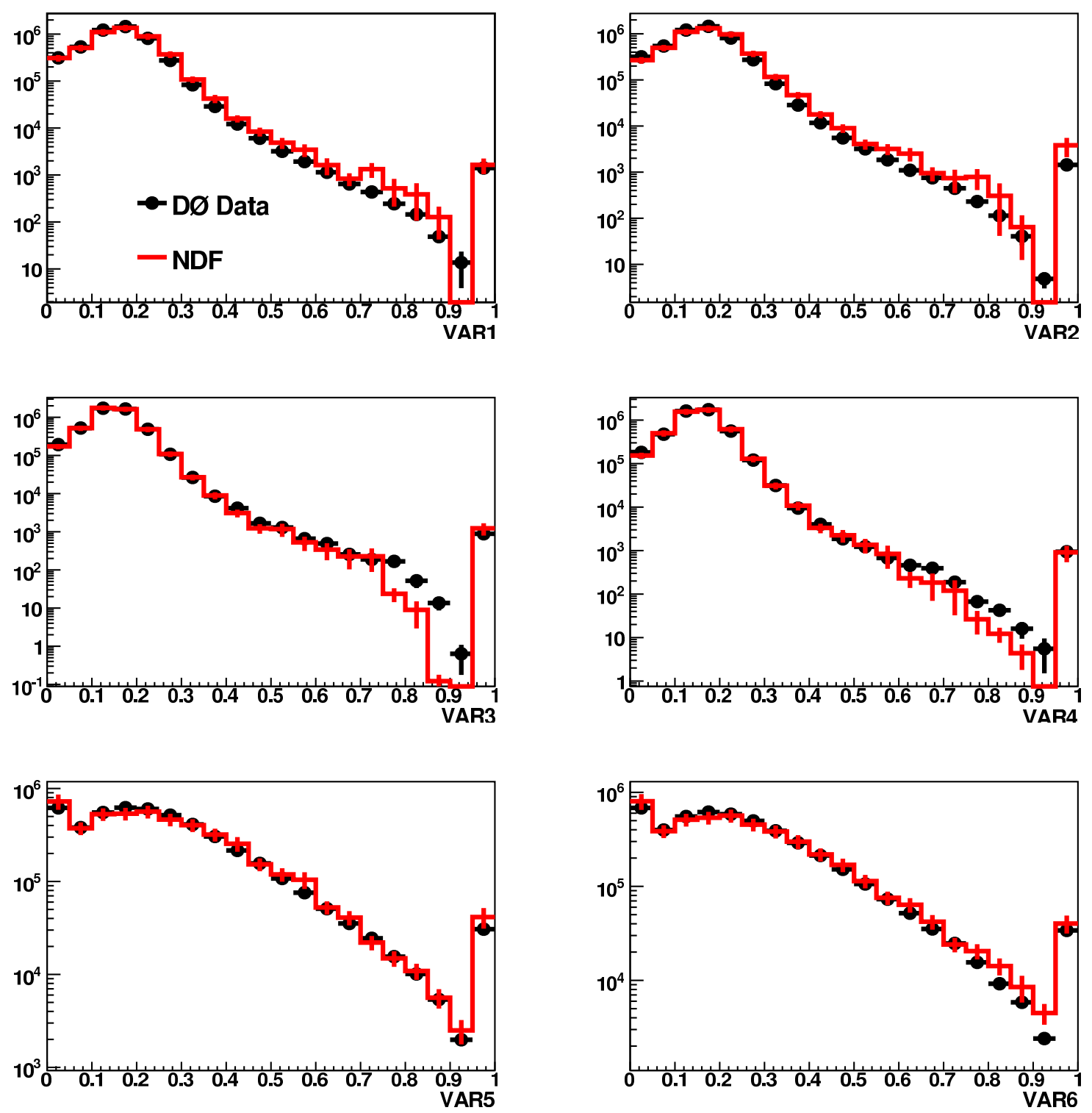

Figura 6.12: Distribuição das variáveis definidas na equação 6.9. 

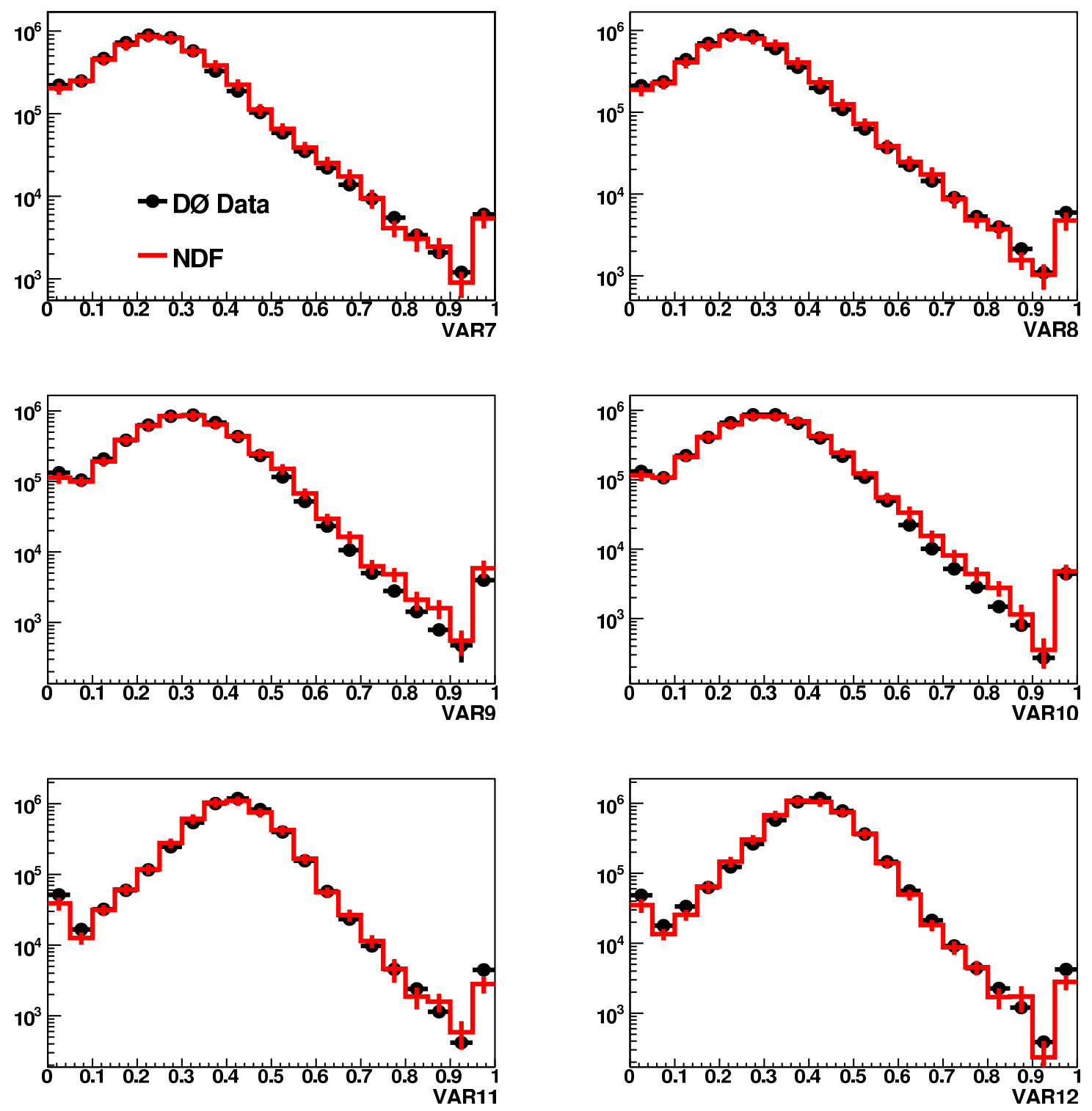

Figura 6.13: Distribuição das variáveis definidas na equação 6.9. 

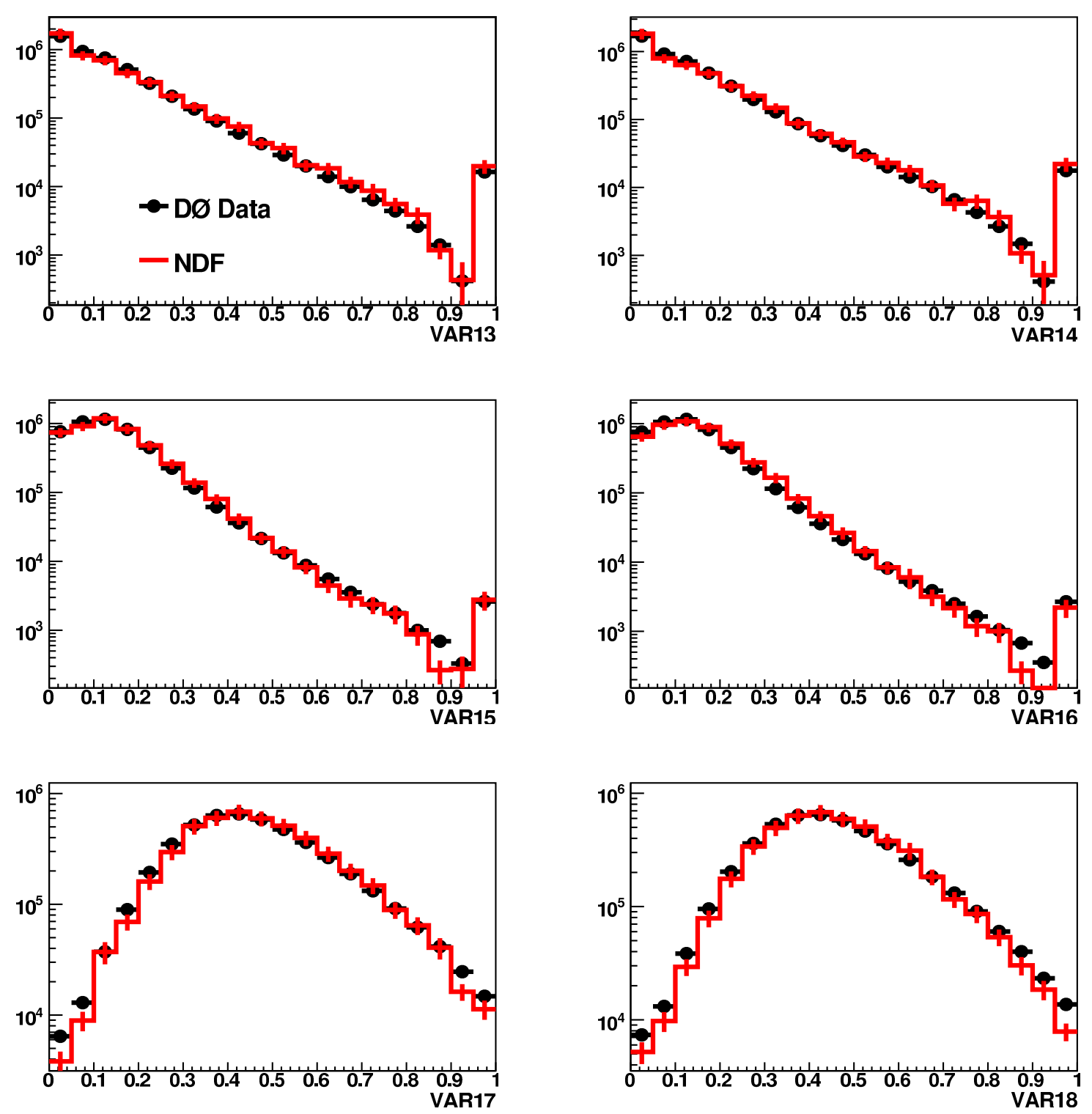

Figura 6.14: Distribuição das variáveis definidas na equação 6.9. 

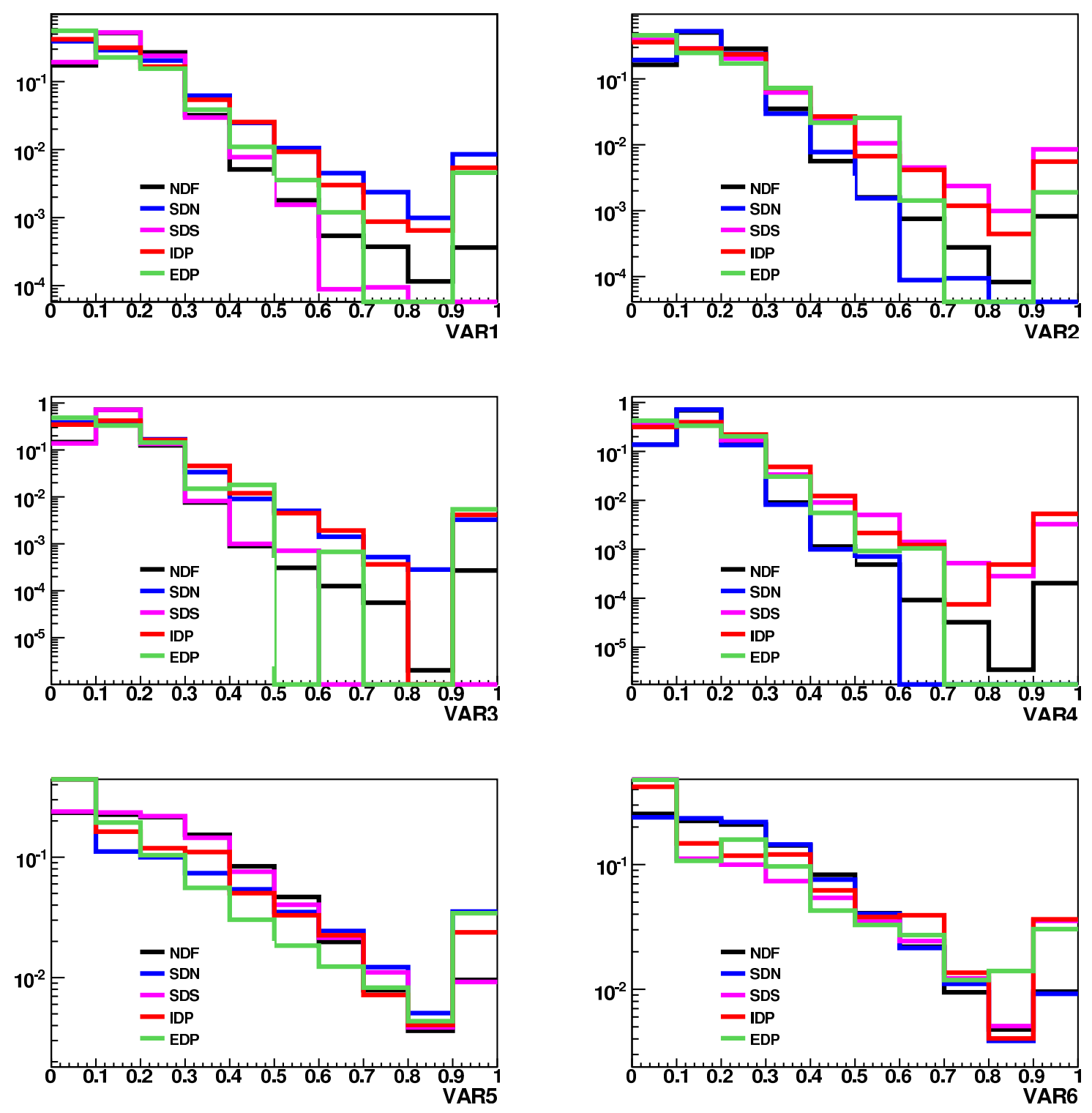

Figura 6.15: Distribuição das variáveis definidas na equação 6.9 para todos os modos de produção simulados. 

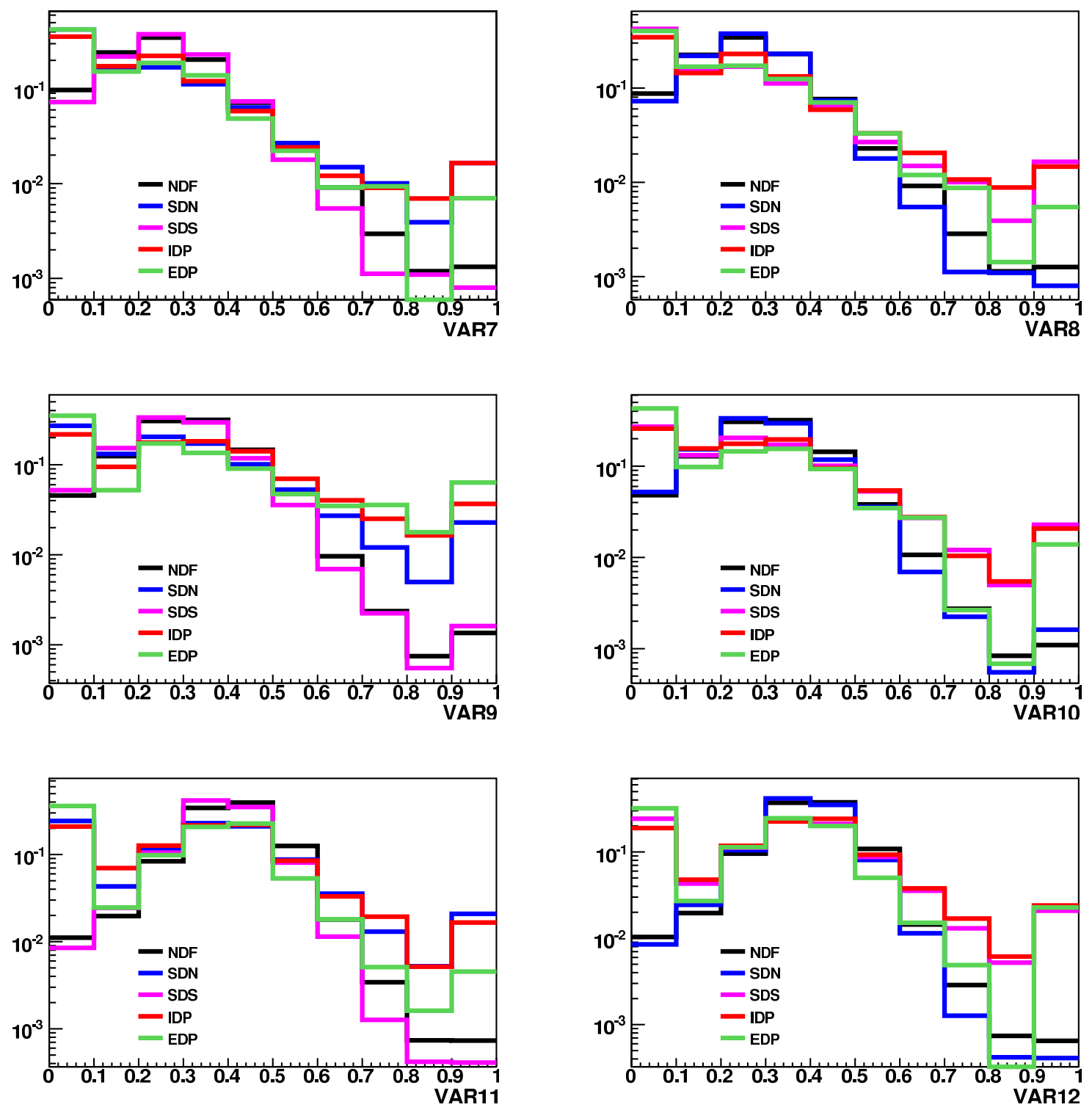

Figura 6.16: Distribuição das variáveis definidas na equação 6.9 para todos os modos de produção simulados. 

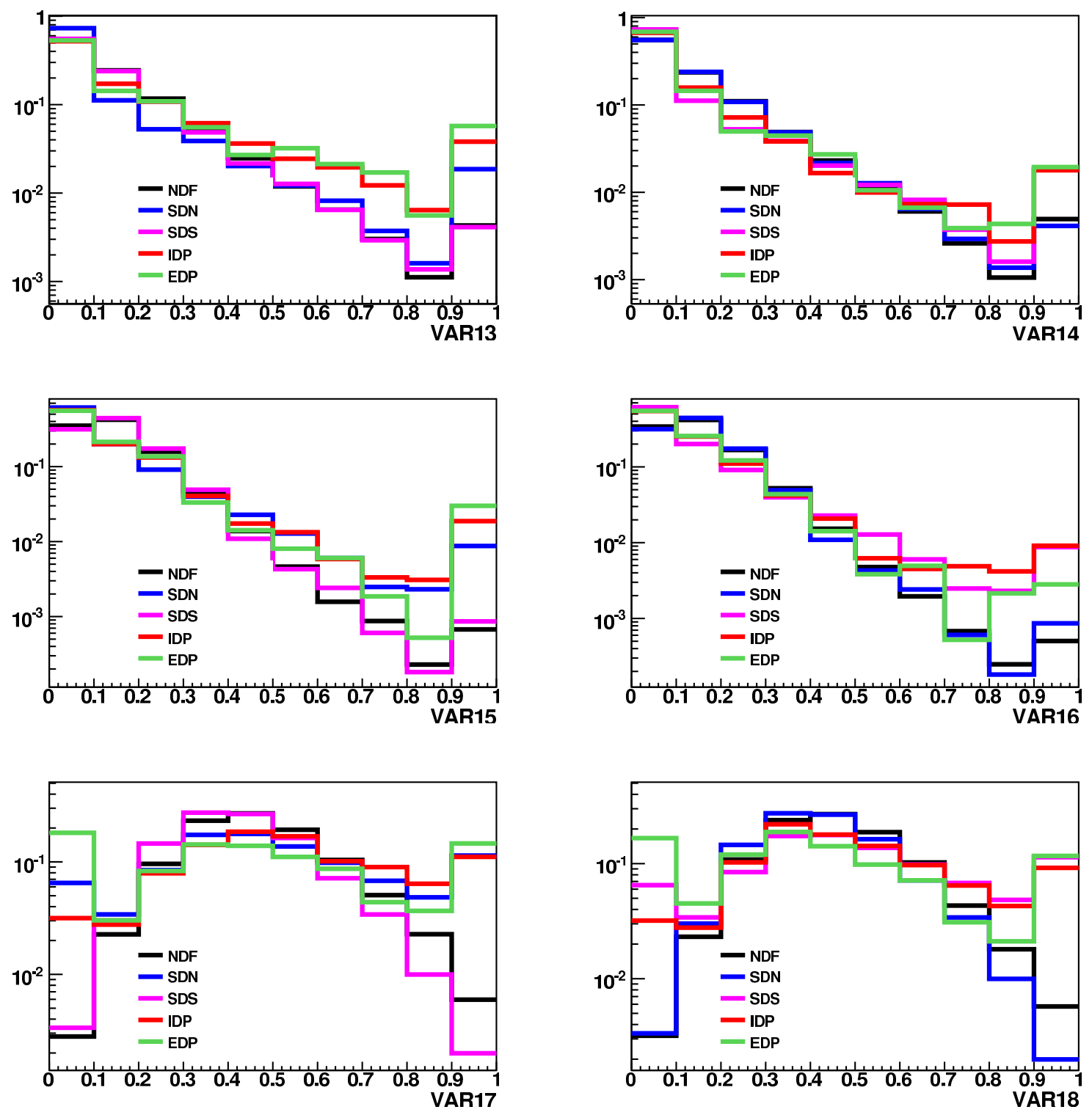

Figura 6.17: Distribuição das variáveis definidas na equação 6.9 para todos os modos de produção simulados. 


\subsection{Resultados}

Para determinar a contribuição de cada processo difrativo, seis cortes foram escolhidos de tal forma que esses apresentassem excessos dos dados sobre a simulação NDF (ver figura 6.18). Os cortes e excessos são mostrados na tabela 6.4 .

A variável $R_{j j}$ é definida como:

$$
R_{j j}=\frac{M_{j j}}{M_{X}}
$$

onde $M_{X}$ é a massa do total reconstruída pelo calorímetro, definida pela soma dos 4momenta das células com o os 4-momenta dos jatos.

Nota-se que, para eventos EDP, $R_{j j}$ deve ser próximo de 1.

\begin{tabular}{lccccc} 
Corte difrativo & Excesso & \multicolumn{1}{c}{$N_{S D N}$} & $N_{S D S}$ & $N_{I D P}$ & $N_{E D P}$ \\
\hline$l l(s d n / n d f)>0,8$ & $1127 \pm 312$ & $579 \pm 23$ & $1,9 \pm 1,1$ & $121 \pm 11$ & $369 \pm 19$ \\
$l l(s d s / n d f)>0,8$ & $1386 \pm 258$ & $1,9 \pm 1,1$ & $594 \pm 24$ & $139 \pm 11$ & $383 \pm 20$ \\
$l l(i d p / n d f)>0,9$ & $112 \pm 52$ & $4.4 \pm 1,7$ & $3.8 \pm 1.6$ & $180 \pm 15$ & $398 \pm 20$ \\
$l l(e d p / n d f)>0,95$ & $275 \pm 105$ & $12 \pm 3$ & $12 \pm 3$ & $227 \pm 16$ & $428 \pm 21$ \\
$l l(e d p / n d f)>0,95$ & $69 \pm 43$ & $4,6 \pm 1,8$ & $4,0 \pm 1,6$ & $96 \pm 9$ & $393 \pm 20$ \\
e $R_{j j}=[0,95 ; 1]$ & & & & & \\
$l l(e d p / n d f)>0,95$ & $133,4 \pm 51,3$ & $5,8 \pm 2,6$ & $3,5 \pm 2,2$ & $86,1 \pm 8,8$ & $21,1 \pm 4,4$ \\
e $R_{j j}=[0,9,0,95)$ & & & & &
\end{tabular}

Tabela 6.4: Número de eventos reais em excesso com relação à simulação NDF.

Após minimizar a seguinte função:

$$
\chi^{2}=N_{E X C}^{i}-\left(w_{S D N} \times N_{S D N}^{i}+w_{S D S} \times N_{S D S}^{i}+w_{I D P} \times N_{I D P}^{i}+w_{E D P} \times N_{E D P}^{i}\right)
$$

onde $N_{E X C}$ é o número de eventos em excesso. Usando os pontos mostrados na tabela 6.4, obtêm-se as razões difrativas expostas na tabela 6.5. Nota-se que o erro estatístico da simulação foi considerado no processo de minimização, porém, ao retirar sua contribuição, o resultado final não se altera, provando que o erro estatístico dos dados reais é a maior limitação desta análise.

\begin{tabular}{lrr} 
Produção Difrativa & peso & razão (\%) \\
\hline SDN & $1,82 \pm 0,55$ & $0,28 \pm 0,06$ \\
SDS & $2,17 \pm 0,45$ & $0,33 \pm 0,06$ \\
IDP & $0,72 \pm 0,22$ & $0,05 \pm 0,01$ \\
EDP & $0 \pm 0,1$ & $0 \pm 0,002$
\end{tabular}

Tabela 6.5: Razão entre eventos difrativos e eventos não difrativos medida através do método explicado no texto. 


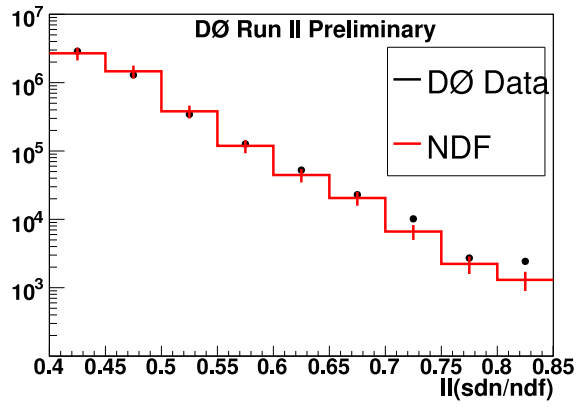

(a)

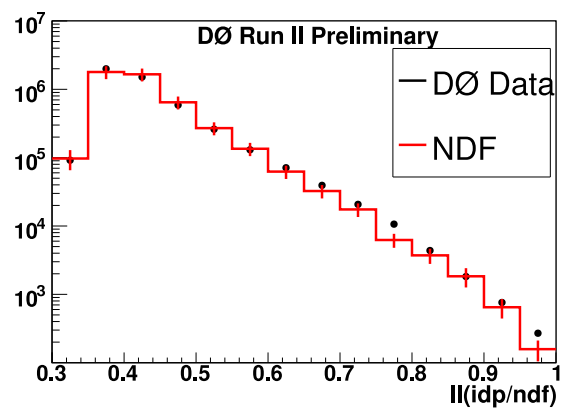

(c)

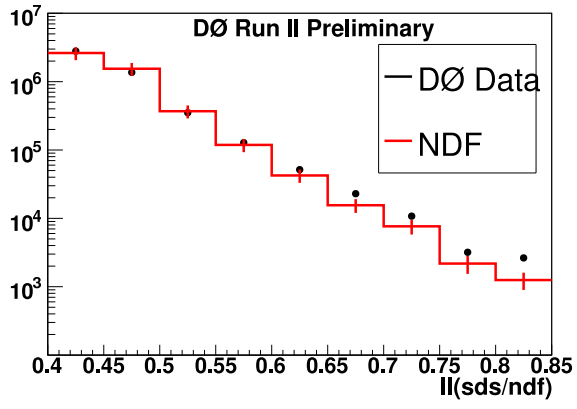

(b)

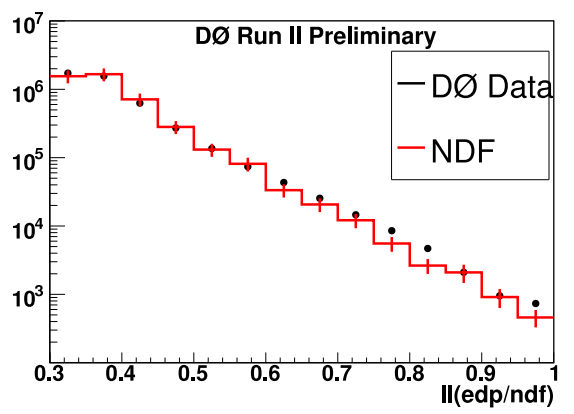

(d)

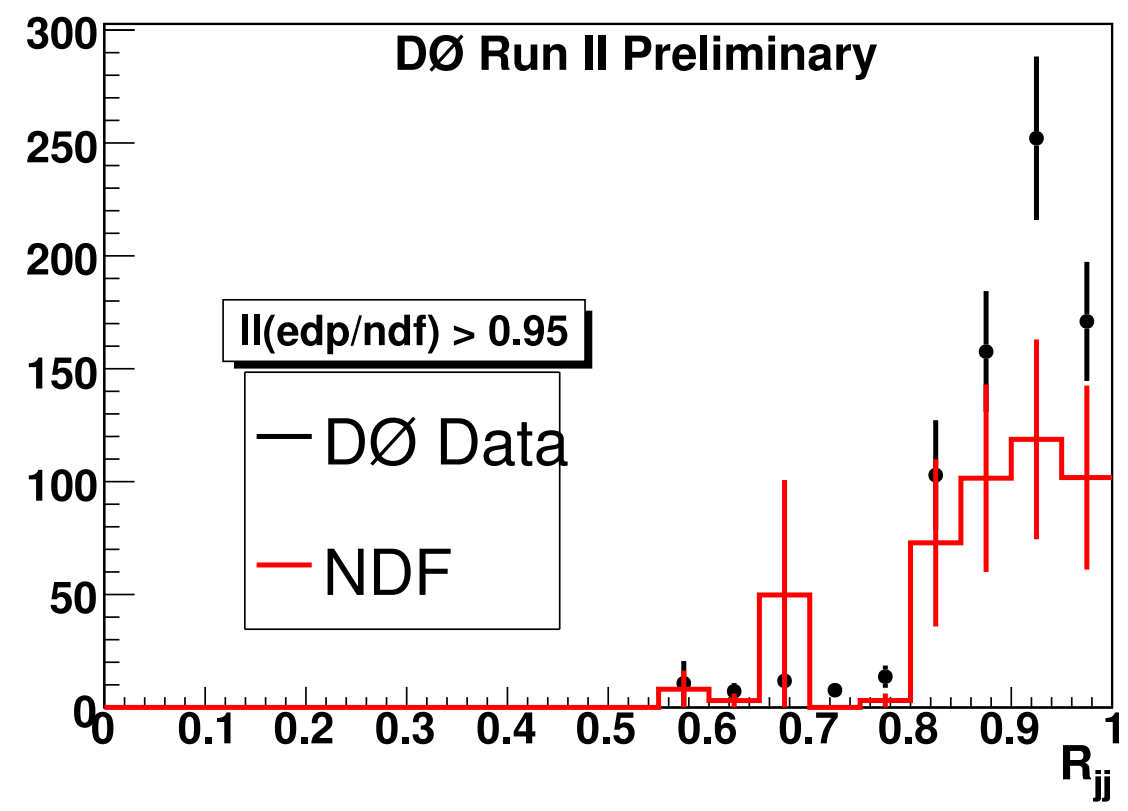

(e)

Figura 6.18: Distribuições do discriminante construído pelo método multivariável de verossimilhança para as quatro produções difrativas e a distribuição $R_{j j}$ depois do corte $l l(e d p / n d f)>0,95$. Apenas dados reais e a simulação NDF são mostrados.

Os resultados encontrados (ver tabela 6.5) são compatíveis com os esperados (ver tabela 6.3) e as distribuições dos discriminantes, após adição dos eventos difrativos, evi- 
denciam a boa comparação entre dados reais e eventos simulados (ver figura 6.19). Nota-se que a variável mostrada na figura 6.5 também apresenta boa concordância entre dados reais e simulação após a adição dos eventos difrativos simulados segundo os pesos encontrados nesta análise (ver figura 6.20).

Sendo a incerteza estatística dos dados dominante, acredita-se que erros sistemáticos não devam contribuir significativamente. De fato, duas fontes de erro sistemático foram estudadas: 1- incerteza nos fatores de calibração do calorímetro apresentados na seção 5.2; 2- incerteza na correção da energia dos jatos. Os resultados deste estudo encontram-se na tabela 6.6.

Com relação à calibração do calorímetro, as constantes de calibração foram deslocadas de $\pm 3 \sigma$, em que $\sigma$ representa os erros das constantes. Esse deslocamento altera a energia medida do calorímetro, porém, como as variáveis são baseadas em frações, esse erro sistemático deve ser pequeno.

Para a incerteza da correção da energia dos jatos, os fatores de correção foram deslocados de $\pm 1 \sigma_{J E S}$, em que $\sigma_{J E S}$ representa a incerteza na escala de energia dos jatos. Com isso, a flutuação de eventos para a seleção de jatos realizada pôde ser observada. Como as medidas realizadas são, de certa forma, pouco dependentes da energia dos jatos, espera-se também um pequeno erro sistemático para esse fonte.

\begin{tabular}{lccrr} 
Produção & -calib $(\%)$ & + calib $(\%)$ & -jes $(\%)$ & + jes $(\%)$ \\
Difrativa & & & & \\
\hline SDN & $0,27 \pm 0,06$ & $0,28 \pm 0,06$ & $0,30 \pm 0,06$ & $0,26 \pm 0,06$ \\
SDS & $0,33 \pm 0,06$ & $0,33 \pm 0,06$ & $0,33 \pm 0,06$ & $0,32 \pm 0,06$ \\
IDP & $0,04 \pm 0,01$ & $0,04 \pm 0,01$ & $0,07 \pm 0,01$ & $0,04 \pm 0,01$ \\
EDP & $0 \pm 0,004$ & $0 \pm 0,002$ & $0 \pm 0,006$ & $0 \pm 0,002$
\end{tabular}

Tabela 6.6: Razão entre o número de eventos difrativos e o número de eventos não difrativos após variar os fatores de calibração do calorímetro ( \pm calib) e os fatores de correção da energia dos jatos ( \pm jes).

Observa-se, na tabela 6.6, que os erros sistemáticos são, de fato, baixos. Na tabela 6.7, os resultados finais para as razões entre o número de eventos difrativos e não difrativos são apresentados. Os erros sistemáticos da calibração do calorímetro e da correção da energia dos jatos são somados em quadratura e considerados simétricos.

\begin{tabular}{lr} 
Produção Difrativa & Razão $(\%)$ \\
\hline SDN & $0,28 \pm 0,06 \pm 0,02$ \\
SDS & $0,33 \pm 0,06 \pm 0,01$ \\
IDP & $0,05 \pm 0,01 \pm 0,02$ \\
EDP & $0 \pm 0,002 \pm 0$
\end{tabular}

Tabela 6.7: Resultados finais: o primeiro erro é estatístico e o segundo, sistemático. 


\subsubsection{Limite para Produção Exclusiva de Dijatos}

Devido à falta de estatística nos dados obtidos pelo experimento $\mathrm{D} \varnothing$, a produção de eventos de dijato por dupla troca de pomeron exclusiva não pôde ser observada. Dos 4 eventos mais exclusivos da amostra (ver figura 6.20), 9,1 $\pm 1,9 \pm 1,6$ são explicados pelas produções NDF, SDN, SDS e especialmente IDP.

Pode-se, então, calcular um limite para a produção de eventos de dijato por dupla troca de pomeron exclusiva. Para isso, o método explicado no apêndice $\mathrm{C}$ foi usado e, com 95\% de nível de confiança, o limite superior para a razão entre o número de eventos EDP e o número de eventos NDF é:

$$
\frac{N_{E D P}}{N_{N D F}}<5,2 \times 10^{-6}
$$

excluindo os modelos BL e KMR, tendo em vista as previsões apresentadas na tabela 6.3.

A fim de confirmar esse resultado, medidas obtidas na tabela (6.7) foram utilizadas e uma nova variável discriminante foi definida $1 \mathrm{l}(\mathrm{edp} / \mathrm{bkg})$, tal que, bkg representa a soma de todos os ruídos conhecidos (NDF+SDN+SDS+IDP) propriamente normalizados. A variável $V A R_{E}$ foi também acrescentada no treino do discriminante de verossimilhança. Dessa forma, pode-se realizar um corte sensível à produção EDP ll(edp/bkg) $=[0,94 ; 0,96)$ (ver figura 6.21). Nesse caso, 2 eventos são identificados nos dados reais e 7,4 $\pm 2,4 \pm 1$ são previstos pelas fontes de ruído. Dessa forma, com 95\% de nível de confiança, o limite superior para a razão entre o número de eventos EDP e o número de eventos NDF é:

$$
\frac{N_{E D P}}{N_{N D F}}<7,5 \times 10^{-6}
$$

sendo compatível com o resultado anterior, reforçando a exclusão dos modelos BL e KMR. 


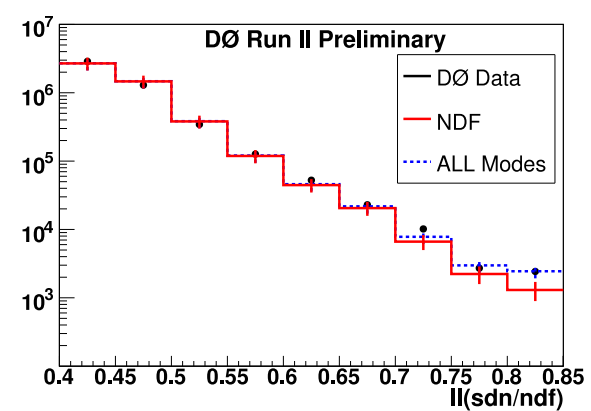

(a)

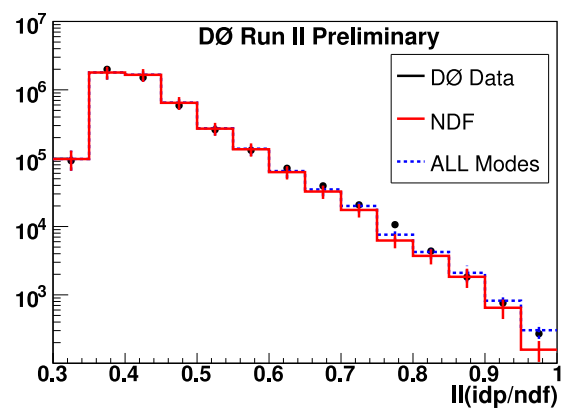

(c)

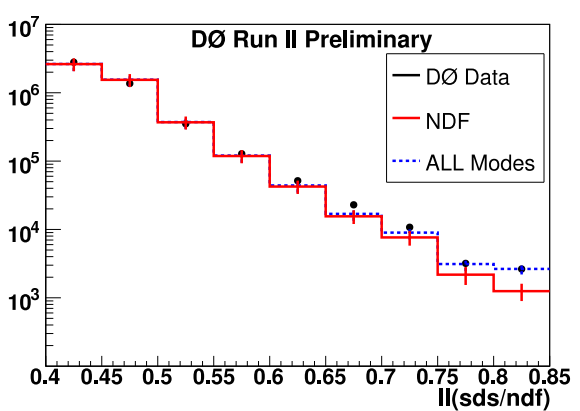

(b)

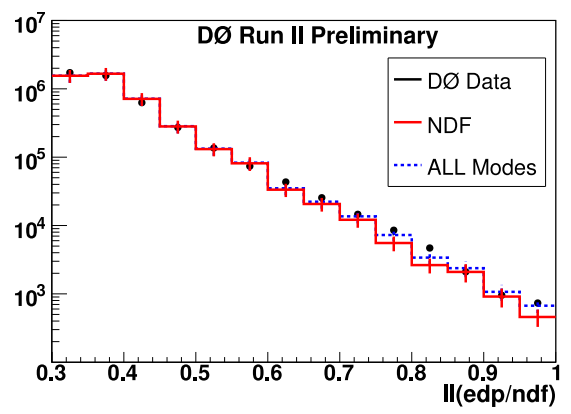

(d)

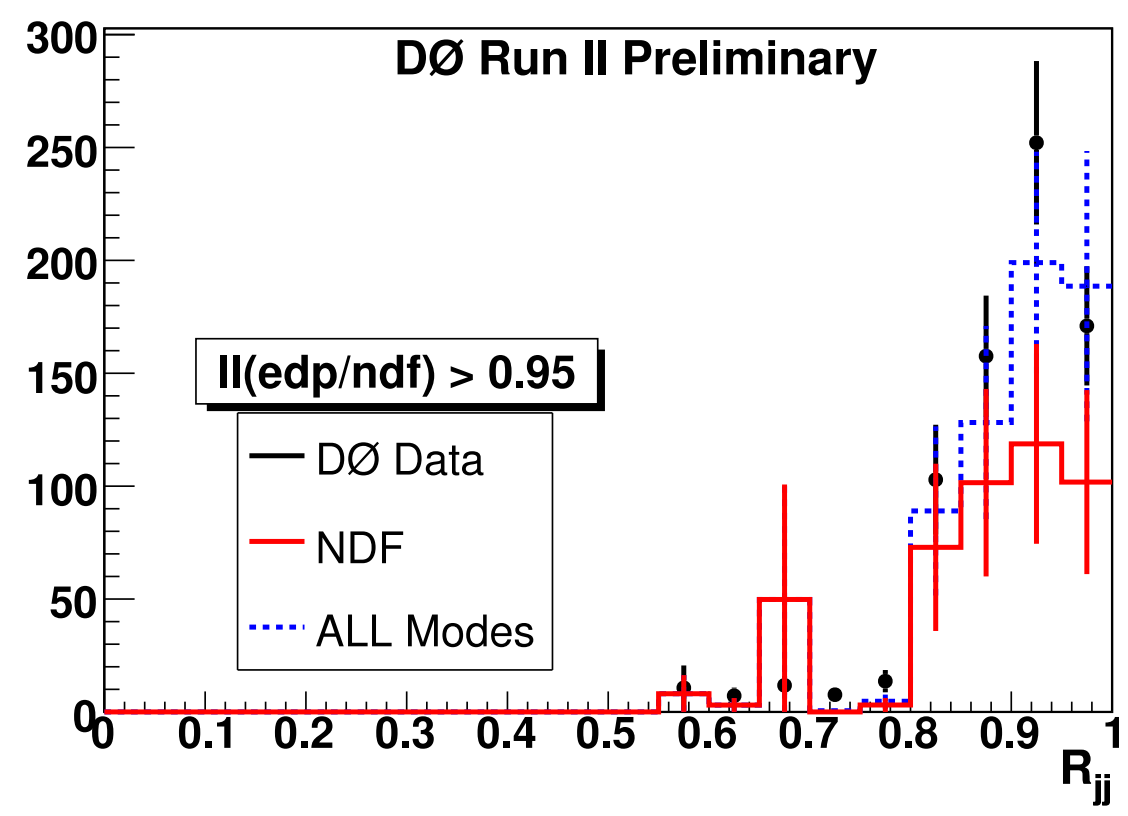

(e)

Figura 6.19: Distribuições do discriminante construído pelo método multivariável de verossimilhança para as quatro produções difrativas e a distribuição $R_{j j}$ depois do corte $l l(e d p / n d f)>0,95$. 


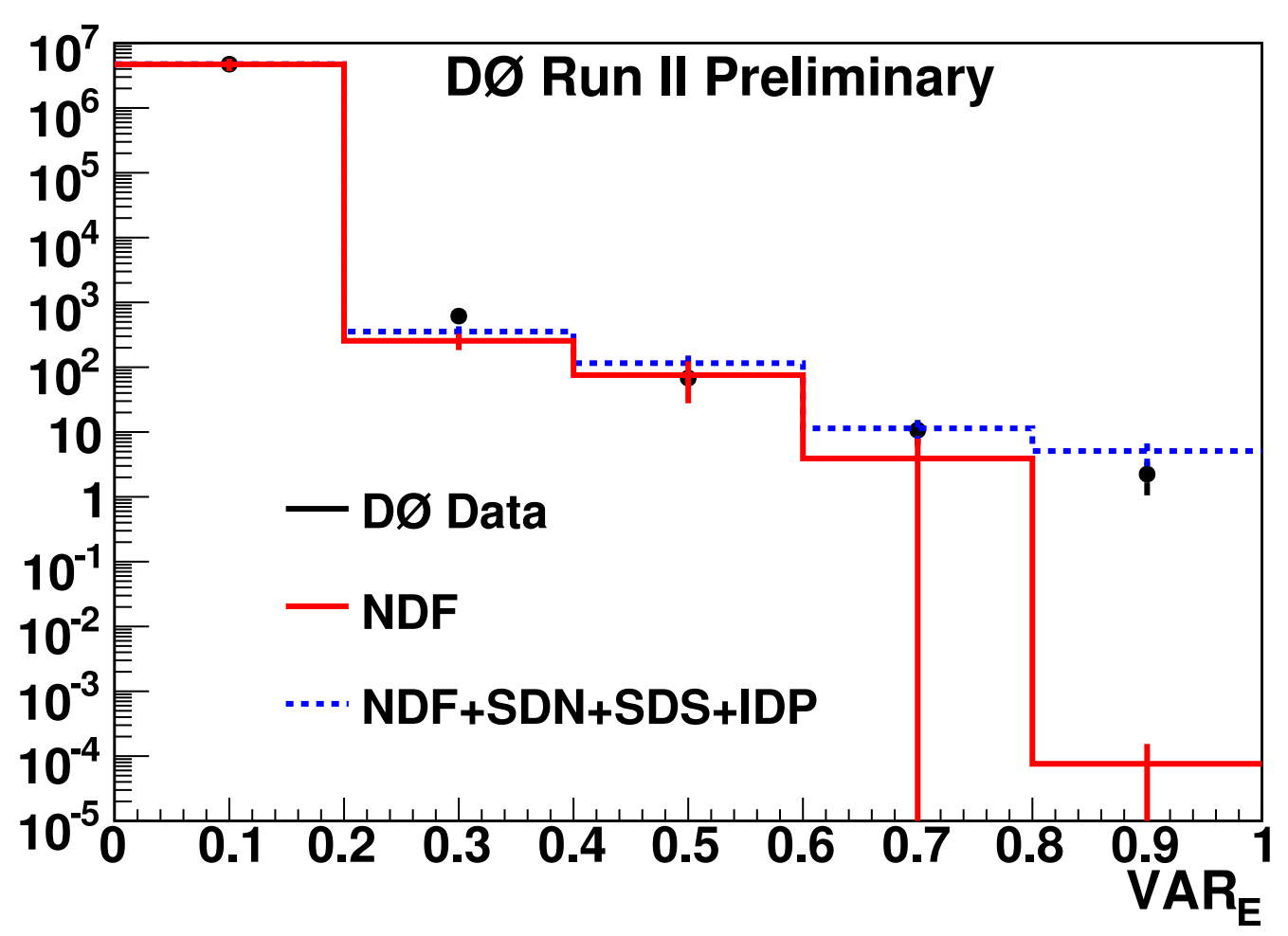

Figura 6.20: Variável da energia fora do sistema de dijato para dados reais e simulação, considerando todas as produções, exceto a EDP.

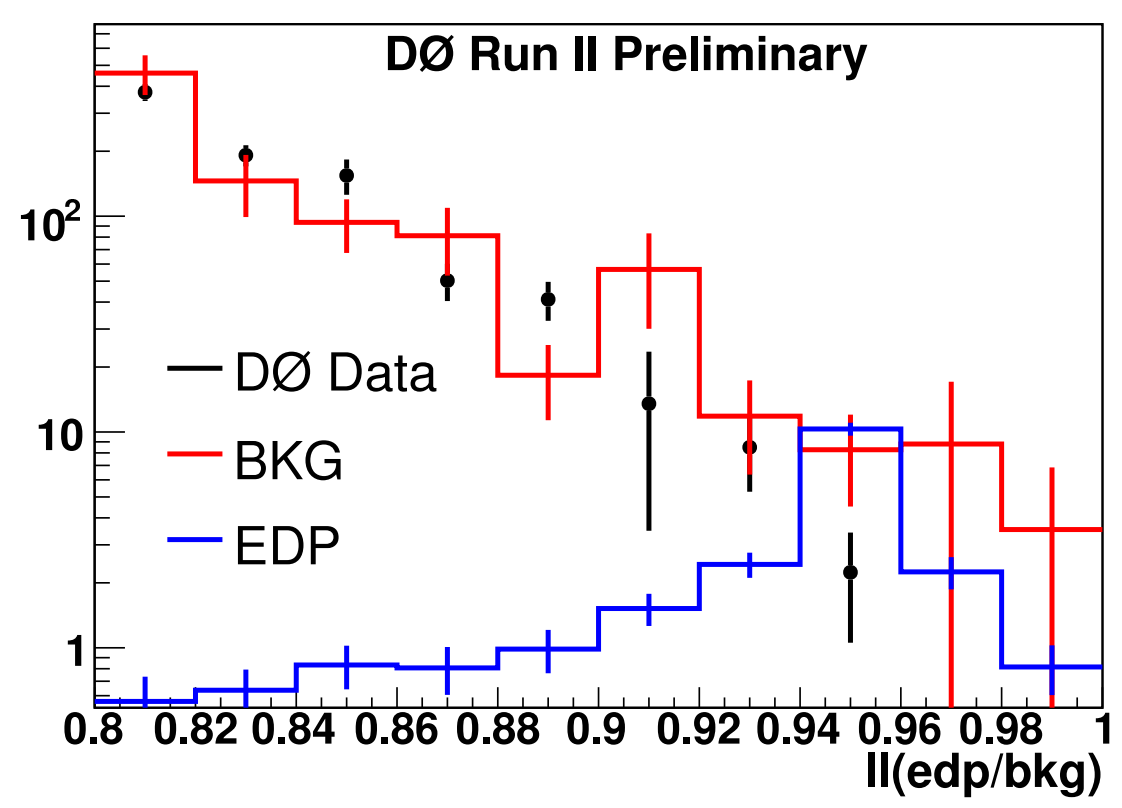

Figura 6.21: Distribuição do discriminante construído pelo método multivariável de verossimilhança considerando NDF, SDN, SDS e IDP como ruídos (BKG), e EDP como sinal, sendo esse normalizado pela seção de choque do modelo KMR. 


\section{Capítulo 7}

\section{Conclusões}

Nesta tese, um estudo de difração hadrônica com produção de dois jatos centrais no experimento D $\varnothing$ foi apresentado. Estudou-se a reconstrução e identificação de jatos no DØ e importantes contribuições para o experimento foram realizadas (ver capítulo 4). Estudando a calorimetria no $\mathrm{D} \varnothing$, verificou-se a necessidade de remover células calorimétricas problemáticas e calibrar o calorímetro simulado, como discutido no capítulo 5. Por fim, uma análise detalhada da produção difrativa com dois jatos centrais foi desenvolvida e executada, produzindo resultados em uma região cinemática nunca estudada anteriormente (ver capítulo 6).

De fato, uma busca por eventos com dois jatos centrais de alto $\mathrm{p}_{\mathrm{T}}$ produzidos exclusivamente em colisões próton-antipróton a $\sqrt{s}=1,96 \mathrm{TeV}$, utilizando dados do detector DØ foi realizada. Nenhum excesso compatível com a produção exclusiva foi observado, levando-se em conta a produção nos diversos modos conhecidos. Utilizando esse resultado, um limite superior para a razão entre o número de eventos de dupla troca de pomeron exclusiva e o número de eventos inelásticos é apresentado, validando apenas um dos três modelos propostos.

Dentro da sensibilidade experimental, pode-se interpretar esse resultado como uma indicação de que ambos os modelos BL e KMR prevêem uma dependência da seção de choque com relação ao $\mathrm{p}_{\mathrm{T}}$ dos jatos mais suave do que a observada, sendo que o modelo híbrido está de acordo com a observação. De certa forma, o modelo híbrido pode ser considerado uma versão melhorada do BL, portanto, é necessário compreender por que o modelo KMR apresenta uma seção de choque maior do que o limite estabelecido.

De acordo com os resultados apresentados nesta tese, as estimativas para a produção exclusiva de objetos massivos no LHC devem ser feitas utilizando-se o modelo híbrido ao invés do modelo KMR. Esses resultados encontram-se atualmente em revisão pela colaboração DØ, com o objetivo de apresentação pública em conferências e revistas indexadas.

Esta tese originou um importante resultado experimental na área da física difrativa, além de contribuições para outras análises experimentais, tendo dado origem a sete notas internas do experimento $\mathrm{D} \varnothing[51,76,78,80,88,90,95]$, dois artigos publicados $[47,83] \mathrm{e}$ 
um artigo submetido [45] em revistas indexadas. 


\section{Apêndice A}

\section{Melhoria da Resolução da Energia dos Jatos}

Um método para melhorar a resolução da energia dos jatos foi proposto e estudado como parte desta tese. Utiliza-se o detector CPS, detalhado na subseção 3.2.3, para aumentar a informação contida no jato calorimétrico e, portanto, reduzir as flutuações na medida da energia desse.

O primeiro passo é identificar a energia do jato depositada no detector CPS. Como esse detector possui três camadas de tiras, a primeira opção seria usar apenas aquelas que formem um ponto no espaço com o cruzamento das tiras dos outros dois planos. No entanto, foi observado, que para jatos de baixa energia $\left(p_{\mathrm{T}} \lesssim 40 \mathrm{GeV}\right)$, a eficiência dessa identificação é muito baixa [81].

Para resolver esse problema, mudou-se a identificação da energia do jato no detector CPS ao nível de tiras individuais, ou seja, se uma tira do detector cruza o cone do jato em questão, a energia depositada nessa será usada na melhoria da resolução. Essa iden-

tificação baseou-se no cálculo da distância $\Delta R=\sqrt{\Delta \varphi^{2}+\Delta \eta^{2}}$ entre reta definida pela tira no espaço $\eta-\varphi$ e o centro do cone do jato. A tira é considerada se $\Delta R<R_{\text {cone }}$, onde $R_{\text {cone }}$ é o raio do algorítmo usado para a reconstrução do jato. Pode-se ver que essa identificação funciona (ver figura A.1), já que a distribuição de $\Delta R$ apresenta duas regiões de pico como esperado. A região para $\Delta R \sim 0$ é identificada com o jato em questão, e a região em $\Delta \sim \pi$ representa o objeto que contrabalança o momentum transverso do evento.

Para melhorar a resolução da energia dos jatos é preciso diminuir a flutuação nesta medida, acrescentando-se informações sobre o jato, nesse caso, a energia do detector CPS. Além de melhorar a resolução da energia dos jatos calorimétricos, não é desejado que se mudem os fatores de correção da energia (ver seção 4.3). Dessa forma, a seguinte energia melhorada é proposta: 
Eventos de dijato para $R_{\text {cone }}=0,5$ - MC (esquerda) and DADOS (direita)
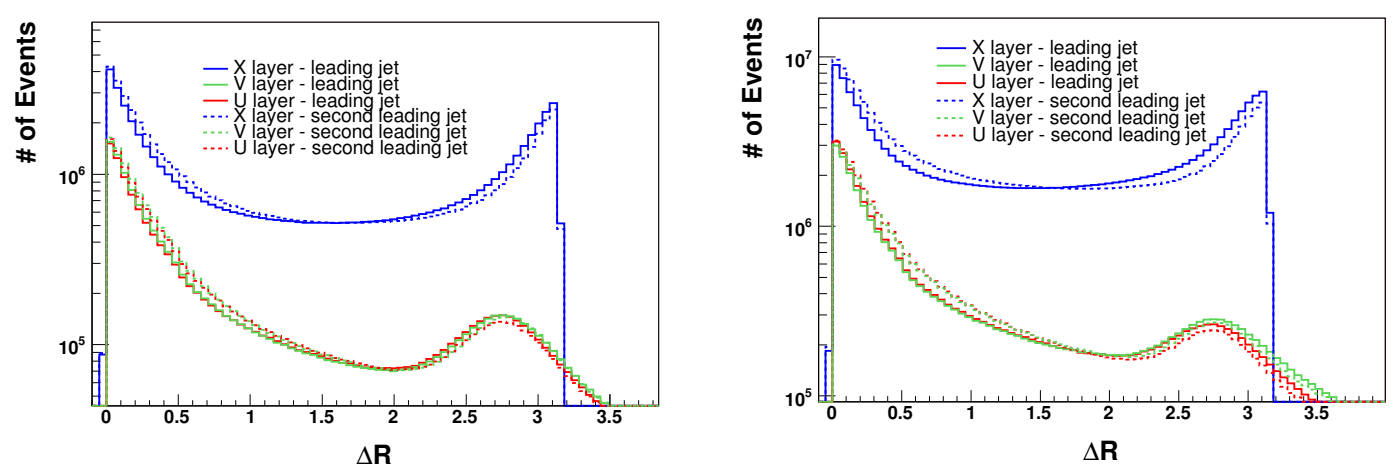

Eventos de fóton+jet para $R_{\text {cone }}=0,7-\mathrm{MC}$ (esquerda) and DADOS (direita)
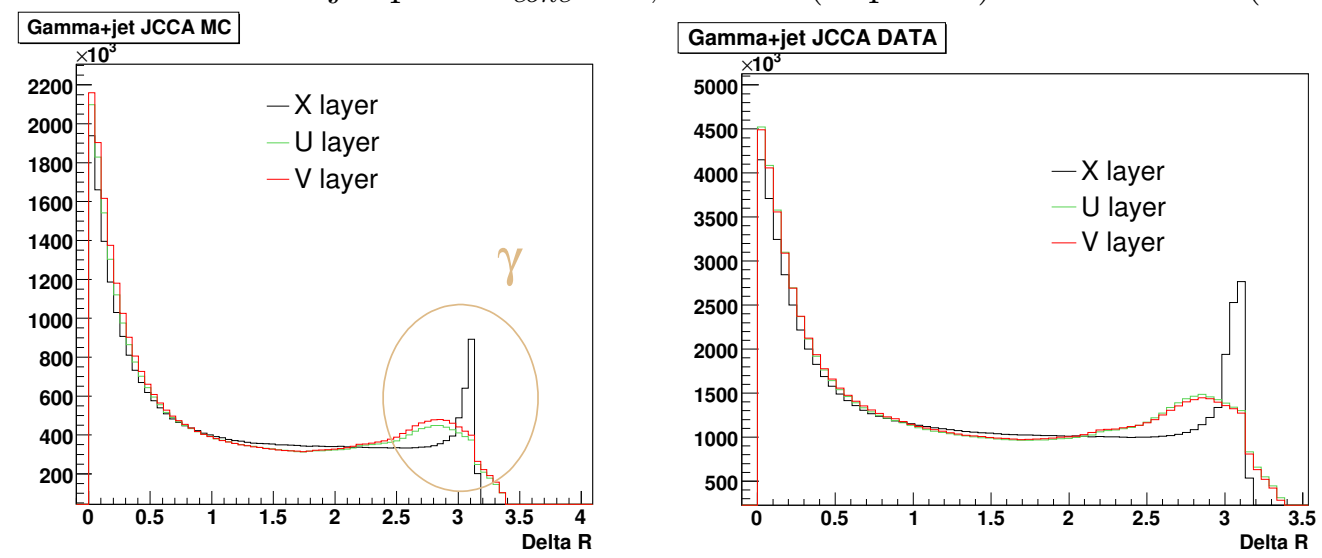

Figura A.1: Distância mínima entre a reta formada por uma tira do detector CPS e o centro do cone do jato

$$
E_{J E S+C P S}=\operatorname{kjes} \frac{E_{C A L O}+\alpha E_{C P S}}{1+\alpha<E_{C P S}>/<E_{C A L O}>},
$$

onde kjes é fator de correção da energia do jato calorimétrico (ver seção 4.3), $E_{C A L O}$ é a energia não corrigida do jato calorimétrico, $E_{C P S}$ é a energia depositada no detector CPS identificada com o jato, o operador $<>$ representa a média das variáveis, e $\alpha$ é uma constante que maximiza a melhoria da energia do jato. De fato, $\alpha$ é um parâmetro livre desse método, sendo seu valor definido pela maximização da melhoria da resolução da energia do jato.

Nota-se que $<E_{C P S}>/<E_{C A L O}>\equiv f_{C P S}$ precisa ser medida a priori. De fato, essa função pode depender de várias características do jato, mas, em primeira ordem, apenas são consideradas as dependências com a pseudorapidez e energia dos jatos.

A função $f_{C P S}$ foi medida em diferentes regiões de pseudorapidez nas coordenadas do detector $(0-0,4 ; 0,4-0,8 ; 0,8-1,0 ; 1,0-1,2$ e 1,2-1,4) e, para cada região, a dependência com a energia foi ajustada com a função:

$$
f_{C P S}(x)=a+b \log (x)+c \log ^{2}(x),
$$


onde $x=<E_{J E S}>/ \cosh \left(\eta_{b i n}\right),<E_{J E S}>$ é medido para diferentes regiões de energia como descrito a seguir e $\eta_{b i n}$ é uma constante definida para diferentes regiões de pseudorapidez (ver tabela A.1) usada para que $x$ esteja na mesma escala para diferentes regiões de pseudorapidez.

\begin{tabular}{|c|c|}
\hline Região de Pseudorapidez & $\eta_{\text {bin }}$ \\
\hline $0-0,4$ & 0,2 \\
$0,4-0,8$ & 0,6 \\
$0,8-1,0$ & 0,9 \\
$1,0-1,2$ & 1,1 \\
$1,2-1,4$ & 1,3 \\
\hline
\end{tabular}

Tabela A.1: Valores usados para $\eta_{b i n}$

Nota-se que a pseudorapidez estudada é limitada pela geometria do detector e que as regiões mais frontais são mais segmentadas, pois espera-se maior dependência com a pseudorapidez na região do ICD $(0,8<|\eta|<1,4)$. Tal região é muito prejudicada pelos problemas instrumentais explicados na subseção 3.2.3.

Como primeiro resultado, deve-se mostrar que é possível melhorar a resolução da energia do jato na simulação. Para isso, uma amostra de fóton+jato foi usada com a seleção sugerida pelo experimento D $\varnothing$. A resolução nesse caso é medida como:

$$
R_{J E S, C P S}=R M S\left(\frac{E_{J E S, J E S+C P S}}{E_{p t c l}}\right) /<\frac{E_{J E S, J E S+C P S}}{E_{p t c l}}>
$$

onde $E_{p t c l}$ é a energia do jato ao nível de partículas, medida usando o algorítmo de reconstrução com as partículas geradas e a função $R M S(x)$ retorna o desvio padrão da variável $x$.

Os eventos são separados em regiões de $E_{p t c l}$, onde o valor de $\left\langle E_{J E S}>\right.$ é medido. Dessa forma, pode-se ajustar a função A.2 com os pontos medidos como mostra a Fig. A.2. Também pode-se estimar a melhoria da resolução, calculando a razão $R_{C P S} / R_{J E S}$ (ver Fig. A.3).

A resolução definida pela equação A.3 só pode ser utilizada na simulação, pois precisa da energia das partículas, porém, pode-se estimar a energia do jato de partículas como

$$
E^{\prime}=E_{T}^{\gamma} \times \cosh \left(\eta_{j}\right)
$$

onde $E_{T}^{\gamma}$ é a energia transversa do fóton e $\eta_{j}$ a pseudorapidez do jato.

Usando $E^{\prime}$ ao invés de $E_{p t c l}$, obtém-se o ajuste de $f_{C P S}$ mostrado na Fig. A.4 e as melhorias para resolução da energia do jato na Fig. A.5. Nota-se que a melhoria na energia dos jatos é confirmada se $E^{\prime}$ é usado ao invés de $E_{p t c l}$, comprovando que $E^{\prime}$ pode ser usado no estudo com dados reais. 


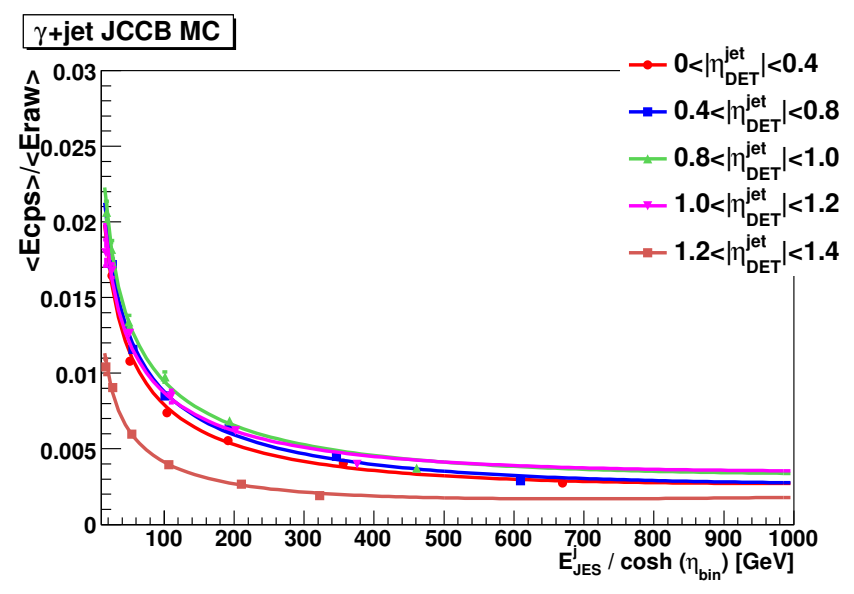

Figura A.2: Ajuste da função $f_{C P S}$ para eventos simulados de fóton+jato com jatos reconstruídos com cone $\Delta R=0,5$.

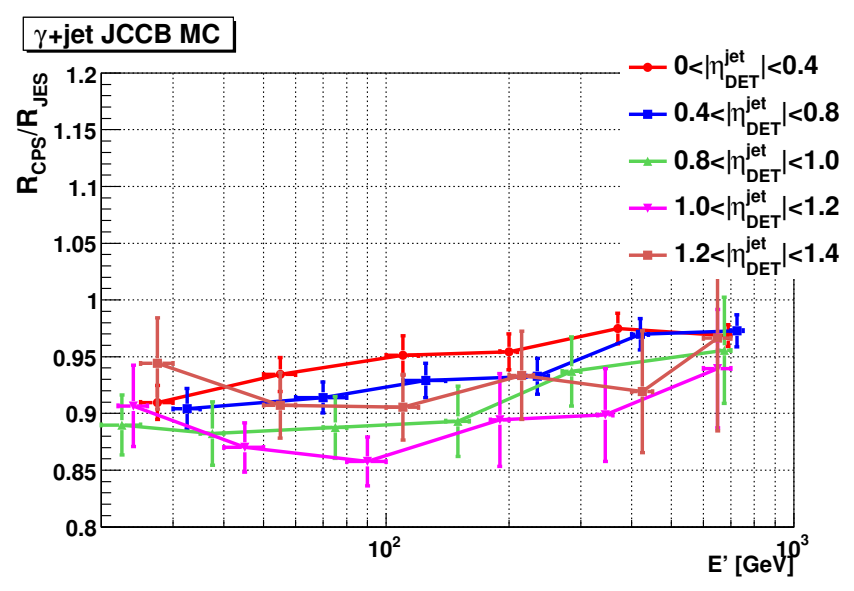

Figura A.3: Melhoria na resolução da energia do jato para eventos simulados de fóton + jato com jatos reconstruídos com cone $\Delta R=0,5\left(E^{\prime}=E_{p t c l}\right)$.

$\mathrm{Na}$ amostra de dados de fóton+jato, o mesmo procedimento é realizado. Como o calorímetro pode conter efeitos diferentes para pseudorapidez negativas e positivas, cada lado é tratado separadamente nos dados. O ajuste para $f_{C P S}$ é mostrado na Fig. A.6 e as melhorias da resolução da energia do jato na Fig. A.7.

Porém, para aplicar em eventos com produção do bóson de Higgs decaindo em $b \bar{b}$, a função $f_{C P S}$ ajustada para eventos de fóton+jato não é compatível (ver Fig. A.8). Por outro lado, eventos de dijato reproduzem a função $f_{C P S}$ para produção de dois quarks b em todas regiões de pseudorapidez (ver Figs. A.9 e A.10).

No caso de eventos de dijato, ao invés de se dividir os eventos em regiões de $E^{\prime}$, divide-se em regiões da varíavel

$$
p_{T}^{A}=\frac{p_{T}^{j 1}+p_{T}^{j 2}}{2}
$$




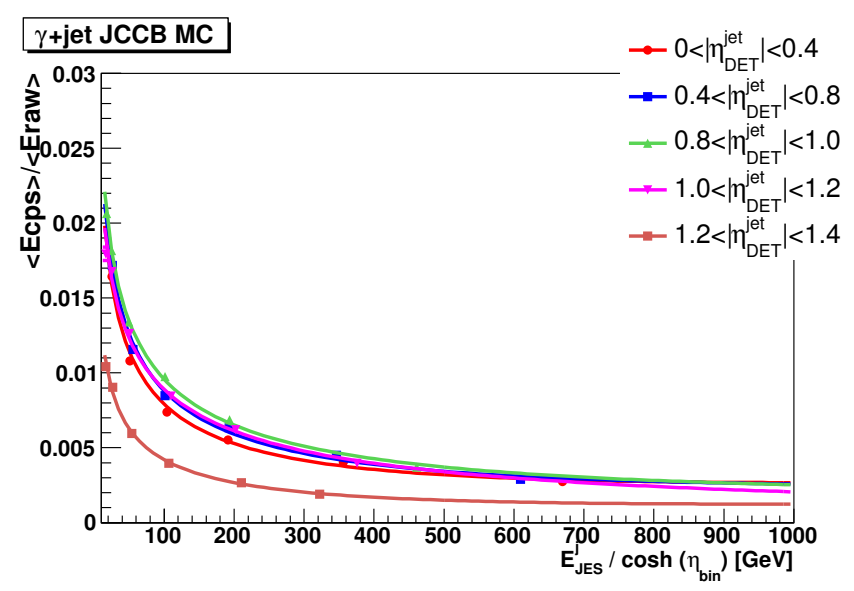

Figura A.4: Ajuste da função $f_{C P S}$ para eventos simulados de fóton+jato com jatos reconstruídos com cone $\Delta R=0,5$ usando $E^{\prime}$ ao invés de $E_{p t c l}$.

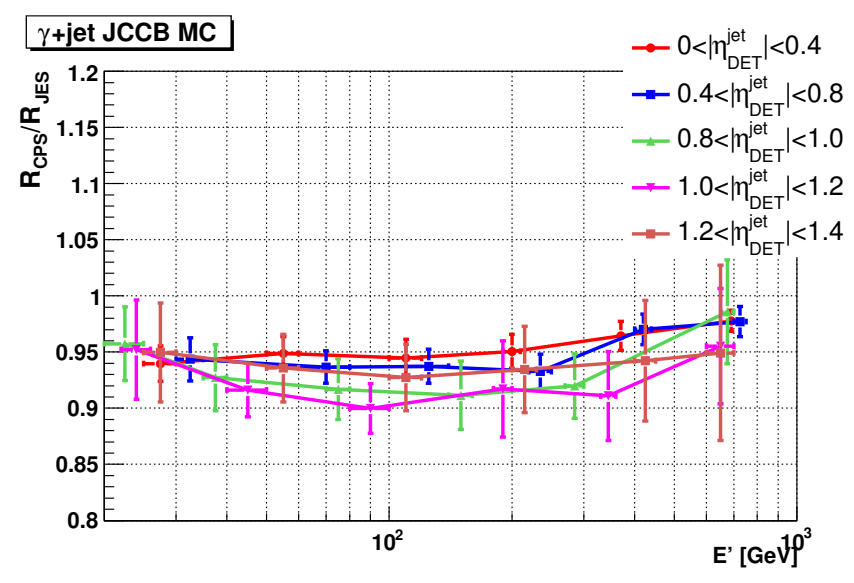

Figura A.5: Melhoria na resolução da energia do jato para eventos simulados de fóton + jato com jatos reconstruídos com cone $\Delta R=0,5$.
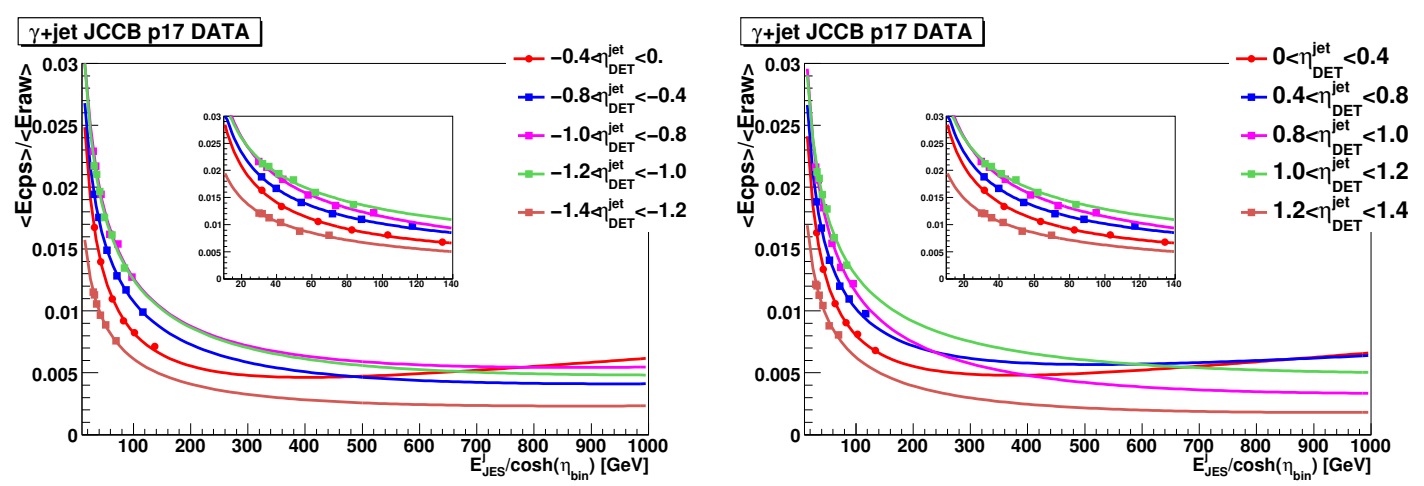

Figura A.6: Ajuste da função $f_{C P S}$ para eventos reais de fóton+jato com jatos reconstruídos com cone $\Delta R=0,5$. 

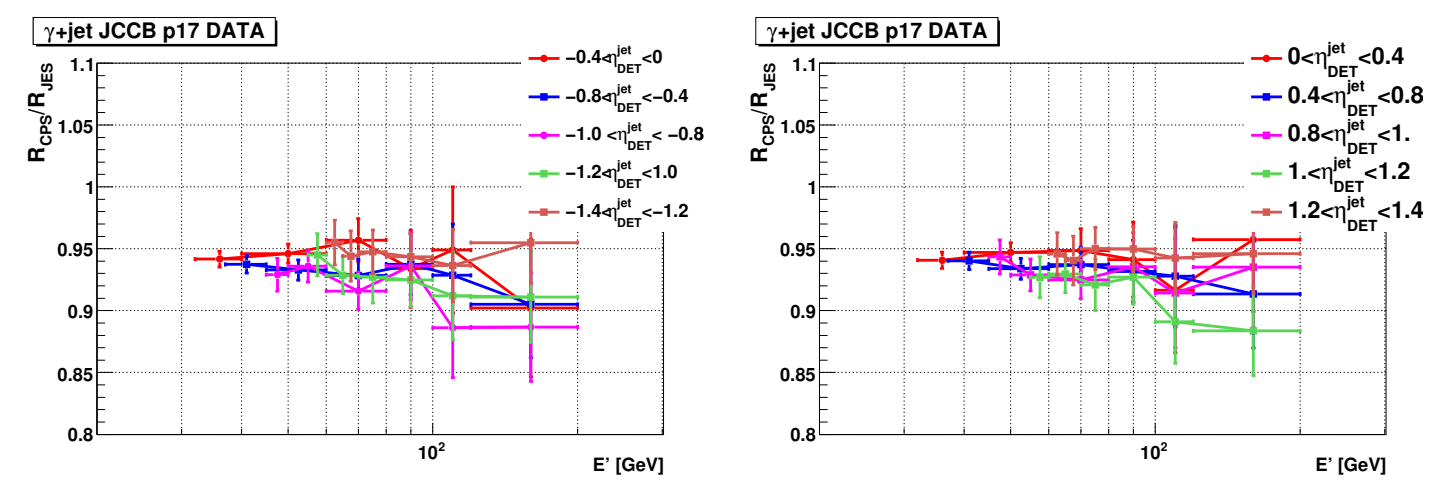

Figura A.7: Melhoria na resolução da energia do jato para eventos reais de fóton + jato com jatos reconstruídos com cone $\Delta R=0,5$.

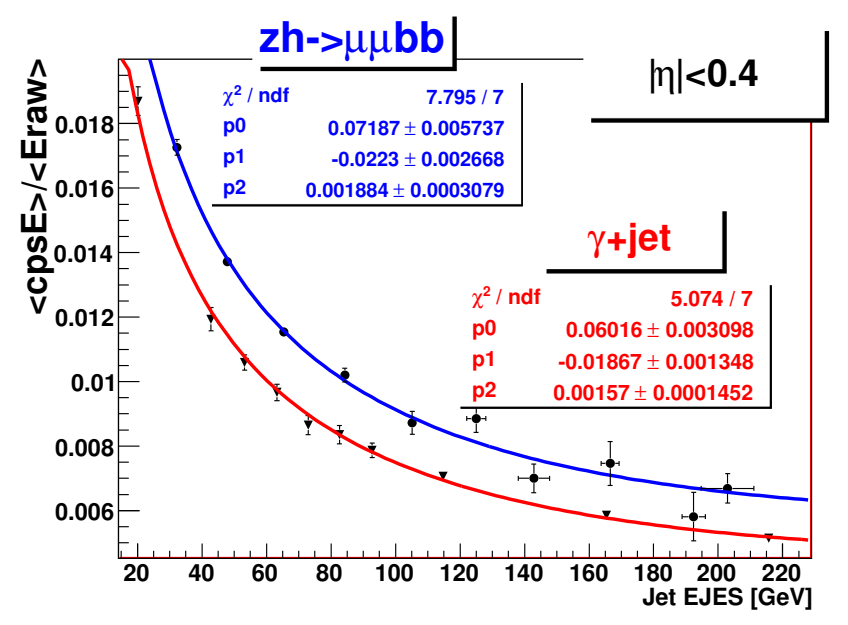

Figura A.8: Comparação das funções $f_{C P S}$ para eventos simulados de fóton+jato e produção de Higgs para jatos centrais reconstruídos com cone $\Delta R=0,5$.

onde $p_{T}^{j 1}$ é o momentum transverso do jato de maior energia e $p_{T}^{j 2}$ o de segunda maior energia.

As funções ajustadas para eventos simulados de dijato são, portanto, propostas para serem usadas em eventos selecionados na busca do bóson de Higgs. Ainda existe uma discussão sobre qual algorítmo de reconstrução usar nas análises de Higgs, portanto, foram ajustadas funções $f_{C P S}$ para ambos $\Delta R=0,5$ e $\Delta R=0,7$ eventos simulados e reais. (ver Fig. A.15, A.16, A.17 e A.18). Nota-se que para todos os casos, houve uma melhoria na resolução da energia de 5 a $10 \%$ (ver Fig. A.15, A.16, A.17 e A.18).

Um último estudo realizado foi a extrapolação das funções $f_{C P S}$ de dados tomados antes Fevereiro de 2006 ( $R$ un IIa ou p17) para dados tomados depois de Junho de 2006 ( Run IIb ou p20), já que o calorímetro sofreu alterações para o Run IIb. Eventos de dijato não estavam disponíveis até a finalização do estudo, portanto, eventos de fóton+jato foram usados, supondo que as diferenças sejam as mesmas. Elas podem ser vistas na Fig. A.19. 

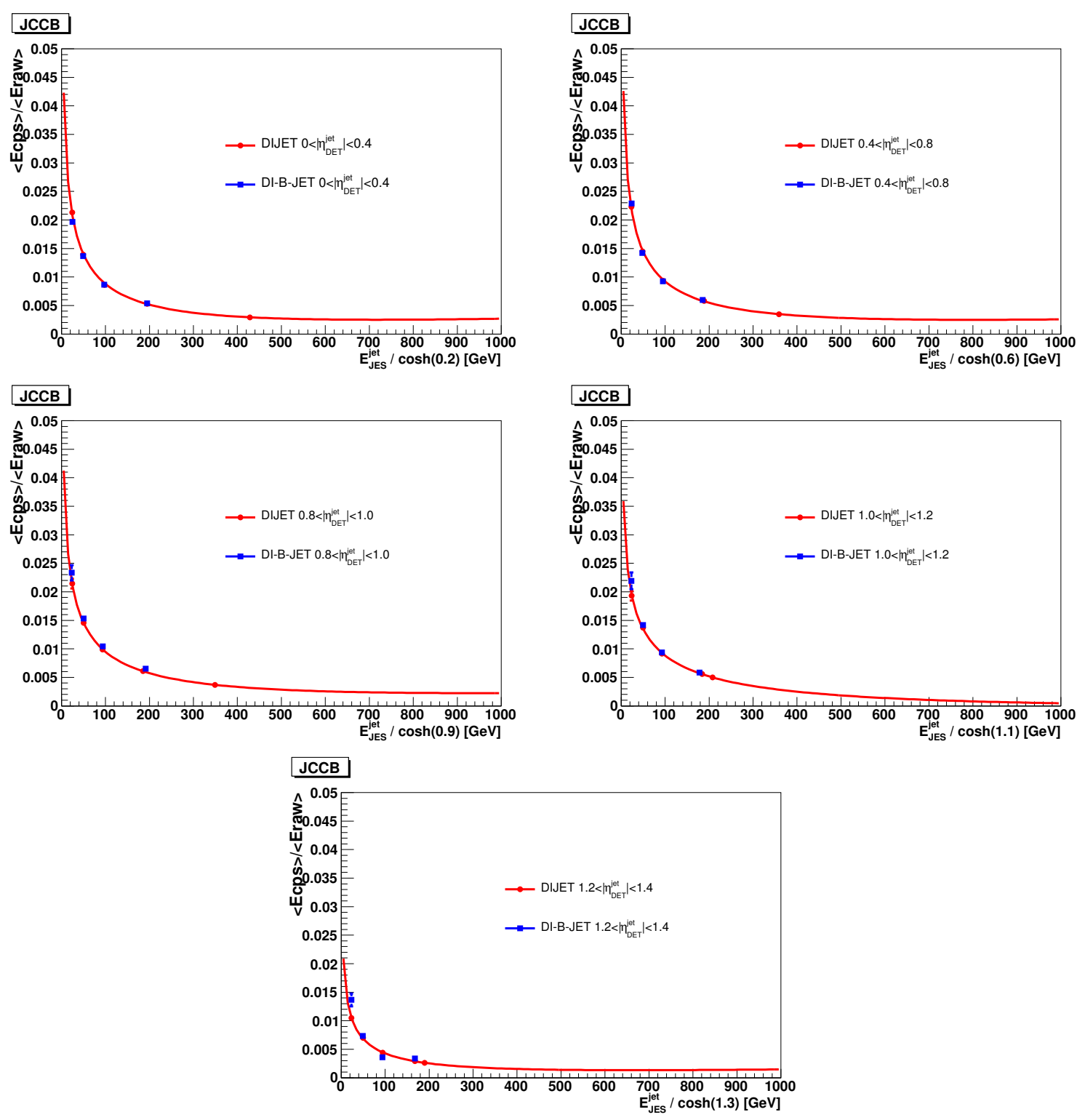

Figura A.9: Comparação das funções $f_{C P S}$ para eventos simulados de dijato e de produção de dois quarks b para jatos centrais reconstruídos com cone $\Delta R=0,5$.

na forma de um fator de escala ajustado para cada região de pseudorapidez.

Finalmente, todos os resultados desse estudo foram codificados num algorítmo que atualmente está sendo testado pela colaboração DØ [80]. 

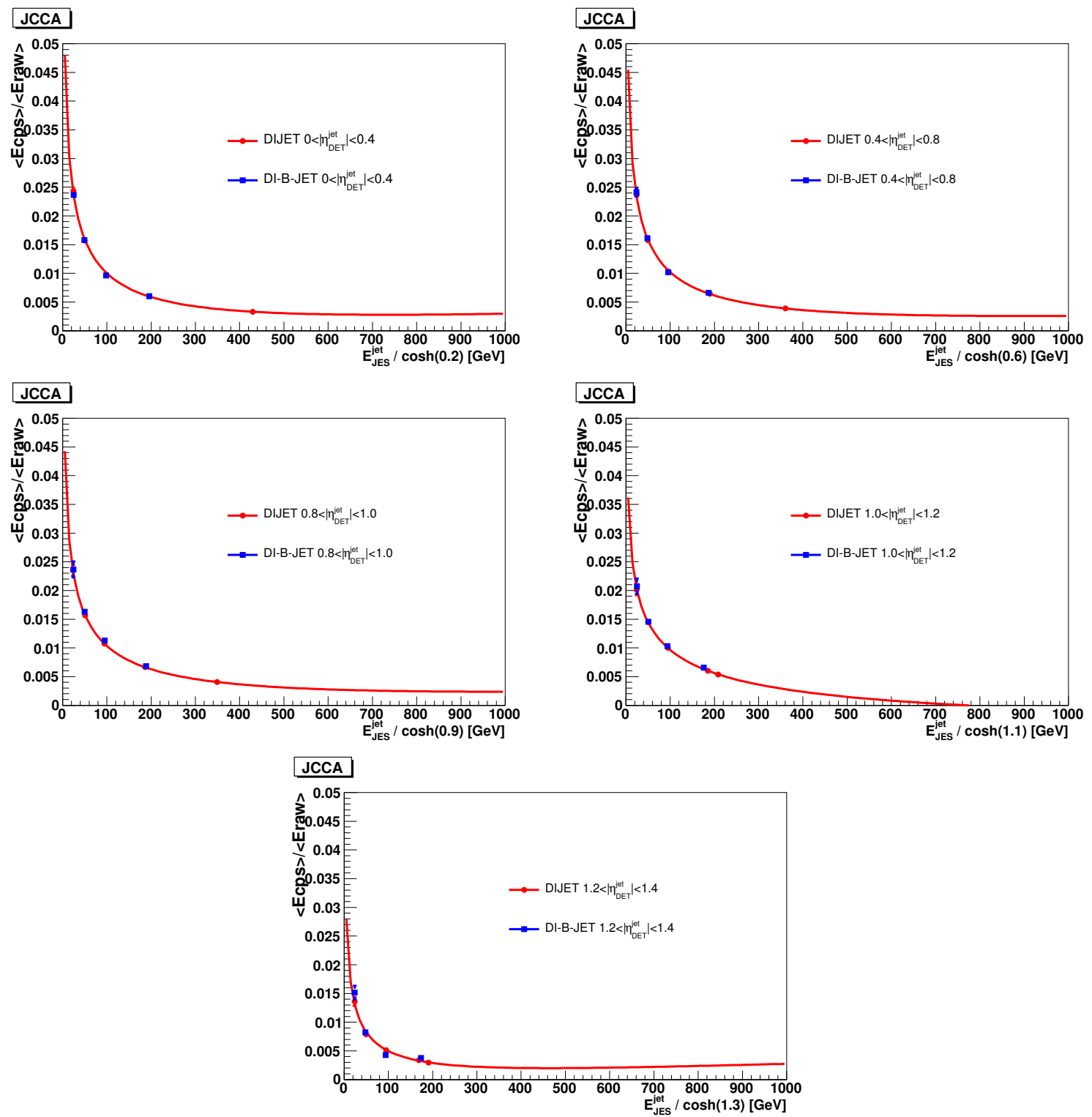

Figura A.10: Comparação das funções $f_{C P S}$ para eventos simulados de dijato e produção de dois quarks b para jatos centrais reconstruídos com cone $\Delta R=0,7$. 


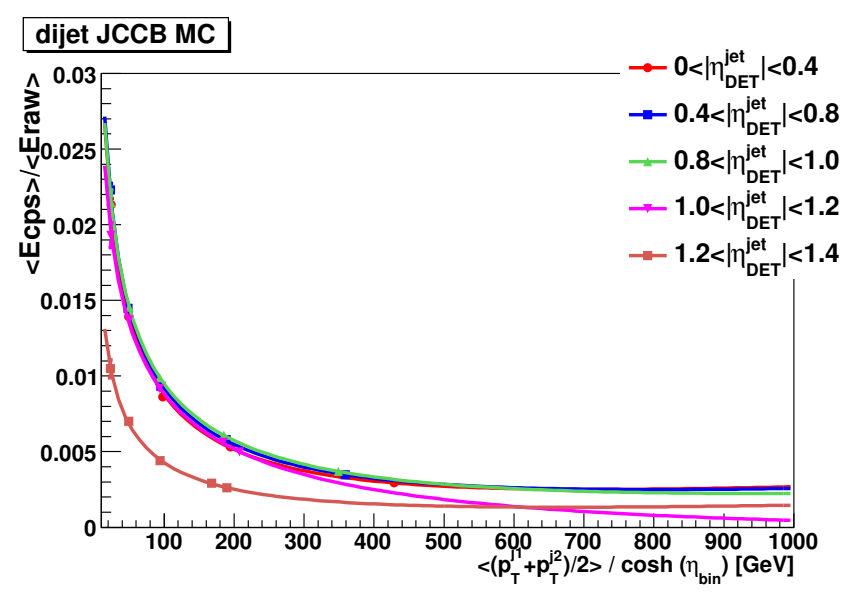

Figura A.11: Ajuste da função $f_{C P S}$ para eventos simulados de dijato com jatos reconstruídos com cone $\Delta R=0,5$.

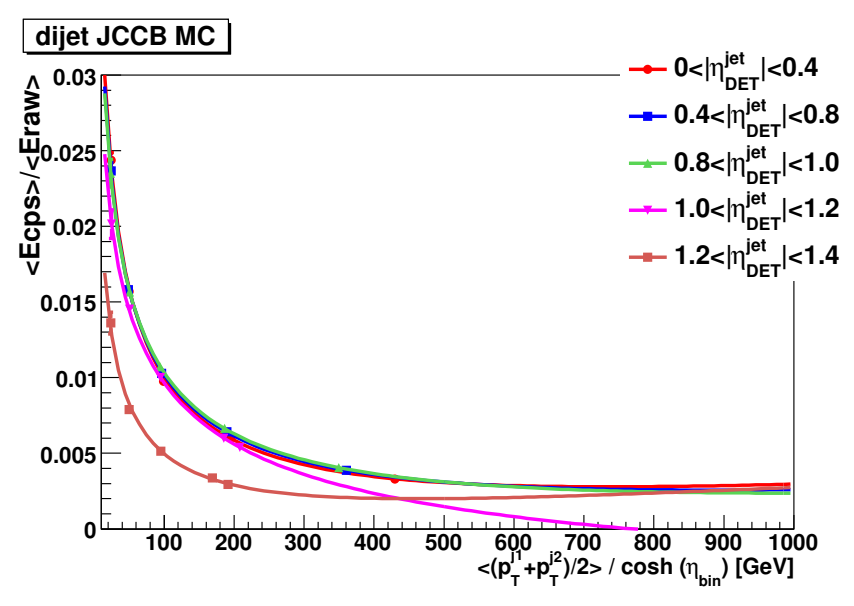

Figura A.12: Ajuste da função $f_{C P S}$ para eventos simulados de dijato com jatos reconstruídos com cone $\Delta R=0,7$.
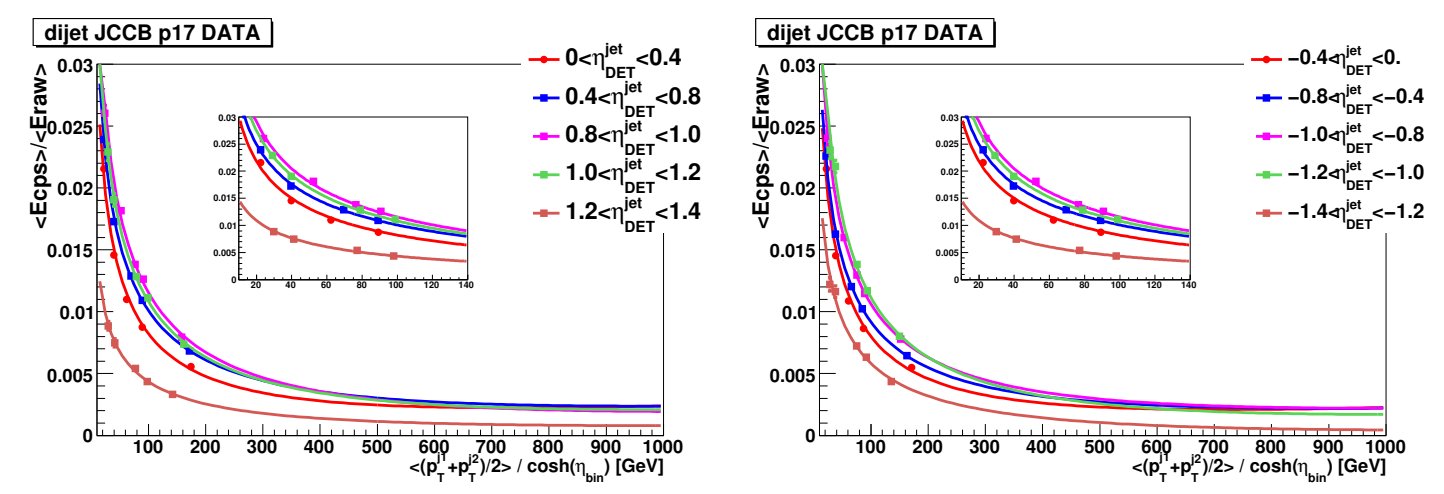

Figura A.13: Ajuste da função $f_{C P S}$ para eventos reais de dijato com jatos reconstruídos com cone $\Delta R=0,5$. 

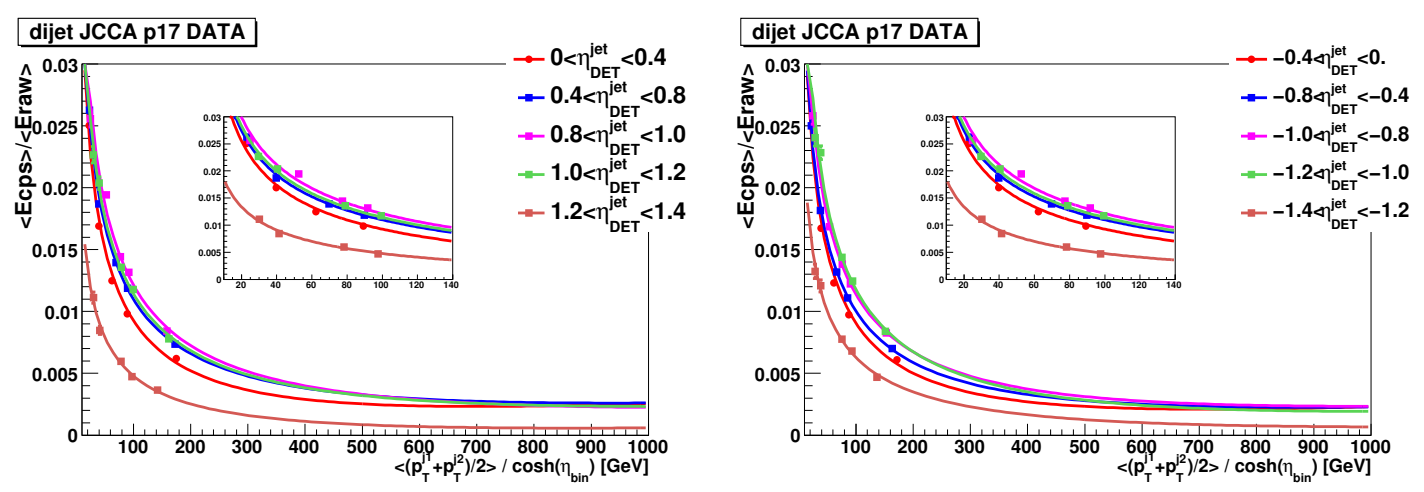

Figura A.14: Ajuste da função $f_{C P S}$ para eventos reais de dijato com jatos reconstruídos com cone $\Delta R=0,7$.

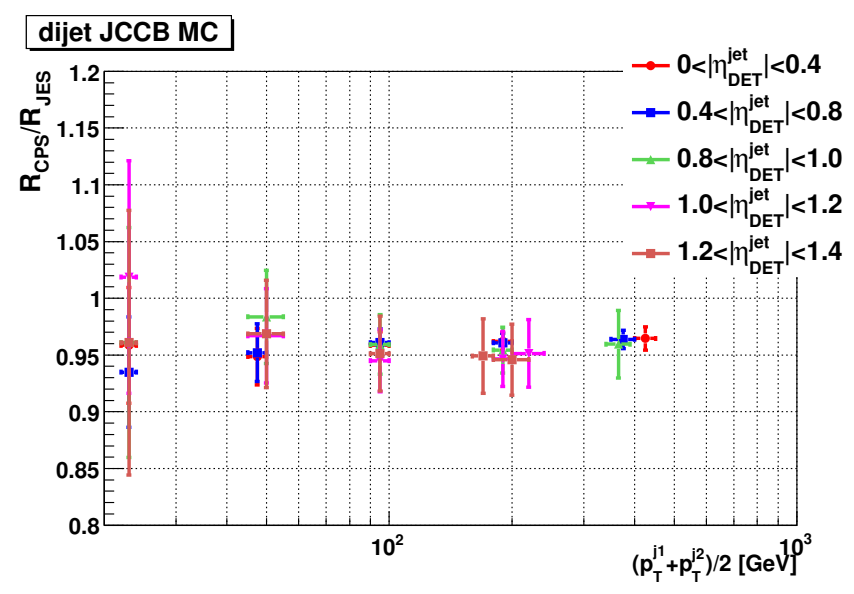

Figura A.15: Melhoria da resolução da energia do jato para eventos simulados de dijato com jatos reconstruídos com cone $\Delta R=0,5$.

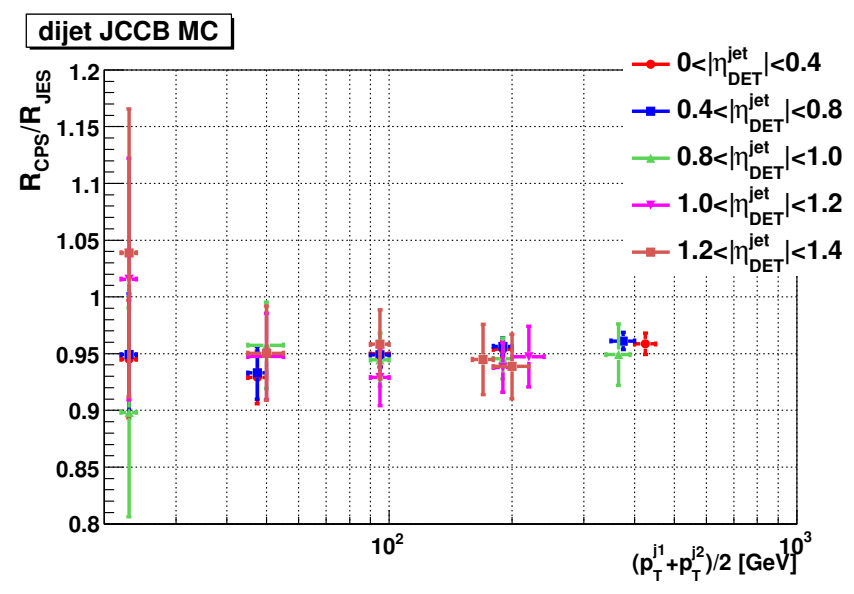

Figura A.16: Melhoria da resolução da energia do jato para eventos simulados de dijato com jatos reconstruídos com cone $\Delta R=0,7$. 

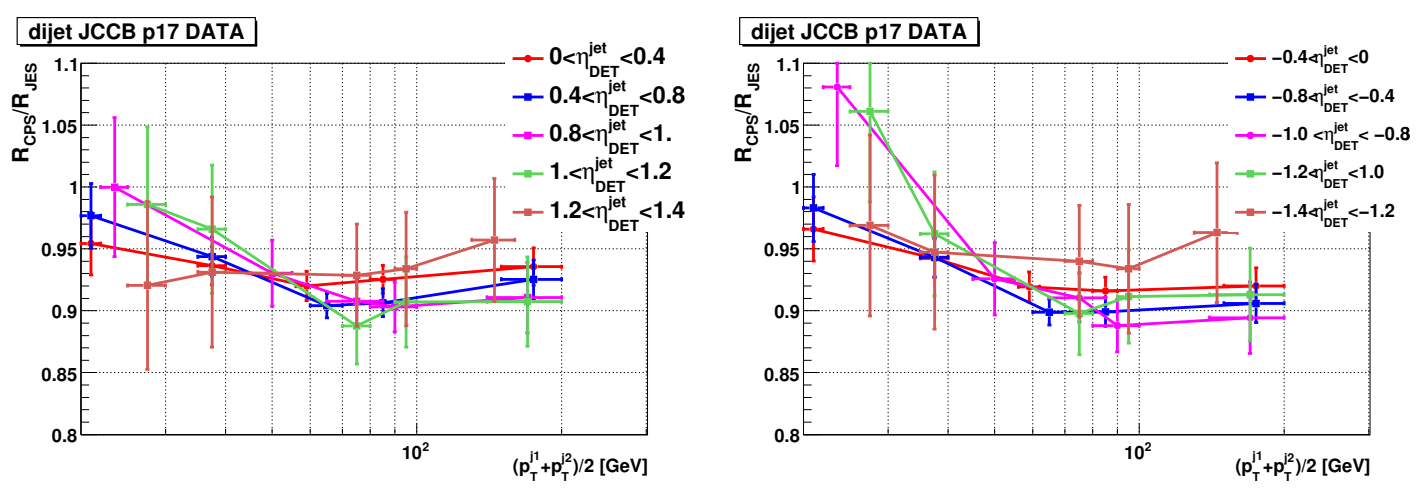

Figura A.17: Melhoria da resolução da energia do jato para eventos reais de dijato com jatos reconstruídos com cone $\Delta R=0,5$.
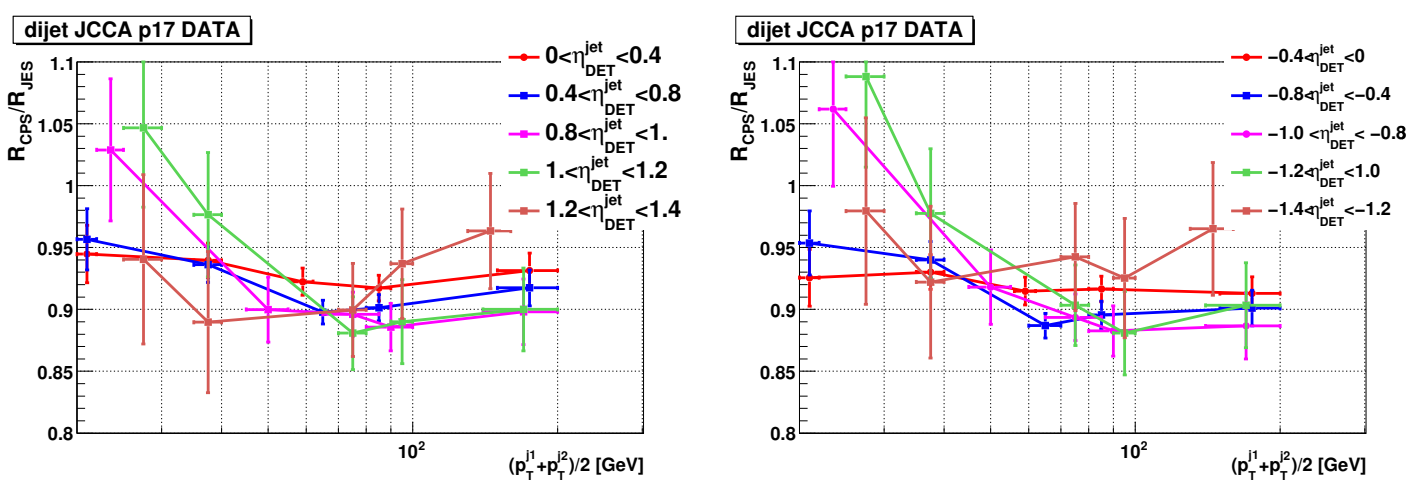

Figura A.18: Melhoria da resolução da energia do jato para eventos reais de dijato com jatos reconstruídos com cone $\Delta R=0,7$. 

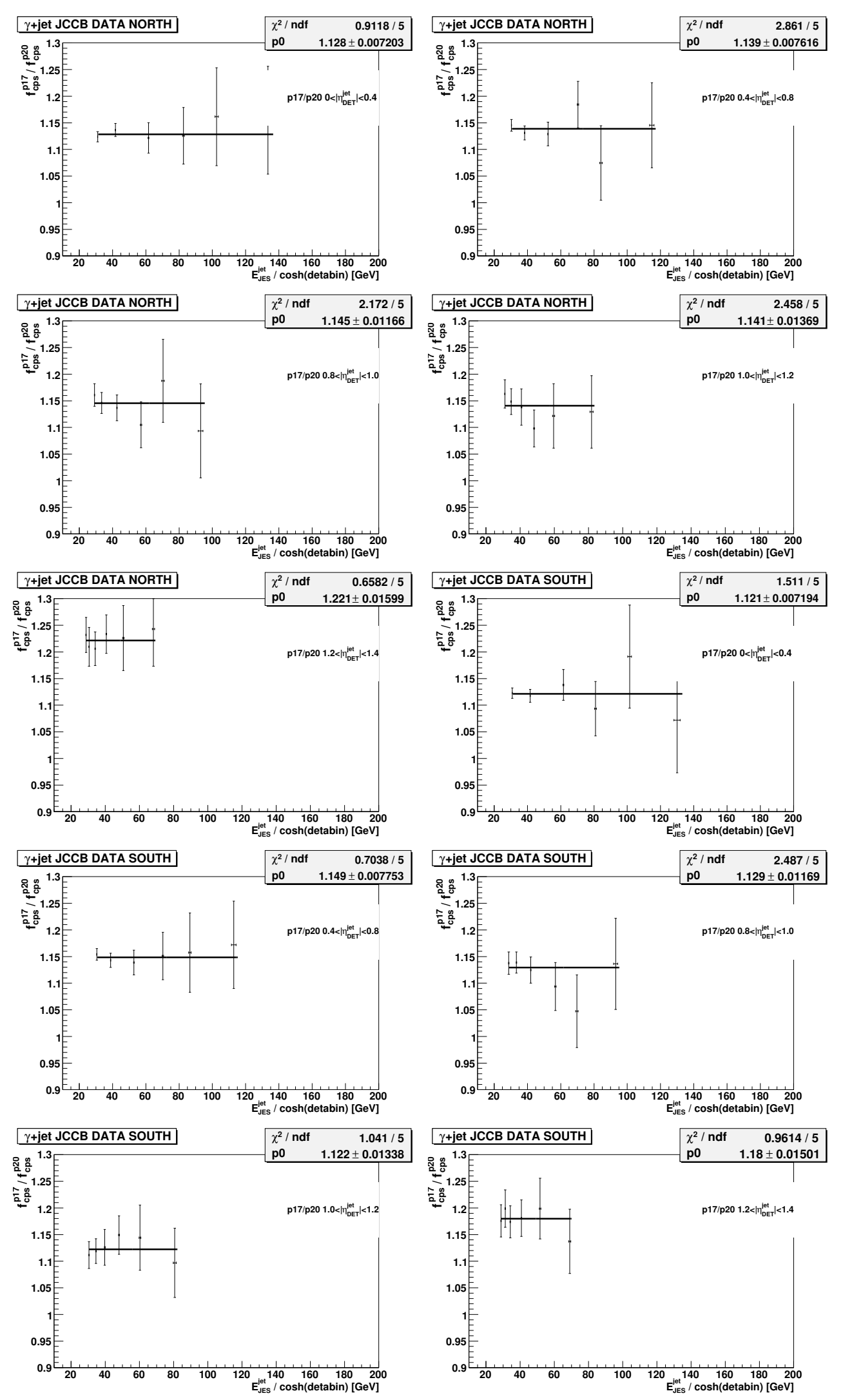

Figura A.19: Comparação da função $f_{C P S}$ para eventos reais de dijato entre as amostras p17 e p20 com jatos reconstruídos com cone $\Delta R=0,5$. 


\section{Apêndice B}

\section{Lista de Células Calorimétricas Problemáticas}

Utilizando o método discutido na seção 5.1, a lista de células problemáticas, exposta nas tabelas B.1 e B.2, é encontrada. Alguns casos são detalhados a seguir.

A distribuição de energia de duas células identificadas como problemáticas nos três conjuntos de dados simultaneamente são comparadas com uma de suas vizinhas (ver figura B.1). Pode-se ver que a célula $(7,10,45)^{1}$ apresenta um ganho muito maior do que suas vizinhas. Já a célula $(1,-3,37)$ possui um problema instrumental que causa um pico em um certo valor de energia.

Na figura B.2, a ocupação para o anel de $\varphi(7,10)$ é mostrada para os três diferentes conjuntos de dados. Pode-se verificar facilmente o problema na célula $(7,10,45)$. O mesmo pode ser dito para a célula $(1,-3,37)$ na figura B.3.

A célula $(7,16,55)$ é identificada como problemática no conjunto ZBMB, mas não nos outros conjuntos de dados (ver figuras B.4a e B.5). Fica claro que a influência do trigger faz a ocupação da célula ser menor que $10 \sigma$ para o conjunto de dados EMInclusive e QCD.

Por outro lado, a célula $(11,11,61)$ apenas pode ser identificada como problemática para o conjunto de dados QCD (ver figura B.4b e B.6)). Para o conjunto de dados ZBMB, há falta de estatística e, para o EMInclusive, o espectro de energia suprime o problema.

A célula $(14,23,46)$ é identificada como problemática nos conjuntos de dados QCD e EMInclusive, mas não no ZBMB devido à falta de estatística (ver figuras B.7a e B.8).

A célula $(14,-14,47)$ não é identificada como sendo deficiente no conjunto de dados ZBMB por falta de estatística (a célula apresenta ocupação menor que 50), porém, claramente ela é identificada no EMInclusive (ver figuras B.7b e B.9). Já no conjunto de dados QCD, a influência do trigger esconde o problema da célula.

\footnotetext{
${ }^{1}$ Por simplicidade, as células são identificadas com suas variáveis (ilayer,ieta,iphi).
} 


\begin{tabular}{|c|c|c||c|c|c||c|c|c||c|c|c||c|c|c|}
\hline $\mathrm{L}$ & $\mathrm{E}$ & $\mathrm{P}$ & $\mathrm{L}$ & $\mathrm{E}$ & $\mathrm{P}$ & $\mathrm{L}$ & $\mathrm{E}$ & $\mathrm{P}$ & $\mathrm{L}$ & $\mathrm{E}$ & $\mathrm{P}$ & $\mathrm{L}$ & $\mathrm{E}$ & $\mathrm{P}$ \\
\hline 1 & -29 & 31 & 1 & -22 & 38 & 1 & -12 & 48 & 1 & -11 & 7 & 1 & -9 & 27 \\
1 & -8 & 43 & 1 & -8 & 46 & 1 & -5 & 25 & 1 & -3 & 37 & 1 & -1 & 22 \\
1 & -1 & 29 & 1 & -1 & 47 & 1 & 3 & 30 & 1 & 3 & 60 & 1 & 5 & 28 \\
1 & 7 & 58 & 1 & 8 & 58 & 1 & 9 & 52 & 1 & 12 & 5 & 1 & 16 & 21 \\
1 & 16 & 59 & 1 & 17 & 16 & 1 & 20 & 54 & 1 & 24 & 31 & 1 & 24 & 40 \\
2 & -35 & 51 & 2 & -12 & 48 & 2 & -11 & 48 & 2 & -10 & 5 & 2 & -9 & 27 \\
2 & -8 & 43 & 2 & -8 & 52 & 2 & -5 & 25 & 2 & -3 & 47 & 2 & -3 & 48 \\
2 & -1 & 47 & 2 & 3 & 30 & 2 & 5 & 28 & 2 & 6 & 63 & 2 & 7 & 58 \\
2 & 8 & 58 & 2 & 9 & 52 & 2 & 10 & 9 & 2 & 10 & 45 & 2 & 12 & 42 \\
2 & 16 & 21 & 2 & 16 & 59 & 2 & 20 & 7 & 2 & 20 & 53 & 2 & 20 & 54 \\
2 & 23 & 31 & 2 & 24 & 31 & 2 & 25 & 32 & 2 & 26 & 7 & 2 & 27 & 14 \\
2 & 31 & 18 & 2 & 32 & 18 & 2 & 33 & 3 & 3 & -30 & 43 & 3 & -29 & 31 \\
3 & -21 & 29 & 3 & -17 & 5 & 3 & -11 & 48 & 3 & -10 & 5 & 3 & -8 & 43 \\
3 & -3 & 37 & 3 & -1 & 47 & 3 & 2 & 42 & 3 & 15 & 13 & 3 & 15 & 45 \\
3 & 16 & 21 & 3 & 16 & 59 & 3 & 24 & 31 & 3 & 26 & 7 & 4 & -25 & 54 \\
4 & -21 & 29 & 4 & -10 & 5 & 4 & -9 & 24 & 4 & -8 & 43 & 4 & -3 & 37 \\
4 & -1 & 47 & 4 & 4 & 29 & 4 & 6 & 20 & 4 & 16 & 21 & 4 & 16 & 59 \\
4 & 20 & 6 & 4 & 20 & 7 & 4 & 24 & 31 & 4 & 24 & 33 & 4 & 26 & 7 \\
5 & -22 & 2 & 5 & -21 & 29 & 5 & -12 & 48 & 5 & -10 & 5 & 5 & -8 & 43 \\
5 & -3 & 37 & 5 & -1 & 47 & 5 & 14 & 5 & 5 & 14 & 6 & 5 & 16 & 21 \\
5 & 16 & 59 & 5 & 23 & 3 & 5 & 23 & 31 & 5 & 24 & 31 & 6 & -21 & 29 \\
6 & -16 & 53 & 6 & -12 & 48 & 6 & -10 & 5 & 6 & -9 & 43 & 6 & -8 & 43 \\
6 & -3 & 37 & 6 & -1 & 47 & 6 & 3 & 4 & 6 & 14 & 5 & 6 & 14 & 6 \\
6 & 16 & 21 & 6 & 16 & 59 & 6 & 23 & 31 & 6 & 24 & 31 & 6 & 25 & 18 \\
6 & 26 & 7 & 7 & -34 & 37 & 7 & -30 & 43 & 7 & -26 & 35 & 7 & -25 & 33 \\
7 & -23 & 1 & 7 & -21 & 39 & 7 & -20 & 39 & 7 & -18 & 46 & 7 & -11 & 42 \\
7 & -11 & 44 & 7 & -11 & 46 & 7 & -11 & 48 & 7 & -11 & 49 & 7 & -11 & 55 \\
7 & -3 & 37 & 7 & 2 & 48 & 7 & 10 & 45 & 7 & 11 & 45 & 7 & 11 & 46 \\
7 & 14 & 5 & 7 & 14 & 6 & 7 & 14 & 13 & 7 & 14 & 14 & 7 & 16 & 21 \\
7 & 16 & 55 & 7 & 16 & 59 & 7 & 21 & 32 & 7 & 23 & 31 & 7 & 23 & 53 \\
7 & 24 & 31 & 7 & 25 & 12 & 7 & 26 & 12 & 7 & 29 & 34 & 7 & 30 & 7 \\
7 & 30 & 34 & 7 & 30 & 63 & 7 & 31 & 7 & 7 & 31 & 54 & 7 & 32 & 7 \\
7 & 34 & 7 & 11 & -31 & 32 & 11 & -26 & 4 & 11 & -26 & 32 & 11 & -25 & 32 \\
\hline
\end{tabular}

Tabela B.1: Lista de células problemáticas para o Run IIa para camadas do calorímetro EM. A coluna L representa a camada, a coluna E o ieta e a coluna P o iphi das células. 


\begin{tabular}{|c|c|c||c|c|c||c|c|c||c|c|c||c|c|c|}
\hline $\mathrm{L}$ & $\mathrm{E}$ & $\mathrm{P}$ & $\mathrm{L}$ & $\mathrm{E}$ & $\mathrm{P}$ & $\mathrm{L}$ & $\mathrm{E}$ & $\mathrm{P}$ & $\mathrm{L}$ & $\mathrm{E}$ & $\mathrm{P}$ & $\mathrm{L}$ & $\mathrm{E}$ & $\mathrm{P}$ \\
\hline 11 & -25 & 33 & 11 & -24 & 5 & 11 & -22 & 32 & 11 & -21 & 29 & 11 & -21 & 32 \\
11 & -20 & 5 & 11 & -17 & 49 & 11 & -15 & 31 & 11 & -14 & 37 & 11 & -14 & 45 \\
11 & -14 & 55 & 11 & -9 & 62 & 11 & -8 & 2 & 11 & -8 & 50 & 11 & -3 & 37 \\
11 & 4 & 58 & 11 & 6 & 64 & 11 & 10 & 18 & 11 & 11 & 61 & 11 & 14 & 50 \\
11 & 16 & 13 & 11 & 16 & 53 & 11 & 17 & 57 & 11 & 18 & 57 & 11 & 19 & 57 \\
11 & 21 & 32 & 11 & 23 & 31 & 11 & 23 & 46 & 11 & 23 & 53 & 11 & 26 & 7 \\
11 & 26 & 15 & 12 & -30 & 32 & 12 & -25 & 33 & 12 & -23 & 10 & 12 & -21 & 29 \\
12 & -20 & 5 & 12 & -18 & 7 & 12 & -16 & 16 & 12 & -14 & 37 & 12 & -14 & 45 \\
12 & -14 & 55 & 12 & -8 & 2 & 12 & -3 & 5 & 12 & -3 & 37 & 12 & 2 & 58 \\
12 & 14 & 5 & 12 & 14 & 6 & 12 & 14 & 50 & 12 & 16 & 21 & 12 & 16 & 59 \\
12 & 16 & 64 & 12 & 18 & 1 & 12 & 18 & 31 & 12 & 18 & 32 & 12 & 18 & 55 \\
12 & 20 & 44 & 12 & 21 & 32 & 12 & 23 & 31 & 12 & 23 & 46 & 12 & 26 & 7 \\
12 & 26 & 15 & 12 & 28 & 35 & 12 & 29 & 36 & 12 & 30 & 23 & 12 & 30 & 63 \\
13 & -25 & 33 & 13 & -24 & 1 & 13 & -21 & 29 & 13 & -19 & 32 & 13 & -17 & 44 \\
13 & -16 & 42 & 13 & -15 & 42 & 13 & -14 & 24 & 13 & -14 & 37 & 13 & -14 & 45 \\
13 & -14 & 55 & 13 & -8 & 17 & 13 & -8 & 28 & 13 & -8 & 33 & 13 & -8 & 40 \\
13 & -8 & 41 & 13 & -8 & 42 & 13 & -8 & 49 & 13 & -8 & 50 & 13 & -7 & 14 \\
13 & -7 & 15 & 13 & -7 & 37 & 13 & -7 & 62 & 13 & -6 & 62 & 13 & -3 & 37 \\
13 & 1 & 46 & 13 & 4 & 58 & 13 & 5 & 54 & 13 & 6 & 37 & 13 & 7 & 37 \\
13 & 7 & 58 & 13 & 8 & 21 & 13 & 8 & 48 & 13 & 8 & 50 & 13 & 14 & 5 \\
13 & 14 & 6 & 13 & 14 & 39 & 13 & 14 & 50 & 13 & 15 & 31 & 13 & 16 & 21 \\
13 & 16 & 59 & 13 & 17 & 38 & 13 & 21 & 32 & 13 & 23 & 46 & 13 & 23 & 53 \\
13 & 26 & 7 & 13 & 30 & 3 & 13 & 30 & 63 & 14 & -25 & 33 & 14 & -24 & 1 \\
14 & -21 & 29 & 14 & -20 & 39 & 14 & -20 & 63 & 14 & -18 & 7 & 14 & -18 & 43 \\
14 & -18 & 44 & 14 & -17 & 44 & 14 & -14 & 37 & 14 & -14 & 45 & 14 & -14 & 47 \\
14 & -14 & 55 & 14 & -13 & 55 & 14 & 13 & 42 & 14 & 14 & 5 & 14 & 14 & 6 \\
14 & 14 & 50 & 14 & 15 & 31 & 14 & 16 & 21 & 14 & 16 & 59 & 14 & 16 & 61 \\
14 & 17 & 60 & 14 & 17 & 61 & 14 & 17 & 62 & 14 & 18 & 50 & 14 & 18 & 61 \\
14 & 21 & 32 & 14 & 23 & 46 & 14 & 23 & 53 & 14 & 24 & 31 & 14 & 26 & 7 \\
14 & 28 & 55 & 14 & 29 & 45 & 14 & 30 & 45 & 14 & 30 & 63 & & & \\
\hline
\end{tabular}

Tabela B.2: Lista de células problemáticas para o Run IIa para camadas do calorímetro FH. A coluna L representa a camada, a coluna $\mathrm{E}$ o ieta e a coluna $\mathrm{P}$ o iphi das células. 

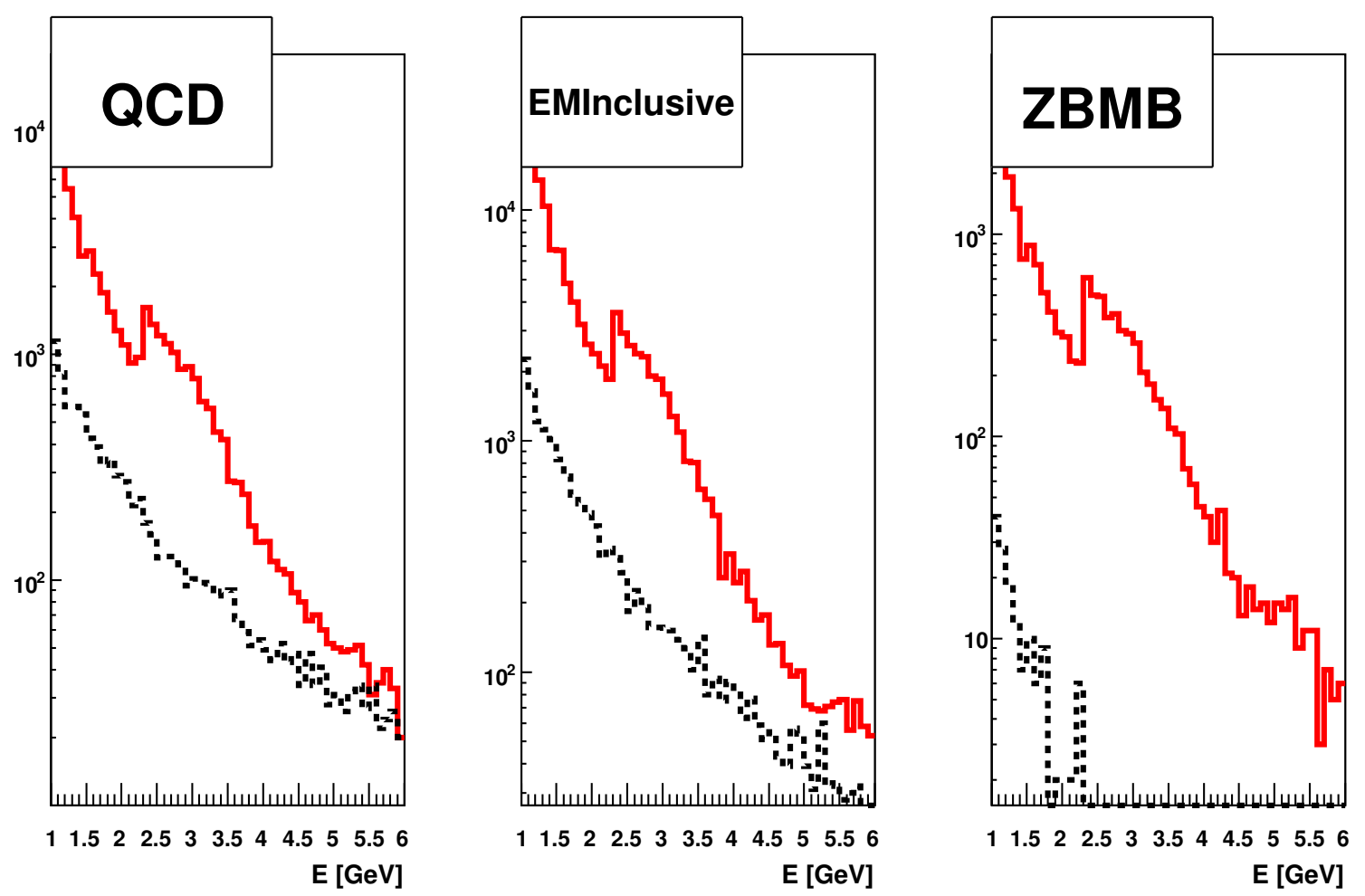

(a) Distribuição de energia da célula (ilayer $=7$, ieta $=10$, iphi=45) no período 6 .
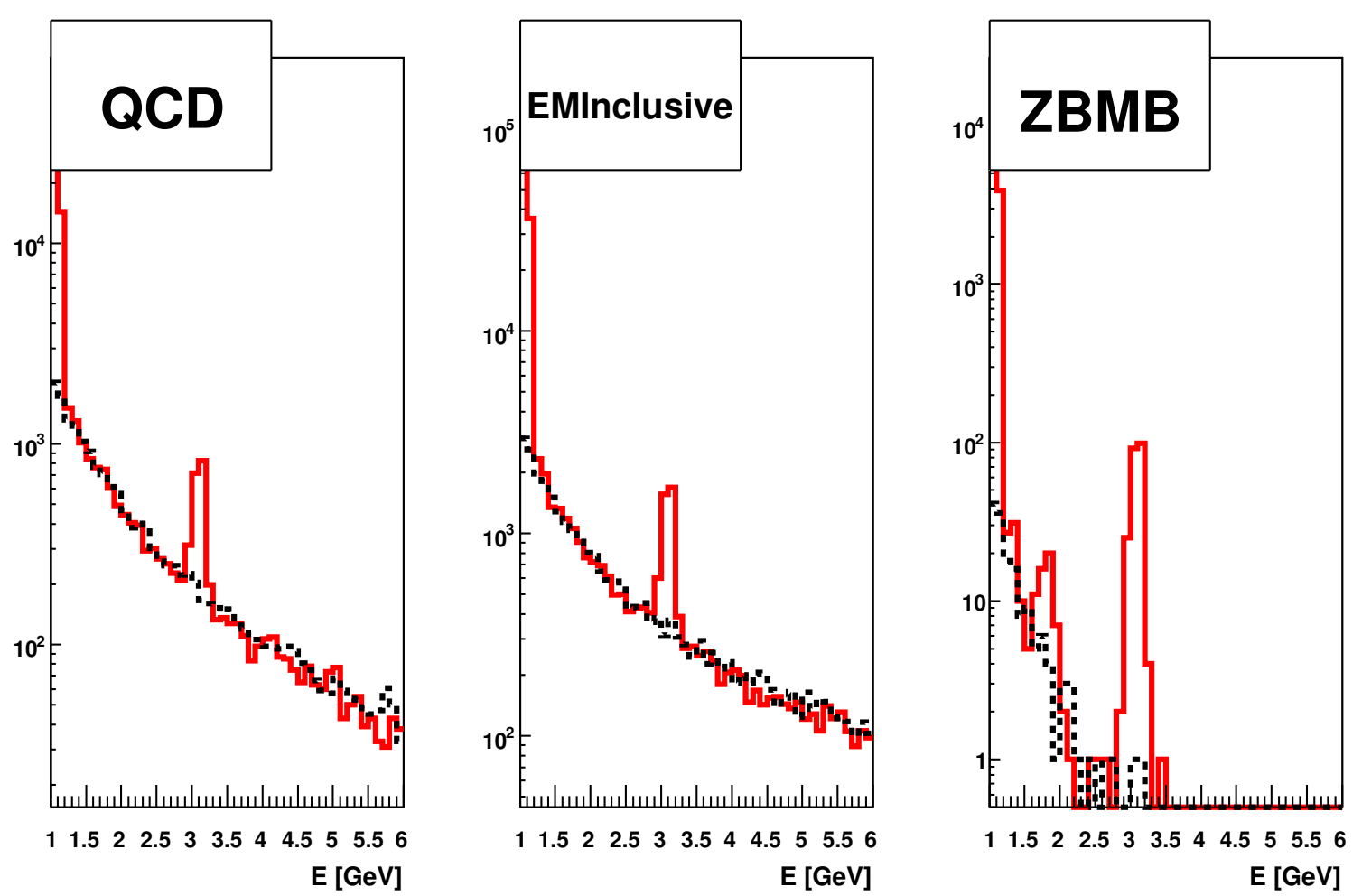

(b) Distribuição de energia da célula (ilayer=1, ieta=-3, iphi=37) no período 2.

Figura B.1: Distribuições de energia de células problemáticas (vermelho) de células normais (linha preta pontilhada). 

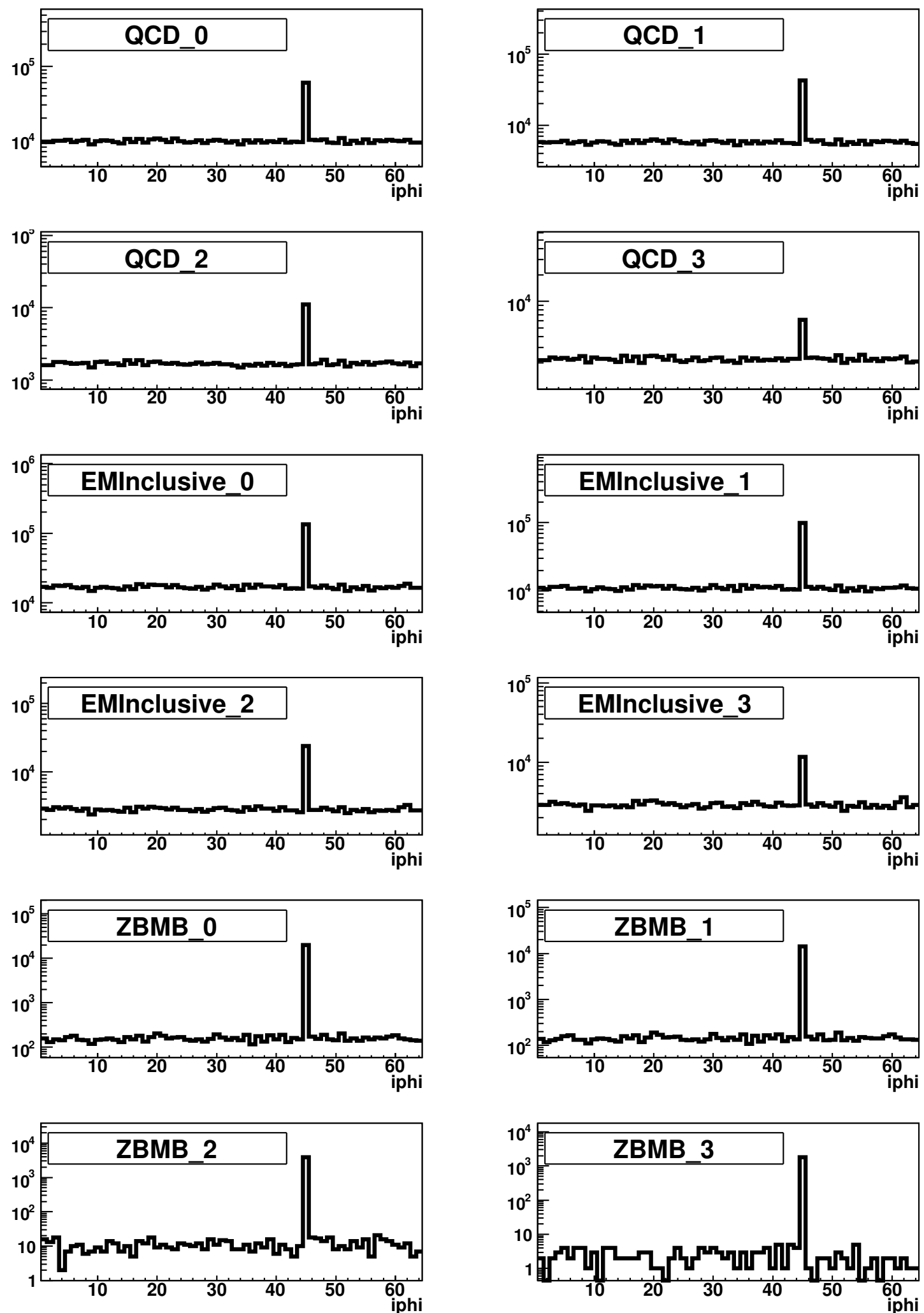

Figura B.2: Ocupação das células do anel de $\varphi(7,10)$ no período 6 . 

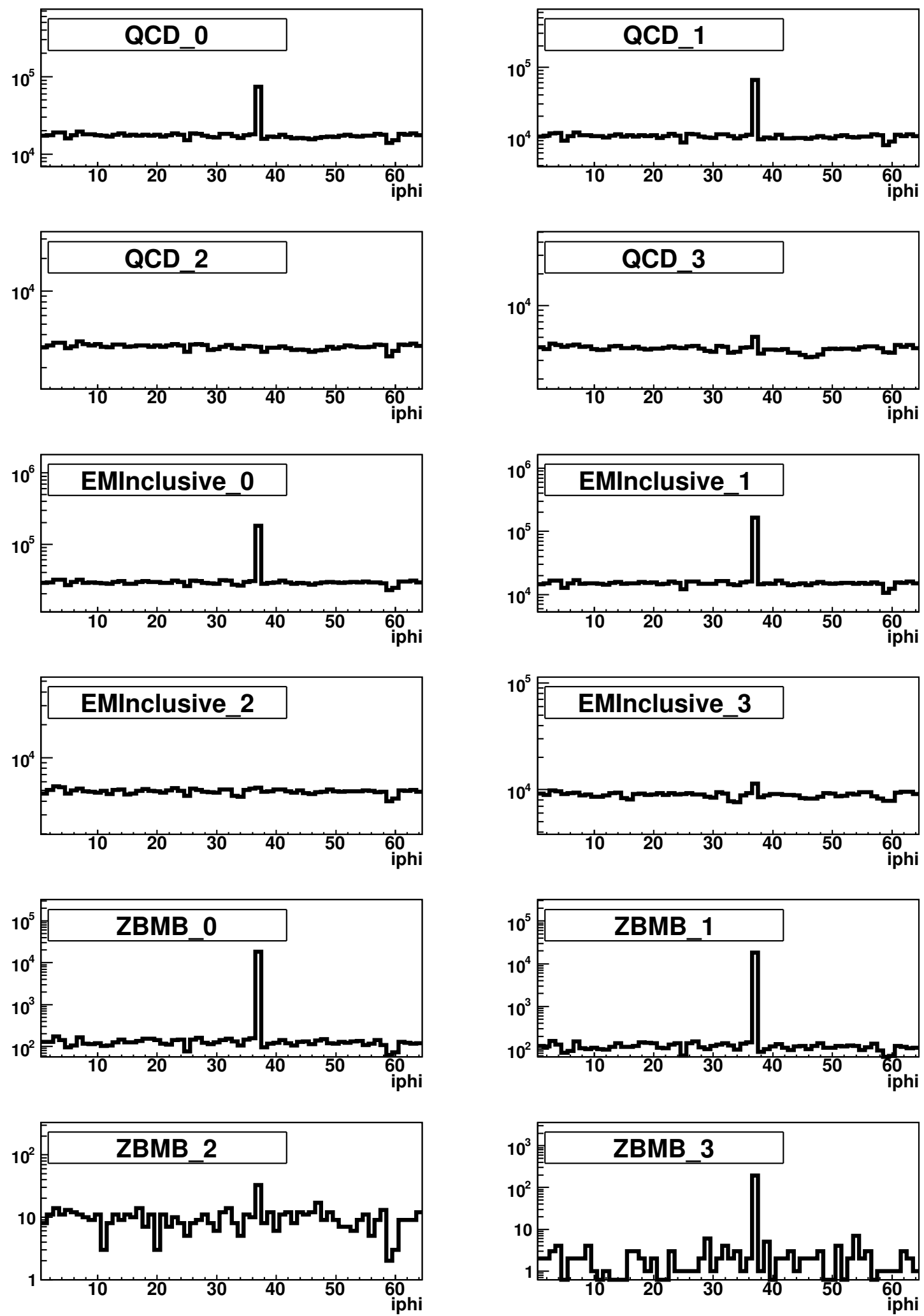

Figura B.3: Ocupação das células do anel de $\varphi(1,-3)$ no período 2. 

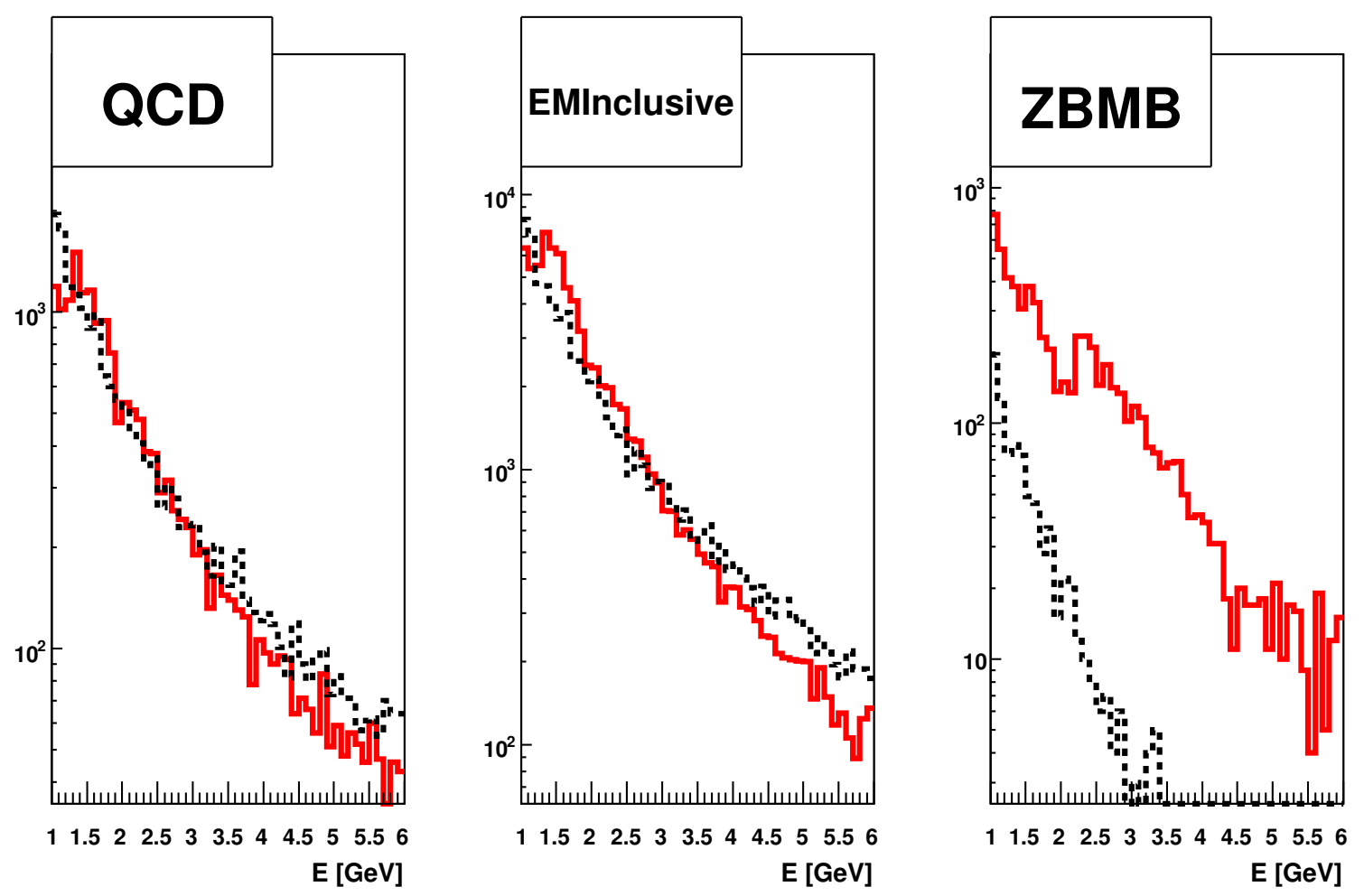

(a) Distribuição de energia da célula (ilayer $=7$, ieta $=16$, iphi=55) no período 1.
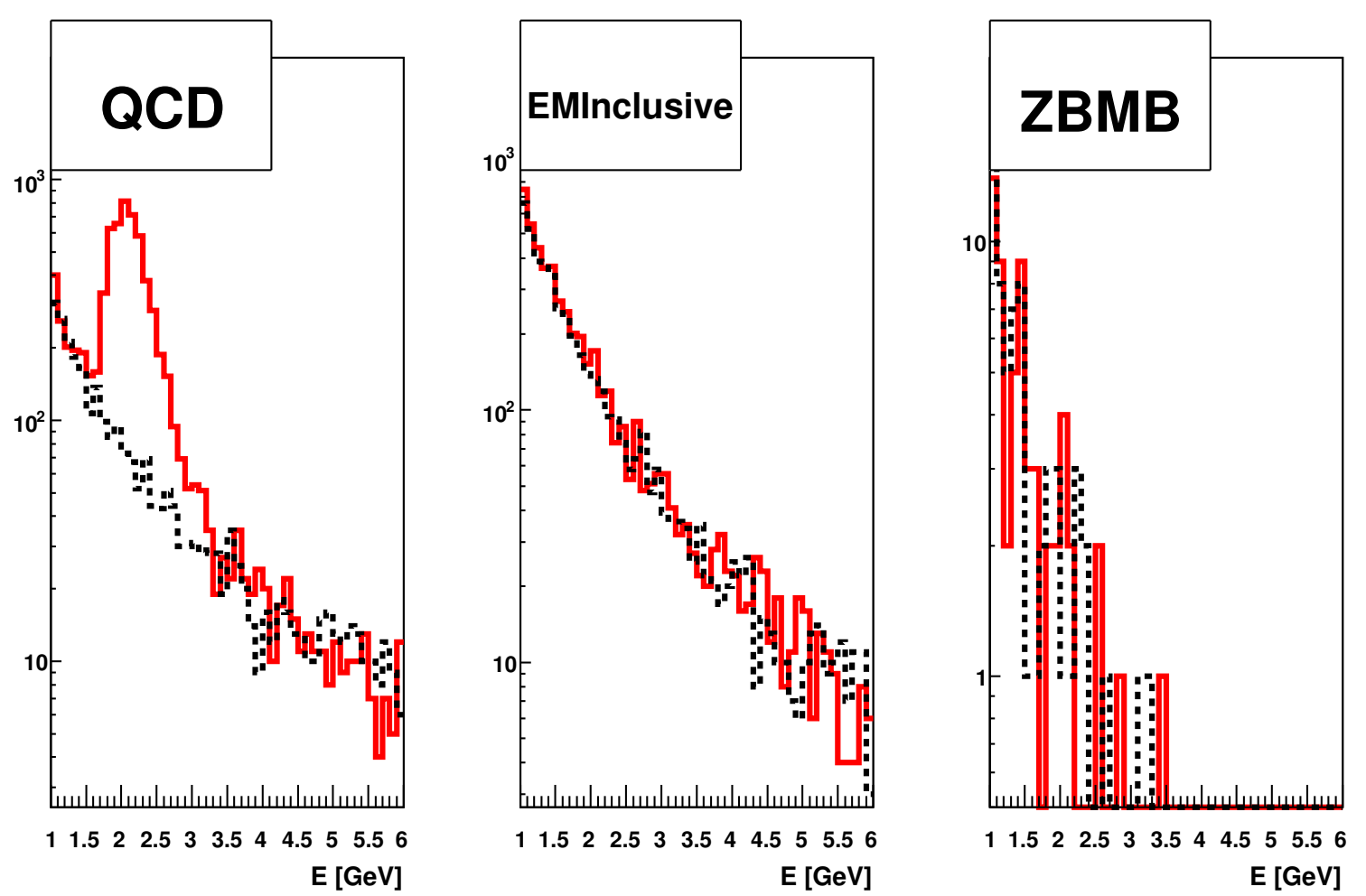

(b) Distribuição de energia da célula (ilayer=11, ieta=11, iphi=61) no período 1.

Figura B.4: Distribuições de energia para células problemáticas (vermelho) e células normais (linha preta pontilhada). 

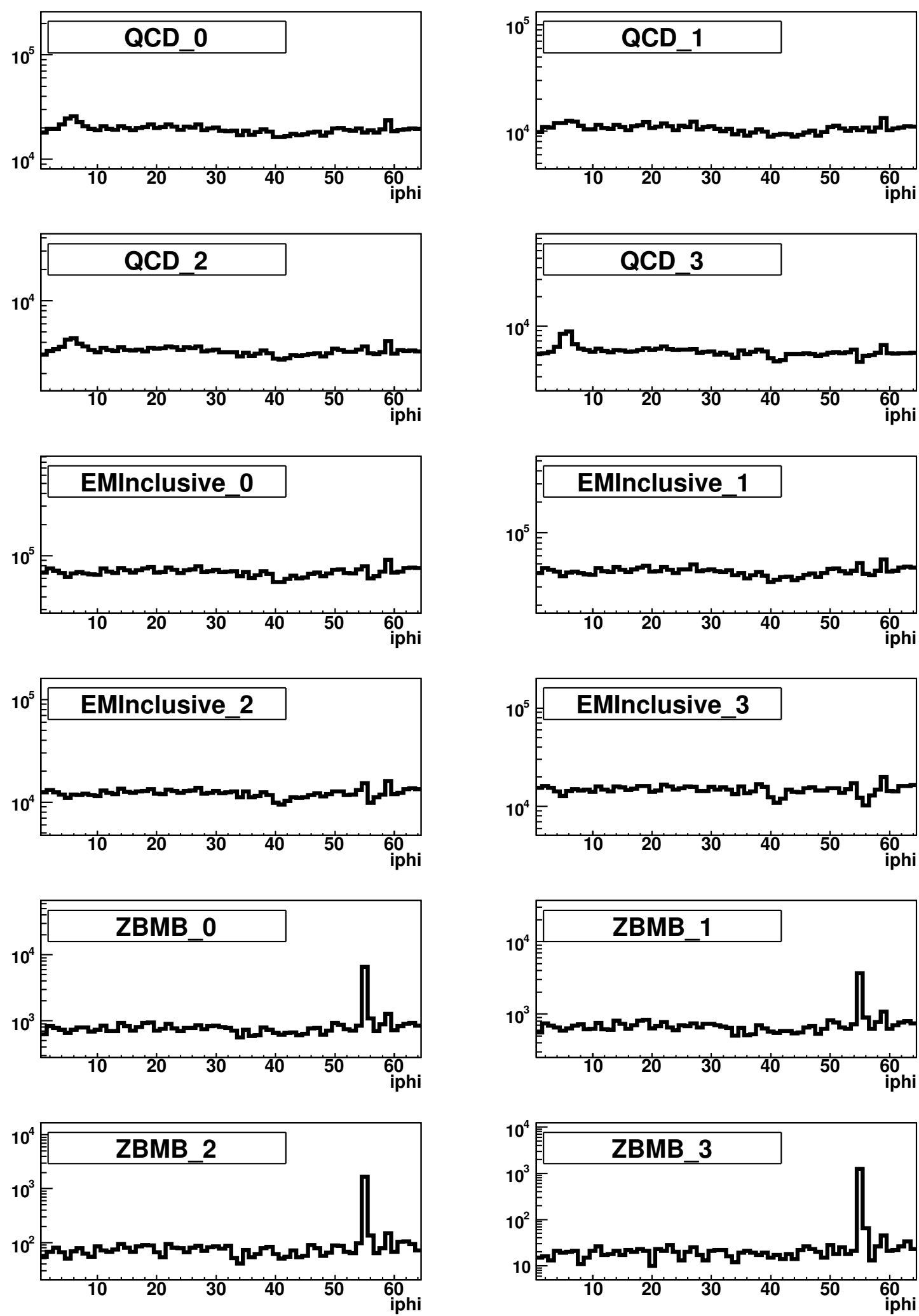

Figura B.5: Ocupação das células do anel de $\varphi(7,16)$ para o período 1. 

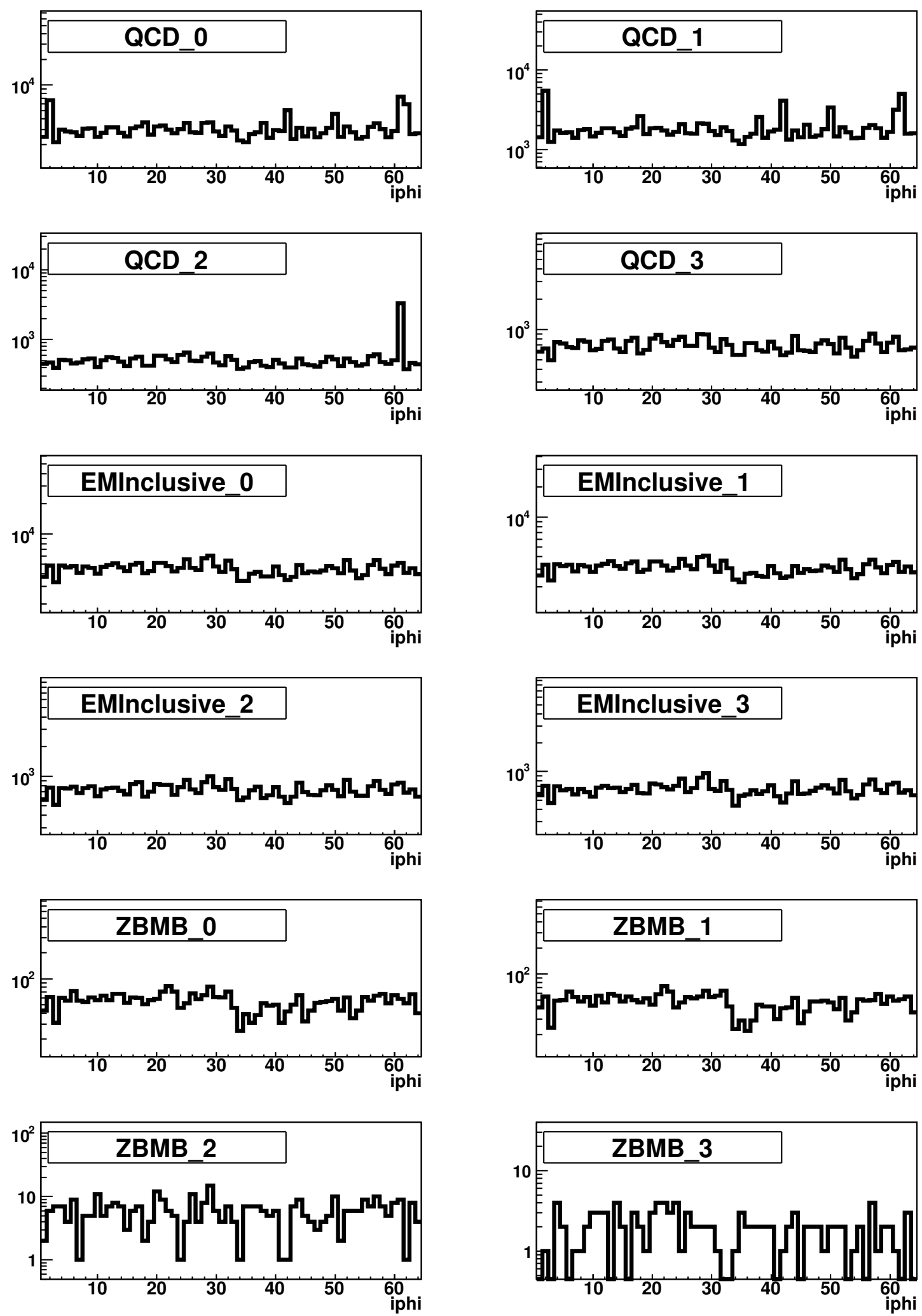

Figura B.6: Ocupação das células do anel de $\varphi(11,11)$ para o período 1. 

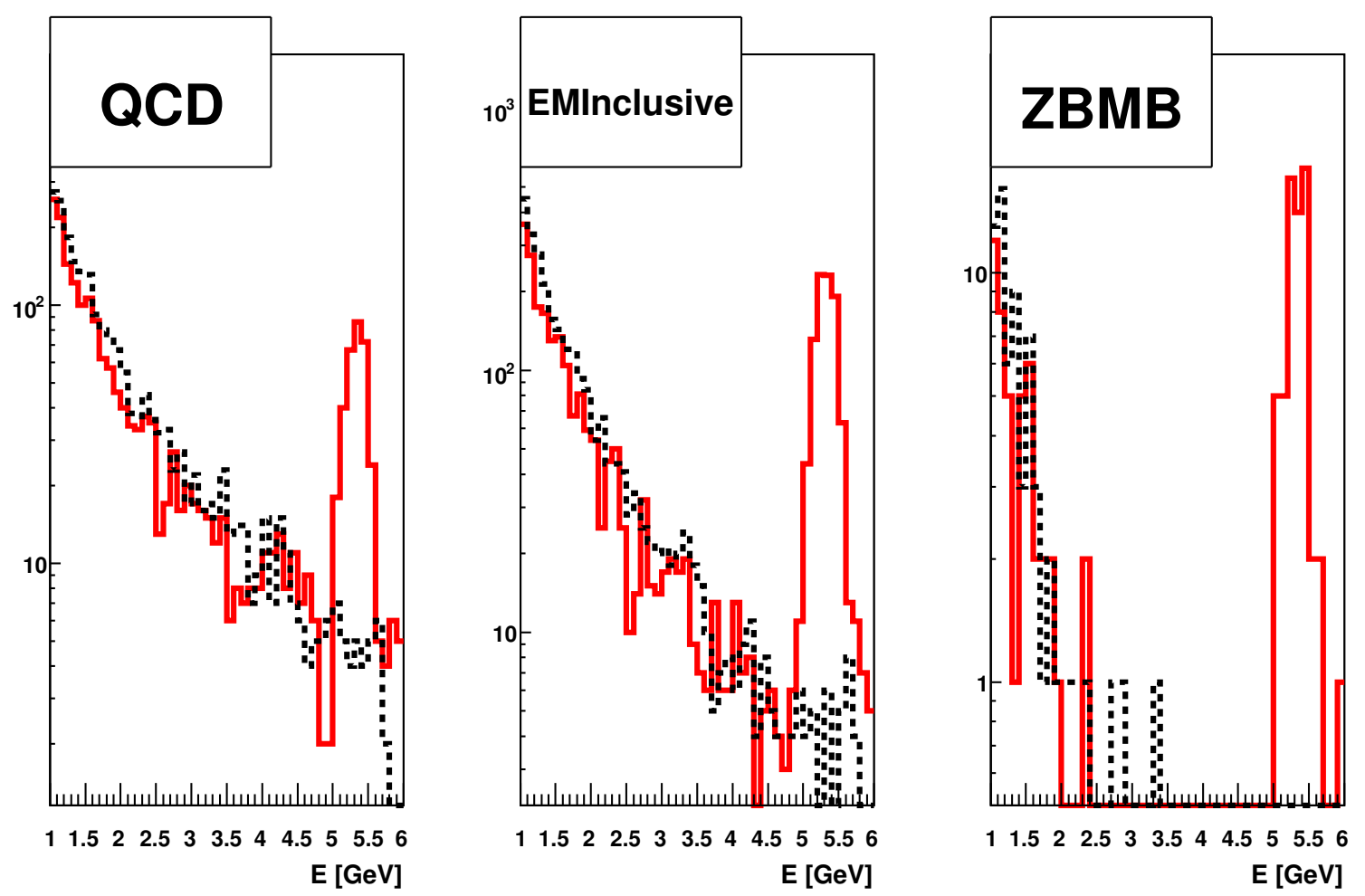

(a) Distribuição de energia da célula (ilayer $=14$, ieta $=23$, iphi=46) para o período 2 .
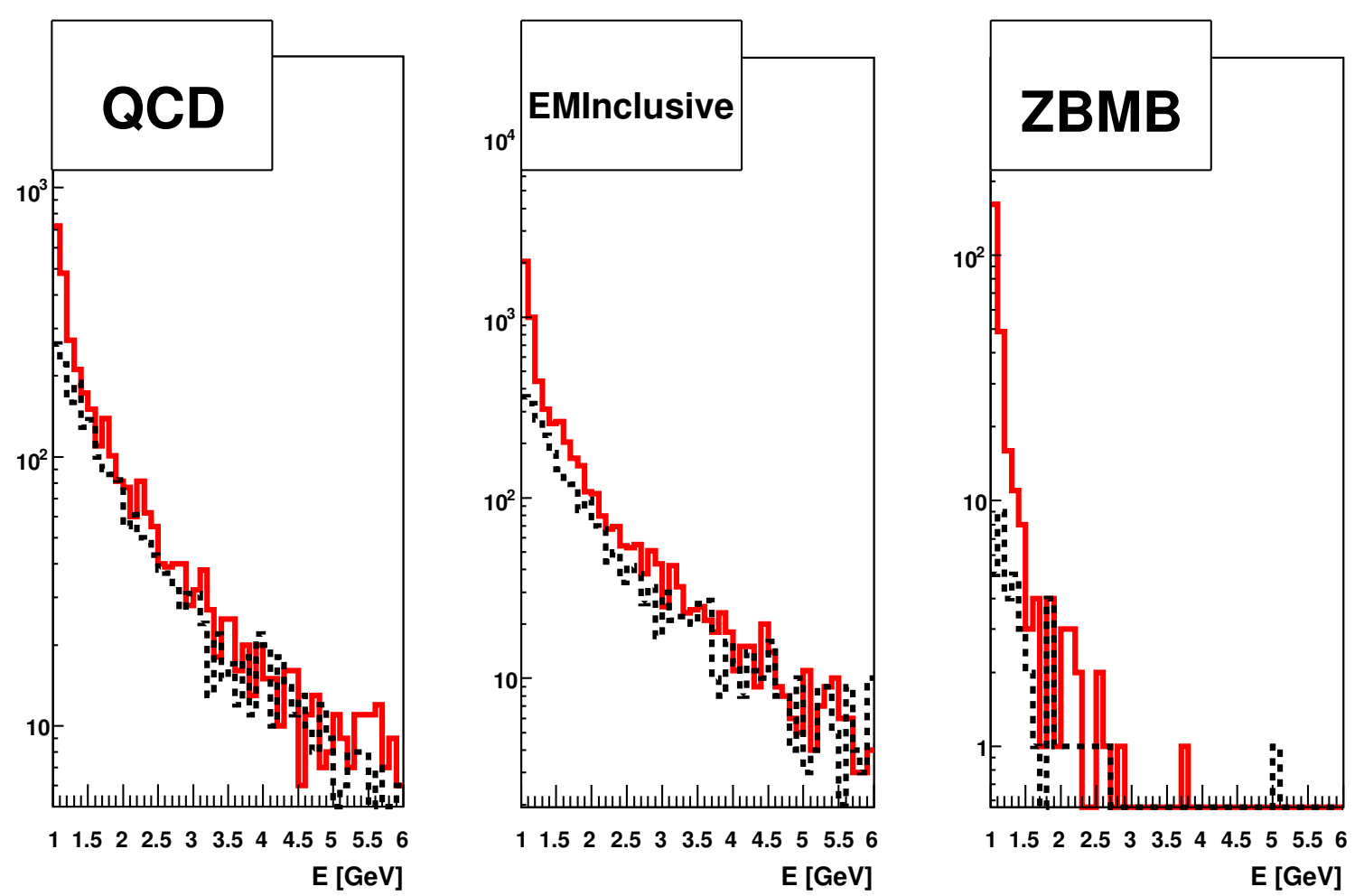

(b) Distribuição de energia da célula (ilayer=14, ieta=-14, iphi=47) para o período 9.

Figura B.7: Distribuições de energia de células problemáticas (vermelho) e células normais (linha preta pontilhada). 

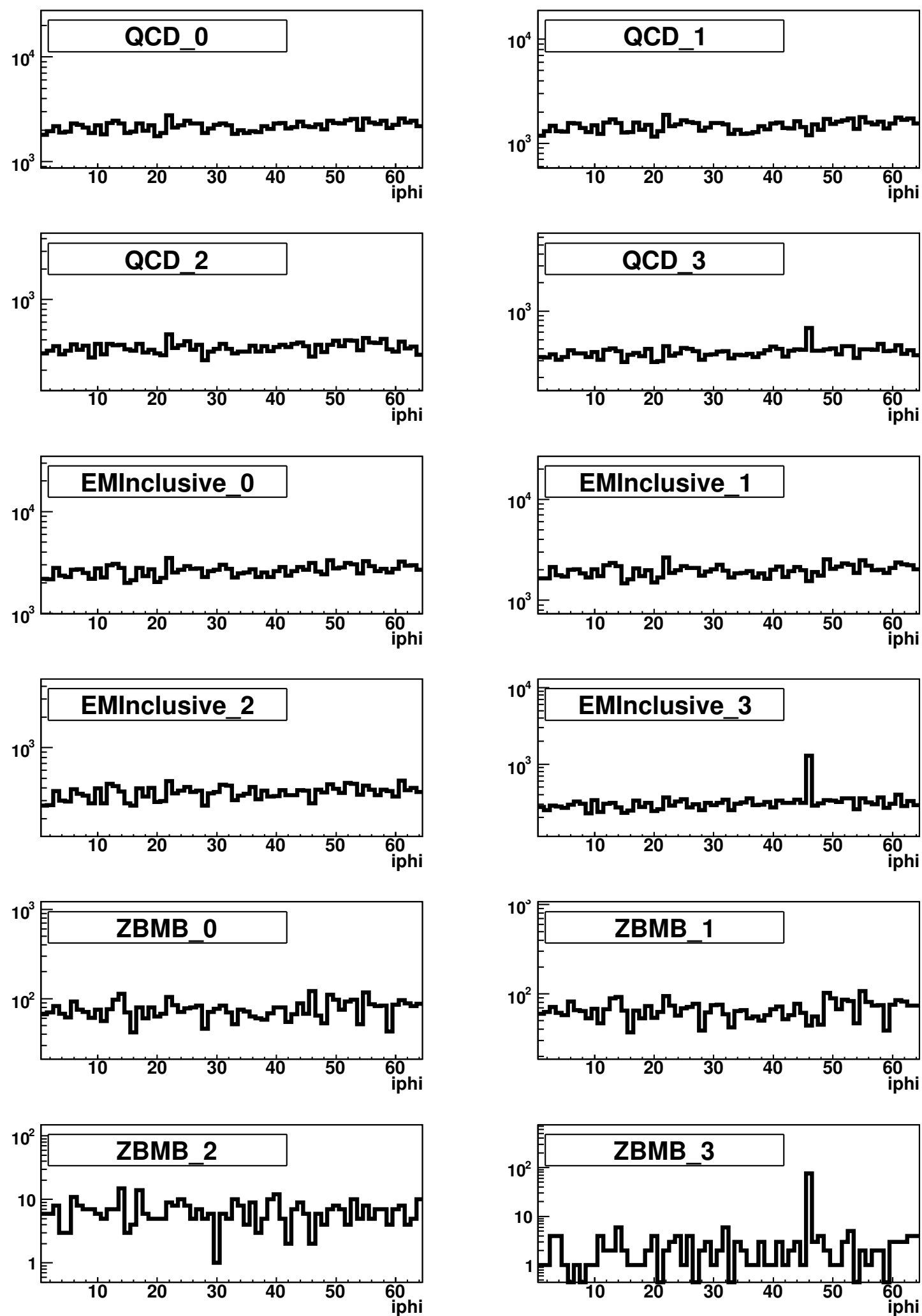

Figura B.8: Ocupação das células do anel de $\varphi(14,23)$ para o período 2. 

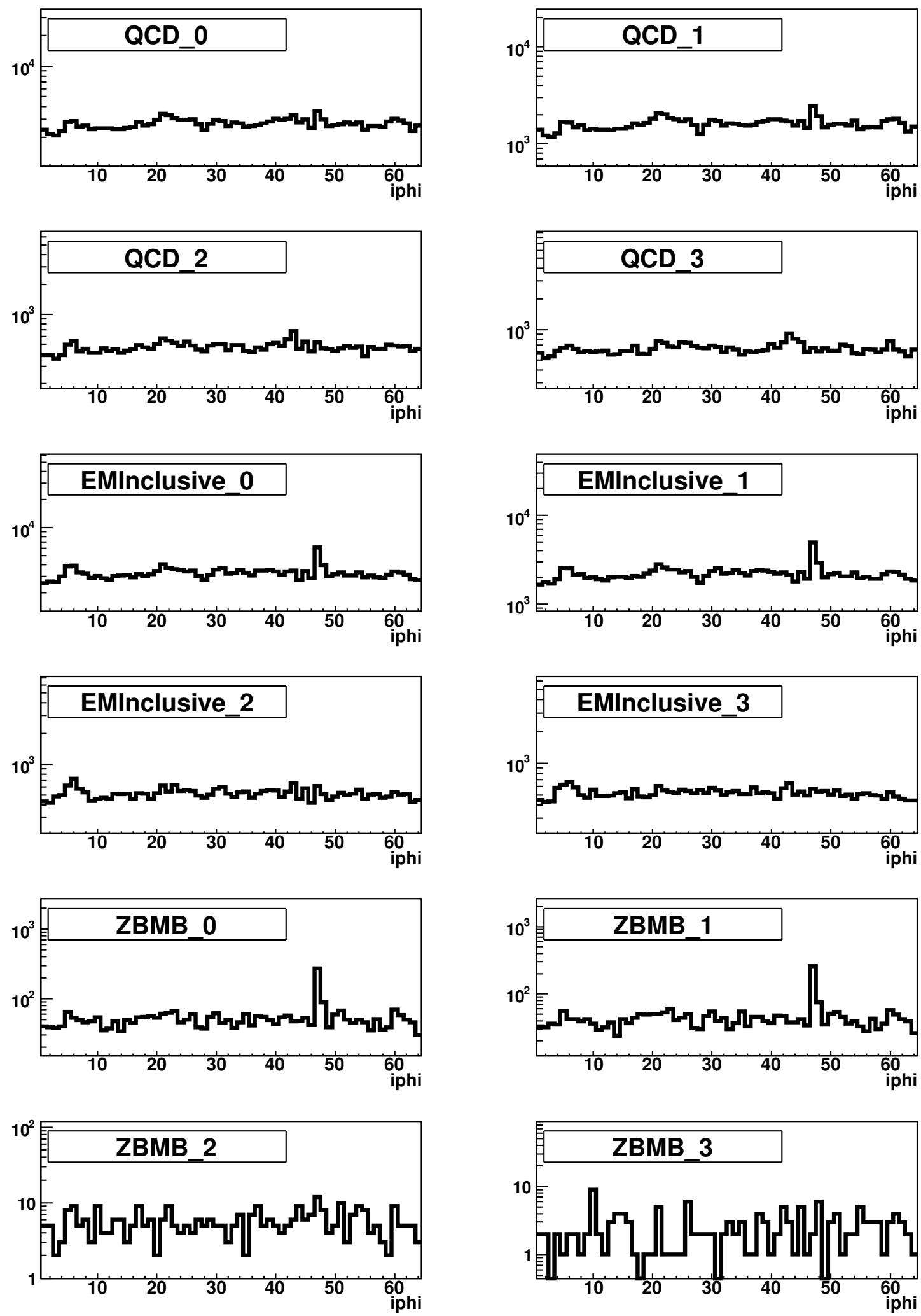

Figura B.9: Ocupação das células do anel de $\varphi(14,-14)$ para o período 9. 


\section{Apêndice $\mathrm{C}$}

\section{Estatística de Bayes}

Uma das interpretações de probabilidade mais usadas é a de Bayes [96]. Um dos métodos para o cálculo de limites adotado pelo experimento DØ é o baseado na estatística de Bayes [97].

Dado um conjunto de hipóteses, onde A e B são elementos desse conjunto, o teorema de Bayes afirma que [96]:

$$
P(A \mid B)=\frac{P(B \mid A) P(A)}{P(B)},
$$

onde $P(A \mid B)$ é a probabilidade de $A$ dado $B ; P(B \mid A)$, a probabilidade de $B$ dado $A$; $P(X)$, o grau de confiança da hipótese $X$ ser verdadeira $(X=A, B)$.

A equação acima pode ser estendida para o caso de variáveis contínuas, como:

$$
g(x \mid y)=\frac{h(y \mid x) f_{x}(x)}{f_{y}(y)}
$$

onde $g(x \mid y)$ é a função da densidade de probabilidade (p.d.f.) condicional para $x$ dado $y$; $h(y \mid x)$, a p.d.f. condicional para $y$ dado $x$; e $f_{i}$ a p.d.f. de $i(i=x, y)$.

Usando a fato de que:

$$
f_{y}(y)=\int h(y \mid x) f_{x}(x) d y
$$

pode-se escrever que:

$$
g(x \mid y)=\frac{h(y \mid x) f_{x}(x)}{\int h(y \mid x) f_{x}(x) d y} .
$$

Define-se $f_{x}(x)=0$ para $x<0$ e $f_{x}(x)=1$ para $x \geq 0$ e para $h(y \mid x)$ usa-se uma distribuição de Poisson [97]:

$$
h(y \mid x)=\frac{e^{-x} x^{y}}{y !}
$$

Dessa forma, a probabilidade de $x$ ser menor que $x_{l}$ dado $y$ é escrita como: 


$$
C L=\int_{0}^{x_{l}} g(x \mid y) d x .
$$

Fazendo com que $y$ represente o número de eventos de dados e $x$ o número de eventos previstos na simulação, pode-se, portanto, calcular o limite superior de $x$. Se $x$ é a soma de eventos previstos por uma teoria estabelecida $\left(x_{B K G}\right)$ com eventos previstos por uma produção ainda não observada $\left(x_{S I G}\right)$, o limite para $x_{S I G}$ é:

$$
x_{S I G}^{l}=x_{l}-x_{B K G} .
$$

Em geral, $x_{S I G}^{l}$ é determinado para $C L=0.95$, i.e., nível de confiança de $95 \%$. 


\section{Apêndice D}

\section{Matriz de Correlação}

A correlação entre as variáveis calorimétricas apresentadas no capítulo 6 está apresentada nas matrizes D.1-D.4. A matriz original é de tamanho 32x32 e as regiões calorimétricas obedecem à seguinte ordem: EM2N,EM1N,EM2S,EM1S,FH2N,FH1N,FH2S,FH1S.

\begin{tabular}{|c|c|c|c|c|c|c|c|}
\hline 1 & 0.316 & -0.256 & -0.428 & 0.0476 & 0.0162 & -0.00834 & -0.0338 \\
\hline 0.316 & 1 & 0.147 & -0.644 & 0.0108 & 0.0433 & 0.0349 & -0.0492 \\
\hline-0.256 & 0.147 & 1 & -0.599 & -0.0177 & 0.0264 & 0.0637 & -0.0363 \\
\hline-0.428 & -0.644 & -0.599 & 1 & -0.0114 & -0.0364 & -0.0437 & 0.064 \\
\hline 0.0476 & 0.0108 & -0.0177 & -0.0114 & 1 & 0.0433 & -0.414 & -0.422 \\
\hline 0.0162 & 0.0433 & 0.0264 & -0.0364 & 0.0433 & 1 & 0.0514 & -0.541 \\
\hline-0.00834 & 0.0349 & 0.0637 & -0.0437 & -0.414 & 0.0514 & 1 & -0.474 \\
\hline-0.0338 & -0.0492 & -0.0363 & 0.064 & -0.422 & -0.541 & -0.474 & 1 \\
\hline 0.00212 & 0.00326 & -0.00339 & -0.000584 & 0.00219 & -0.00177 & -0.00269 & 0.00117 \\
\hline 0.00115 & 0.0153 & 0.00217 & -0.00954 & -0.00452 & 0.00492 & 0.00373 & -0.0019 \\
\hline 0.000314 & 0.00464 & 0.00329 & -0.00335 & -0.00244 & 0.00345 & 0.0039 & -0.000705 \\
\hline-0.00193 & -0.0113 & 0.000866 & 0.00781 & 0.00163 & -0.00232 & -0.0013 & 0.0011 \\
\hline 0.00329 & -0.000358 & $3.35 e-05$ & -0.000511 & 0.00564 & -0.000779 & -0.0019 & -0.00237 \\
\hline-0.000838 & 0.00782 & 0.00444 & -0.00536 & -0.00062 & 0.00711 & 0.00496 & -0.00568 \\
\hline-0.00221 & 0.00355 & 0.00547 & -0.00215 & -0.0022 & 0.00314 & 0.0051 & -0.00206 \\
\hline-0.000853 & -0.00578 & -0.00417 & 0.0046 & -0.00164 & -0.00455 & -0.00411 & 0.00598 \\
\hline-0.0514 & -0.0508 & -0.0205 & 0.0958 & -0.00727 & -0.000952 & 0.0127 & 0.00511 \\
\hline 0.0155 & 0.0242 & 0.0307 & -0.0279 & 0.00324 & 0.0067 & 0.00833 & -0.00609 \\
\hline 0.0292 & 0.0357 & 0.0248 & -0.0459 & 0.00679 & 0.00455 & -0.00306 & -0.00353 \\
\hline 0.042 & 0.0375 & 0.0139 & -0.0543 & 0.0104 & $-3.82 e-05$ & -0.012 & -0.00175 \\
\hline 0.00108 & 0.00653 & 0.0224 & -0.00123 & -0.0418 & -0.0116 & 0.00638 & 0.0498 \\
\hline-0.00475 & 0.00097 & 0.00901 & 0.0064 & 0.0116 & 0.0147 & 0.0187 & -0.0241 \\
\hline-0.00328 & -0.0044 & -0.00182 & 0.0117 & 0.0184 & 0.00992 & 0.00557 & -0.021 \\
\hline-0.000243 & 0.000105 & -0.00626 & 0.00889 & 0.0287 & 0.0106 & -0.00359 & -0.0247 \\
\hline-0.00344 & -0.00826 & 0.00218 & 0.00445 & -0.00163 & 0.000495 & 0.0015 & 0.000669 \\
\hline$-3.28 e-05$ & -0.00139 & 0.00411 & -0.000284 & 0.00154 & 0.00482 & 0.00183 & -0.00324 \\
\hline 0.0023 & 0.00645 & $4.12 e-05$ & -0.0021 & 0.000697 & 0.000751 & 0.000503 & -0.000731 \\
\hline 0.00355 & 0.00971 & -0.00128 & -0.00702 & 0.000583 & -0.00365 & -0.000218 & 0.000671 \\
\hline-0.00141 & 0.00156 & 0.00906 & -0.000732 & -0.000992 & 0.00545 & 0.00607 & -0.0031 \\
\hline 0.00124 & -0.000185 & 0.00122 & -0.000144 & 0.000522 & 0.00118 & 0.00312 & -0.00197 \\
\hline 0.000283 & 0.00114 & 0.000326 & -0.000983 & 0.00234 & 0.000376 & 0.000548 & -0.00182 \\
\hline 0.000492 & 0.000435 & -0.00272 & 0.000878 & 0.00158 & -0.00151 & -0.00314 & 0.0013 \\
\hline
\end{tabular}




\begin{tabular}{|c|c|c|c|c|c|c|c|}
\hline 0.00212 & 0.00115 & 0.000314 & -0.00193 & 0.00329 & -0.000838 & -0.00221 & -0.000853 \\
\hline 0.00326 & 0.0153 & 0.00464 & -0.0113 & -0.000358 & 0.00782 & 0.00355 & -0.00578 \\
\hline-0.00339 & 0.00217 & 0.00329 & 0.000866 & $3.35 e-05$ & 0.00444 & 0.00547 & -0.00417 \\
\hline-0.000584 & -0.00954 & -0.00335 & 0.00781 & -0.000511 & -0.00536 & -0.00215 & 0.0046 \\
\hline 0.00219 & -0.00452 & -0.00244 & 0.00163 & 0.00564 & -0.00062 & -0.0022 & -0.00164 \\
\hline-0.00177 & 0.00492 & 0.00345 & -0.00232 & -0.000779 & 0.00711 & 0.00314 & -0.00455 \\
\hline-0.00269 & 0.00373 & 0.0039 & -0.0013 & -0.0019 & 0.00496 & 0.0051 & -0.00411 \\
\hline 0.00117 & -0.0019 & -0.000705 & 0.0011 & -0.00237 & -0.00568 & -0.00206 & 0.00598 \\
\hline 1 & 0.314 & -0.266 & -0.427 & 0.0469 & 0.016 & -0.0054 & -0.0342 \\
\hline 0.314 & 1 & 0.142 & -0.648 & 0.0131 & 0.0414 & 0.0327 & -0.0486 \\
\hline-0.266 & 0.142 & 1 & -0.595 & -0.0152 & 0.0233 & 0.0594 & -0.0338 \\
\hline-0.427 & -0.648 & -0.595 & 1 & -0.0117 & -0.0359 & -0.041 & 0.0619 \\
\hline 0.0469 & 0.0131 & -0.0152 & -0.0117 & 1 & 0.033 & -0.423 & -0.424 \\
\hline 0.016 & 0.0414 & 0.0233 & -0.0359 & 0.033 & 1 & 0.0453 & -0.534 \\
\hline-0.0054 & 0.0327 & 0.0594 & -0.041 & -0.423 & 0.0453 & 1 & -0.462 \\
\hline-0.0342 & -0.0486 & -0.0338 & 0.0619 & -0.424 & -0.534 & -0.462 & 1 \\
\hline-0.00437 & -0.00611 & 0.00315 & 0.00528 & 0.00162 & -0.00136 & $-9.95 e-05$ & 0.000741 \\
\hline 0.00184 & -0.0015 & 0.00271 & -0.00102 & -0.000494 & 0.00277 & 0.00398 & -0.00275 \\
\hline 0.00452 & 0.00674 & -0.00156 & -0.00455 & 0.000481 & 0.00249 & $8.34 e-05$ & -0.00179 \\
\hline 0.000284 & 0.00504 & -0.00283 & -0.00147 & -0.00224 & 0.000665 & -0.000348 & 0.000868 \\
\hline 0.000665 & -0.000824 & 0.0037 & 0.00227 & 0.00261 & 0.00585 & 0.00373 & -0.00349 \\
\hline 0.00221 & 0.00133 & 0.0017 & -0.0012 & 0.00132 & 0.000589 & 0.00212 & -0.00174 \\
\hline-0.00186 & 0.00137 & 0.000789 & -0.00024 & -0.00137 & 0.000791 & -0.000111 & 0.000881 \\
\hline-0.000611 & 0.000854 & -0.00183 & 0.000165 & 0.000289 & -0.00298 & -0.00102 & 0.00116 \\
\hline-0.0507 & -0.0506 & -0.0245 & 0.0976 & -0.00998 & 0.00166 & 0.012 & 0.00732 \\
\hline 0.02 & 0.0229 & 0.0297 & -0.0288 & 0.00532 & 0.00195 & 0.00557 & -0.00314 \\
\hline 0.0287 & 0.0364 & 0.0253 & -0.0458 & 0.00728 & 0.00622 & $-4.14 e-05$ & -0.00709 \\
\hline 0.04 & 0.0411 & 0.0134 & -0.0563 & 0.00882 & 0.000227 & -0.0112 & -0.00204 \\
\hline-0.000385 & 0.00498 & 0.0214 & 0.00149 & -0.0402 & -0.0106 & 0.00675 & 0.0518 \\
\hline-0.00392 & 0.000747 & 0.00474 & 0.00896 & 0.0113 & 0.0156 & 0.0181 & -0.0245 \\
\hline-0.0025 & -0.00109 & -0.000978 & 0.00804 & 0.02 & 0.0106 & 0.00673 & -0.0259 \\
\hline-0.000858 & 0.00253 & -0.00147 & 0.00231 & 0.0258 & 0.00861 & -0.00244 & -0.0229 \\
\hline-0.0514 & 0.0155 & 0.0292 & 0.042 & 0.00108 & -0.00475 & -0.00328 & -0.000243 \\
\hline-0.0508 & 0.0242 & 0.0357 & 0.0375 & 0.00653 & 0.00097 & -0.0044 & 0.000105 \\
\hline-0.0205 & 0.0307 & 0.0248 & 0.0139 & 0.0224 & 0.00901 & -0.00182 & -0.00626 \\
\hline 0.0958 & -0.0279 & -0.0459 & -0.0543 & -0.00123 & 0.0064 & 0.0117 & 0.00889 \\
\hline-0.00727 & 0.00324 & 0.00679 & 0.0104 & -0.0418 & 0.0116 & 0.0184 & 0.0287 \\
\hline-0.000952 & 0.0067 & 0.00455 & $-3.82 e-05$ & -0.0116 & 0.0147 & 0.00992 & 0.0106 \\
\hline 0.0127 & 0.00833 & -0.00306 & -0.012 & 0.00638 & 0.0187 & 0.00557 & -0.00359 \\
\hline 0.00511 & -0.00609 & -0.00353 & -0.00175 & 0.0498 & -0.0241 & -0.021 & -0.0247 \\
\hline-0.00437 & 0.00184 & 0.00452 & 0.000284 & 0.000665 & 0.00221 & -0.00186 & -0.000611 \\
\hline-0.00611 & -0.0015 & 0.00674 & 0.00504 & -0.000824 & 0.00133 & 0.00137 & 0.000854 \\
\hline 0.00315 & 0.00271 & -0.00156 & -0.00283 & 0.0037 & 0.0017 & 0.000789 & -0.00183 \\
\hline 0.00528 & -0.00102 & -0.00455 & -0.00147 & 0.00227 & -0.0012 & -0.00024 & 0.000165 \\
\hline 0.00162 & -0.000494 & 0.000481 & -0.00224 & 0.00261 & 0.00132 & -0.00137 & 0.000289 \\
\hline-0.00136 & 0.00277 & 0.00249 & 0.000665 & 0.00585 & 0.000589 & 0.000791 & -0.00298 \\
\hline$-9.95 e-05$ & 0.00398 & $8.34 e-05$ & -0.000348 & 0.00373 & 0.00212 & -0.000111 & -0.00102 \\
\hline 0.000741 & -0.00275 & -0.00179 & 0.000868 & -0.00349 & -0.00174 & 0.000881 & 0.00116 \\
\hline 1 & -0.516 & -0.542 & -0.462 & 0.0826 & 0.00344 & -0.0421 & -0.0726 \\
\hline-0.516 & 1 & -0.0819 & -0.187 & -0.0322 & 0.0374 & 0.0284 & 0.0132 \\
\hline-0.542 & -0.0819 & 1 & 0.12 & -0.042 & -0.0127 & 0.0485 & 0.0565 \\
\hline-0.462 & -0.187 & 0.12 & 1 & -0.0372 & -0.02 & 0.00913 & 0.0716 \\
\hline 0.0826 & -0.0322 & -0.042 & -0.0372 & 1 & -0.538 & -0.434 & -0.342 \\
\hline 0.00344 & 0.0374 & -0.0127 & -0.02 & -0.538 & 1 & -0.147 & -0.154 \\
\hline-0.0421 & 0.0284 & 0.0485 & 0.00913 & -0.434 & -0.147 & 1 & -0.022 \\
\hline-0.0726 & 0.0132 & 0.0565 & 0.0716 & -0.342 & -0.154 & -0.022 & 1 \\
\hline 0.00947 & -0.00237 & -0.00492 & -0.00701 & 0.00539 & -0.000867 & 0.00191 & -0.00465 \\
\hline$-5.99 e-05$ & 0.00463 & 0.0004 & 0.000208 & 0.00615 & 0.00248 & -0.00114 & -0.000966 \\
\hline-0.0038 & 0.000814 & 0.00333 & 0.00367 & 0.000918 & 0.00235 & -0.000565 & -0.000278 \\
\hline-0.00837 & 0.0016 & 0.00362 & 0.00727 & -0.00734 & -0.000649 & 0.00052 & 0.00592 \\
\hline 0.00707 & 0.00332 & -0.00331 & -0.00306 & 0.0109 & 0.00428 & -0.00174 & -0.00195 \\
\hline 0.00078 & 0.00337 & 0.00111 & -0.00249 & 0.00674 & 0.00124 & -0.000768 & -0.00282 \\
\hline-0.00179 & -0.00154 & 0.00283 & 0.000856 & -0.00122 & -0.000888 & 0.00277 & 0.000329 \\
\hline-0.00176 & -0.00121 & 0.000517 & 0.00158 & -0.0043 & 0.000126 & 0.00203 & 0.00268 \\
\hline
\end{tabular}




\begin{tabular}{|c|c|c|c|c|c|c|c|}
\hline-0.00344 & $-3.28 e-05$ & 0.0023 & 0.00355 & -0.00141 & 0.00124 & 0.000283 & 0.000492 \\
\hline-0.00826 & -0.00139 & 0.00645 & 0.00971 & 0.00156 & -0.000185 & 0.00114 & 0.000435 \\
\hline 0.00218 & 0.00411 & $4.12 e-05$ & -0.00128 & 0.00906 & 0.00122 & 0.000326 & -0.00272 \\
\hline 0.00445 & -0.000284 & -0.0021 & -0.00702 & -0.000732 & -0.000144 & -0.000983 & 0.000878 \\
\hline-0.00163 & 0.00154 & 0.000697 & 0.000583 & -0.000992 & 0.000522 & 0.00234 & 0.00158 \\
\hline 0.000495 & 0.00482 & 0.000751 & -0.00365 & 0.00545 & 0.00118 & 0.000376 & -0.00151 \\
\hline 0.0015 & 0.00183 & 0.000503 & -0.000218 & 0.00607 & 0.00312 & 0.000548 & -0.00314 \\
\hline 0.000669 & -0.00324 & -0.000731 & 0.000671 & -0.0031 & -0.00197 & -0.00182 & 0.0013 \\
\hline-0.0507 & 0.02 & 0.0287 & 0.04 & -0.000385 & -0.00392 & -0.0025 & -0.000858 \\
\hline-0.0506 & 0.0229 & 0.0364 & 0.0411 & 0.00498 & 0.000747 & -0.00109 & 0.00253 \\
\hline-0.0245 & 0.0297 & 0.0253 & 0.0134 & 0.0214 & 0.00474 & -0.000978 & -0.00147 \\
\hline 0.0976 & -0.0288 & -0.0458 & -0.0563 & 0.00149 & 0.00896 & 0.00804 & 0.00231 \\
\hline-0.00998 & 0.00532 & 0.00728 & 0.00882 & -0.0402 & 0.0113 & 0.02 & 0.0258 \\
\hline 0.00166 & 0.00195 & 0.00622 & 0.000227 & -0.0106 & 0.0156 & 0.0106 & 0.00861 \\
\hline 0.012 & 0.00557 & $-4.14 e-05$ & -0.0112 & 0.00675 & 0.0181 & 0.00673 & -0.00244 \\
\hline 0.00732 & -0.00314 & -0.00709 & -0.00204 & 0.0518 & -0.0245 & -0.0259 & -0.0229 \\
\hline 0.00947 & $-5.99 e-05$ & -0.0038 & -0.00837 & 0.00707 & 0.00078 & -0.00179 & -0.00176 \\
\hline-0.00237 & 0.00463 & 0.000814 & 0.0016 & 0.00332 & 0.00337 & -0.00154 & -0.00121 \\
\hline-0.00492 & 0.0004 & 0.00333 & 0.00362 & -0.00331 & 0.00111 & 0.00283 & 0.000517 \\
\hline-0.00701 & 0.000208 & 0.00367 & 0.00727 & -0.00306 & -0.00249 & 0.000856 & 0.00158 \\
\hline 0.00539 & 0.00615 & 0.000918 & -0.00734 & 0.0109 & 0.00674 & -0.00122 & -0.0043 \\
\hline-0.000867 & 0.00248 & 0.00235 & -0.000649 & 0.00428 & 0.00124 & -0.000888 & 0.000126 \\
\hline 0.00191 & -0.00114 & -0.000565 & 0.00052 & -0.00174 & -0.000768 & 0.00277 & 0.00203 \\
\hline-0.00465 & -0.000966 & -0.000278 & 0.00592 & -0.00195 & -0.00282 & 0.000329 & 0.00268 \\
\hline 1 & -0.523 & -0.54 & -0.452 & 0.0761 & 0.00193 & -0.0362 & -0.0664 \\
\hline-0.523 & 1 & -0.0841 & -0.185 & -0.0304 & 0.0362 & 0.027 & 0.0173 \\
\hline-0.54 & -0.0841 & 1 & 0.117 & -0.0344 & -0.00843 & 0.0397 & 0.0513 \\
\hline-0.452 & -0.185 & 0.117 & 1 & -0.0343 & -0.0168 & 0.00749 & 0.0624 \\
\hline 0.0761 & -0.0304 & -0.0344 & -0.0343 & 1 & -0.543 & -0.43 & -0.331 \\
\hline 0.00193 & 0.0362 & -0.00843 & -0.0168 & -0.543 & 1 & -0.141 & -0.143 \\
\hline-0.0362 & 0.027 & 0.0397 & 0.00749 & -0.43 & -0.141 & 1 & -0.0224 \\
\hline-0.0664 & 0.0173 & 0.0513 & 0.0624 & -0.331 & -0.143 & -0.0224 & 1 \\
\hline
\end{tabular}




\section{Glossário e Acrônimos}

CFT

$\mathrm{CH}$

CHF

CHIP

CPS

CRIOSTATO

DIS

ECN

ECS

EDP

EFICIÊNCIA QUÂNTICA

EM

EMF

ETILENO

$\mathrm{FH}$
Central Fiber Tracker, 45

Coarse Hadronic Camada hadrônica grossa do calorímetro do detector $\mathrm{D} \varnothing, 49$

fração de energia do jato no calorímetro CH., 63

peça que contém microeletrônica, 46

Central Preshower, 41

Compartimento construído para manter temperaturas criogênicas com estabilidade., 49

Deep Inelastic Scattering - Espalhamento profundamente inelástico, 16

END CAP NORTH Calorímetro frontal no lado norte do detector $\mathrm{D} \varnothing, 49$

END CAP SOUTH Calorímetro frontal no lado sul do detector $\mathrm{D} \varnothing, 49$

Dupla Troca de Pomeron Exclusiva, 25

eficiência de um dado dispositivo detectar fótons, e.g., porcentagem de fótons que produzem um par elétronburaco em uma superfície fóton sensível., 47

Eletromagnetic Camada eletromagnética do calorímetro do detector $\mathrm{D} \varnothing, 49$

fração de energia do jato no calorímetro EM., 64

um álcool com dois grupos de -OH, 46

Fine Hadronic Camada hadrônica fina do calorímetro do detector $\mathrm{D} \varnothing, 49$

FIBRAS CINTILADORAS Fibras sensíveis, 47

FPD

Forward Proton DetectorDetector de prótons frontais, 41

FPS

Forward Preshower, 41 
GUIAS DE LUZ

HALO

HDI

HERA

ICD

IDP

L1R

LBN

LM

LO

NLO

PDT

PETRA

PLATEAU

PMT

QCD

QED cabos feitos de materiais dielétricos de alta transmissividade enrolados com materiais de baixa transmissividade, permitindo reflexão interna total da luz, 47

Partícula que orbita ao redor dos feixes colimados, 56 High Density Interconnect, 46

Hadron-Elektron-Ringanlage - colisor de elétronpróton localizado em Hamburgo, Alemanha, 9

Intercryostat detector, 41

Dupla Troca de Pomeron Inclusiva, 25

razão da energia do jato reconstruído com a energia das torres do nível 1 do sistema de trigger que se encontram dentro do cone do jato correspondente $\left(\Delta R<R_{\text {cone }}\right)$., 64

Luminosity Block Number., 58

Luminosity Monitor (Monitor de Luminosidade), 56

Leading Order cálculo de primeira ordem para seção de choque, 14

Next to leading order cálculo de ordem seguinte à dominante, 22

Proportional Drift Tubes, 53

Positron-Electron Tandem Ring Accelerator - Acelerador de partículas usado para colisões de elétrons e pósitrons entre 1978 e 1986, localizado no laboratório DESY, em Hamburgo, Alemanha., 14

região de uma distribuição na qual o valor permanece constante., 68

Photon Multiplyer (Fotomultiplicadora), 57

Quantum Chromodynamics, 12

Quantum Electrodynamic, 12

Roman Pot, 55 
SÍNCROTRON

SMT

SVXIIe

TRIGGER MB

TRIGGER ZB

VLPC
Acelerador de partículas circular., 40

Silicon Microstrip Tracker, 45

chip de 128 canais usados para a conversão analógicadigital de tiras de silício, 46

trigger que grava eventos que possuem um vértice primário identificado pelo detector LM, 80

trigger que grava eventos aleatoriamente sem utilizar informação do detector, 80

Visible Light Photon Counter, 47 


\section{Bibliografia}

[1] D. J. Griffiths. Introduction to Elementary Particles, Wiley (1987), 392 p.

[2] F. Halzen e A. D. Martin. Quarks and Leptons: An Introductory Course In Modern Particle Physics, Wiley (1984), 396 p.

[3] A. K. Das e T. Ferbel, Introduction to nuclear and particle physics, World Scientific (2003), 399 p.

[4] W. Greiner e B. Muller, Gauge theory of weak interactions, Springer (1993), 308 p.

[5] S. F. Novaes, arXiv:hep-ph/0001283.

[6] S. Abachi et al. [D0 Collaboration], Phys. Rev. Lett. 74, 2632 (1995) [arXiv:hepex/9503003].

F. Abe et al. [CDF Collaboration], Phys. Rev. Lett. 74, 2626 (1995) [arXiv:hepex/9503002].

[7] K. Kodama et al. [DONUT Collaboration], Phys. Lett. B 504, 218 (2001) [arXiv:hepex/0012035].

[8] D. P. Barber et al., Phys. Rev. Lett. 43, 830 (1979).

[9] G. Altarelli, The Development of perturbative QCD (1994) $362 \mathrm{p}$

[10] P. W. Higgs, Phys. Lett. 12, 132 (1964).

P. W. Higgs, Phys. Rev. Lett. 13, 508 (1964).

P. W. Higgs, Phys. Rev. 145, 1156 (1966).

[11] http://lhc.web.cern.ch/lhc/

[12] M. Gell-Mann, Phys. Lett. 8, 214 (1964).

G. Zweig, CERN-TH-412 (1964) 74 p.

[13] R. K. Ellis, W. J. Stirling e B. R. Webber, Camb. Monogr. Part. Phys. Nucl. Phys. Cosmol. 8, 1 (1996).

[14] R. Brandelik et al. [TASSO Collaboration], Phys. Lett. B 86, 243 (1979). 
[15] W. M. Yao et al. [Particle Data Group], J. Phys. G 33, 1 (2006).

[16] G. Hanson et al., Phys. Rev. Lett. 35, 1609 (1975).

[17] T. Sjostrand, S. Mrenna e P. Skands, arXiv:0710.3820 [hep-ph]

T. Sjostrand, Comput. Phys. Commun. 82, 74 (1994).

[18] G. Corcella et al., arXiv:hep-ph/0210213

G. Marchesini, B. R. Webber, G. Abbiendi, I. G. Knowles, M. H. Seymour e L. Stanco, Comput. Phys. Commun. 67, 465 (1992).

[19] B. Andersson, G. Gustafson, G. Ingelman e T. Sjostrand, Phys. Rept. 97, 31 (1983).

[20] B. R. Webber, Nucl. Phys. B 238, 492 (1984).

[21] G. Altarelli e G. Parisi, Nucl. Phys. B 126, 298 (1977).

[22] B. L. Combridge, J. Kripfganz e J. Ranft, Phys. Lett. B 70, 234 (1977).

[23] M. L. Mangano e S. J. Parke, Phys. Rept. 200, 301 (1991) [arXiv:hep-th/0509223].

[24] M. Voutilainen, A. Kupco, C. Royon. Measurement of the Inclusive Jet Cross Section in $p \bar{p}$ Collisions in D0 Run II at sqrt(s)=1.96 TeV. DØ Note 5551.

[25] M. L. Good e W. D. Walker, Phys. Rev. 120, 1857 (1960).

[26] V. Barone e E. Predazzi, High-Energy Particle Diffraction, Springer (2002), 408 p.

[27] J. R. Forshaw e D. A. Ross, Quantum chromodynamics and the pomeron, Cambridge University Press (1997), 248 p.

[28] T. Regge, Nuovo Cim. 14, 951 (1959).

T. Regge, Nuovo Cim. 18, 947 (1960).

[29] A. Donnachie e P. V. Landshoff, Z. Phys. C 2, 55 (1979) [Erratum-ibid. C 2, 372 (1979)]. A. Donnachie e P. V. Landshoff, Nucl. Phys. B 244, 322 (1984). A. Donnachie e P. V. Landshoff, Phys. Lett. B 296, 227 (1992) [arXiv:hep-ph/9209205].

[30] G. Ingelman e P. E. Schlein, Phys. Lett. B 152, 256 (1985).

[31] G. Ingelman, Int. J. Mod. Phys. A 21, 1805 (2006) [arXiv:hep-ph/0512146].

[32] R. Bonino et al. [UA8 Collaboration], Phys. Lett. B 211, 239 (1988).

[33] M. Derrick et al. [ZEUS Collaboration], Phys. Lett. B 315, 481 (1993).

T. Ahmed et al. [H1 Collaboration], Nucl. Phys. B 435, 3 (1995). 
[34] V. N. Gribov e L. N. Lipatov, Sov. J. Nucl. Phys. 15, 438 (1972) [Yad. Fiz. 15, 781 (1972)].

I. I. Balitsky e L. N. Lipatov, Sov. J. Nucl. Phys. 28, 822 (1978) [Yad. Fiz. 28, 1597 (1978)].

A. Berera e D. E. Soper, Phys. Rev. D 50, 4328 (1994) [arXiv:hep-ph/9403276].

A. Edin, G. Ingelman e J. Rathsman, Phys. Lett. B 366, 371 (1996) [arXiv:hepph/9508386].

F. O. Duraes, F. S. Navarra e G. Wilk, Braz. J. Phys. 35, 3 (2005) [arXiv:hep$\mathrm{ph} / 0412293]$.

[35] K. Goulianos [CDF Collaboration], Nucl. Phys. Proc. Suppl. 99A, 37 (2001) [arXiv:hep-ex/0011059].

[36] J. Pumplin, D. R. Stump, J. Huston, H. L. Lai, P. Nadolsky e W. K. Tung, JHEP 0207, 012 (2002) [arXiv:hep-ph/0201195].

[37] M. Boonekamp, R. B. Peschanski e C. Royon, Phys. Rev. Lett. 87, 251806 (2001) [arXiv:hep-ph/0107113].

M. Boonekamp, R. B. Peschanski e C. Royon, Nucl. Phys. B 669, 277 (2003) [Erratum-ibid. B 676, 493 (2004)] [arXiv:hep-ph/0301244].

M. Boonekamp, R. B. Peschanski e C. Royon, Phys. Lett. B 598, 243 (2004) [arXiv:hep-ph/0406061].

[38] B. Cox, J. R. Forshaw e B. Heinemann, Phys. Lett. B 540, 263 (2002) [arXiv:hep$\mathrm{ph} / 0110173]$.

[39] A. A. Affolder et al. [CDF Collaboration], Phys. Rev. Lett. 85, 4215 (2000).

[40] P. V. Landshoff e O. Nachtmann, Z. Phys. C 35, 405 (1987).

[41] R. S. Fletcher and T. Stelzer, Phys. Rev. D 48, 5162 (1993) [arXiv:hep-ph/9306253]. E. Gotsman, E. Levin and U. Maor, Phys. Rev. D 60, 094011 (1999) [arXiv:hep$\mathrm{ph} / 9902294]$.

[42] T. Aaltonen et al. [CDF Run II Collaboration], Phys. Rev. D 77, 052004 (2008) [arXiv:0712.0604 [hep-ex]].

[43] A. Bialas e P. V. Landshoff, Phys. Lett. B 256, 540 (1991).

[44] V. A. Khoze, A. D. Martin e M. G. Ryskin, Eur. Phys. J. C 14, 525 (2000) [arXiv:hep-ph/0002072].

V. A. Khoze, A. D. Martin e M. G. Ryskin, Eur. Phys. J. C 19, 477 (2001) 
[Erratum-ibid. C 20, 599 (2001)] [arXiv:hep-ph/0011393].

[45] R. Peschanski, M. Rangel and C. Royon, arXiv:0808.1691 [hep-ph].

[46] O. Kepka e C. Royon, Phys. Rev. D 76, 034012 (2007) [arXiv:0704.1956 [hep-ph]].

[47] M. Rangel, C. Royon, G. Alves, J. Barreto and R. B. Peschanski, Nucl. Phys. B 774, 53 (2007) [arXiv:hep-ph/0612297].

[48] M. Gallinaro [On behalf of the CDF Collaboration], Acta Phys. Polon. B 35, 465 (2004) [arXiv:hep-ph/0311192].

[49] M. Boonekamp and T. Kucs, Comput. Phys. Commun. 167, 217 (2005) [arXiv:hepph/0312273] .

http://boonekam.home.cern.ch/boonekam/dpemc.htm

[50] C. Royon, L. Schoeffel, R. B. Peschanski e E. Sauvan, Nucl. Phys. B 746, 15 (2006) [arXiv:hep-ph/0602228].

C. Royon, L. Schoeffel, S. Sapeta, R. B. Peschanski e E. Sauvan, Nucl. Phys. B 781, 1 (2007) [arXiv:hep-ph/0609291].

[51] M. Rangel, G. Alves e J. Barreto. Forward Proton Tracking at DØ . D Note 5222.

[52] A. D. Martin e M. G. Ryskin, Phys. Rev. D 64, 094017 (2001) [arXiv:hep$\mathrm{ph} / 0107149]$.

[53] C. Marquet, R. B. Peschanski and G. Soyez, Phys. Rev. D 76, 034011 (2007) [arXiv:hep-ph/0702171].

G. Soyez, Phys. Lett. B 655, 32 (2007) [arXiv:0705.3672 [hep-ph]].

[54] A. Bialas, W. Szeremeta, Phys. Lett. B296 (1992) 191;

W. Szeremeta,Acta Phys. Polon. B 24, 1159 (1993).

[55] http://www.fnal.gov/pub/about/whatis/history.html

[56] W. R. Innes et al., Phys. Rev. Lett. 39, 1240 (1977) [Erratum-ibid. 39, 1640 (1977)].

[57] http://www-ad.fnal.gov/public/index.html

[58] V. M. Abazov et al. [D0 Collaboration], Nucl. Instrum. Meth. A 565, 463 (2006) [arXiv:physics/0507191].

[59] M. S. Weber [D0 Collaboration], Nucl. Instrum. Meth. A 560 (2006) 14.

E. Kajfasz [D0 Collaboration], Nucl. Instrum. Meth. A 511, 16 (2003) [arXiv:hepex/0112014]. 
[60] W. Bruckner et al., Nucl. Instrum. Meth. A 357 (1995) 274.

[61] M. D. Petroff,M. .G. Stapelbroek, IEEE Trans. Nucl. Sci. 36 (1989) 158.

M. D. Petroff,M. Atac, IEEE Trans. Nucl. Sci. 36 (1989) 163.

[62] S. Abachi et al. [D0 Collaboration], Nucl. Instr. Meth. A 338 (1994) 185.

[63] B. Acharya et al., Nucl. Instr. Meth. A 401 (1997) 45.

[64] C. Brandt et al., Fermilab-Conf-97-377-E, 1997.

[65] U. Amaldi et al., Phys. Lett. B 43 (1973) 231.

[66] C. Miao, Fermilab-Conf-98-395-E, 1998.

[67] C. Miao, Nucl. Phys. Proc. Suppl. 78 (1999) 342.

[68] R. K. Bock, H. Grote, D. Notz, M. Regler and M. Regler, Data analysis techniques for high-energy physics experiments, Camb. Monogr. Part. Phys. Nucl. Phys. Cosmol. 11, 1 (2000).

[69] http://www-d0.fnal.gov/computing/algorithms/

[70] http://www-d0.fnal.gov/phys_id/jes/public_RunIIa/

[71] E. Busato e B. Andrieu. Jet Algorithms in D0 RunII Software: Description and User's Guide. DØ Note 4457.

[72] G. C. Blazey et al., arXiv:hep-ex/0005012.

[73] A. Harel. jet ID optimization. DØ Note 4919.

[74] A. Harel e R. Wagner. Improved L1 Confirmation. DØ Note 4932.

[75] M. Voutilainen. Jet Four-vector Scale Determination for Dijets in D0 Run IIa (final p17 version). DØ Note 5550.

[76] B. Andrieu, A. Harel, H. Nogima, M. Rangel e M. Voutilainen. Measuring Reconstruction*Jet-ID efficiencies using the tag and probe method in p17. DØ Note 5250 .

[77] B. Andrieu, A. Harel. Jet Efficiency Measurement and Monte Carlo Correction Lessons and Options. DØ Note 5169.

[78] A. Harel, H. Nogima, M. Rangel e M. Voutilainen. Combined JetID efficiency for p17. DØ Note 5218. 
[79] M. Voutilainen. Jet $\mathrm{p}_{\mathrm{T}}$ resolution for Run IIa final JES (v7.2) with dijet J4S jet corrections. DØ Note 5499.

[80] M. Rangel, B. Casey e A. Juste. Improving the Jet Energy Resolution with the CPS Detector. DØ Note 5767.

[81] F. Lacroix e A. Juste. Study of the jet energy resolution including the central preshower information, DØ Note 5673.

[82] V. M. Abazov et al. [D0 Collaboration], Phys. Rev. Lett. 98, 181802 (2007) [arXiv:hep-ex/0612052].

[83] V. M. Abazov et al. [D0 Collaboration], Phys. Rev. Lett. 101, 062001 (2008), arXiv:0802.2400 [hep-ex].

[84] Laurent Duflot, Viatcheslav Shary, Ingo Torchiani e Robert Zitoun. cal_event_quality package. DØ Note 4614.

[85] J.Hays, H.Schellman e J.Steele. Calorimeter Event Quality Flag Rates for W/Z Production Cross-section Measurement (second pass). DØ Note 5412.

[86] O. Atramentov. Search for Warm Regions in the EM Calorimeter in 2003-2006 p17 Data. DØ Note 5080.

[87] O. Atramentov e E. Carrera. Search for Warm Regions in the EM Calorimeter in p20 Data. DØ Note 5539.

[88] M. Rangel e O. Atramentov. Calorimeter Bad Cell List for RunIIa. DØ Note 5749.

[89] JetMet group. Jets in Run II. DØ Note 3985.

[90] M. Rangel. Calorimeter Response Correction for p17 MC. DØ Note 5748.

[91] Mikko Voutilainen. Single jet trigger efficiencies in Run IIa. DØ Note 5549.

[92] Jiri Kvita e Krisztian Peters. Run II Phi-Intercalibration of the Fine Hadronic Calorimeter. DØ Note 5005.

[93] B. E. Cox and J. R. Forshaw, Comput. Phys. Commun. 144, 104 (2002) [arXiv:hep$\mathrm{ph} / 0010303]$.

[94] J.P. Vuolo, Fundamentos da teoria de errors, Editora Edgard Blücher LTDA (1992), $250 \mathrm{p}$.

[95] M. Rangel, G. Alves, J. Barreto e C. Royon. Search for exclusive diffractive dijet production. DØ Note 5769. 
[96] G. Cowan, Statistical data analysis, Oxford (1998), 197 p.

[97] V. Buescher, J.-F. Grivaz, J. Hobbs, A. Kharchilava, G. Landsberg, J. Linnemann, H. Prosper e S. Soldner-Rembold. Recommendation of the Ad-Hoc Committee on Limit-Setting Procedures to be Used by D0 in Run II. DØ Note 4629. 